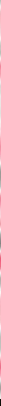

PROfile

\title{
Well seismic \\ surveying and \\ acoustic logging
}

Jean-Luc Mari and Christophe Vergniault

edpsciences

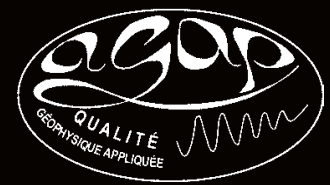





\section{Well seismic surveying and acoustic logging}

An overview of the current state of knowledge in the geotechnical field and possible methodology transfers from the oil industry to near surface studies 



\section{Well seismic surveying and acoustic logging}

An overview of the current state of knowledge in the geotechnical field and possible methodology transfers from the oil industry to near surface studies

\section{Jean-Luc Mari \\ Christophe Vergniault}

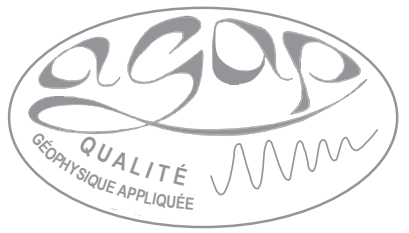

edpsciences 
DOI: $10.1051 / 978-2-7598-2263-8$

ISBN(ebook) : 978-2-7598-2263-8

This book is published in under Open Access Creative Commons License CC-BY-NC-ND (https://creativecommons.org/licenses/by-nc-nd/4.0/en/) allowing non-commercial use, distribution, reproduction of the text, via any medium, provided the source is cited.

(c) EDP Sciences, 2018 


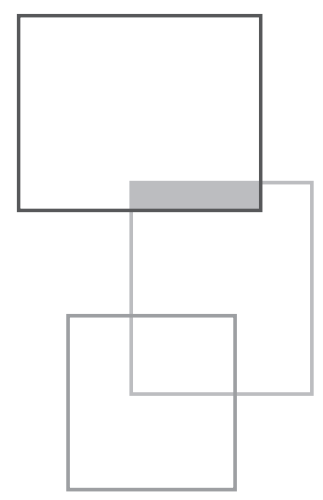

\section{Contents}

Foreword

Introduction

Chapter 1 - Shear velocity measurement in boreholes

1.1 Context 15

1.1.1 Overview of invasive and non-invasive $\mathrm{V}_{\mathrm{s}}$ measurements $\quad 15$

$\begin{array}{lll}1.1 .2 & \text { Applications } & 17\end{array}$

1.1.3 Environmental conditions 18

$\begin{array}{lll}1.2 \mathrm{~V}_{\mathrm{s}} \text { measurements by borehole seismic method } & 19\end{array}$

1.2.1 Downhole 21

1.2.1.1 The acquisition device 21

1.2.1.2 Analysis of a downhole (DH) 26

1.2.1.3 The specific example of offshore 29

$\begin{array}{ll}\text { 1.2.2 Uphole } 30 & 30\end{array}$

1.2.3 Crosshole 30

1.2.3.1 Prerequisites 31

1.2.3.2 The acquisition device $\quad 32$

1.2.3.3 Crosshole analysis 36

$1.3 \mathrm{~V}_{\mathrm{s}}$ measurement by logging $\quad 39$

1.3.1 Acoustic logging with high vertical resolution 39

1.3.2 PS Suspension Logging (PSSL) 41 
1.4 Case study of a downhole acquisition, PSSL and acoustic logging, in the same borehole

1.5 Conclusion 46

$\begin{array}{ll}\text { References } & 47\end{array}$

Chapter 2 - Well seismic surveying 49

2.1 Introduction 49

2.2 Well seismic data acquisition 53

2.2.1 Necessary resources for data acquisition 53

2.2.2 Implementation in the field 53

2.2.2.1 Description of classical VSP operation in a vertical well $\quad 53$

2.2.2.2 Well probes $\quad 54$

2.2.2.3 Seismic source $\quad 56$

2.2.2.4 Acquisition parameters $\quad 56$

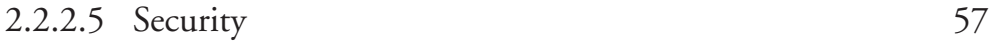

2.2.2.6 Quality Control $\quad 57$

2.2.2.7 Production $\quad 57$

$\begin{array}{ll}2.3 & \text { Seismic waves } \\ 2.4 & 57\end{array}$

2.4 Processing sequence $\quad 62$

$\begin{array}{ll}\text { 2.5 Application with a geotechnical dataset } & 71\end{array}$

2.6 Conclusion $\quad 74$

$\begin{array}{ll}\text { References } & 76\end{array}$

Chapter 3 • Acoustic logging 77

$\begin{array}{lll}3.1 & \text { Introduction } & 77\end{array}$

3.2 Acoustic logging data acquisition $\quad 79$

3.2.1 Necessary resources for data acquisition $\quad 80$

3.2.2 Implementation in the field 80

3.2.2.1 Description of an acoustic logging operation in a vertical borehole $\quad 80$

3.2.2.2 Acoustic probes $\quad 81$

3.2.2.3 Acquisition and visualization parameters 84

3.2.2.4 Acoustic logging in deviated well 84

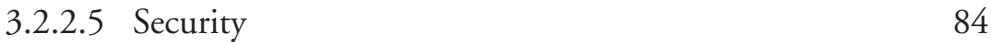

3.2.2.6 Quality control 84

3.2.2.7 Production 84

$\begin{array}{lll}3.3 & \text { Acoustic waves } & 85\end{array}$

$\begin{array}{ll}3.4 & \text { Processing sequence }\end{array}$ 
3.5 Acoustic imaging 91

3.5.1 Refraction acoustic imaging 91

3.5.2 Reflection acoustic imaging 95

3.6 Characterization of a formation using Stoneley waves 97

$\begin{array}{ll}3.7 \text { Conclusion } & 100\end{array}$

References 101

Chapter 4 • Tying surface seismic data 103

4.1 Introduction 103

4.2 3D VHR seismic survey and VSP 104

4.3 Acoustic logging 108

4.4 Acoustic logs 109

4.5 Time conversion of acoustic logs and calculation of the synthetic seismogram 111

4.6 Integrated sonic time and VSP vertical time 113

$\begin{array}{lll}4.7 \text { Conclusion } & 116\end{array}$

References 116

Chapter 5 - Contribution of seismic and acoustic methods to the characterization of karstic formations 117

$\begin{array}{lll}5.1 \text { Introduction } & 117\end{array}$

$\begin{array}{ll}5.2 \text { Geological context } & 118\end{array}$

$\begin{array}{ll}5.3 \text { 3D seismic acquisition and processing } & 120\end{array}$

$\begin{array}{lll}5.4 \text { Well seismic measurements } & 124\end{array}$

5.5 Monopole full waveform acoustic logging 127

$\begin{array}{ll}5.6 \text { Conclusion } & 131\end{array}$

5.7 Acknowledgements 132

References 132

$\begin{array}{ll}\text { Conclusion } & 135\end{array}$ 


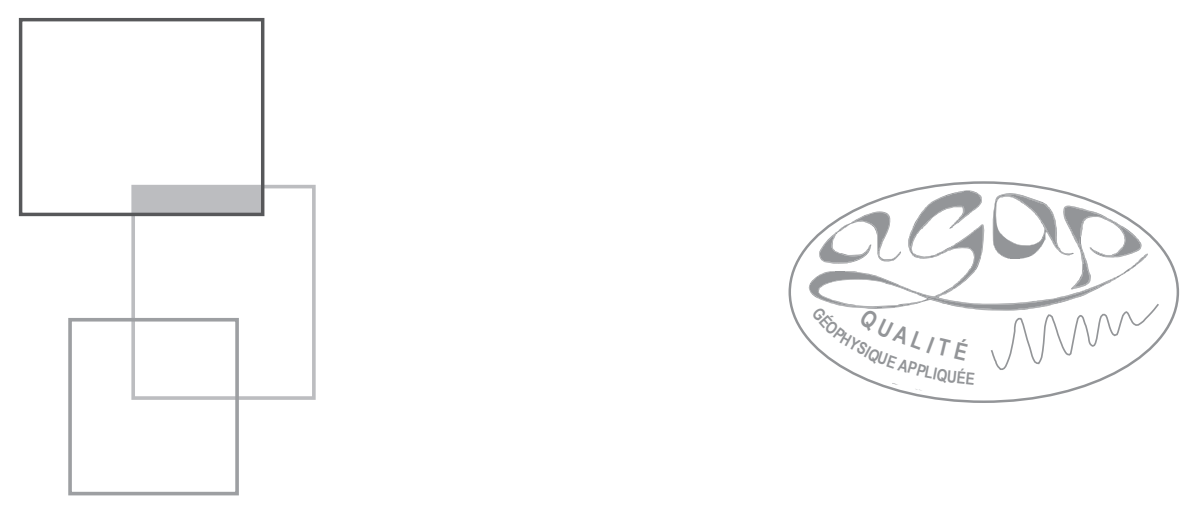

\section{Foreword}

\section{J.-L. Mari, C. Vergniault}

Based on their experience in geophysics applied to the oil and gas industry and the geotechnical field, the authors have set out to explain how conventional approaches used in deep exploration geophysics can be applied to certain geotechnical and hydrogeological surveys, and site characterizations in the framework of seismic hazard studies. After reviewing the current state of knowledge in the geotechnical field regarding borehole measurements of subsurface shear velocities, the book aims to illustrate the feasibility of carrying out vertical seismic profiles, logs and $3 \mathrm{D}$ seismic reflection blocks. In addition to these examples, the authors have sought to provide readers with guidelines to carry out these operations, in terms of acquisition, as well as processing and interpretation.

The authors thank Françoise Coppens, Patrick Meynier and Gilles Porel for their contributions to this book.

Many thanks to Jim Johnson and Katell Guernic from Tamarin (www.tamarintext.com) for the English translation of the book

This chapter of Well seismic surveying and acoustic logging is published under Open Source Creative Commons License CC-BY-NC-ND allowing non-commercial use, distribution, reproduction of the text, via any medium, provided the source is cited.

(C) EDP Sciences, 2018

DOI: $10.1051 / 978-2-7598-2263-8 . c 001$ 


\section{The authors}

A graduate of the Institut Physique du Globe Strasbourg and IFP School (petroleum geosciences, major in geophysics in 1978), Jean-Luc Mari was employed by IFP Energies Nouvelles in 1979 as a research engineer in the Geophysics Department, where he worked on several research projects, such as high-resolution seismic surveying, reservoir monitoring, and the development of borehole tools, in collaboration with industrial partners GdF-Suez, CGG, Total and ELF Aquitaine. In 1986, he was seconded to ELF Aquitaine where he worked on reservoir geophysics. He joined IFPEN in 1987 and was seconded to the Reservoir Department, where he studied, in particular, the benefits of using geophysical methods in horizontal wells. In 1994 he was appointed to IFP School as a professor and obtained the accreditation to supervise research in earth sciences at the Université Pierre et Marie Curie. Currently geophysics professor at IFP School, and an expert in geophysics for IFP Energies Nouvelles, Jean-Luc Mari is a member of the EAGE. He is associate editor for Near Surface Geophysics. In 2010, he received a Knighthood from the Ordre des Palmes Académiques.

After gaining experience in various roles involving physical measurements, Christophe Vergniault has worked as a geophysicist in the Geosciences Department at EDF's Industrial Division (EDF-DIPNN-DI-TEGG) for eight years. Trained as a geophysics ingénieur (EOST) and with a geology degree from Montpellier (master in advanced studies in structure and evolution of the lithosphere), he worked as a geophysicist in a company specializing in offshore surveying (Géodia), as a petrophysicist and wellsite geologist at Gaz De France (Exploration \& Production and underground storage department), and as physical measurement analyst for inspecting EDF hydropower. The result of this accumulation of experiences is reflected in this book through his outlook on geophysical measurements applied to the geotechnical field. 

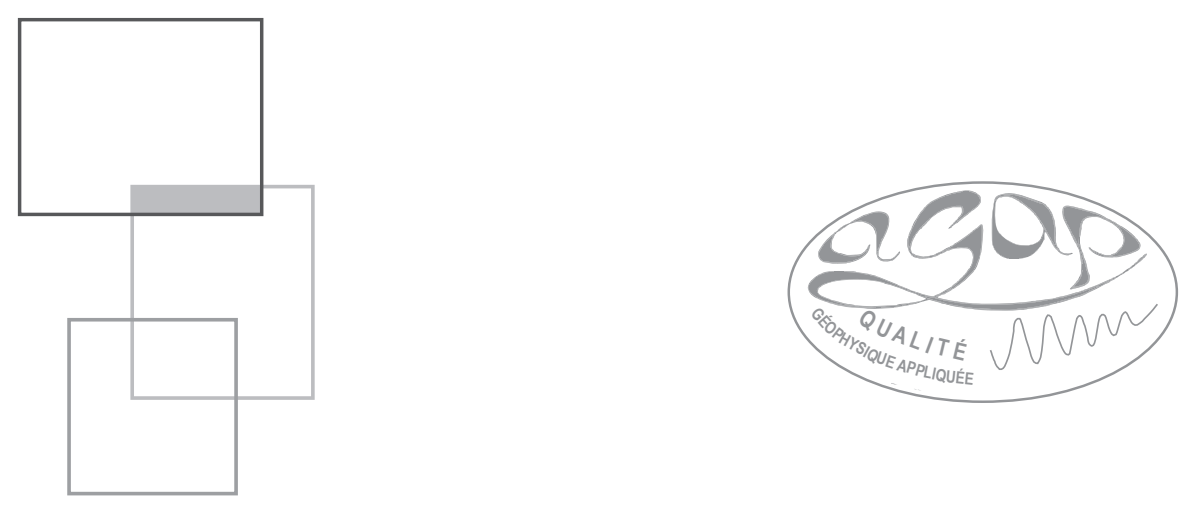

\section{Introduction}

\section{J.-L. Mari, C. Vergniault}

In the geophysics of oil exploration and reservoir studies, the seismic method is the most commonly used method to obtain a subsurface model. This method plays an increasingly important role in soil investigations for geotechnical, hydrogeological and site characterization studies regarding seismic hazard issues (Mari et al, 1999).

The surface seismic method involves:

- Seismic refraction (P or $S$ waves), which provides a subsurface velocity model. This method, applied to P waves, is commonly used in the geotechnology field to identify changes in the position of the bedrock, as well as longitudinal changes of its physical state or that of its overburden (see AGAP's Guide Sismique réfraction, O. Magnin, Y. Bertrand, 2005).

- Seismic reflection, a type of two or three-dimensional subsurface ultrasound method, which initially provides an image of the acoustic impedance contrasts of the subsurface. Depending on the means implemented, an investigation can reach hundreds of meters to several thousand meters in depth. However, the method does not perform well in the first 20 to 50 meters.

This chapter of Well seismic surveying and acoustic logging is published under Open Source Creative Commons License CC-BY-NC-ND allowing non-commercial use, distribution, reproduction of the text, via any medium, provided the source is cited.

(C) EDP Sciences, 2018

DOI: 10.1051/978-2-7598-2263-8.c002 
- Multiple Analysis of Surface Waves (MASW) which, by analyzing the Rayleigh or Love wave phase velocity in the frequency domain (scatter diagram), enables the calculation of the evolution of the shear wave velocity $\left(V_{S}\right)$ within the first tens of meters of subsurface. This method is increasingly used in geotechnology in combination with the seismic refraction method to determine the shear modulus.

The vertical resolution of all surface geophysical methods decreases as a function of the depth investigated. To obtain a precise model of the deep subsoil's seismic parameters (propagation velocities of $P$ waves $\left(V_{P}\right)$ and $S$ waves $\left(V_{S}\right)$, and density), geophysicists use borehole data such as those provided by the well seismic and acoustic logging methods, in particular to carry out the tying and calibration at depth of surface measurements. In addition, processing provides both a model for the propagation velocities of waves ( $\mathrm{P}$ and $\mathrm{S}$ waves) and also for density, such as the examples presented at the end of this introduction.

The examples presented in Figure 1 are extracted from 3D seismic data. Figure 1(a) is a near-surface example (Mari and Porel, 2007). The P velocity distribution was obtained by seismic refraction (tomography) for the very near surface (up to $30 \mathrm{~m}$ deep) and by seismic reflection (acoustic inversion) for the deep seismic horizons (20 to $120 \mathrm{~m}$ ). This first example is the subject of the case study in Chapter 5. It should be noted that a similar approach could be made by combining the MASW method and the S-wave seismic method. Figures 1(b), 1(c) and 1(d) are derived from the processing of a seismic reflection survey carried out to map horizons down to $1,500 \mathrm{~m}$ deep (Mari and Yven, 2014). The distribution of velocity $\left(\mathrm{V}_{\mathrm{P}}\right.$ and $\mathrm{V}_{\mathrm{S}}$ ) and density were obtained by elastic inversion.

The examples presented in this introduction already make it possible to highlight the fact that surface and well seismic methods combined with acoustic methods can be used successfully to estimate mechanical modules (Poisson's ratio, shear modulus and Young's modulus...). The objective of this book is to illustrate that the processes applied in deep geophysical exploration, combining different seismic and logging methods, can be applied to certain geotechnical and hydrogeological surveys, and site characterization in the context of seismic hazard studies.

This book, which is composed of five chapters, aims to present some of these approaches and their applications for near surface surveys $(<150 \mathrm{~m})$ :

- The first chapter provides an overview of the state-of-the-art technology in the geotechnical field regarding borehole measurements of subsoil shear wave velocity. It highlights the benefits of combining different methods: VSP-type well survey measurement with $S_{H}$ waves, generally called downhole, transmission between boreholes generally called crosshole, and dipole type acoustic logging (PSSL).

- The second chapter is devoted to the well seismic method. It describes the implementation procedure, the means of acquisition (sources and sensors) used in the civil engineering field, the different types of waves that make up the well seismic recordings (volume waves and guided modes) and the processing sequences. For more information, see "Well seismic surveying" by J.L. Mari and F. Coppens, 2003, Editions Technip. 
Profile IL-405: Velocity model in depth
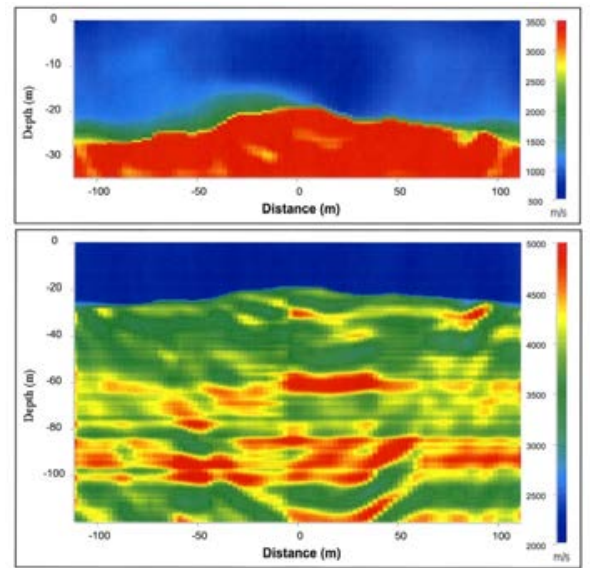

Near surface example

$P$ velocity distribution (a)

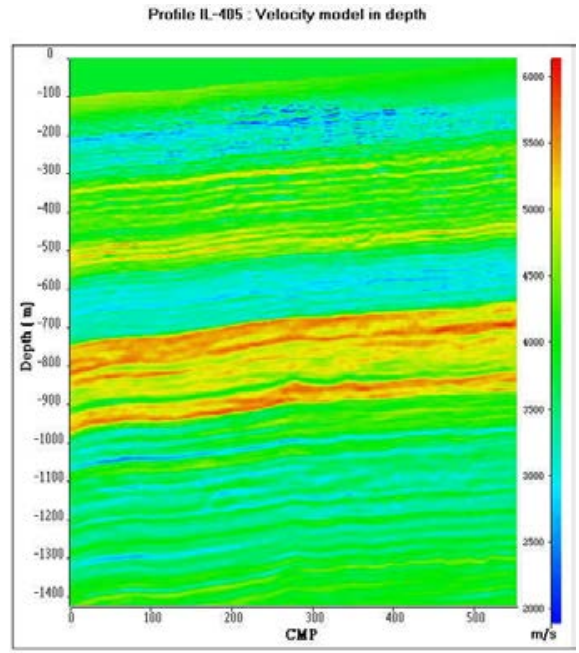

$P$ velocity distribution (b)

Profile IL-405: Density model in depth

Profile IL-405: Shear Velocity model in depth

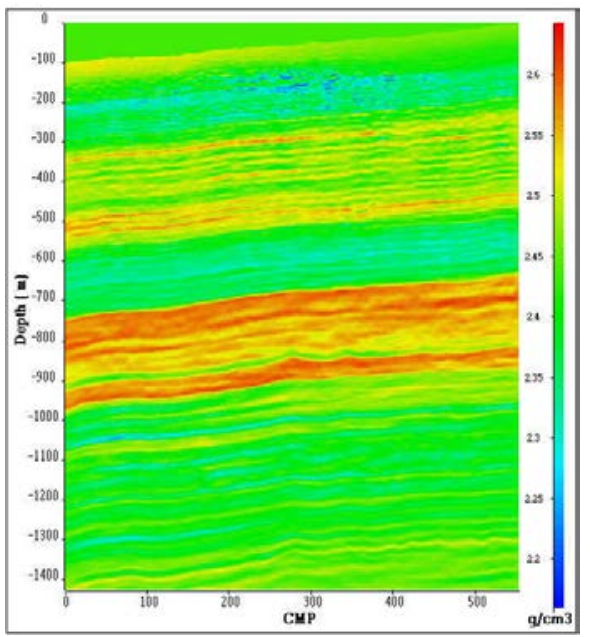

Density distribution (c)

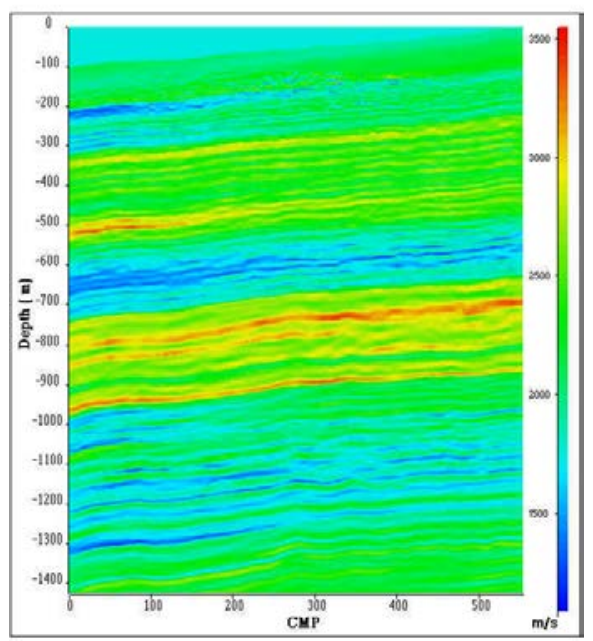

$S$ velocity distribution (d)

Figure 1 Distributions of velocities and densities obtained by seismic surveying Near surface example (a), petroleum type example $(b, c, d)$

- The third chapter is about full waveform acoustic logging and its main applications in the civil engineering field. It briefly describes: the logging tools implemented (monopole or dipole), the different wave types that make up acoustic recordings, and the contribution of acoustic measurements to the description of geological formations (mechanical parameters). There is also a discussion on the contribution of Stoneley waves for the estimation of $S$ velocities of formations 
and fractured zone detection. In addition, it shows how acoustic logging can be used to evaluate the quality of well cementation.

- The fourth chapter describes the benefits of combining measurements of formation velocities provided by VSP-type well tools and acoustic (sonic) tools. Based on a near surface example, it shows a tying method between sonic and check shots (VSP), which is used to obtain a time-depth relationship, tied to the seismic data and used for the conversion of logs into time and the calculation of synthetic seismograms.

- The fifth chapter is an integrated case study of a karstic limestone aquifer that is relatively close to the surface (20 to $130 \mathrm{~m}$ ). We show how multi-scale description of the reservoir can be realized by integrating the information provided by different 3D-THR surface seismic methods, full waveform acoustic logging, VSP with hydrophones, borehole optical televiewer and flow measurement.

Note: In the oil sector, the word 'well' is commonly used to mean borehole. This notion is not ideal for geotechnology usage, where boreholes are drilled for investigation and not production. In this document, we will therefore use the word 'well' for all descriptions relating to a transfer of technology from the oil world to geotechnology. However, borehole' will be used in relation to common geotechnical methods.

\section{References}

Mari J. L., Arens G., Chapellier D., Gaudiani P., 1999, Geophysics of reservoir and civil engineering, Éditions Technip, Paris, ISBN 2-7108-0757-2.

Mari J.L., Porel G, 2007, 3D seismic imaging of a near - surface heterogeneous aquifer: a case study, Oil and Gas Science and Technology, Rev IFP 63, 179-201. Doi: $10.2516 /$ ogst/2007077.

Mari J.L., Yven B., 2014, The application of high-resolution 3D seismic data to model the distribution of mechanical and hydrogeological properties of a potential host rock for the deep storage of radioactive waste in France, Marine and Petroleum Geology 53, 133-153. 

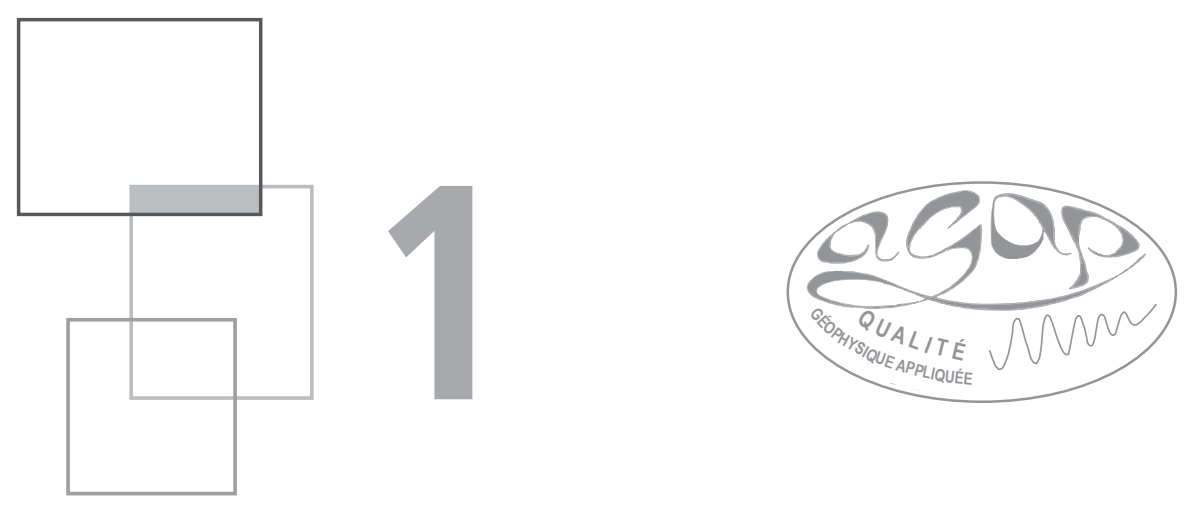

\title{
Shear velocity measurement in boreholes
}

\author{
C. Vergniault, J.-L. Mari
}

\subsection{Context}

\subsubsection{Overview of invasive and non-invasive $V_{s}$ measurements}

Measurement of shear waves $(S)$ can be invasive (borehole seismic surveys and logging) or non-invasive (surface waves (Multi analysis of surface waves: MASW) and ambient noise (Ambiance measurement vibration: AMV)). Obviously, each method has advantages and disadvantages that the project manager (client or subcontractor) must evaluate to select the most suitable method for the project. To assist in this process, Table 1.1 summarizes the pros and cons of each method.

This chapter of Well seismic surveying and acoustic logging is published under Open Source Creative Commons License CC-BY-NC-ND allowing non-commercial use, distribution, reproduction of the text, via any medium, provided the source is cited.

(C) EDP Sciences, 2018

DOI: $10.1051 / 978-2-7598-2263-8 . c 003$ 
Table 1.1 Pros and cons of invasive and non-invasive methods.

\begin{tabular}{|c|c|c|c|c|c|}
\hline & Method & Target depth & $\begin{array}{l}\text { Vertical } \\
\text { resolution }\end{array}$ & Limitations & $\begin{array}{c}\text { Offshore } \\
\text { application }\end{array}$ \\
\hline \multirow{3}{*}{ 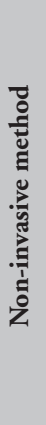 } & $S$ refraction & $\begin{array}{l}50 \mathrm{~m} \text {, but } \\
\text { sometimes less } \\
\text { than } 10 \mathrm{~m} \text { in } \\
\text { an industrial } \\
\text { environment }\end{array}$ & Several meters & $\begin{array}{l}\text { Affected by noise } \\
\text { in an industrial } \\
\text { environment, } \\
\text { limited by velocity } \\
\text { reversals }\end{array}$ & Yes \\
\hline & MASW & 15 to $20 \mathrm{~m}$ & Several meters & $\begin{array}{l}\text { Need for a tabular } \\
\text { medium in the } \\
\text { investigated area }\end{array}$ & Yes \\
\hline & AMV & $\begin{array}{l}\text { Several hundred } \\
\text { meters }\end{array}$ & $\begin{array}{l}\text { Several meters } \\
\text { to decameters }\end{array}$ & $\begin{array}{l}\text { Need for a tabular } \\
\text { medium in the } \\
\text { investigated area }\end{array}$ & Not currently \\
\hline \multirow{2}{*}{ 占 } & $\begin{array}{l}\text { Monopole sonic } \\
\text { logging }\end{array}$ & $\begin{array}{l}>1,000 \mathrm{~m}, \text { for } \\
\text { deep boreholes, } \\
\text { of prospective } \\
\text { exploration }\end{array}$ & $\begin{array}{l}\text { Several } \\
\text { decameters }\end{array}$ & $\begin{array}{l}\text { Requires an } \\
\text { uncased borehole } \\
\text { and for } V_{s} \text { to be } \\
\text { greater than } V_{p} \text { in } \\
\text { the borehole fluid }\end{array}$ & Yes \\
\hline & $\begin{array}{l}\text { PSSL or dipole } \\
\text { sonic logging }\end{array}$ & $\begin{array}{l}\text { Up to } 300 \mathrm{~m} \text { for } \\
\text { geotechnical deep } \\
\text { boreholes }\end{array}$ & $1 \mathrm{~m}$ & $\begin{array}{l}\text { Preferably in an } \\
\text { uncased borehole } \\
\text { but it's also possible } \\
\text { to use PSSL } \\
\text { through a sealed } \\
\text { case }\end{array}$ & $\begin{array}{l}\text { Yes, but with } \\
\text { uncased holes }\end{array}$ \\
\hline \multirow{3}{*}{ 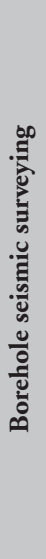 } & Crosshole & $\begin{array}{l}\text { Up to } 50 \mathrm{~m} \text {, } \\
\text { exceptionally } 100 \mathrm{~m}\end{array}$ & $1 \mathrm{~m}$ & $\begin{array}{l}\text { Requires } 2 \\
\text { boreholes, either } \\
\text { uncased or with } \\
\text { sealed casings and } \\
\text { limited deviation }\end{array}$ & $\begin{array}{l}\text { Generally too } \\
\text { expensive }\end{array}$ \\
\hline & Downhole & $\begin{array}{l}\text { Up to } 50 \mathrm{~m} \text {, } \\
\text { exceptionally } \\
100 \mathrm{~m} \text {, for S-waves. } \\
\text { Can also be very } \\
\text { deep for P-waves } \\
(>1,000 \mathrm{~m})\end{array}$ & Several meters & $\begin{array}{l}\text { Requires } 1 \\
\text { borehole, uncased } \\
\text { or sealed cased }\end{array}$ & $\begin{array}{l}\text { Yes for P-waves. } \\
\text { Remains too } \\
\text { complicated for } \\
\text { S-waves }\end{array}$ \\
\hline & Uphole & $\begin{array}{l}10 \mathrm{~m} \text { for } \mathrm{S} \text {-waves, } \\
50 \mathrm{~m} \text { for } \mathrm{P} \text {-waves }\end{array}$ & Several meters & $\begin{array}{l}\text { Difficult to have a } \\
\text { powerful S source } \\
\text { without damaging } \\
\text { the casing }\end{array}$ & $\begin{array}{l}\text { Difficult to have } \\
\text { an adapted } S \\
\text { source }\end{array}$ \\
\hline
\end{tabular}

Based on the capabilities and limitations of each method, described in Table 1.1, several choices are possible depending on the project's objective and the level of knowledge about the site. These choices are summarized in Table 1.2. Finally, the economic aspect is also a key factor in choosing between the possible options. 
Table 1.2 Method suitability according to objective.

\begin{tabular}{|l|l|l|l|l|}
\hline Requirement & \multicolumn{2}{|l|}{$\begin{array}{l}\text { Modeling the ground response for the } \\
\text { purposes of sensitive construction design }\end{array}$} & $\begin{array}{l}\text { Designing a construction to conform to } \\
\text { the Eurocode 8 soil classification }\end{array}$ \\
\hline $\begin{array}{l}\text { Level of } \\
\text { knowledge } \\
\text { about the site }\end{array}$ & $\begin{array}{l}\text { Overall knowledge } \\
\text { of the site is } \\
\text { insufficient to } \\
\text { establish velocity } \\
\text { logging of the } \\
\text { ground under the } \\
\text { proposed building }\end{array}$ & $\begin{array}{l}\text { Detailed knowledge } \\
\text { (velocity logging) } \\
\text { available at several } \\
\text { points around the } \\
\text { site, but not in the } \\
\text { ground below the } \\
\text { proposed building }\end{array}$ & $\begin{array}{l}\text { No special } \\
\text { knowledge }\end{array}$ & $\begin{array}{l}\text { The } \mathrm{V}_{\mathrm{s}} 30 \text { is known } \\
\text { in several points } \\
\text { around the site, but } \\
\text { not for the ground } \\
\text { below the proposed } \\
\text { building }\end{array}$ \\
\hline $\begin{array}{l}\text { Recommended } \\
\text { measurement }\end{array}$ & $\begin{array}{l}\text { Crosshole coupled } \\
\text { with downhole or } \\
\text { PSSL coupled with } \\
\text { crosshole in the top } \\
10 \text { meters }\end{array}$ & $\begin{array}{l}\text { Downhole or } \\
\text { PSSL coupled with } \\
\text { MASW and AMV }\end{array}$ & $\begin{array}{l}\text { Downhole coupled } \\
\text { with MASW and } \\
\text { AMV }\end{array}$ & $\begin{array}{l}\text { MASW and AMV } \\
\text { if space is sufficient } \\
\text { and unaffected } \\
\text { by multiple } \\
\text { underground } \\
\text { networks }\end{array}$ \\
\hline
\end{tabular}

This chapter addresses invasive geophysical methods to obtain a $V_{s} \log$, i.e. the following methods: downhole, uphole, crosshole and logging. The case studies presented are from EDF feedback from numerous soil surveys conducted over the last 5 years, as well as from the Inter Pacific research project whose objective was to compare geophysical methods for site seismic characterization (Garofalo, 2016). Non-invasive methods are not covered in this document.

\subsubsection{Applications}

The most common application concerns the design and sizing of civil engineering structures. Indeed, in the Eurocode 8 soil classification, one of the three main parameters for classifying soils is based on a average of shear wave propagation velocity within the top 30 meters. This parameter is conventionally called " $\mathrm{V}_{s} 30$ ".

Table 1.3 Mechanical parameters according to $V_{p}, V_{s}$ and $\rho$ (from Bourbié, 1986).

\begin{tabular}{|l|c|}
\hline Mechanical parameter & Equation with $\mathbf{V}_{\mathbf{p}}, \mathbf{V}_{\mathbf{s}}$ and $\rho$ \\
\hline Young's modulus, $\mathbf{E}_{\mathbf{d m a x}}(\mathrm{Pa}):$ & $\rho \mathrm{V}_{\mathrm{S}}^{2} \frac{3 \mathrm{~V}_{\mathrm{P}}^{2}-4 \mathrm{~V}_{S}^{2}}{\mathrm{~V}_{\mathrm{P}}^{2}-\mathrm{V}_{S}^{2}}$ \\
\hline Lamé constant, $\boldsymbol{\lambda}(\mathrm{Pa})$ & $\rho\left(\mathrm{V}_{\mathrm{P}}^{2}-2 \mathrm{~V}_{\mathrm{S}}^{2}\right)$ \\
\hline Bulk modulus, $\mathbf{K}(\mathrm{Pa})$ & $\rho\left(\mathrm{V}_{\mathrm{P}}^{2}-\frac{4}{3} \mathrm{~V}_{\mathrm{S}}^{2}\right)$ \\
\hline The shear modulus, rigidity or Coulomb's coefficient $\left(\mathbf{G}_{\mathrm{dmax}}\right.$ or $\boldsymbol{\mu}$ in $\left.\mathrm{Pa}\right)$ & $\rho \mathrm{V}_{\mathrm{S}}^{2}$ \\
\hline Poisson's ratio, $\boldsymbol{\gamma}$ (without dimension) & $\frac{\mathrm{V}_{\mathrm{P}}^{2}-2 \mathrm{~V}_{\mathrm{S}}^{2}}{2\left(\mathrm{~V}_{\mathrm{P}}^{2}-\mathrm{V}_{\mathrm{S}}^{2}\right)}$ \\
\hline
\end{tabular}


Moreover, for a given density, the P and S measurements in boreholes also enable the determination of in-situ parameters necessary to define a model that remains elastic under small deformations (Table 1.3). There are essentially two moduli: the Young's modulus and the shear modulus.

\subsubsection{Environmental conditions}

It is important to note that, in the geotechnics field, drilling for invasive measurements generally crosses unstable terrain. Hence, they are often lined with a casing or PVC tubing that is sealed to the formation with cement grout.

Seal quality is paramount to enable a good transmission of seismic signals. Therefore, drilling and sealing must meet the standards described in ASTM D7400 for downhole and D4428 for crosshole.

The key points of this phase can be summarized in Table 1.4.

Table 1.4 Summary of hole parameters according to ASTM standards for geophysical borehole measurements.

\begin{tabular}{|l|l|}
\hline Max drilling diameter & $175 \mathrm{~mm}$ (7 in) \\
\hline Internal casing diameter & 50 to $100 \mathrm{~mm}$ (2 to 4 in) \\
\hline Tubing type & PVC or aluminum, closed at the base \\
\hline Sealing grout & $\begin{array}{l}\text { Bentonite-cement grout with a density close to that of the surrounding } \\
\text { soil to limit the energy loss by this waveguide }\end{array}$ \\
\hline
\end{tabular}

For PVC-cased boreholes, it is possible to carry out a cementation control through a Cement Bond Log and Variable Density Log (CBL-VDL), even though this tool was initially developed for steel casings (see Chapter 3). The CBL-VDL log is a recording carried out with an acoustic tool centered in the borehole, with a piezoelectric source and receiver that are distinct with a distance between them of $3 \mathrm{ft}$ and $5 \mathrm{ft}$ for CBL and VDL respectively. If the coupling is good (low acoustic velocity contrast) most of the energy is transmitted and the energy of the refracted waves is low, which visually translates into low CBL and VDL amplitudes (gray rectangles in Figure 1.1). If this is not the case, the amplitude of the recorded waves is high. This signal is somewhat "rectilinear" in nature (red rectangle in Figure 1.1). It should be noted that if the formation has a high velocity compared to that of the casing $(2,100$ to $2,200 \mathrm{~m} / \mathrm{s}$ for PVC compared to $5,600 \mathrm{~m} / \mathrm{s}$ for steel), then the refracted waves in the formation will arrive first, thus masking the refracted waves in the casing (orange rectangle in Figure 1.1). On the other hand, if these waves dominate, it means that the entirety of the casing, grout and formation is adherent. 

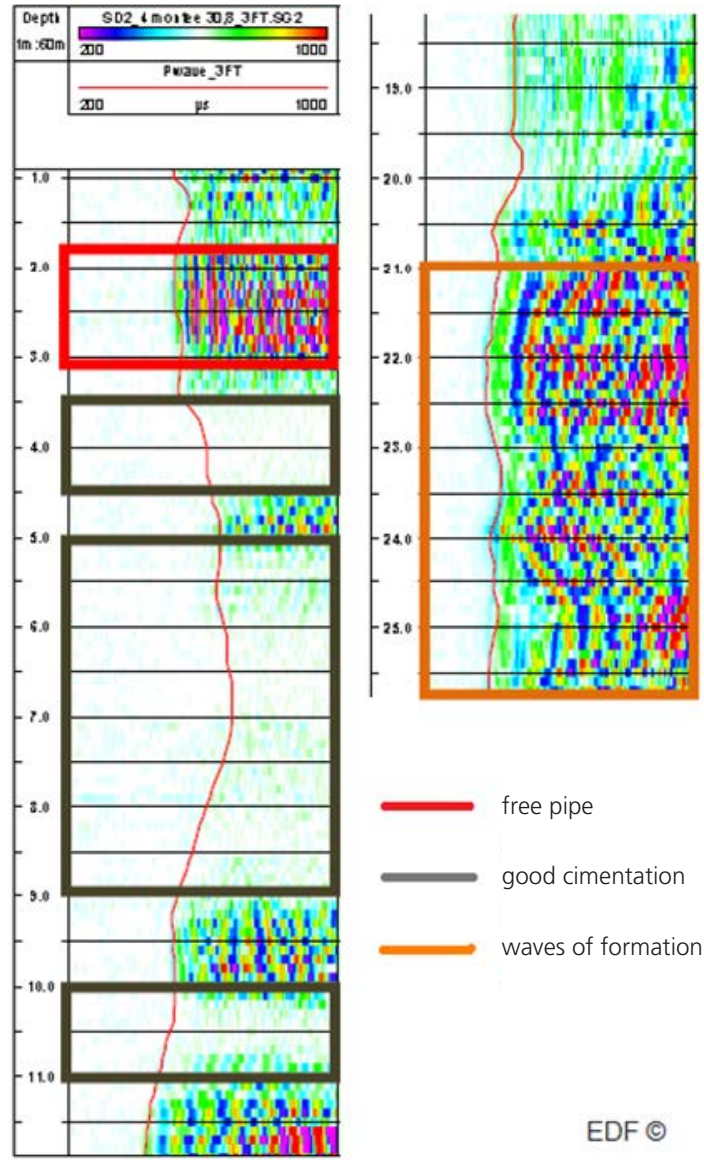

EDF $\odot$

Figure 1.1 Illustration of a Full wave sonic log used as a CBL-VDL to evaluate the quality of the cementation (LIM Logging acquisition for EDF).

This logging can be carried out with an acoustic tool of the sonic full waveform type. This is a necessity for a crosshole through an unstable formation (sandygravelly). Indeed, depending on the results, the allocation of emitting and receiving boreholes may be reviewed.

\section{$1.2 \quad \mathbf{V}_{\mathrm{s}}$ measurements by borehole seismic method}

Borehole transmission seismic surveying can be illustrated as a special type of Vertical Seismic Profiling (VSP, see Chapter 2) where the focus of interest is not the waves reflected at the interfaces, but the time of first arrival of the transmitted wave 
between the source at the surface and the receiver in the borehole. This is illustrated in Figure 1.2 below.
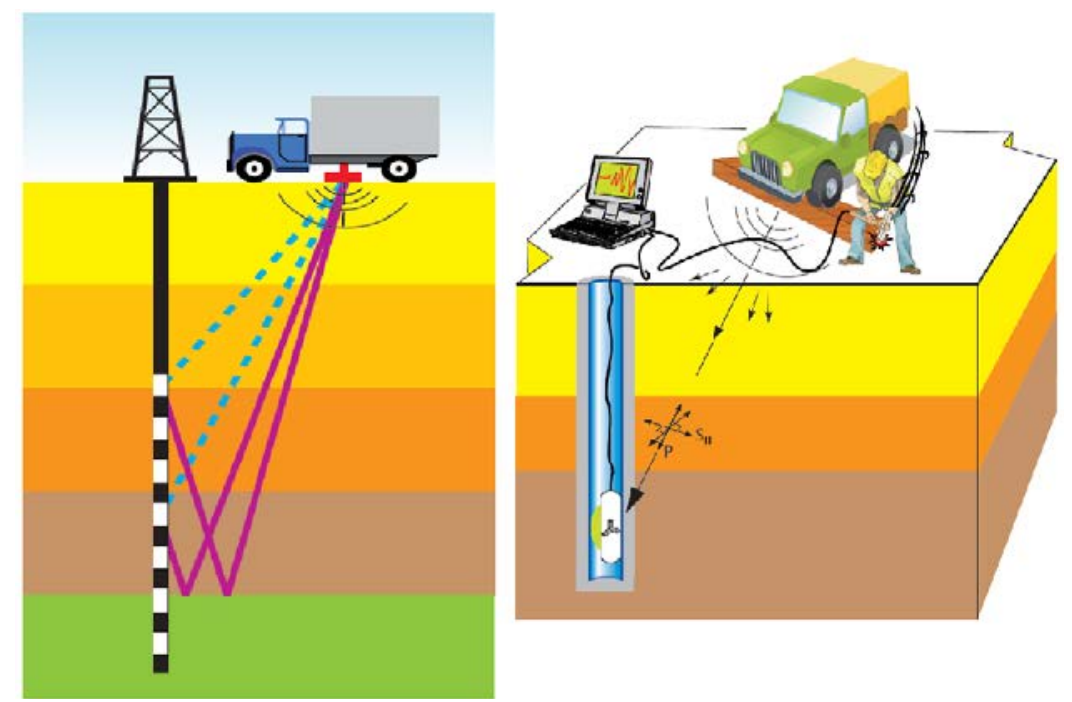

Figure 1.2 Illustration of the seismic raypath during a VSP or check shot (left) and a downhole (right). Reflected waves shown in purple; direct waves shown as dotted lines.

Regarding the study of transmitted or direct waves, in petroleum seismic prospecting, we refer more to check shots and also to seismic coring.

- In general, a check shot is carried out on the whole depth of an oil borehole (kilometric scale). It is used for seismic calibration, i.e. the geological characterization of seismic markers. Indeed, check shot results are presented in the form of graphs: time-depth, mean velocities of intervals, mean quadratic velocities as a function of the depth and the geological formations encountered in the borehole.

- Seismic coring is usually carried out in a shallow borehole (hectometric or decametric scale). It is used to determine the weathering zone (WZ) parameters, particularly its thickness and velocity, which are essential parameters for static corrections. Often its acquisition follows an uphole configuration (source in borehole, such as dynamite) rather than downhole (source on surface).

Geotechnics tends to focus on downhole $(\mathrm{DH})$, and also on shear waves $(\mathrm{S})$ in particular. For applications requiring a detailed evaluation of the $\mathrm{V}_{\mathrm{s}}$ logging as a function of depth (modeling ground response for construction design purposes), we often favor the measurement of transmission between boreholes, enabling the establishment of a velocity profile with a metric step, referred to as crosshole. 


\subsubsection{Downhole}

During a downhole acquisition, the seismic receiver is inside the borehole and the source is on the surface. Alternative configurations can be implemented with a seismic receiver in a cone penetrometer (Seismic Cone Penetration Testing - SCPT) or in a dilatometer (SDMT). In addition, a configuration with two receivers separated by a fixed distance is also possible. Depending on the type of strike on the ground surface (vertical or horizontal), the seismic source can generate a signal containing a maximum of energy in the compression wave $(\mathrm{P})$ or the shear wave $(\mathrm{S})$, see Figure 1.3.

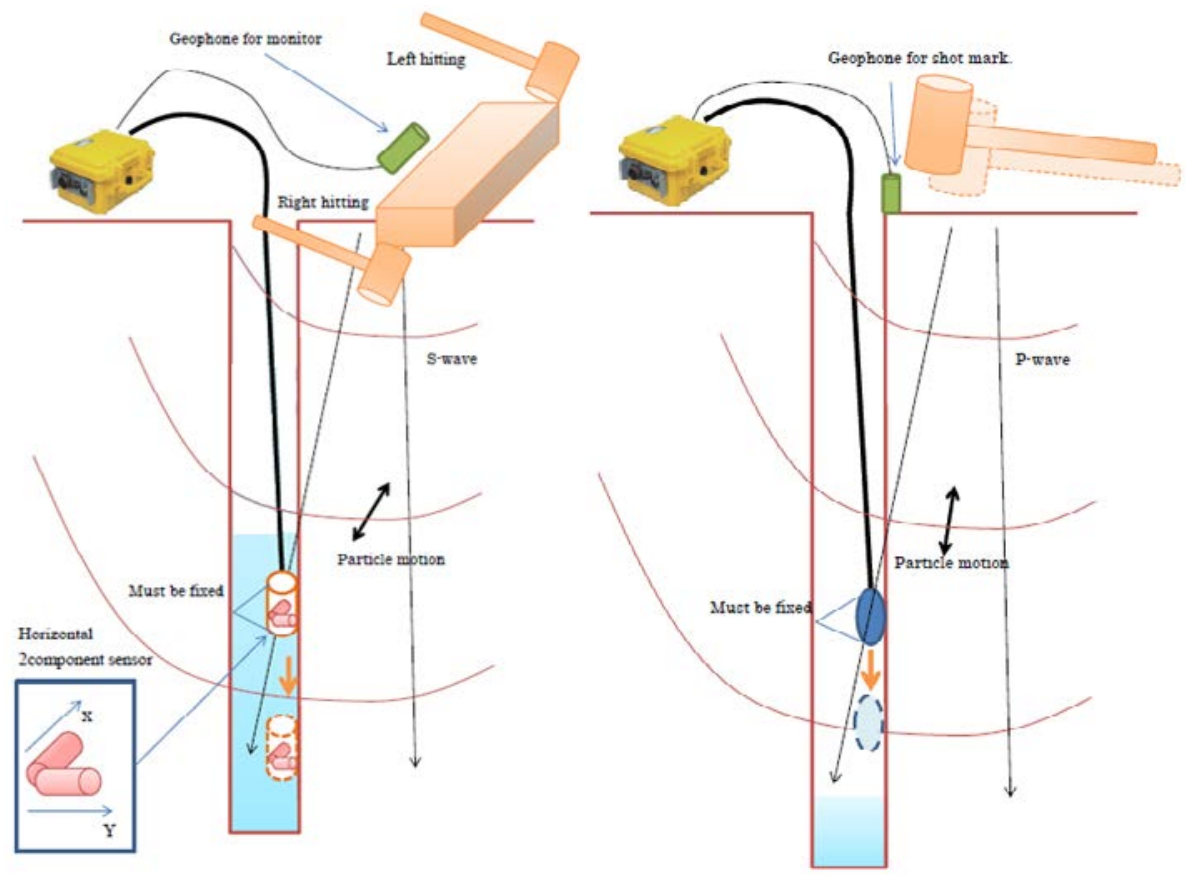

Figure 1.3 Typical configuration of a downhole where the shear waves are mainly recorded by horizontal components and the compression wave by the vertical component of the geophone in the borehole (according to Seis/mager technical documents, 2013).

\subsubsection{The acquisition device}

It is necessary to dissociate the acquisition and analysis of compression waves (P) and shear waves $(S)$. 


\subsection{Sources}

The standard ASTM D7400-08 (Standard Test Methods for Downhole Seismic Testing) clearly defines the most common $S$ source. It utilizes a beam of $2.4 \mathrm{~m}$ long and $15 \mathrm{~cm}$ thick, on which a vehicle can be positioned to ensure good coupling. An $S_{H}$ wave-rich signal is then obtained by lateral strikes on the sides of the beam, with a hammer of 5 to $15 \mathrm{~kg}$. The hammer can be mounted onto a pivoting axis as shown in the photos in Figure 1.4.
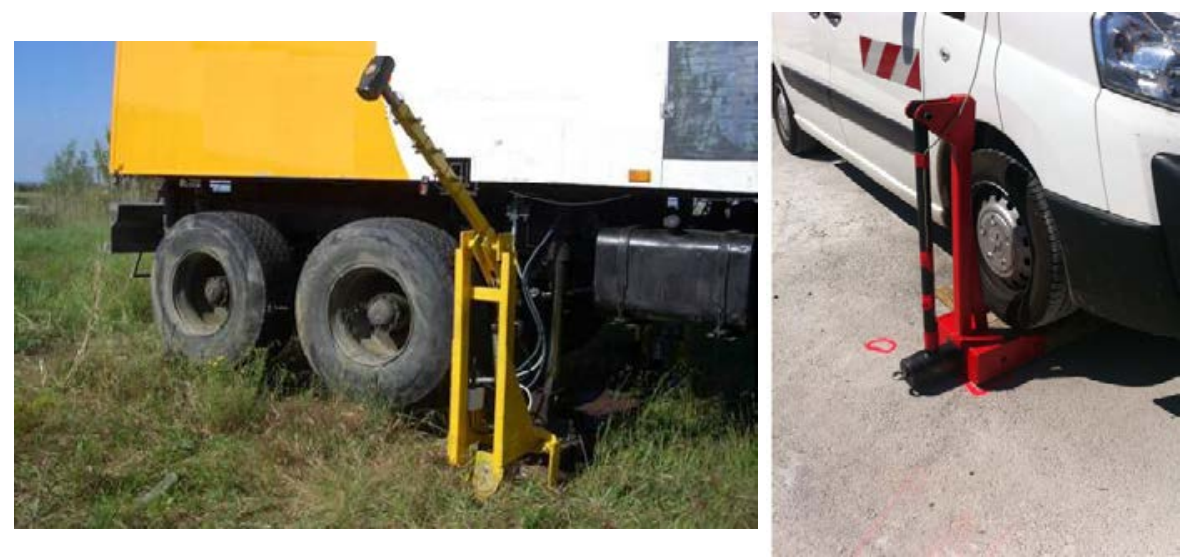

Figure 1.4 Illustration of an S source used in downhole testing which complies with the ASTM standard (IgeoTest source on the left, IMG source on the right).

To generate $P$ waves, an anvil can be vertically struck, either next to the beam on the axis between the midpoint and the borehole head, or next to each end of the beam.

\section{Choice of source location}

The distance between the midpoint of the beam and the probe (offset) must be carefully selected to limit the impact of tube waves, refracted waves and the angle of incidence. This distance is generally between 1 and $3 \mathrm{~m}$. If a larger offset is required ( 4 to $6 \mathrm{~m}$ ) or if the medium has several different velocity layers in the first 10 meters, then the refracted waves and actual paths (Snell-Descartes law) must be taken into account in the analysis (see Figure 1.5).

The impact of tube waves is a reality that must be taken into account. Figure 1.6 shows downhole data from a borehole full of water (blue signal), and then without water (black signal). This shows the complexity of the tube wave signal: a time of $60 \mathrm{~ms}$ at $30 \mathrm{~m}$ is not consistent with a simple signal reflected at the bottom and transiting through the water. The velocity corresponds more to that of a guided mode transiting at the water-casing interface (see Chapter 2, paragraphs on acoustic waves). 

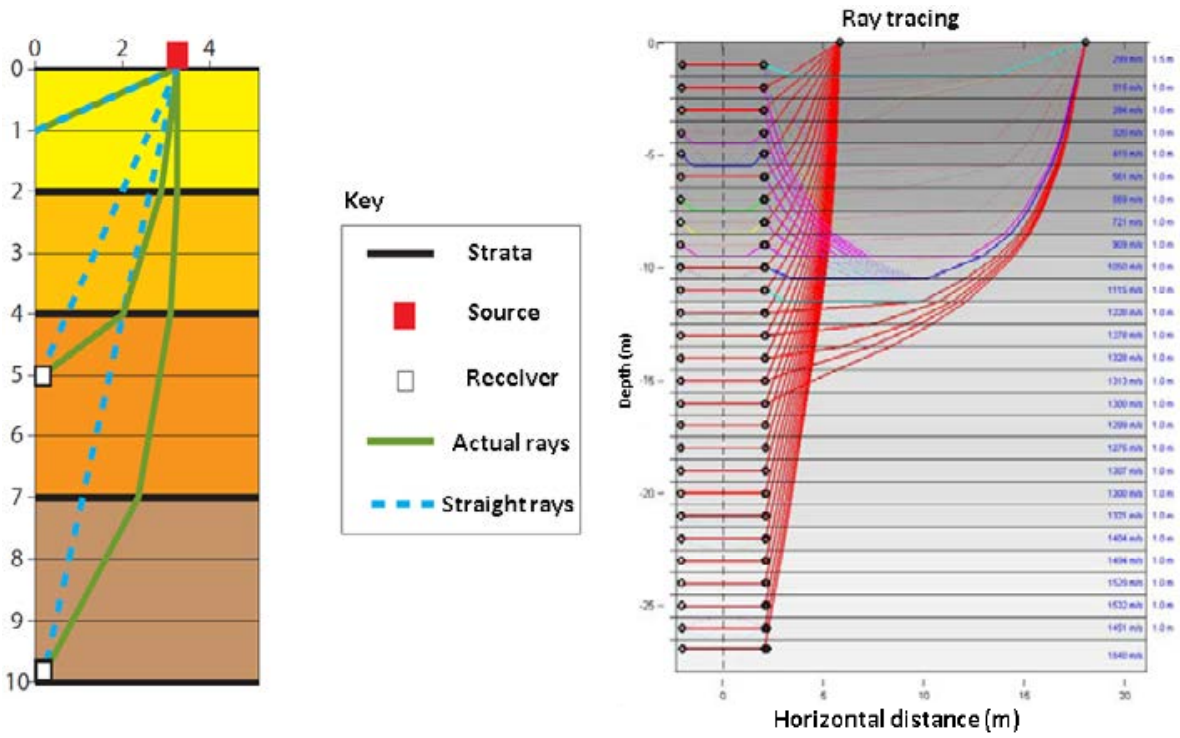

Figure 1.5 Illustration of the difference between actual path and straight rays in a classic downhole analysis (left). On the right, a ray model after joint inversion (Fugro for EDF) of a crosshole and 2 downholes with different offsets, illustrating that refracted waves are more present when the source offset is increased.

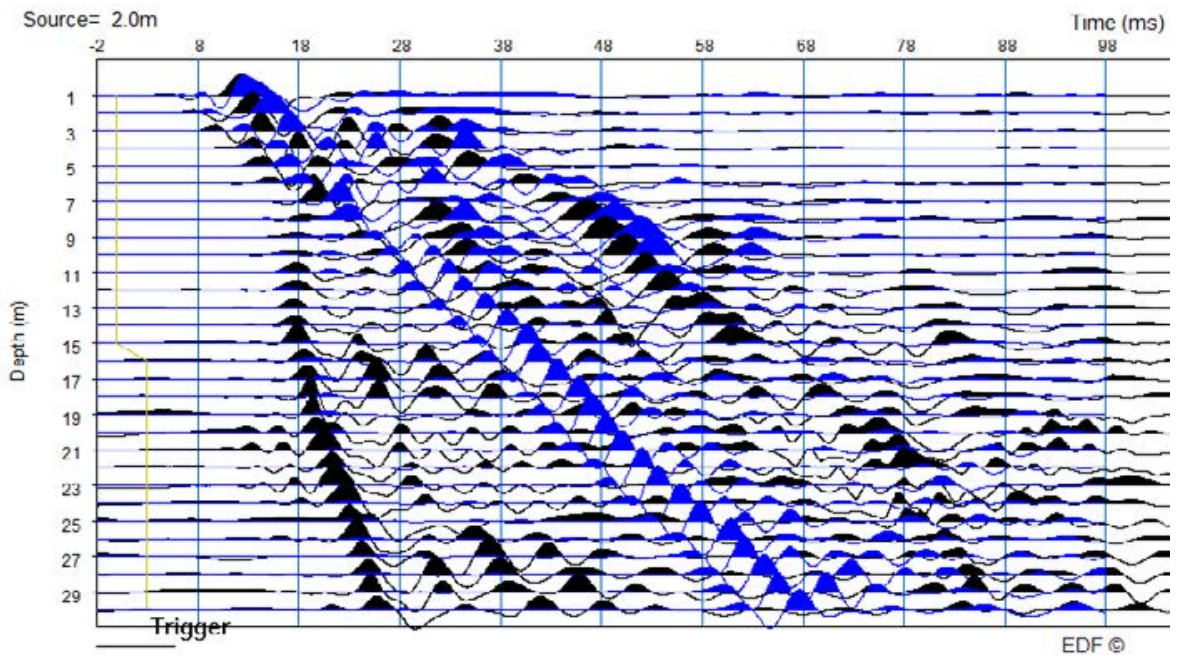

Figure 1.6 Illustration of a tube wave in a water-filled borehole. 
Figure 1.7 shows that air waves also exist in a borehole without water, but they are significantly less energetic ( $95 \mathrm{~ms}$ reflection at $30 \mathrm{~m}$ ). The effect can be reduced by placing a plug at the borehole head.

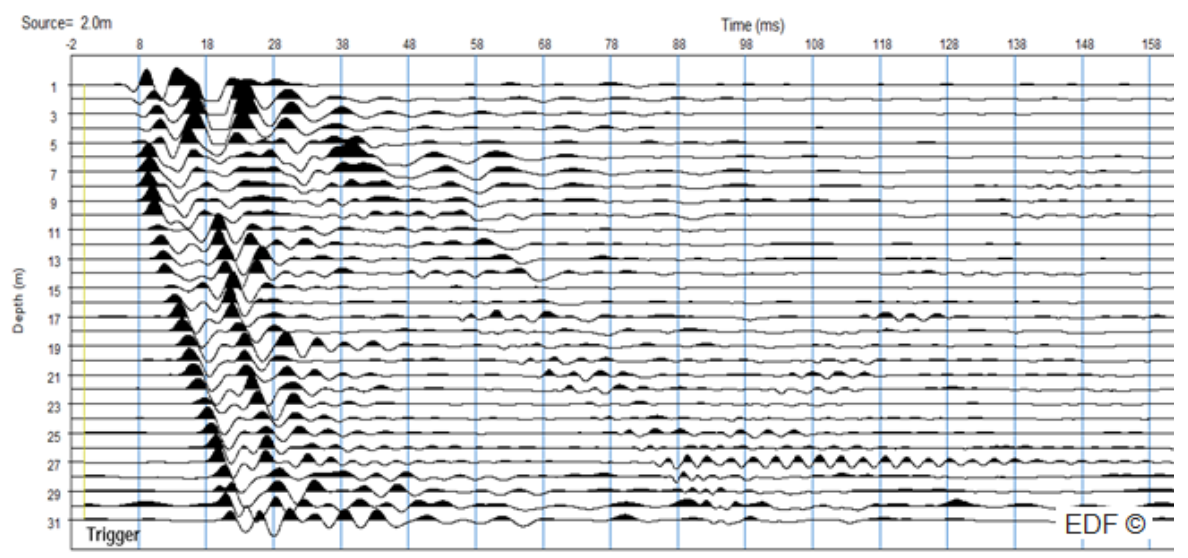

Figure 1.7 Illustration of a tube wave in a borehole without water.

Depending on the velocity of the medium, the tube wave in the water can mask $\mathrm{P}$ or $\mathrm{S}$ arrivals (see Figure 1.8). To avoid this it is essential to empty the borehole as much as possible or to increase the distance between the source and the borehole head. However, this last option will facilitate the generation of refracted waves (see Figure 1.5).
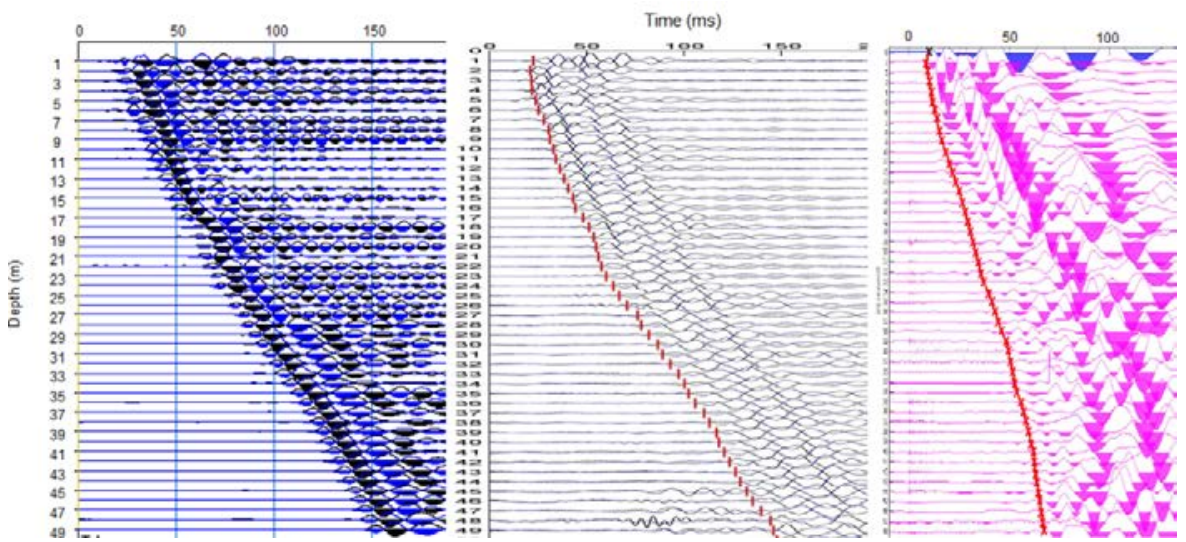

Figure 1.8 Illustration of tube wave impact (InterPacific Project), with a $3 \mathrm{~m}$ offset and borehole that has been emptied of water in the first example; with a $5 \mathrm{~m}$ offset and a borehole with water for the second example; and finally a third example showing a $3 \mathrm{~m}$ offset and borehole with water. This last example shows tube waves (InterPacific Project). 


\section{Seismic source coupling}

The coupling of the seismic source is also an important point (Figure 1.9). Ideally, the source should be positioned on natural ground (Figure 1.9a). In the presence of backfill, which strongly attenuates seismic waves (Figure 1.9b), it may be advisable to dig out the area until the natural terrain can be accessed. It should be noted that drilling and cementing techniques have a strong influence on signal transmission quality, as shown in the example in Figure 1.9c.
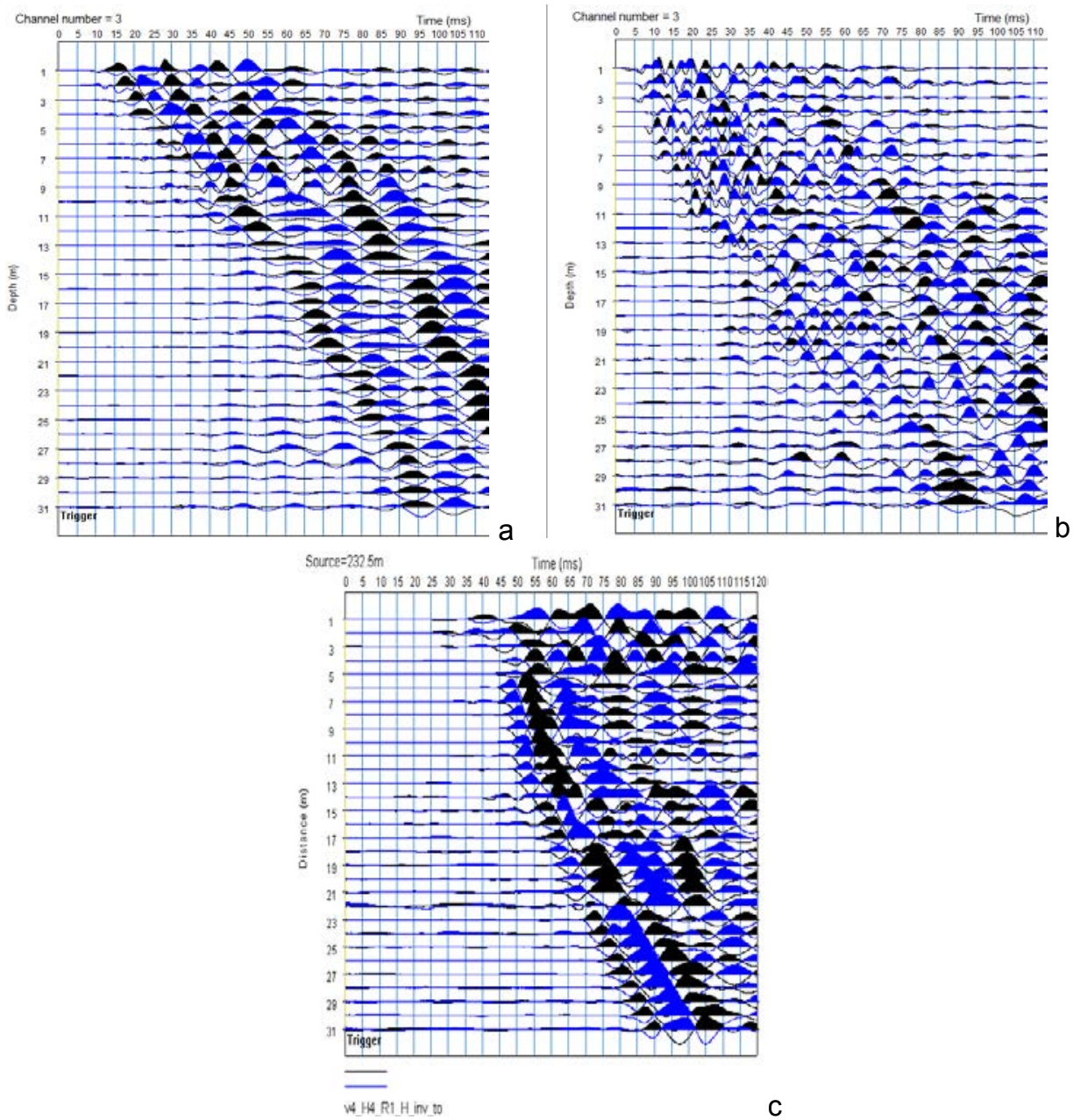

Figure 1.9 Effect of source coupling in downhole operation; a: Downhole with a source positioned on natural ground; b: Downhole with a source positioned on backfill (water table at $9.8 \mathrm{~m}$ ); c: Downhole on the same site as for a and $b$, but drilling carried out with sonic corer (4 $m$ water table, outside of water table the signal is polluted by refracted waves because the offset is too large). 
However, it is not always possible to situate the source on natural ground, but it is possible to make a short borehole to be able to use a borehole source directly under a backfilled area, in addition to that on the surface. However, it is important to use the surface source, because borehole sources are usually less powerful and there can be too much attenuation to make measurements for paths greater than $10 \mathrm{~m}$ (limitation on uphole measurement without the addition of a large number of stacks).

\subsection{Receivers}

In downhole surveys, P-wave energy arrives mainly on the vertical component of the receiver and $S_{H}$ wave energy is distributed on the horizontal components. Given that a short "offset" was applied (1 to $3 \mathrm{~m}$ ), it was necessary to pump the water out of the borehole to avoid tube waves. However, for a deep downhole, the casing should not be emptied to a depth greater than $50 \mathrm{~m}$, otherwise the risk of crushing the tube becomes too great. Consequently, it is not possible to use hydrophones near to the surface to make a P-wave downhole survey. A 3-component receiver anchored to the borehole wall, either a geophone or accelerometer type, is therefore recommended.

\subsubsection{Analysis of a downhole (DH)}

The initial step of the analysis involves picking the first $\mathrm{P}$ and $\mathrm{S}$ arrivals. A good quality signal will ensure that $\mathrm{P}$-waves can be picked without difficulty. For S-waves, it is essential to exploit the polarization property of the wave according to the direction of the strike (Figure 1.10). For this purpose, the phase opposition of shots in the opposite direction makes it possible to unambiguously identify $S$ arrivals (blue and black signals are of opposite sign, in Figure 1.10). Without this opposition, the recorded signal should be viewed with caution, because it may translate tube wave pollution or P-wave interference.

Figure 1.10 illustrates that with a conventional source, the phase opposition characterizing the $S$-waves can be observed down to $50 \mathrm{~m}$ deep. In favorable terrain, the same types of signals are observed down to a depth of $100 \mathrm{~m}$.

As with seismic refraction, the first step of the analysis is to view the distance-time graph (source-receiver distance curve as a function of time). In the first 10 meters this curve differs significantly from the depth-time curve due to the offset of the source (see Figure 1.5). At this point, the path between the source and the receiver is considered linear. However, this approximation is false if the medium has noticeable velocity variations in the first 10 meters. The impact increases with the offset of the source. From the distance-time graph, a downhole analysis is carried out in depth ranges (slices). The division into slices must be related to the slope break on the distance-time graph, but also and especially in connection with the geological log obtained from cores.

On the slices thus defined, the slope between the variations of distance and time of each segment provides the average velocity over the corresponding interval (see Figure 1.11). The slope of the radius linking a point to the origin gives the average velocity of the ground at the corresponding depth. Due to the picking uncertainty, 
each slice must contain a minimum of 3 measurement points, ideally 4 or 5 (see Figure 1.12). As a result, it is not recommended to carry out downhole acquisition with 2 receivers simultaneously to perform velocity calculations based on these 2 measurements. Finally, we also note that a downhole analysis, even with a metric measurement interval, is more integrative than a crosshole measurement.

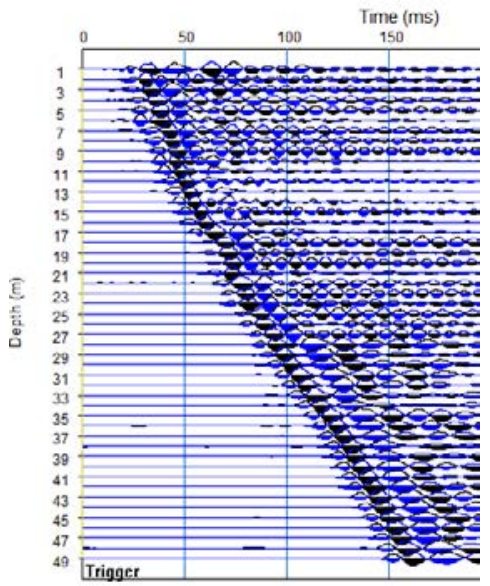

Figure $1.10 \mathrm{~S}$ downhole, up to $50 \mathrm{~m}$ in depth (InterPacific).

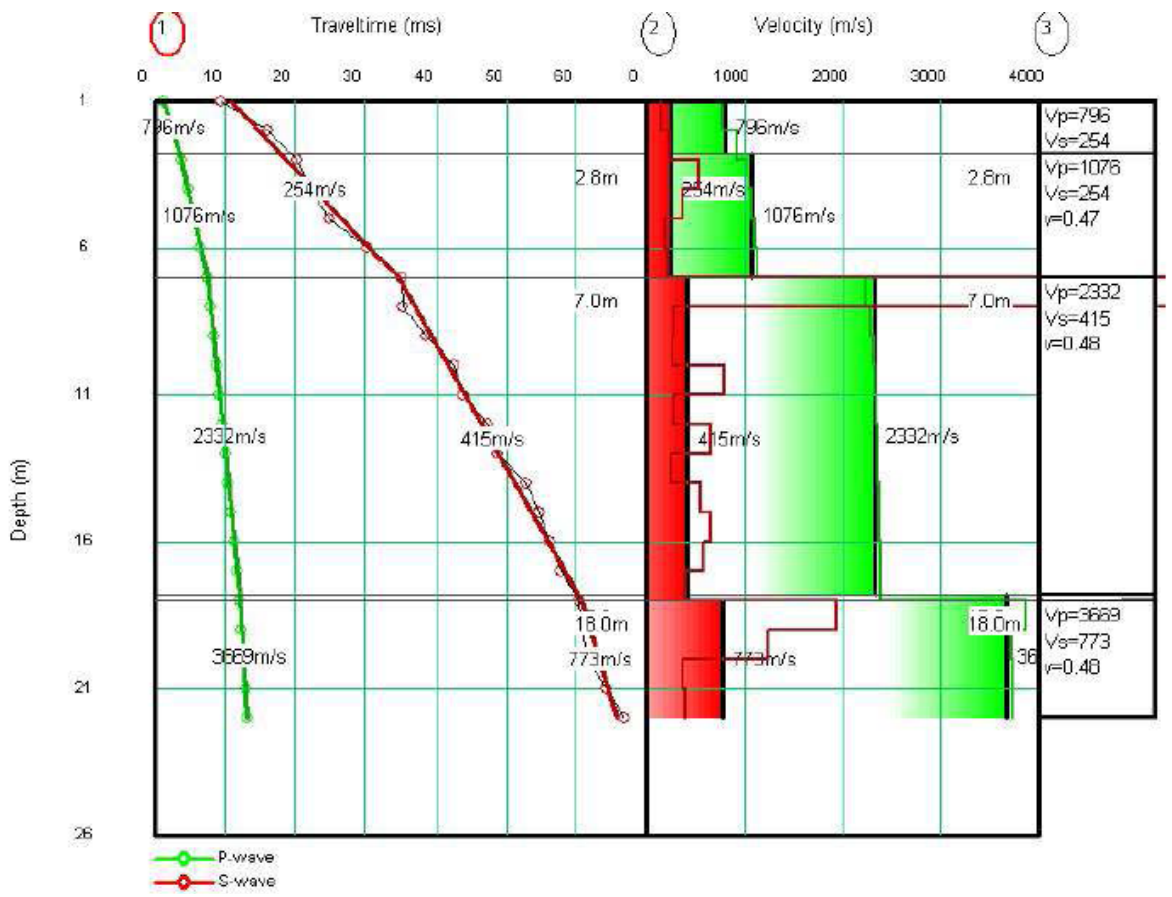

Figure 1.11 Illustration of a downhole (DH) analysis in P and S-waves based on 4 slices. 

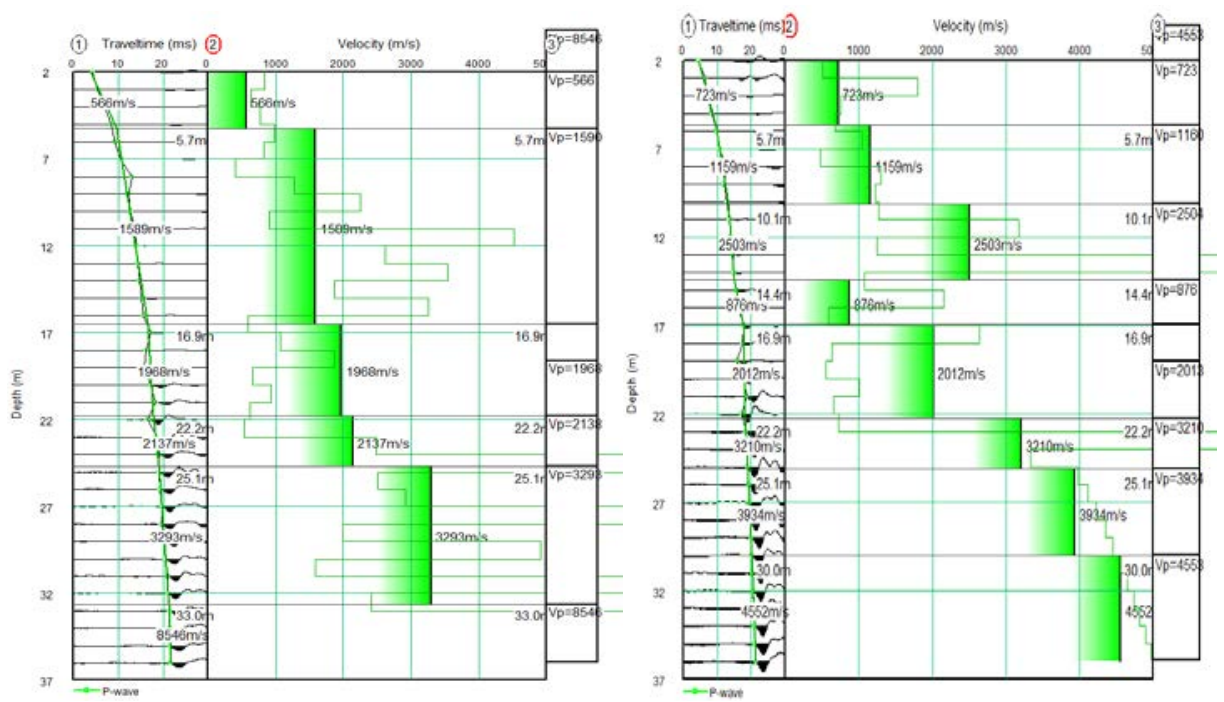

Figure 1.12 Illustration of the sensitivity of the analysis of the same Downhole (DH) according to slice selection.

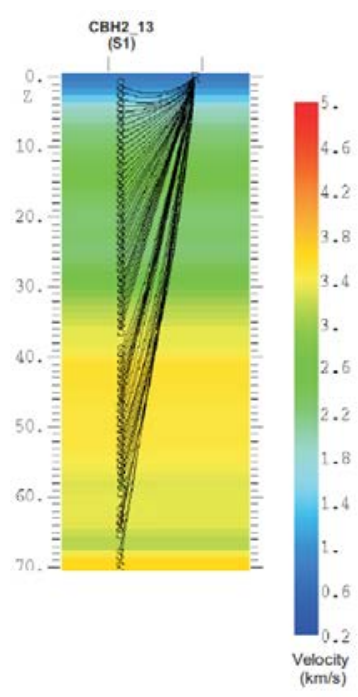

Uphole P-wave tomogram (8m offset)

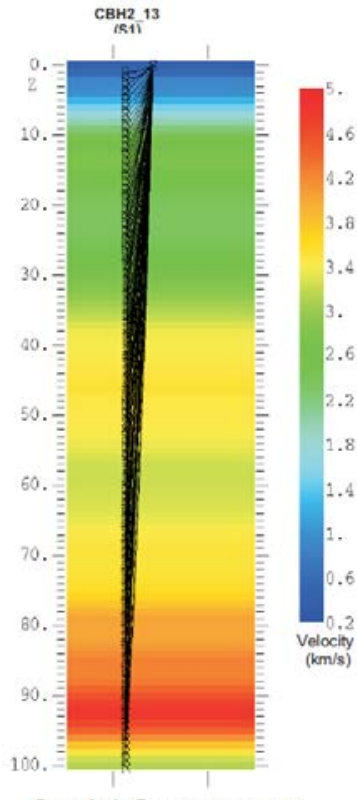

Downhole P-wave tomogram ( $3 \mathrm{~m}$ offset)

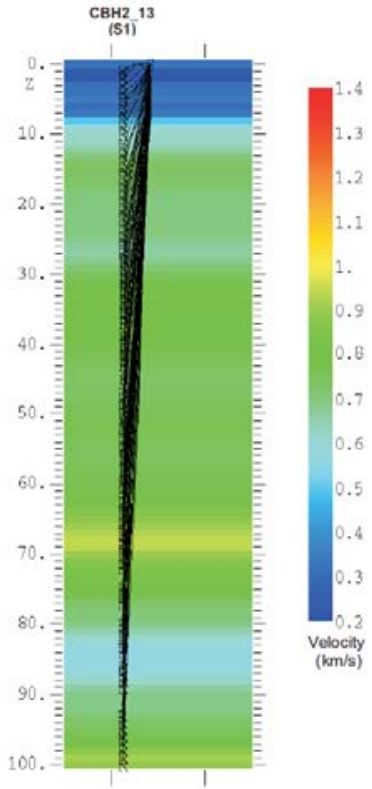

Downhole Sh-wave tomogram ( $3 \mathrm{~m}$ offset)

Figure 1.13 Uphole and downhole result after inversion with GEOTOMGC software (Terradata for EDF). 
To ensure the reliability of the analysis for the first 10 meters, a direct modeling or iterative inversion approach is possible (Figure 1.13). That is to say that, the direct calculation of travel times, for a given velocity model, must integrate the direct and refracted paths. Then, depending on the difference between the measured times and the calculated times, the model is adjusted. This iteration is repeated until the error criterion is acceptable.

Currently, software packages available on the market are not optimized for borehole measurements and do not directly differentiate between direct and refracted waves but take straight and curved raypaths into account. The straight rays correspond to the transmitted travel paths and the curved rays to the refracted waves.

\subsubsection{The specific example of offshore}

It is possible to carry out a $\mathrm{P}$ downhole survey at sea in an uncased borehole, using a source such as an air gun or sparker near to the surface. It is, however, much more complicated to find an $S$ source that is operational underwater and a 3-component receiver. Finally, if the ground is unstable, a P downhole survey through an unsealed protective casing can work if the terrain crossed is sufficiently plastic to establish an acceptable coupling with the casing (see Figure 1.14).
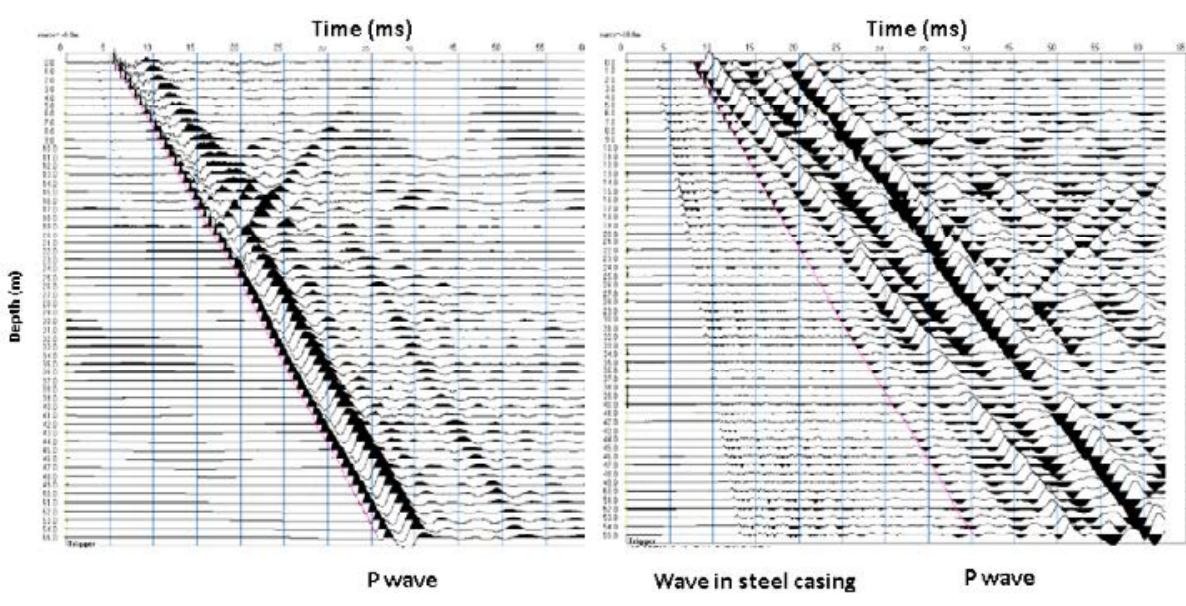

Figure 1.14 Downhole at sea in an uncased hole and through an unsealed protective casing (Fugro for EDF). 


\subsubsection{Uphole}

An uphole is similar to a downhole, but with the source in the borehole and the receiver on the surface. The practice is more limited because $S$ sources in boreholes generate a signal that fades over a relatively short distance. Even for P-waves, with a relatively powerful source (sparker) it is necessary to perform a large number of stacks. However, Figure 1.13 shows that depending on the context it is possible to obtain interesting results with P-waves (left graph). In addition, it can be useful to carry out an uphole when the measurement is coupled to crosshole acquisition, because this only requires the addition of a 3-component receiver on the surface.

\subsubsection{Crosshole}

The principle consists of measuring the travel time of compressional and shearing seismic waves, transmitted directly between a seismic source in a borehole and a 3 -component receiver in a neighboring borehole.

The compressional wave $(\mathrm{P})$ propagates through the horizontal plane as well as the horizontal component of the shear wave $\left(\mathrm{S}_{\mathrm{H}}\right)$. The vertical component of the shear wave $\left(S_{V}\right)$ propagates in the vertical plane. Therefore, the energy of the $P$ and $S_{H}$ wave is mainly distributed on the horizontal receivers and that of the $S_{v}$ wave on the vertical receiver.

The result of a crosshole measurement is often blindly accepted as a reference, but the method can face the following limitations, it can:

- be strongly affected by refracted waves in surrounding indurated strata,

- present "spatial aliasing" if bed thickness is less than that of the intervals,

- be affected by highly inclined formations,

- be strongly affected by poor cementation (casing-sealant-formation connection),

- be strongly affected by damage in the vicinity of the borehole.

Consequently, it is recommended to perform a downhole and/or uphole recording to complete and validate the crosshole, assuming that the anisotropic attenuation is negligible.

Specific cases:

- With highly heterogeneous geology, only seismic tomography can provide reliable information for the $\mathrm{P}$-wave profile. Therefore, in an environment with a known heterogeneous nature, it is also recommended to carry out an additional $\mathrm{P}$ crosshole acquisition with a hydrophone array so as to exploit the tomography data. For $S$-waves, the implementation of more than 2 anchored sensors is complex in the geotechnical field and therefore downhole or uphole recording generally has to suffice.

- Similarly, if the test is carried out in an environment with high horizontal anisotropy (e.g. beds fractured in a certain direction), the measurement system and 
results interpretation must be adapted (receiving boreholes at $90^{\circ}$ with directions parallel and perpendicular to those of the anisotropy).

- Finally, if the test is carried out in a medium with strong vertical anisotropy related to thin beds, the measurement system must also include a specific $\mathrm{S}_{\mathrm{H}}$ source (sparker $\left.\mathrm{P}-\mathrm{S}_{\mathrm{H}}\right)$.

\subsubsection{Prerequisites}

The quality of the casing sealing has a much stronger impact on the crosshole measurement than it does on the downhole measurement, because the signals are of higher frequency.

Velocity calculation requires the precise knowledge of the distance between the boreholes. Human error is possible with inclination measurements (see Figure 1.15) and a calibration defect can affect the trajectory measurements (see Figure 1.16). It is therefore vital to apply a procedure on the surface to control for the directions given by these measurements.
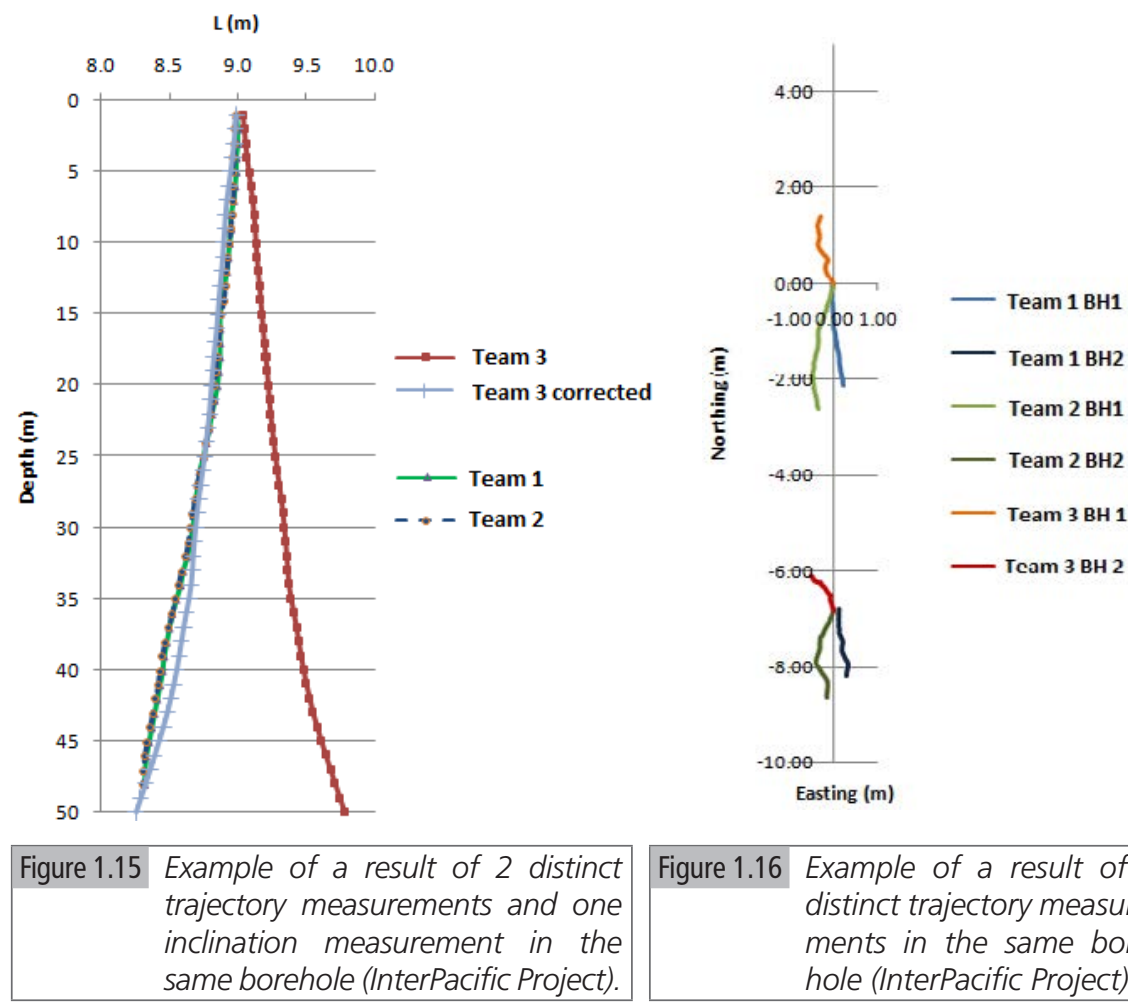
Figure 1.16 Example of a result of 3 distinct trajectory measure- ments in the same bore- hole (InterPacific Project).




\subsubsection{The acquisition device}

It is necessary to dissociate the acquisition and the analysis of the compression (P) and shear (S) waves. Until the start of the 1980s (Figure 1.17), the crosshole test was carried out as the source moved forward by striking the head of the drill string. This method has evolved through the development of an emission probe pressed against the borehole wall. This has the major advantage of separating the activities of the borehole drilling group from those of the geophysics measurements team. However, this brings source coupling problems.

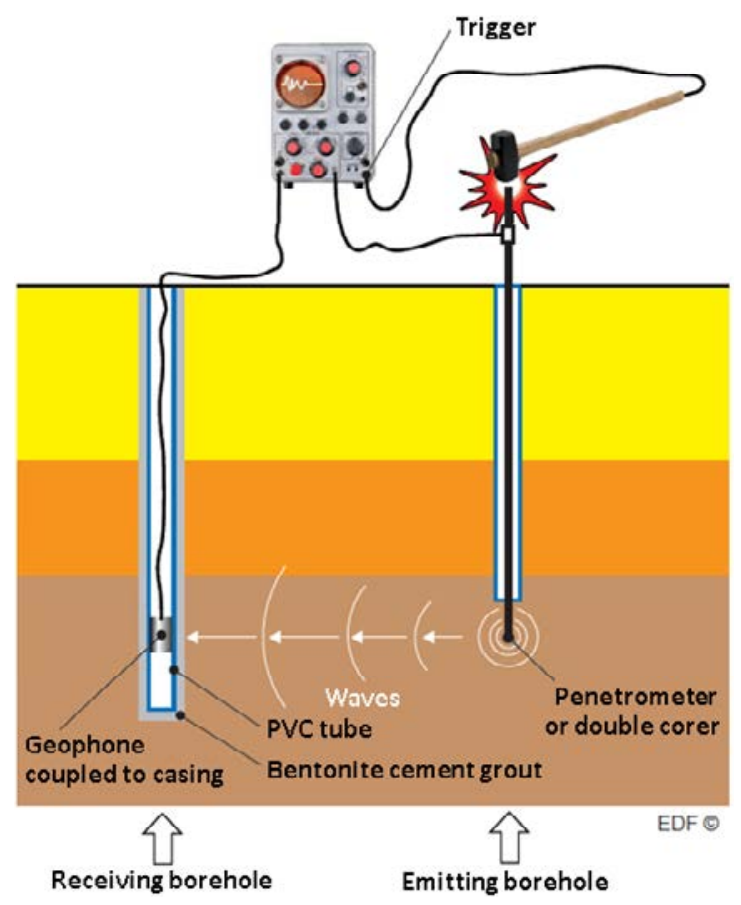

Figure 1.17 Historical crosshole measurement method, applied in France until the beginning of the 1980s.

The typically recommended crosshole method (Figure 1.18) requires 3 boreholes to calculate the velocity between two receiving boreholes without needing precise knowledge of the wave generation time ( $\mathrm{t} 0$, zero time). Today, this approach is questionable because very often the attenuation is such that the signal of the second borehole is difficult to exploit, and also the shot recording is no longer a technical limitation. Nevertheless, working with only one receiving borehole requires greater rigor, in particular, a calibrated measurement chain is required. As an example, there can be drift between the electric impulse and the generation of a sparker signal (Figure 1.19) due to the wearing of electrodes. 


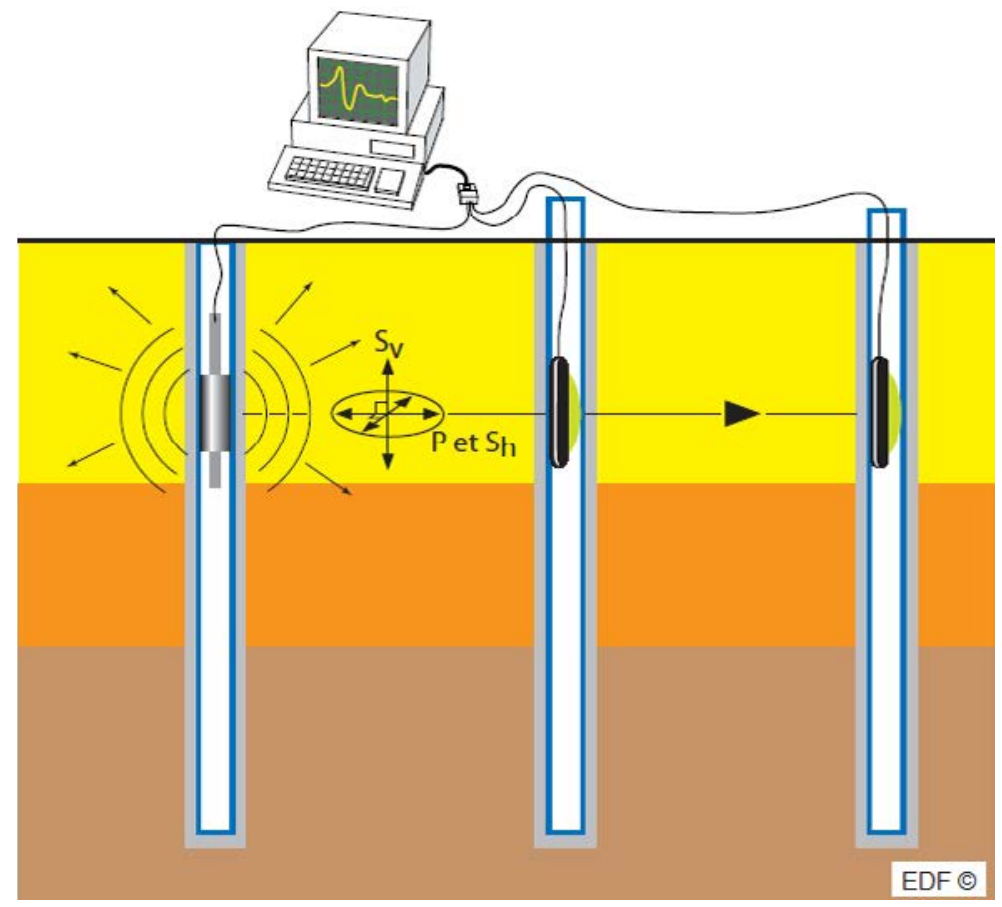

Figure 1.18 Illustration of a 3 borehole crosshole system.
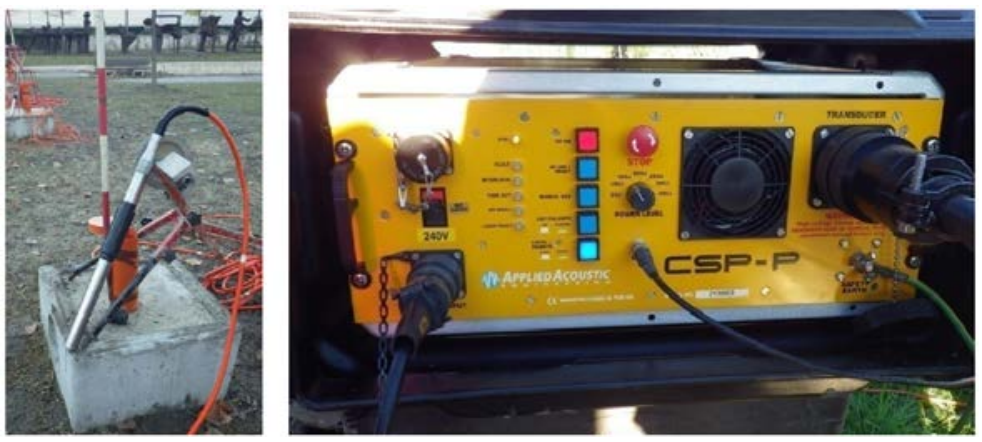

Figure 1.19 Illustration of a $P$ source: sparker (So/Géo).

Moreover, having a single receiver borehole can be disadvantageous if we want to pick the first arrival time at the maximum wave amplitude (apex), rather than at its beginning. Admittedly, this technique makes it possible to work with signals with a signal-to-noise ratio that is not so good. Moreover, due to the signal attenuation, 
too much noise can make it difficult to identify the start of the wave, which is the case particularly with the signal in the most distant borehole.

\subsection{Sources}

To maximize the energy of shear waves, it is recommended that a source that is mechanical (hammer-anvil) or electromechanical (similar to the sources of the PS Suspension Logging (PSSL) tool) should be anchored to the wall (Figure 1.20).
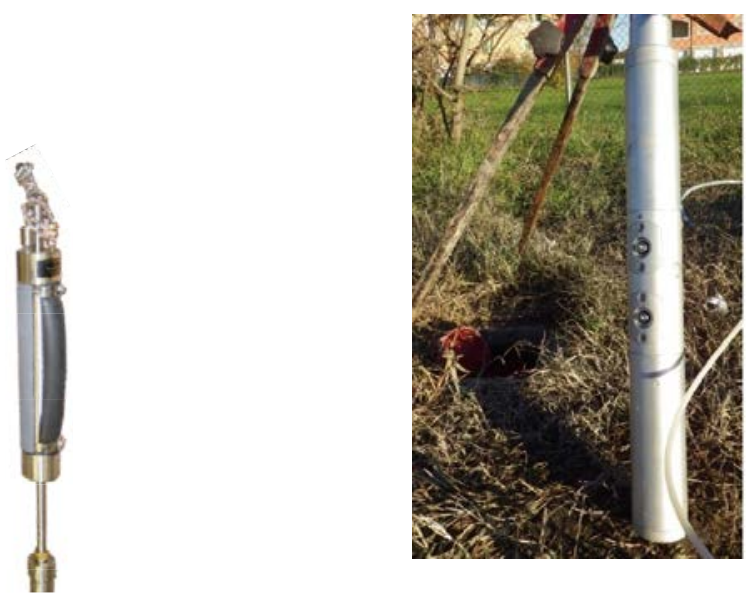

Figure 1.20 Illustration of a mechanical (Ballard anvil hammer) and an electrodynamic (SolGeo, mass moved up or down by an electromagnet) $S$ source.

\subsection{Receivers}

For P-waves, energy is distributed over the horizontal components, which can generate difficulties in picking the first arrivals and requires a mathematical polarization operation to project the energy in the source-receiver direction. Some receivers can be oriented in a given direction. However, the most simple and robust method is to use hydrophones to measure the P arrivals. It should be noted that some hydrophones are directly equipped with an amplification system to optimize recording dynamics.

For S-wave analysis, only a single 1-component receiver is needed. However, having a 3-component receiver associated with the mechanical source makes it possible, if required, to verify $\mathrm{P}$ measurements with the sparker-hydrophone combination (Figure 1.21). 

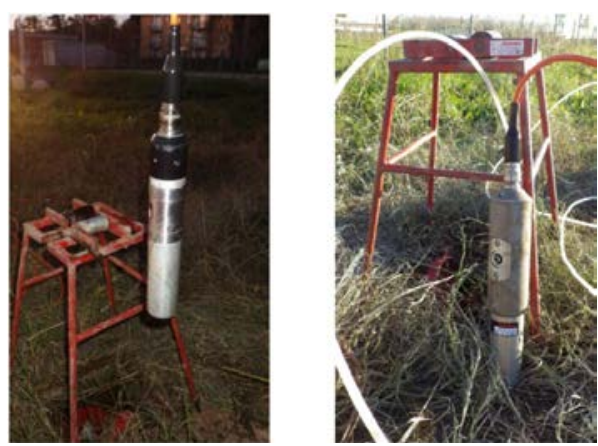

Figure 1.21 Hydrophone with an amplification system and 3C geophone with an anchoring system (Solgéo).

\section{Sampling}

Crosshole data acquisition requires small time sampling intervals.

$50 \mu$ s sampling is acceptable for recording S-waves, whereas higher frequency P-waves require a faster sampling rate until $2.5 \mu$ s (Figure 1.22).
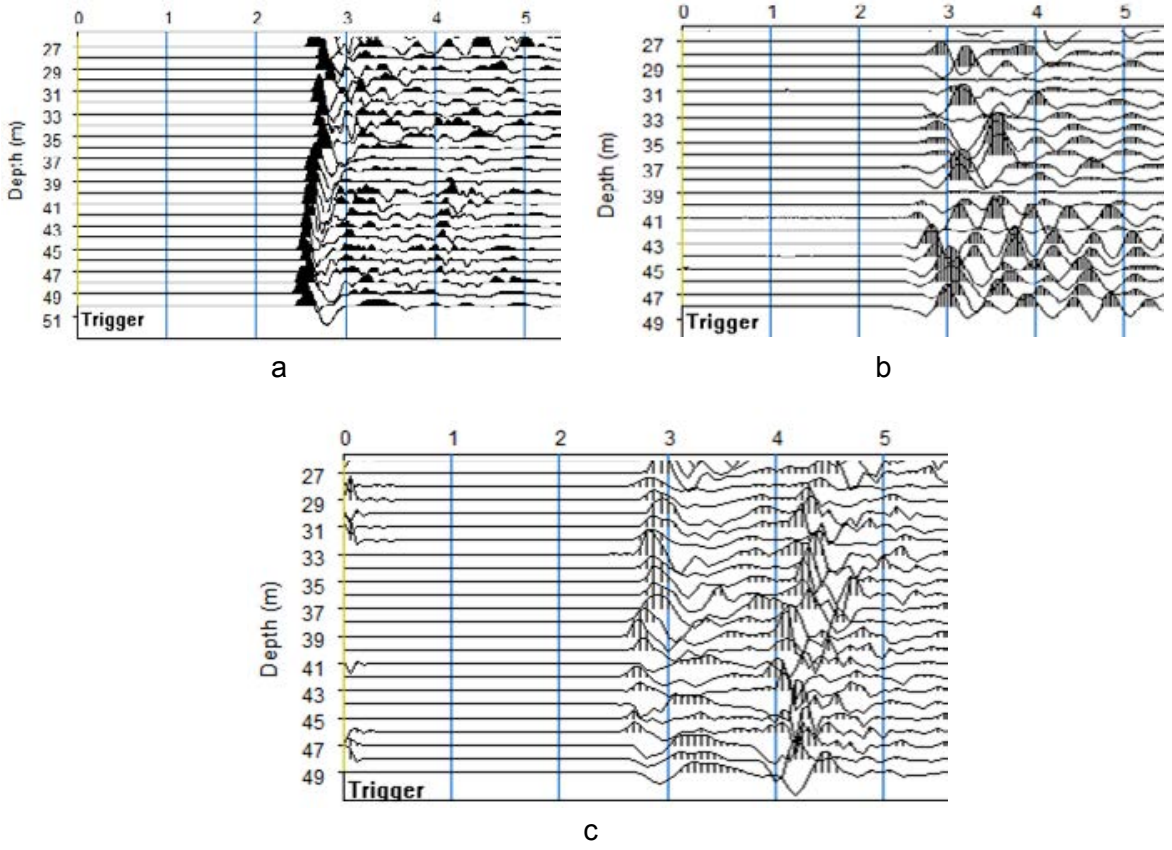

Figure 1.22 $P$ recording in the same borehole with a sampling rate of (a) 2.5, (b) 32.25 and (c) $62.5 \mu \mathrm{s}$. 


\subsubsection{Crosshole analysis}

At first glance crosshole analysis appears simple and robust, and only requires the picking of the first arrival of the selected wave ( $\mathrm{P}$ or $\mathrm{S}$ ), and to divide this travel time by the distance between the source and the receiver, to obtain the velocity of the medium. However, several cautionary notes, described below, should be considered.

As discussed in the section about receivers, $\mathrm{P}$ interpretation using geophones requires the polarization of horizontal traces to optimize the signal amplitude. However, sometimes the result of this operation is less clear than when looking at the results of one of the two components, and sometimes the operation is complex, such as when the receiver has six horizontal components.

Moreover, in alluviums, particularly outside of the water table, sometimes the attenuation of $\mathrm{P}$-waves is such that they are no longer distinguishable from noise. Two causes explain this problem:

- Firstly, drilling and cementing are delicate in this type of terrain and the result of cementing can be highly variable according to the drilling technique used. For this type of terrain there is a risk of forming a thick cement annular that does not adhere to the formation, which can create a waveguide that filters $\mathrm{P}$-waves more than $\mathrm{S}$-waves, because they are of higher frequency (often $1,000 \mathrm{~Hz}$ compared to $200 \mathrm{~Hz}$ ). To limit this effect, the use of a sonic corer is recommended, to avoid destructuring the terrain.

- Secondly, the mechanical source generates insufficient P-wave energy for this type of very attenuating terrain, so a more powerful $\mathrm{P}$-wave source, such as a sparker, should be used.

Figure 1.23 illustrates the above comments. The two crossholes were made in distinct sites, but both had sandy-gravelly alluvial cover down to $22 \mathrm{~m}$ and $21.6 \mathrm{~m}$ respectively, over a clay or marly substratum.

In both cases, there is a change in the frequency content between the alluvium (low frequency signal) and the substratum (high frequency signal). However, in the second case the first identifiable arrivals in the first 19 meters are not P-waves, because the times correspond with those of the $S$-waves probably picked on the horizontal components. On the other hand, in the first case it is possible to identify $\mathrm{P}$ arrivals over the entire depth.

Attenuation mainly affects distant receivers in crossholes with several receiving boreholes. This justifies making an acquisition with a specific $\mathrm{P}$ source that is more powerful than a mechanical source, which is made to maximize the energy of the S-waves. In addition, it is entirely possible to limit the crosshole to two boreholes, but only on the condition that the results are consistent with those of a downhole and/or uphole made in one of the two boreholes.

The crosshole method can also be affected by refracted waves (especially when the offset is greater than $6 \mathrm{~m}$ ). The example presented in Figure 1.24 illustrates that it 
is possible to detect refracted waves and confirm their existence solely based on the visual analysis of the signals, crossed with the information from the cores.
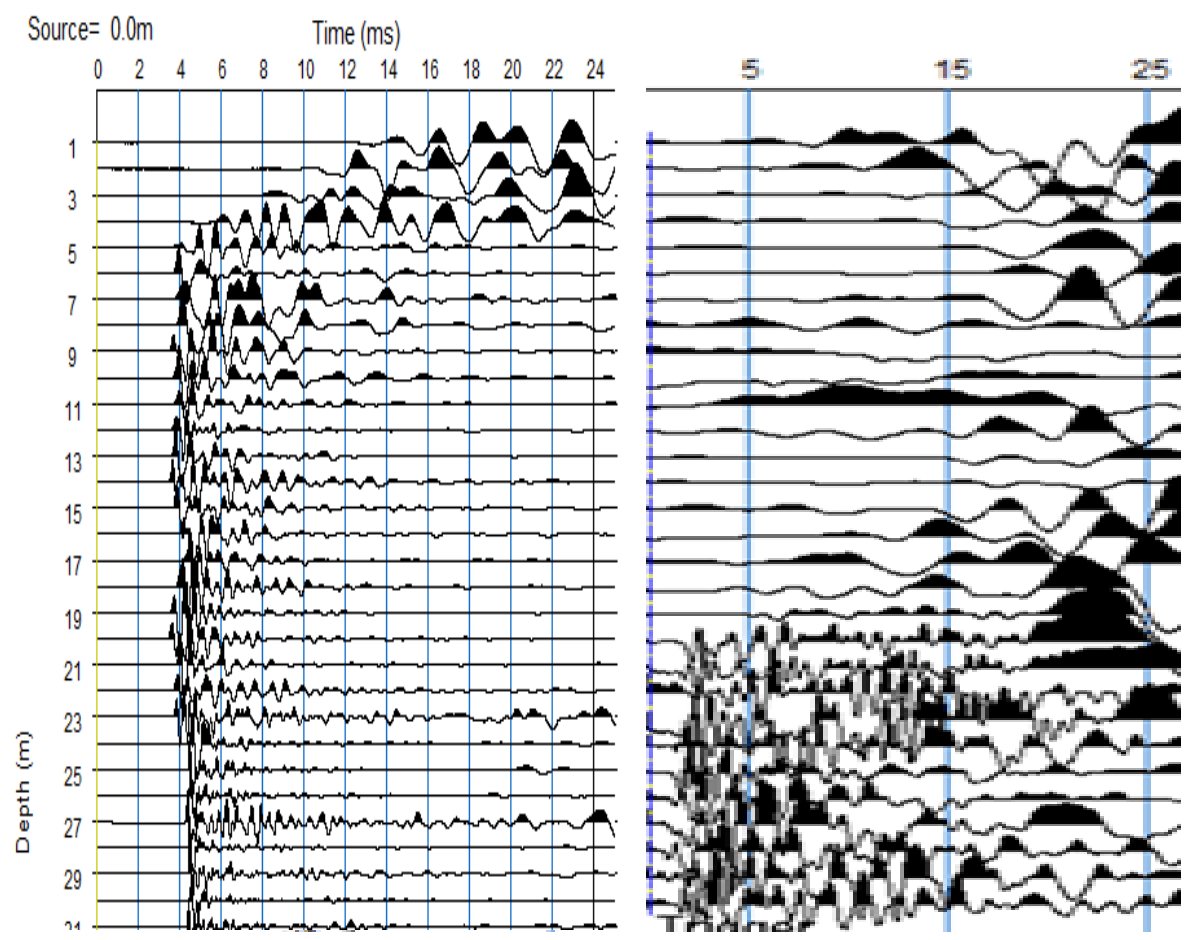

Figure 1.23 Examples of crosshole recording. a) left, $P$ Crosshole (InterPacific, water table at $3 \mathrm{~m}$ ), b) right EDF site (water table at $6 \mathrm{~m}$ ).

On the S-wave crosshole recording, on the left of Figure 1.24a, there is a fast S first arrival at 22 and $23 \mathrm{~m}$ in depth (shown in red). At greater depths, this $S$ arrival is later. There are therefore two areas for which $S$ velocities can be calculated at 500 and $260 \mathrm{~m} / \mathrm{s}$ (see velocity model on the right). Directly under the fast formation, at 24 and $25 \mathrm{~m}$ deep, we observe a first arrival with little energy (shown in green). This is a refracted arrival, with the transmitted arrival (shown in red) keeping the same phase. The phenomenon can be explained by calculating the distancetime graph for example at $2 \mathrm{~m}$ from the interface between the two media (i.e. $25 \mathrm{~m}$ deep, see Figure 1.24b). Figure 1.24b shows that at the distance of the first borehole $(\mathrm{X}=3 \mathrm{~m})$ the direct wave (P: solid blue line, $\mathrm{S}$ : solid green) arrives first, while in the second borehole $(\mathrm{X}=6 \mathrm{~m})$ it arrives after the refracted wave (blue dotted line for the $\mathrm{P}$-wave and green for the $\mathrm{S}$-wave). By carrying out this analysis at depths of 24 and $26 \mathrm{~m}$, we can then draw the fastest paths, which are illustrated by the green arrows on the left of Figure 1.24a. 


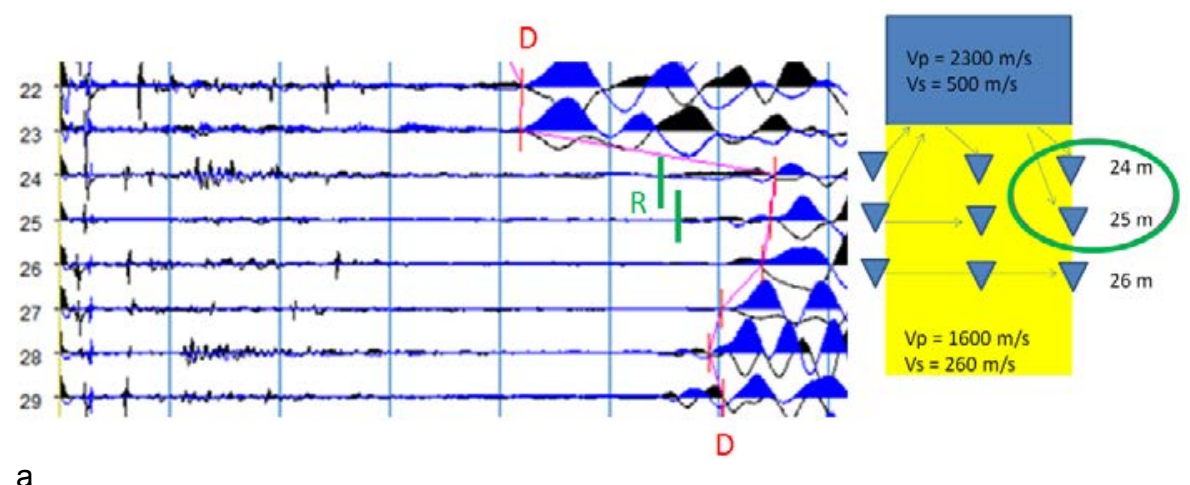

\section{Travel time curve of a crosshole}

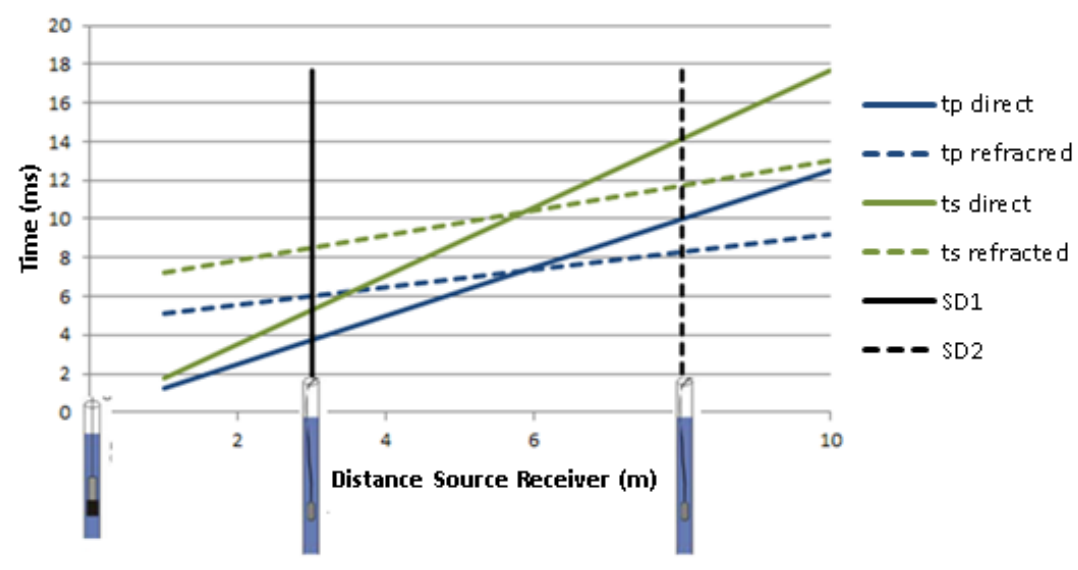

Figure 1.24 Crosshole examples; a: left, S recordings between 22 and $29 \mathrm{~m}$ in depth and, right, associated geological model; $b$ : $P$ and $S$ time-distance curve, with a measurement level at $2 \mathrm{~m}$ from the interface with a faster strata (based on the bottom right model).

The above approach requires time and experience. It is therefore difficult to generalize to apply to all applications. The ASTM standard recommends the implementation of a computer analysis to take into account the different possible paths (inversion). In practice, this was not carried out in France, but has started to be used since 2015.

Figure 1.25 shows an example of tomography results obtained with inversion software. 


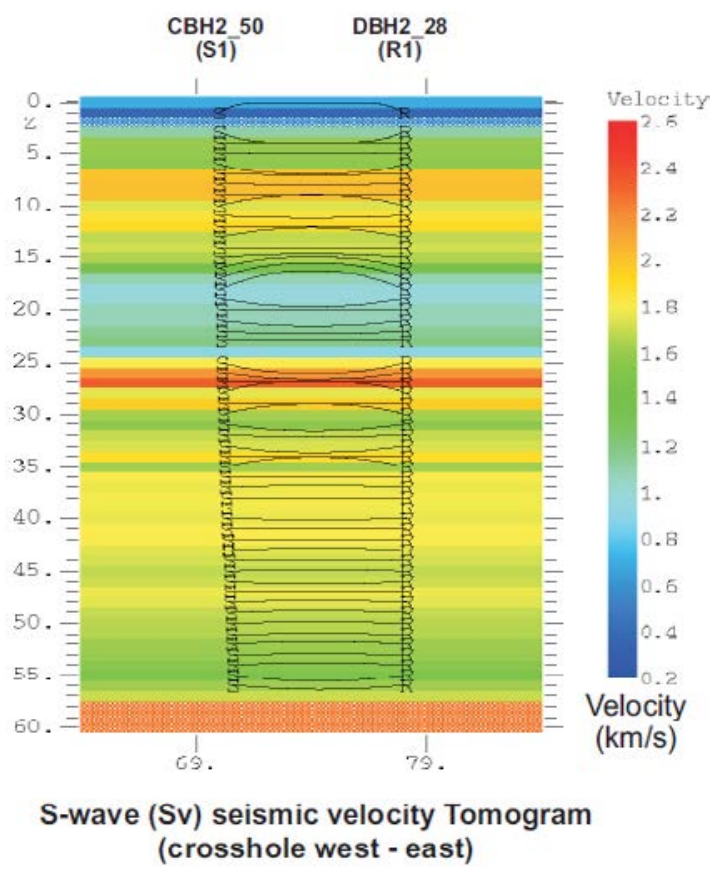

Figure 1.25 Crosshole result after inversion with GEOTOMGC software (Terradata for EDF).

\section{$1.3 \quad \mathrm{~V}_{\mathrm{s}}$ measurement by logging}

\subsubsection{Acoustic logging with high vertical resolution}

In geotechnology, the logging tools that can be used are generally of a small diameter $(<50 \mathrm{~mm})$ and non-stackable, as is practiced in the field of oil exploration. The conventionally used acoustic probes are therefore short probes $(3.5 \mathrm{~m})$, composed of a high frequency monopole-type piezoelectric transmitter (10 to $40 \mathrm{kHz}$ ) (see Chapter 3). It is important to remember that this means that the source is omnidirectional and that it generates $\mathrm{P}$-waves in the fluid. These waves are refracted $(P, S)$ at the level of the borehole wall and guided modes also appear. These are, in particular, Rayleigh waves for a solid-air interface and the Scholte-Stoneley wave for a solid-fluid interface. Therefore, the existence of refracted shear waves implies that the $\mathrm{P}$ velocity of the fluid is lower than the $S$ velocity of the formation for an uncased borehole. $V_{s}$ measurement with acoustic logging is therefore recommended for fast formations. 
When the formation is slow $\left(\mathrm{V}_{\mathrm{s}}\right.$ formation $<\mathrm{V}_{\mathrm{p}}$ fluid), the Scholte-Stoneley waves can enable the estimation of $S$ velocities with an acoustic tool. It is nevertheless necessary to occasionally have the means of tying the conversion between the Scholte-Stoneley velocities and the shear velocities (for example, a downhole log with multi-metric measurement levels).

Figure 1.26 is an example of Full Wave Sonic (FWS) logging obtained with a monopole tool. On the right the figure shows the acoustic section obtained with a sourcereceiver offset of $4 \mathrm{ft}$ and on the left the velocity logs of the different wave trains (P refracted, $\mathrm{S}$ refracted and Stoneley).

\begin{tabular}{|c|c|c|c|c|c|}
\hline & $v_{p}$ & & Depth & 4FT & \\
\hline 0 & $\begin{array}{l}\mathrm{m} / \mathrm{s} \\
\mathrm{vs}\end{array}$ & 5000 & $1: 200$ & $\mu s$ & 3995 \\
\hline 0 & $\begin{array}{l}\mathrm{m} / \mathrm{s} \\
\mathrm{Vst}\end{array}$ & 5000 & & & \\
\hline 0 & $\mathrm{~m} / \mathrm{s}$ & 5000 & & & \\
\hline
\end{tabular}

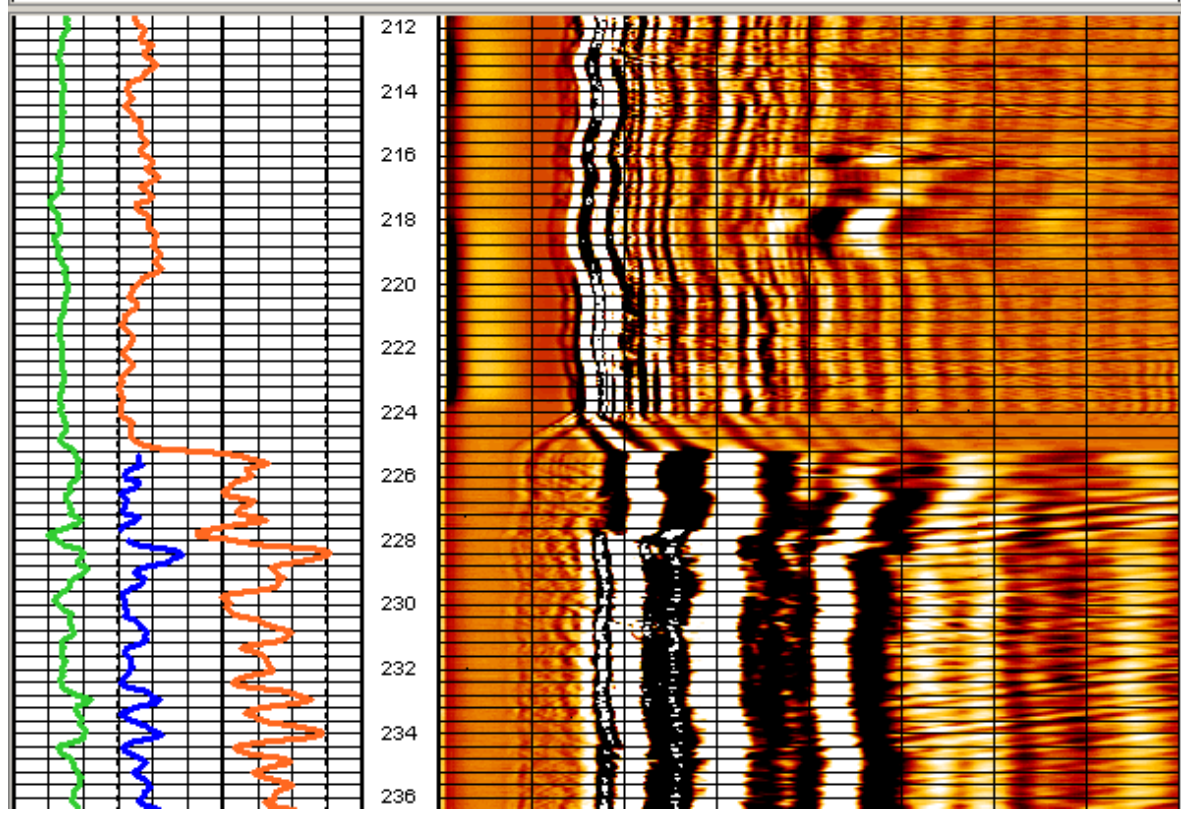

Figure 1.26 Example of sonic FW recording (monopole), showing a low energy $P$ first arrival, for which the arrival time decreases significantly after $225 \mathrm{~m}$ (entry into the rock), the S arrival is only visible below $225 \mathrm{~m}$ where the medium has a velocity that is considered as fast compared to the mud (rock) [SEMM logging for EDF]. 
In slow formations, the measurement of $S$ velocities cannot be obtained by using monopole-type tools. The oil industry has developed dipole-type tools including polarized transmitters and receivers that generate and record bending waves, the propagation velocity of which is close to the $S$ velocity of the formation (see Chapter 3). The problem is that these oil industry tools are rigid and very long. However, a flexible alternative exists for the geotechnology field: PSSL.

\subsubsection{PS Suspension Logging (PSSL)}

PS Suspension Logging (PSSL) is a flexible logging probe for non-continuous measurement with an electromechanical drill source and two receivers (see Chapter 3).

It should be noted that the frequencies used by the PSSL enable measurements to be made in boreholes with PVC casing. Seismic wave velocities are calculated from the difference between the arrival times between the two receivers (Near and Far) spaced $1 \mathrm{~m}$ apart. As a result, the tool needs to be centered in the borehole, but since it is flexible (see Figure 1.27) and it is difficult to find centering rings that are adapted to the borehole, this is not always possible.

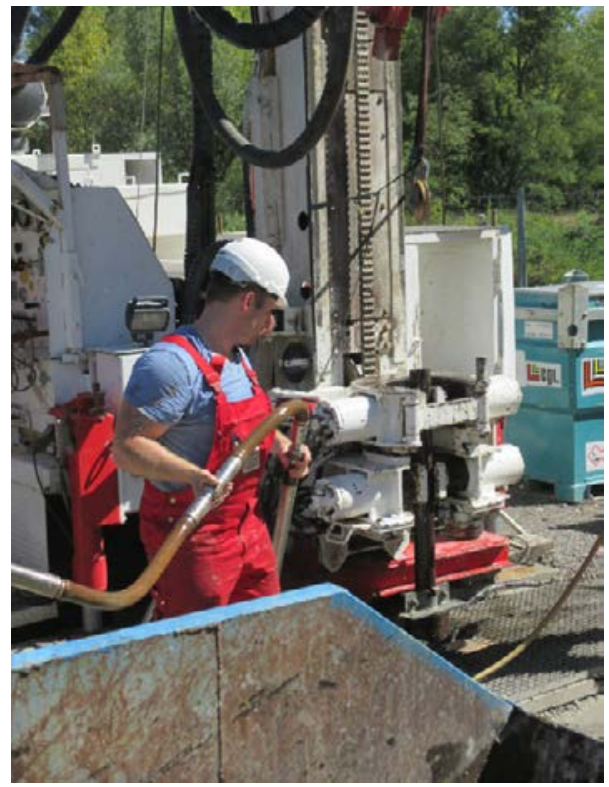

a

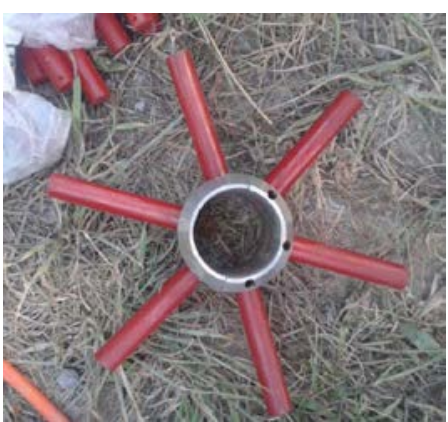

b

Figure 1.27 PSSL tool a) set up of a PSSL tool with a continuously active drill rig (Fugro for EDF), b) typical centering ring component of PSSL tool. 
However, in a vertical borehole, all logging tools rotate during the ascent and when the wall is inclined, they clamp onto the lower part of the wall. In addition, when a borehole is inclined, there is typically a scraping of the formation related to the friction of the drill string (reaming) and this implies anisotropy of the thickness of the cement grout around the casing. In Figure 1.28, this may account for the differences observed between PSSL and downhole measurements between 75 and $120 \mathrm{~m}$ deep, particularly at the level of the clay formation at $75 \mathrm{~m}$, which is typically favorable to the development of "caves".

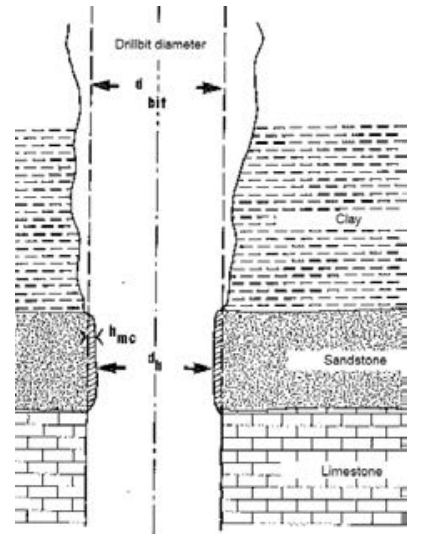

a

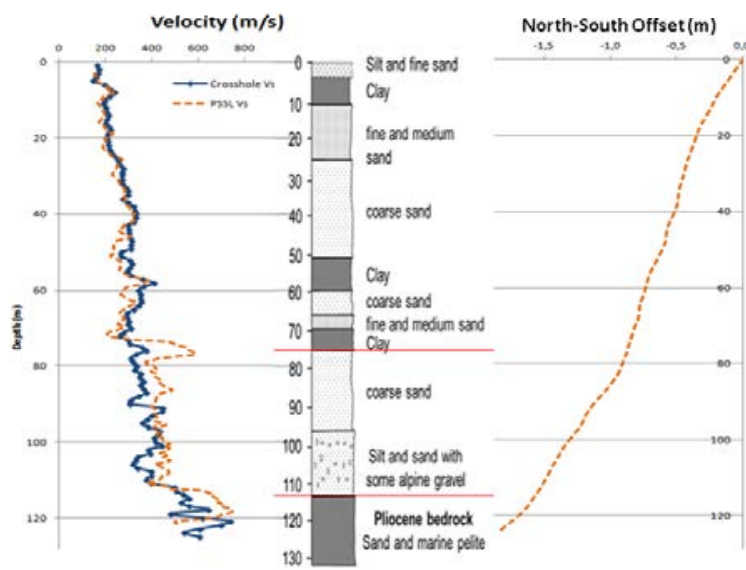

b

Figure 1.28 PSSL tool and downhole DH; a: Caliper variation depending on ground drilling (O. Serra, 1979); b: Mirandola, comparison of DH S and PSSL results, geology and deviation.

This shows that a PSSL analysis also requires control of the diameter (caliper) and the deviation of the borehole (trajectometry), because when its inclination exceeds $30^{\circ}$ the PSSL measurement appears distorted. Finally, due to the length of a PSSL $(5$ to $7 \mathrm{~m}$ ) and the difficulty to achieve a seal that does not overly invade the formation, especially outside of the water table, in a cased hole, there is a frequently observed gap between the measurement of crosshole or downhole and PSSL in the first 10 meters. Figure 1.29 perfectly illustrates this fact. 


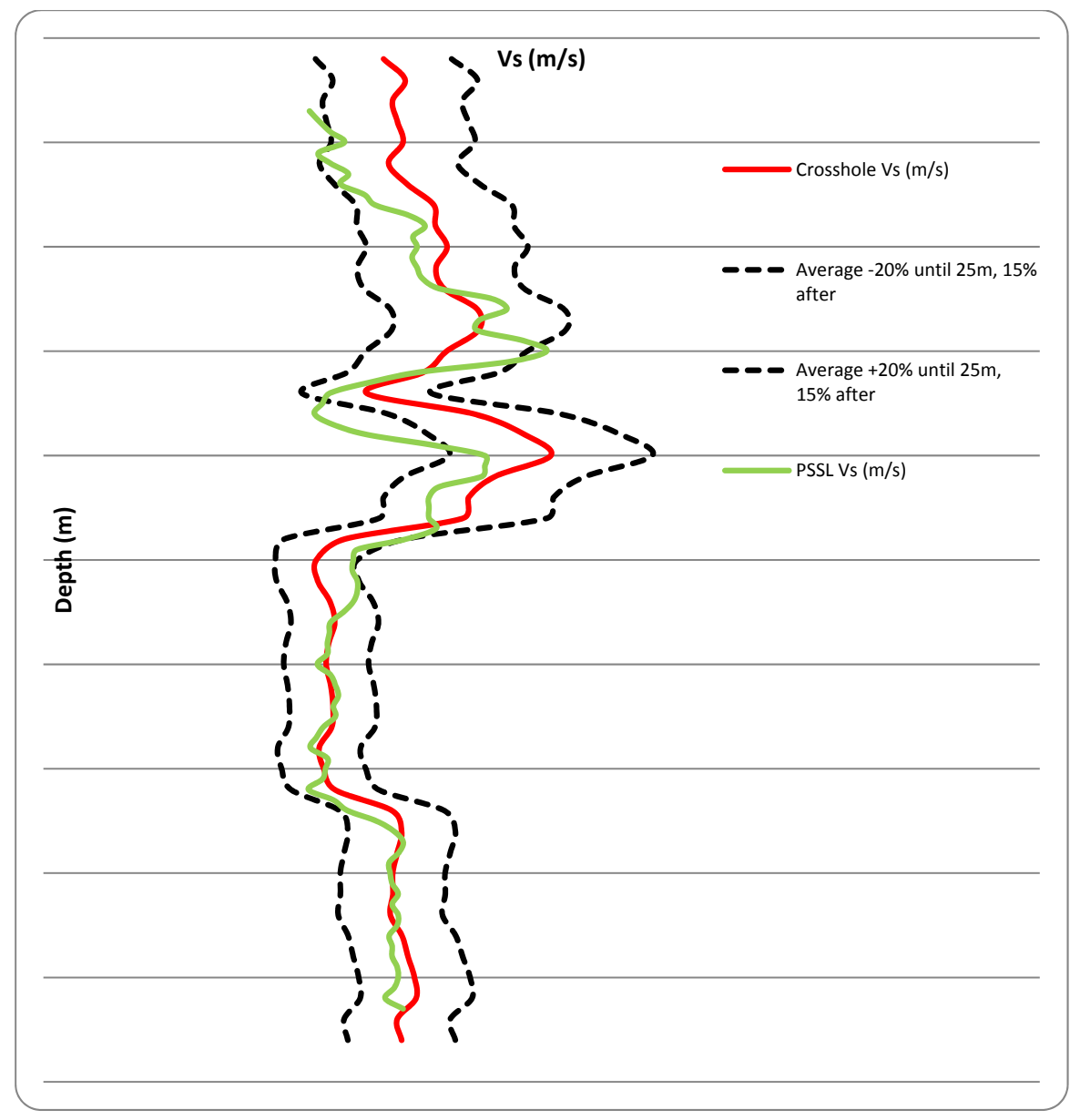

Figure 1.29 Crosshole log vs PSSL in a cased borehole (InterPacific, Grenoble).

Finally, it should be noted that the different probes available on the market clearly have different power levels. Indeed, the 2 acquisitions illustrated in Figure 1.30 were made on the same offshore site, in two open boreholes that were different but did however have key similarities. With the first probe the phase oppositions are clear for the $\mathrm{S}$-waves below $10 \mathrm{~m}$ in depth, while the results of the second probe are unusable. The performance of all PSSL probes is not therefore comparable and a comparative study needs to be carried out. 

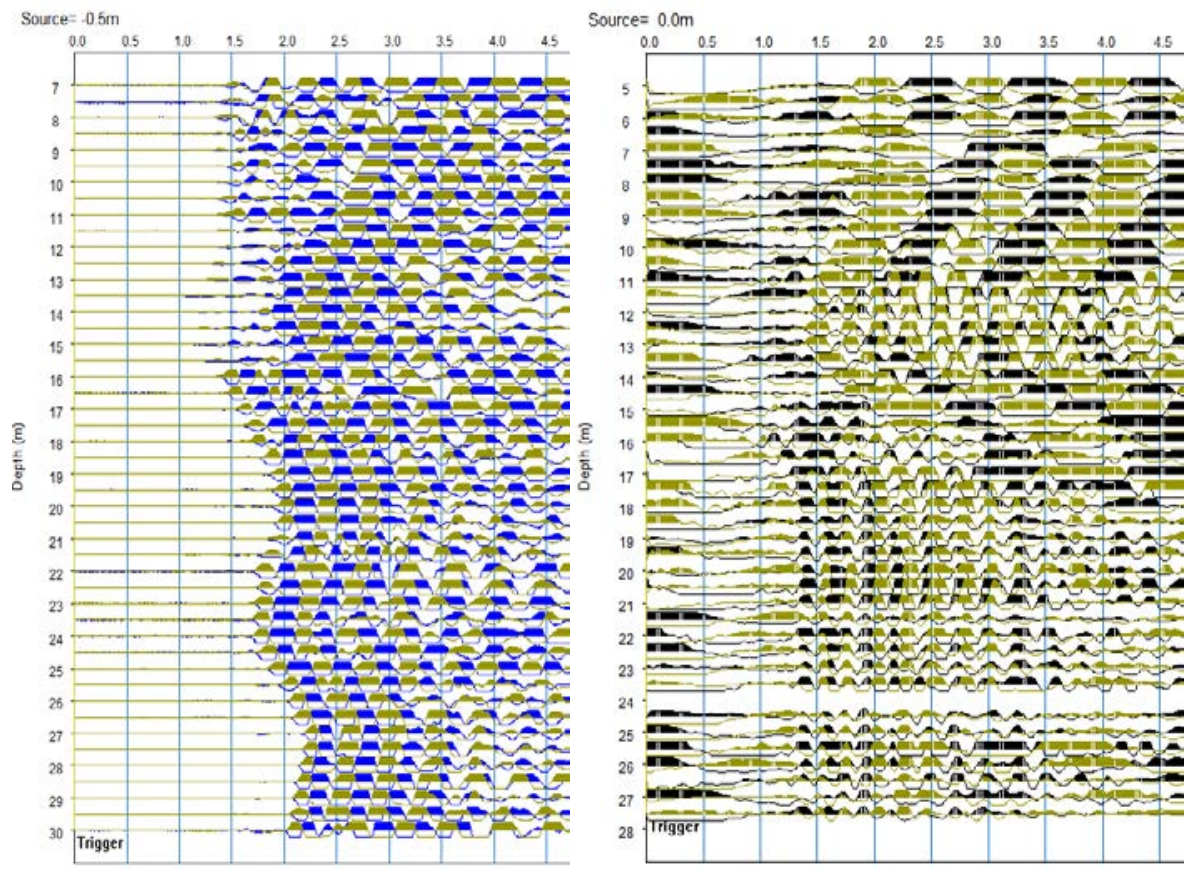

Figure 1.30 PSSL, H component, trace collection for $4.5 \mathrm{~ms}$, in two distinct boreholes but within the same homogeneous site at sea, with $A$ and $B$ probes [EDF-EN].

\subsection{Case study of a downhole acquisition, PSSL and acoustic logging, in the same borehole}

The studied borehole is complex in that it is relatively deep $(280 \mathrm{~m})$, it crosses terrain that is outside of the water table as well as underneath it (the water table is at 3 or $5 \mathrm{~m}$ ), there are unstable formations that require borehole casing (alluvial), and stable ground where the borehole is supported by a bentonite based mud, and finally bedrock at $225 \mathrm{~m}$ deep. This high variability in geological and drilling conditions made it necessary to anticipate the implementation of various techniques for measuring the seismic wave velocity in the borehole. Ultimately, the validated results perfectly illustrate the most suited terrain for each method. Namely:

- Downhole logging is suitable for a borehole that goes through unstable formations and is fitted with PVC casing, 
- PSSL logging is suitable for a borehole going through a "slow" formation, the hole of which is uncased, and which is supported by bentonite-based fluid,

- Acoustic logging is suitable for "fast" formations, i.e. bedrock.

The continuity between cased and uncased hole measurements was ensured by a downhole section in an open hole (see orange dotted line on the "downhole log" in Figure 1.31); it would also have been possible to carry out a PSSL in a cased hole.

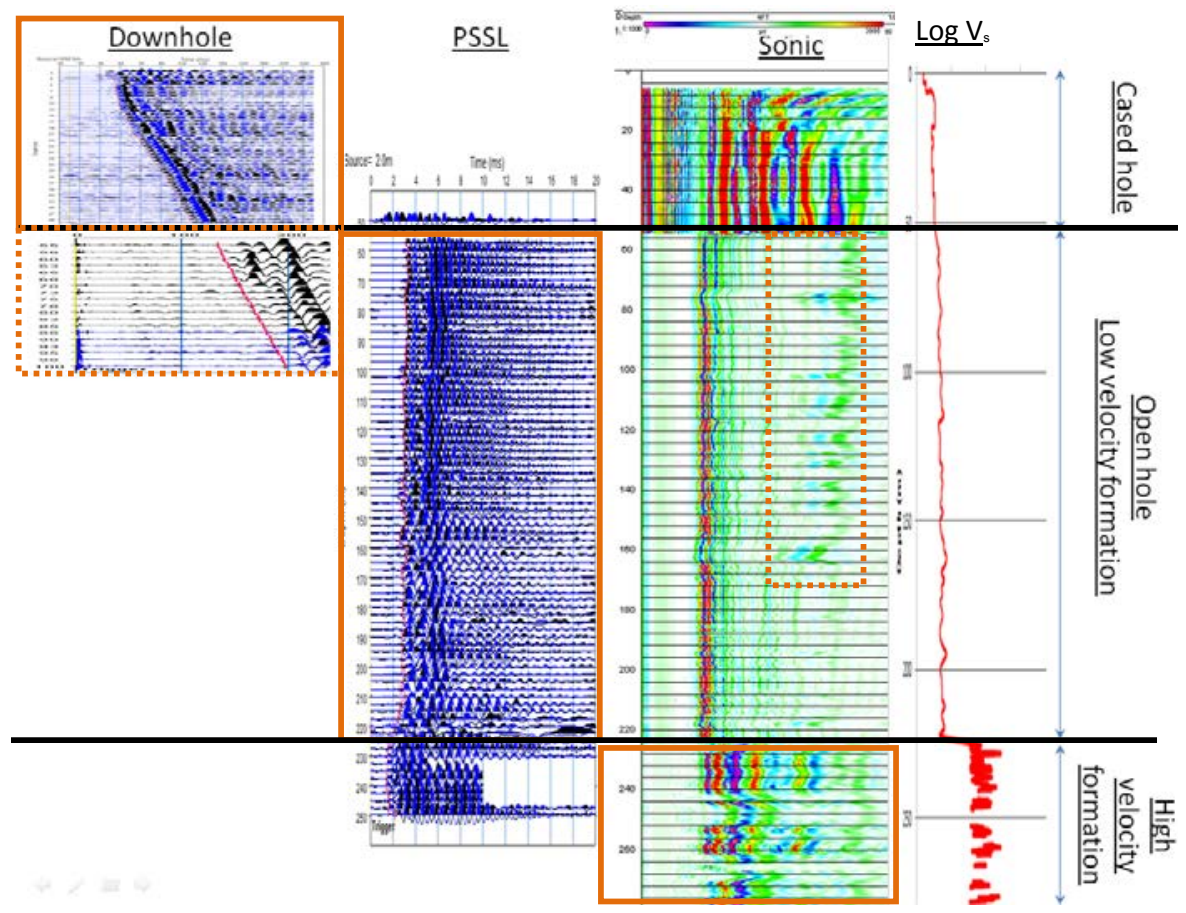

Figure $1.31 V_{s} \log ($ red) obtained from a downhole, PSSL and a "FWF sonic".

The continuity between the measurements in the slow and fast formations was ensured by the recording of Stoneley waves, which are very clear between 55 and $160 \mathrm{~m}$ (see orange dotted line on the "sonic log" in Figure 1.31).

The final log combines the downhole measurement between 0 and $50 \mathrm{~m}$, the PSSL measurement between 56 and $225 \mathrm{~m}$ and the acoustic measurement between 225 and $280 \mathrm{~m}$ (see orange rectangles in Figure 1.31). 
Table 1.5 Velocity measurement $\left(V_{p}, V_{s}\right)$ and tools ( $D H$, sonic, PSSL).

\begin{tabular}{|c|c|c|c|c|c|c|c|c|}
\hline \multirow[b]{2}{*}{ Depth (m) } & \multirow[t]{2}{*}{ Features } & \multicolumn{3}{|c|}{$V_{p}$} & \multicolumn{3}{|c|}{ Vs } & \multirow{2}{*}{$\begin{array}{c}\text { V stonley }=>\text { Vs } \\
\text { Sonic }\end{array}$} \\
\hline & & DH & Sonic & PSSL & DH & Sonic & PSSL & \\
\hline $0-50$ & Cased hole & & & & & & & \\
\hline $55-100$ & Slow formation, & & & & & & & \\
\hline $100-225$ & open hole & & & & & & & \\
\hline $225-280$ & Bedrock, open hole & & & & & & & \\
\hline
\end{tabular}

Table 1.5 summarizes the validated measurements, with dark green shading to show those selected to carry out $\mathrm{V}_{s}$ logging, and light green shading to show those that make it possible to verify the continuity between the different techniques applied. Figure 1.31 is a composite that illustrates all of these conclusions for $S$ measurement.

\subsection{Conclusion}

This chapter has detailed the methodology for the acquisition and analysis of invasive measurements in downhole, uphole and crosshole-type boreholes and loggings. It brings a new perspective compared to the ASTM standards, particularly regarding:

- the possibility of controlling cementation,

- the need to establish calibration procedures for geophysical measurements, and trajectometry and inclinometry tools,

- the impact of downhole tube waves,

- the possibility of working with 2 crosshole boreholes, providing that certain precautions are taken,

- the need to dissociate the P and S acquisition, whether in downhole or crosshole,

- the need for a 2-phase analysis to avoid artefacts related to real paths or refracted waves.

For deep reconnaissance where an uncased hole can be used, PSSL is undoubtedly the best option. The measurement can be complemented by Stoneley wave FWF sonic logging to improve the vertical resolution. However, it is preferable to have a surplus of data for the first meters, with a downhole or crosshole, because this section is usually cased, outside of the water table, and an invasion of the formation by the sealant, which would distort PSSL measurement, cannot be excluded. For the higher part of the borehole, it is also recommended to carry out a "caliper" as well as a deviation measurement (trajectometry). Finally, the choice of PSSL probe is important because PSSL probe performance does not seem to be uniform. A detailed study of the performances of these probes remains to be carried out. 


\section{References}

ASTM D4428/D4428M-14, 2014, Standard test methods for Cross-Hole seismic testing. West Conshohocken (PA): ASTM International, www.astm.org.

ASTM D7400-14, 2014, Standard test methods for Down-Hole seismic testing. West Conshohocken (PA): ASTM International, www.astm.org.

Bourbié Th., Coussy O., Zinszner B., 1986, Acoustique des milieux poreux. Éditions Technip, Paris.

Eurocode 8, Calcul des structures pour leur résistance aux séismes, 2005.

Garofalo F., Foti S., Hollender F., Bard P.Y., Cornou C., Cox B.R., Dechamp A., Ohrnberger M., Perron V., Sicilia D., Teague D., Vergniault C., 2016, InterPacific project: Comparison of invasive and non-invasive methods for seismic site characterization. Part II: Inter-comparison between surface-wave and borehole methods, Soil Dynamics and earthquake Engineering.

SeisImager downhole manual, 2013, Windows Software for Analysis of Downhole Seismic, Pickwin v. 5.1.0.5, PSLog v. 2.0.0.3, Manual v. 1.2. 


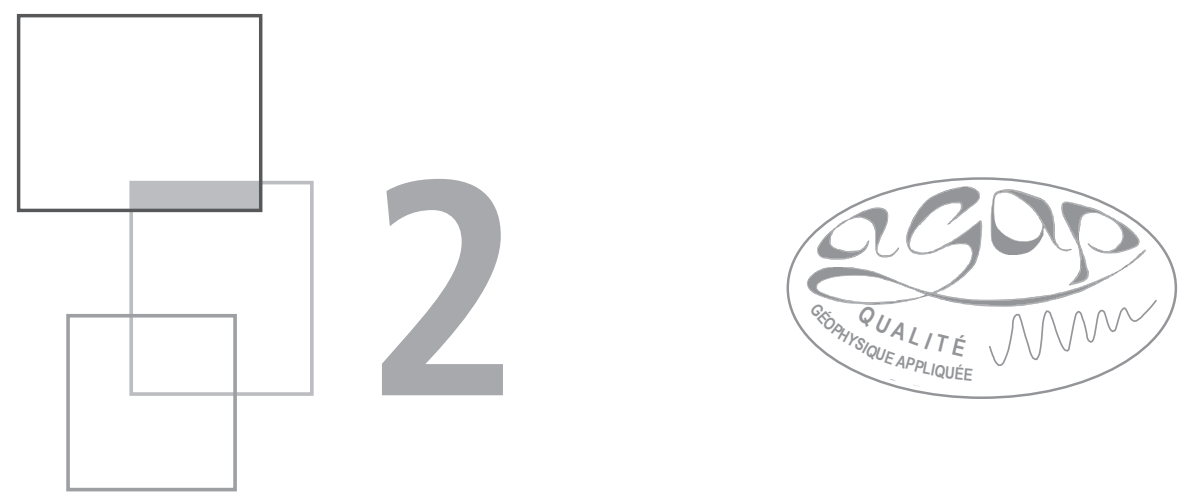

\title{
Well seismic surveying
}

\author{
J.-L. Mari, C. Vergniault, F. Coppens
}

\subsection{Introduction}

Well seismic surveying, the most commonly used form of which is Vertical Seismic Profile or VSP (Hardage 1985, 1992; Mari et al., 1999, 2003), is a seismic method involving a signal that is emitted on the ground surface, which is then recorded by a seismic receiver located at various depths in the well. The earliest type of well seismic measurement is the check shot survey, which is used to measure propagation times between the surface and various well depths.

VSP is a well seismic method for which the source and the receiver are considered to be on the same vertical. The VSP vertical resolution ranges from meters to tens of meters and its lateral range of investigation can reach a few tens of meters (Fresnel zone).

VSP is based on the analysis of different wave trains recorded by the well receiver. The measurement of the arrival time of the first downgoing waves that propagate close to the near-normal incidence is used to provide a velocity distribution in the

This chapter of Well seismic surveying and acoustic logging is published under Open Source Creative Commons License CC-BY-NC-ND allowing non-commercial use, distribution, reproduction of the text, via any medium, provided the source is cited.

(C) EDP Sciences, 2018

DOI: $10.1051 / 978-2-7598-2263-8 . c 004$ 
subsurface. After processing, the VSP provides a seismic trace without multiples, which is directly comparable to a surface seismic section recorded in the vicinity of the well. With the added constraints of log data (sonic and density), this trace represents an acoustic impedance log in the well and below the bottom of the well.

The well may be an open hole, a cased hole (steel and/or PVC) or a cemented cased hole. For the latter, a cementation control (acoustic logging) is recommended.

Figure 2.1 shows an unprocessed VSP recording of a steel-cased vertical well. In this representation, the horizontal axis shows the various depths of the well geophone, and the vertical axis represents listening time. In this example the receiver depth varies between 25 and $90 \mathrm{~m}$, and the surface source is slightly offset $(5 \mathrm{~m})$ with respect to the wellhead. The distance between two successive geophone positions in the well is $5 \mathrm{~m}$. The sampling rate in time is $0.25 \mathrm{~ms}$ for a listening duration of $250 \mathrm{~ms}$. In the Figure, the listening time has been limited to $100 \mathrm{~ms}$.

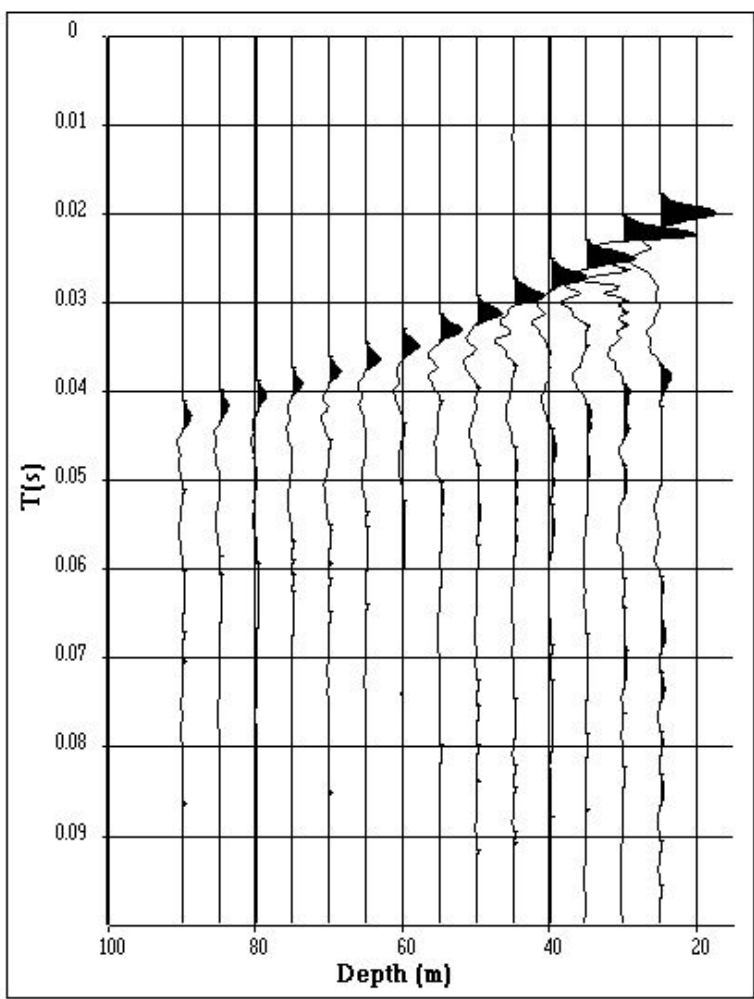

VSP : Raw data (vertical component)

document IFP School , J.L.M., 2015.

Figure 2.1 Example of VSP recorded in a vertical well at depths of between 25 to $90 \mathrm{~m}$. 
The lateral range of investigation of the VSP can be improved by offsetting the source with respect to the well. This technique is called Offset Vertical Seismic Profiling (OVSP). The image obtained after processing is thus a single-fold seismic section.

A Seismic Walkaway is a series of offset VSPs, with the surface source situated at several locations corresponding to successively increasing offsets with respect to the borehole. The image obtained after processing is a section with a low degree of multiple fold coverage. In this type of setup, the number of positions of the well geophone is generally limited. Figure 2.2 illustrates the implementation of a seismic walkaway and shows an example of the type of imagery obtained in the oil industry. The horizontal axis represents the distance of the mirror point with respect to the well.
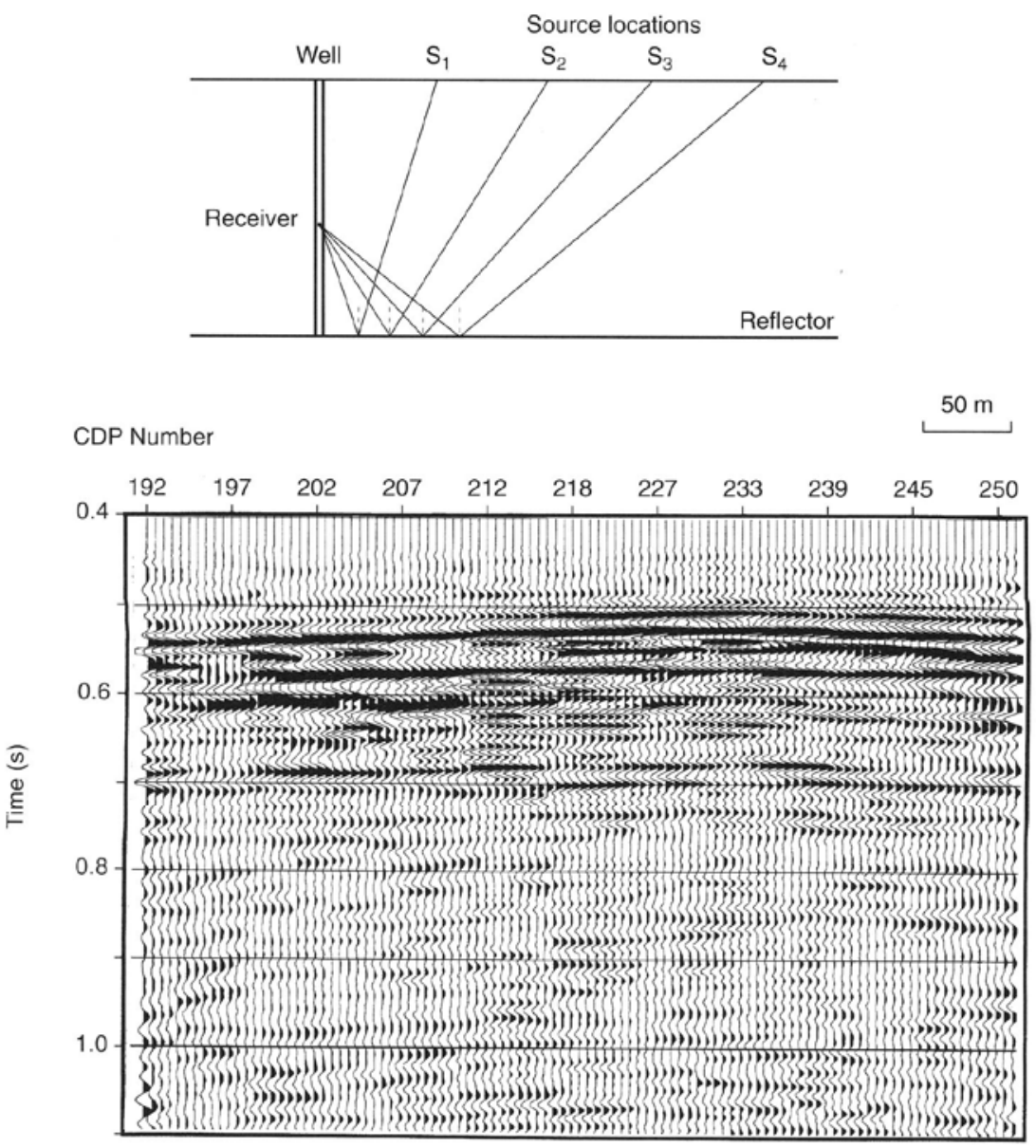

Figure 2.2 Example of imaging with seismic walkaway (document: ENGIE - IFPEN). 
However, the lateral range of investigation of a seismic walkaway is limited (to between several hundred meters up to a kilometer) compared to that of a classic seismic reflection profile. This underlines the local nature of a reservoir study using a well seismic method.

VSP, OVSP and seismic walkaway implementations provide an image of the geological formations below the well. During drilling, the drill bit itself can be used as a well source, thereby permitting the imaging of formations that have not yet been reached while the well is being drilled (prediction ahead of the bit).

The use of a well source enables reverse well seismic surveys (source at the bottom and receiver on the surface) to be carried out, along with well-to-well seismic surveys. This aspect has been developed in Chapter 1, which focuses on the measurement of formation shear velocities. Well-to-well seismic surveying can provide images of formations between wells in the form of seismic reflection sections, which give acoustic impedance contrasts (Figure 2.3 - left) or velocity models obtained by inversion of first arrival times (tomography by transmission, Figure 2.3 - right).
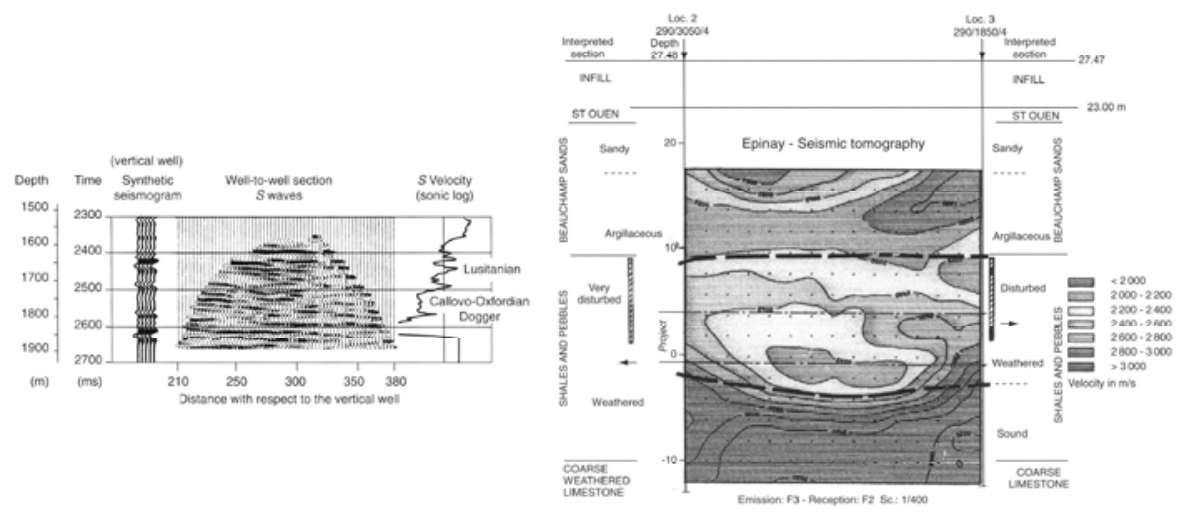

Figure 2.3 Examples of well-to-well seismic surveying. Left: example of well-to-well seismic measurement - reflection of S-waves between a vertical well and a deviated well (from Becquey et al., 1992). Right: Example of transmission tomography in civil engineering (F. Lantier, consultant)

The various implementations of well seismic methods can be grouped under the general term of well seismic profiling. 


\subsection{Well seismic data acquisition}

Typically, well seismic profiling is carried out with a seismic source at the surface and a receiver system in the well. In this paragraph, we present:

- the necessary resources for data acquisition;

- implementation in the field.

\subsubsection{Necessary resources for data acquisition}

We present here a list of the necessary resources, in terms of: equipment, vehicles and personnel.

- Equipment

1. logging unit, which includes:

a receiver system composed of one or more well sensors (geophones and/ or hydrophones), a winch with several hundred meters of cable, that is connected to the well sensor, a recording and digitization unit (digitization can be done at the sensor level), a system for the visualization and printing of the field recordings, and a depth measurement system;

2. one or more surface sensors for source calibration;

3. a seismic source (explosive, hammer, weight drop);

4. a lifting system with pulleys to lower the receiving system;

5. equipment should be checked (maintenance, calibration) periodically.

- Vehicles

1. either: 1 or 2 vehicles (preferably all-terrain/off-road), enabling the transport of personnel and equipment

2. or: one logging unit and one vehicle to transport personnel and the source.

- Personnel and expertise

1. two operators qualified for the implementation (source, winch, acquisition);

2. one geophysicist (Head of Mission) qualified for data quality control at acquisition and who can also be an operator.

\subsubsection{Implementation in the field}

In this section, we describe:

\subsubsection{Description of classical VSP operation in a vertical well}

The well receiver or probe is lowered to a certain depth. The source is positioned on the ground surface at a short distance $(<5 \mathrm{~m})$ from the wellhead. A reference 
geophone is sited near the wellhead. Several seismic shots are carried out to verify the proper functioning of the entire acquisition system (recorder, probe, reference geophone, source) and good data repeatability. The probe is then raised to the surface.

After setting the zero (probe reference) according to a reference plane (raft, rotary table...) or on the ground surface, the probe is lowered to the bottom of the well and anchored to the well wall. Prior to this step, it is important to verify that the probe anchorage is sufficient to make measurements with the loose cable.

The VSP operation at a given depth involves:

1. Checking the depth of the well receiver or probe,

2. Anchoring the probe (if the probe type allows the anchor arms to be opened and closed),

3. Slackening the cable,

4. Recording seismic data and checking them using the visualization system,

5. Verifying the repeatability of the source on the seismic channel dedicated to the reference geophone,

6. Tightening the cable,

7. Unattaching the probe (if the probe type allows the anchor arms to be opened and closed),

8. Positioning the probe at the next depth.

This procedure can be repeated several times at the same depth to evaluate the variations in coupling and the signal-to-noise ratio.

Well seismic operations can be carried out in vertical, deviated or horizontal wells, in open or cased holes.

\subsubsection{Well probes}

- In the petroleum industry, most receiver systems are multi-sensor probes for the purpose of reducing well seismic data acquisition time and thus the costs of well downtime. These systems are array probes that include a master unit and satellite tools. They allow simultaneous recording at several depths and are particularly useful for seismic walkaway operations. The master tool includes a telemetry system that transfers data from the bottom to the surface. Each tool includes an anchoring system and a seismic module. In geotechnics, the drilling probe is usually a single-sensor probe.

- The receiver can be a single-component geophone (vertical geophone) or a three-component geophone (a vertical component and two orthogonal horizontal components). The receiver can also be a hydrophone, or even have four components: a three-component geophone and a hydrophone. In geotechnics, a geophone-type single-sensor probe with 1 or 3 components is conventionally used. The anchoring system can be hydraulic or mechanical, with or without 
anchor arms that open and close. In geotechnics, a single hydrophone or hydrophone array (12 levels, for example) can also be used.

- If the anchoring system allows the anchor arms to be opened and closed, it is recommended to make seismic measurements at several depths while descending and to make measurements at the same depths when ascending, to control depth tying.

- VSP acquisition is carried out from the bottom of the well towards the surface for reasons of data acquisition convenience.

Figure 2.4 shows some well probe types: a 3-component geophone, a single hydrophone, and a hydrophone array. The figure also shows an example of a VSP obtained with a hydrophone.
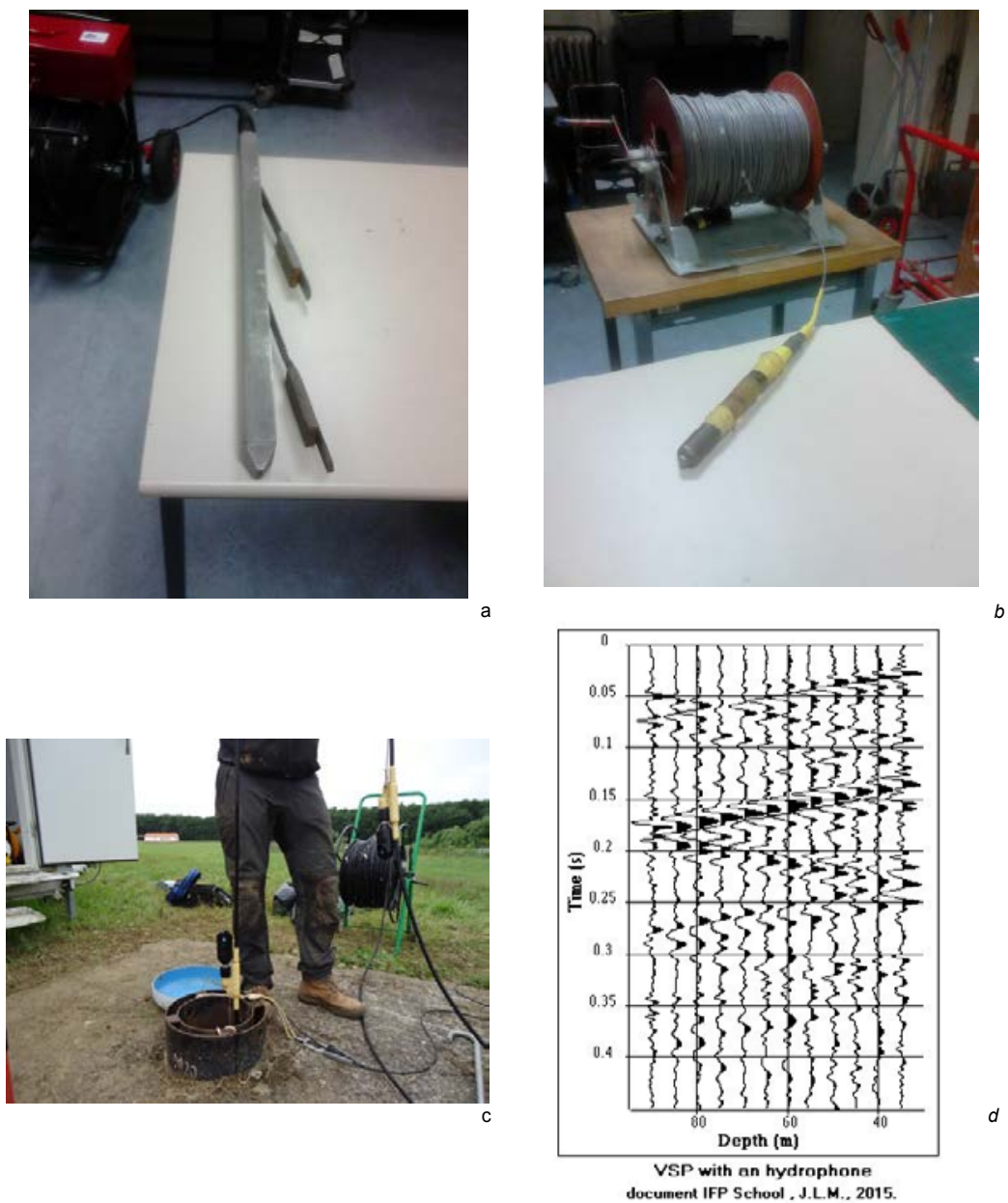

Figure 2.4 Examples of well probes (a: 3C geophone, b: hydrophone, c: hydrophone array, d: example of VSP recorded with a hydrophone). 


\subsubsection{Seismic source}

The seismic source must be the appropriate size for an optimal Signal/Noise ratio for the investigated well depth and for a suitable frequency content. The most used sources are: explosive (high energy but can cause a nuisance and authorization is limiting), gun (cartridge), hammer (practical but low energy) and weight drop (good compromise energy/bulk). These sources emit mainly compression-type volume waves. You can also use a mini-vibrator. The petroleum industry generally uses the seismic source for surface seismic data acquisition (vibrator). In water, an air gun is normally used. To emit $S$-waves, a hammer can be used to laterally strike a target anchored to the ground. This point is developed in Chapter 1.

Figure 2.5 shows examples of seismic sources used in civil engineering.

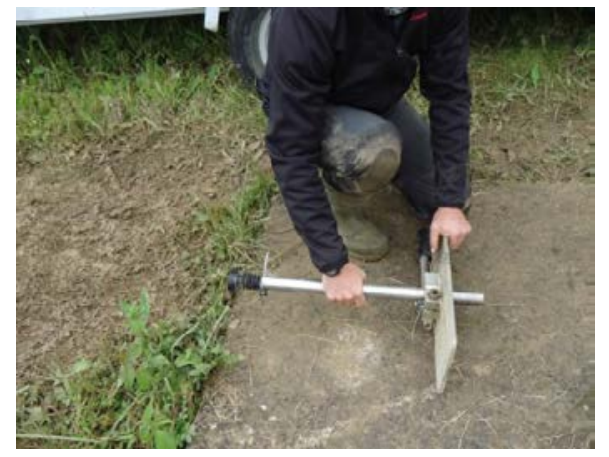

Source: gun

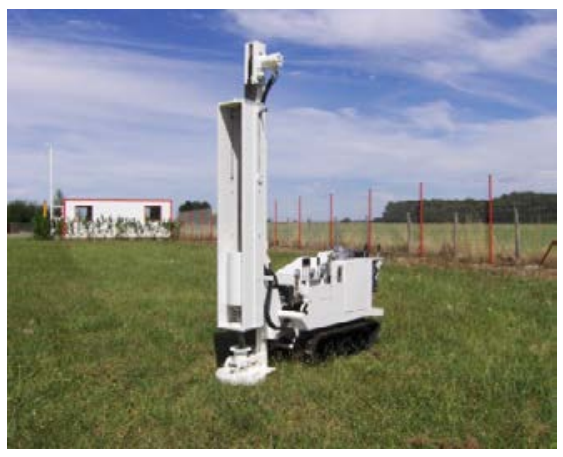

Source: Weight drop (APEC document)

Figure 2.5 Seismic sources used in civil engineering.

\subsubsection{Acquisition parameters}

The VSP recording is a two-dimensional recording (time: vertical axis; depth or length: horizontal axis). The sampling interval is $0.25 \mathrm{~ms}, 0.5 \mathrm{~ms}$ or $1 \mathrm{~ms}$. The listening time ranges from a few hundred $\mathrm{ms}$ to a few seconds. The vertical distance $\Delta \mathrm{z}$ between 2 measurement points (sampling according to depth, i.e. the horizontal axis) must be chosen to be less than the smallest half-wavelength encountered to avoid spatial aliasing phenomenon. $\Delta \mathrm{z}$ is calculated from the lowest propagation velocity $\mathrm{V}_{\min }$ of the seismic waves and the highest frequency $\mathrm{F}_{\max }$ likely to be recorded: $\Delta \mathrm{z} \leq \mathrm{V}_{\min } / 2 \mathrm{~F}_{\max }$. If $\mathrm{V}_{\min }=1500 \mathrm{~m} / \mathrm{s}$ and $\mathrm{F}_{\max }=150 \mathrm{~Hz}$, we will choose $\Delta \mathrm{z} \leq 5 \mathrm{~m}$. 
In practice, vertical distances of between $2 \mathrm{~m}$ and $5 \mathrm{~m}$ are chosen in geotechnical engineering. For a seismic walkaway acquisition, the offset $\mathrm{D}$ of the source relative to the wellhead depends on the depth $\mathrm{H}$ of the objective. For reflection imaging, the angles of incidence should not exceed 30 degrees. As a rule of thumb, $\mathrm{D}<3 / 4 \mathrm{H}$.

\subsubsection{Security}

Site security must be ensured by the Head of Mission, in accordance with the Quality System of the provider. Access to the measurement area must be secured. Only professionally qualified personnel are permitted to use explosives.

\subsubsection{Quality Control}

At each depth interval, the operator controls the quality of the recordings (well and surface receiver, noise level, good coupling of the well receiver...).

\subsubsection{Production}

On average, for a standard VSP: $5 \mathrm{mn} / \mathrm{depth}$.

\subsection{Seismic waves}

The VSP recording is composed of downgoing and upgoing $\mathrm{P}$ and/or $\mathrm{S}$ volume waves as well as of interface/guided waves related to the presence of the well and the well fluid. Guided waves are Stoneley waves, more commonly known as tube waves.

The downgoing volume waves are direct waves emitted by the source. They result in direct arrivals and all the multiple events created by seismic markers located above the well receiver. Upgoing volume waves are primary and multiple reflected waves.

Downgoing waves have positive apparent velocities, upgoing waves have negative apparent velocities.

Tube waves are created when the particles of the sludge column that fills the well are set in motion. Surface waves are the main source of tube waves, which are considered as organized noises that disrupt VSP recordings and interfere with interpretation. There are, however, tube waves that may be useful to the geophysicist. These are the tube waves created in situ in areas of high permeability via compression waves that cross the permeable zone and give rise to two tube waves, one upgoing, the other downgoing as shown in Figure 2.6. The amplitude of these two tube waves is directly proportional to the permeability of the area where they were created and 
the value of the permeability thus found is significant compared to the well over a distance equal to the dominant half-length of the incident compression wave (Huang and Hunter, 1981). An example of tube wave analysis in a reservoir zone is presented by J.L. Mari (1989).

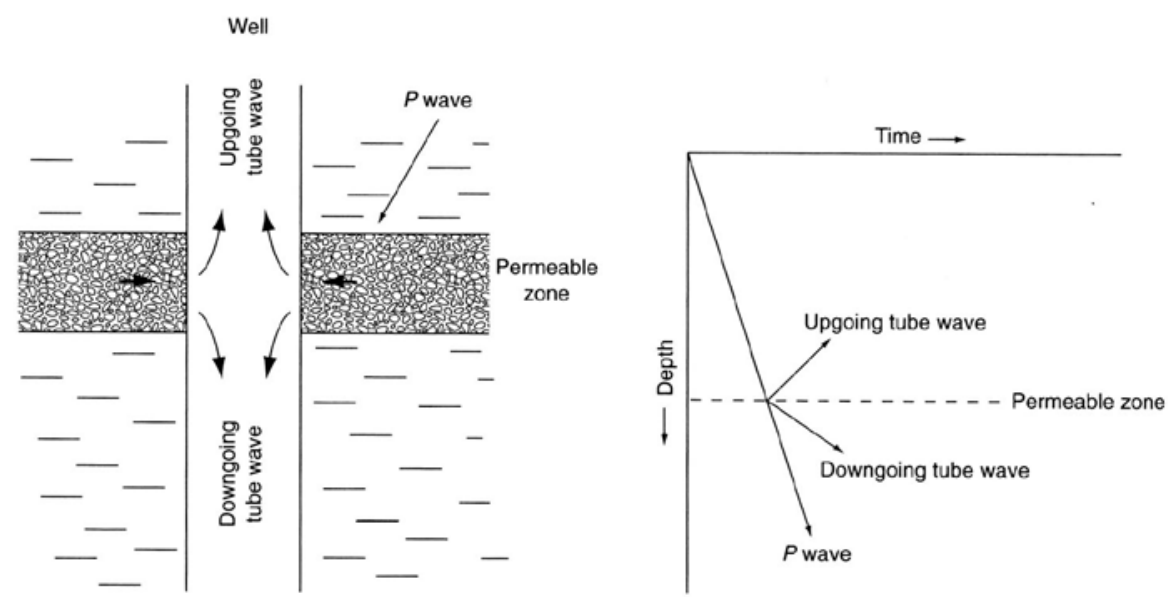

Figure 2.6 Creation of tube waves by compressional waves crossing a permeable zone, and schematic representation of these waves on the VSP record (from Hardage, 1985).

Figure 2.7 shows a VSP with a high level of tube waves, labeled TW1 to TW6. We can identify the direct downgoing wave (first arrival), a set of upgoing reflected arrivals intersecting the direct arrival and some downgoing and upgoing tube waves. The surface waves generated by the source create a field of tube waves (TW3) that is reflected at the well bottom (TW4), and at the top of a porous and permeable zone located at a depth of $440 \mathrm{~m}$ (TW5). TW5 is reflected again at the surface on the fluid-air contact (TW6). The downgoing P-wave that enters the permeable zone at $440 \mathrm{~m}$ creates a tube wave (TW1) that is reflected at the well bottom (TW2). Secondary tube waves with a low apparent velocity can be noted, due to the tool itself. Stoneley waves can also be used to obtain information on the shear wave velocity of the formation, and to detect fracture zones and karsts. An example of the use of tube waves to detect karstic levels of a near-surface carbonate reservoir is presented in Chapter 5. In this case, it is preferable to use a hydrophone as a seismic sensor. 


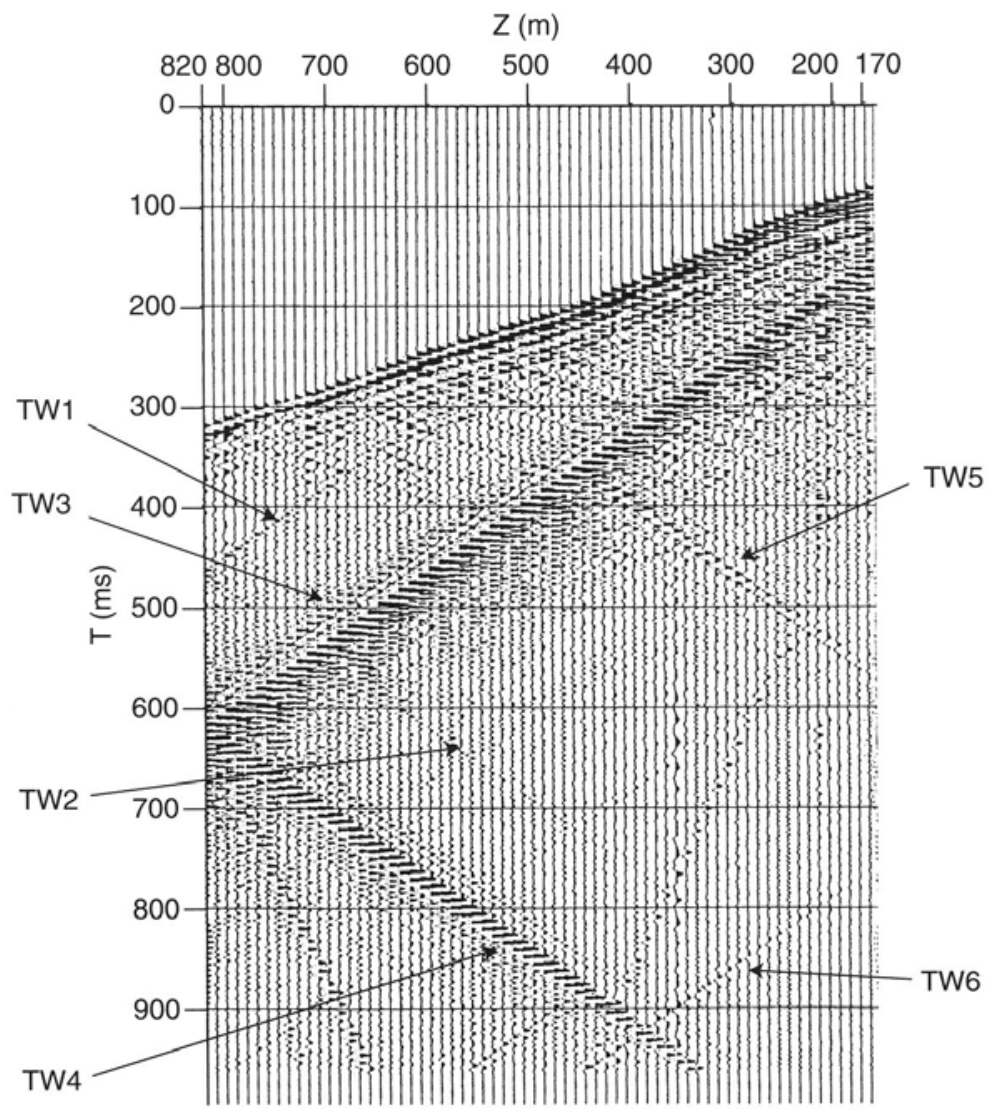

Figure 2.7 Example of VSP with tube waves (ENGIE - IFPEN).

When the source is offset, we can observe conversion phenomena. To properly understand the wave propagation it is necessary to record data with multi-component receivers. Figure 2.8 shows an offset VSP recorded with a two-component well geophone, vertical component $\mathrm{Z}$ and horizontal component $\mathrm{H}$.

For both components the first arrival is the direct P-wave. We can observe a downgoing $S$-wave with a low apparent velocity that is more visible on the horizontal component. Upgoing waves are visible on both components, the apparent velocity of $\mathrm{S}$-waves being lower than that of the P-waves. 


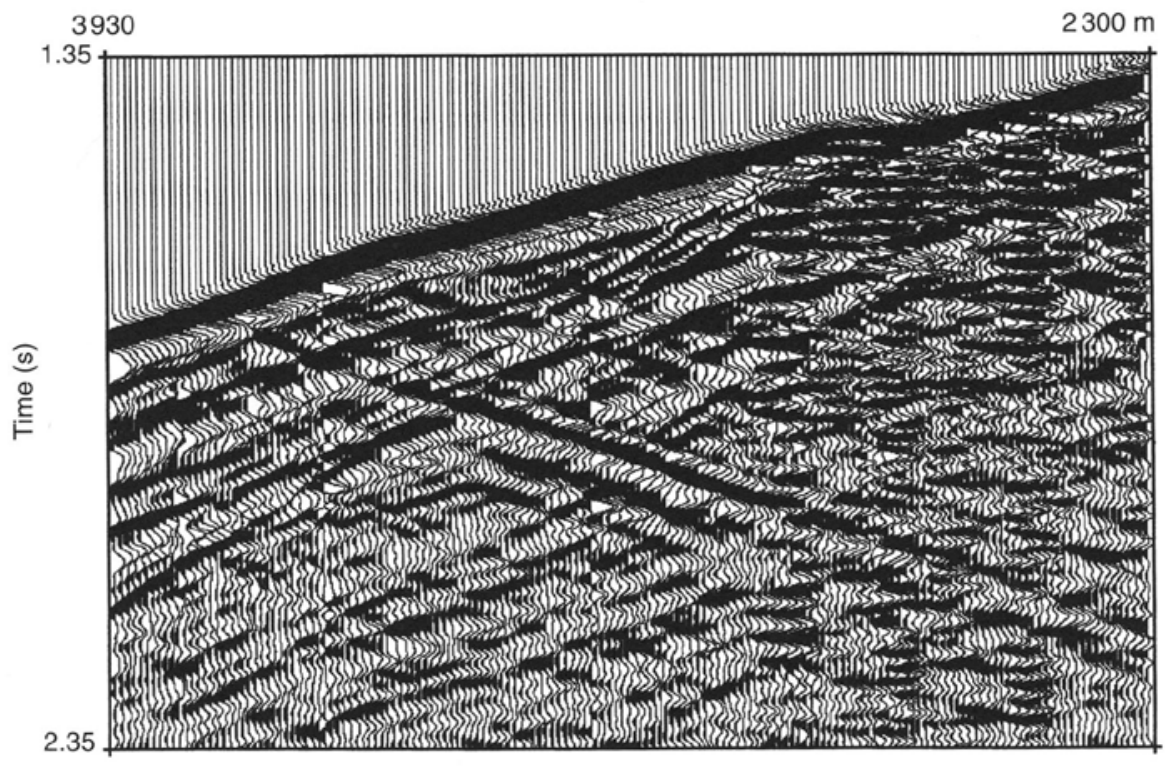

Initial $H$ component

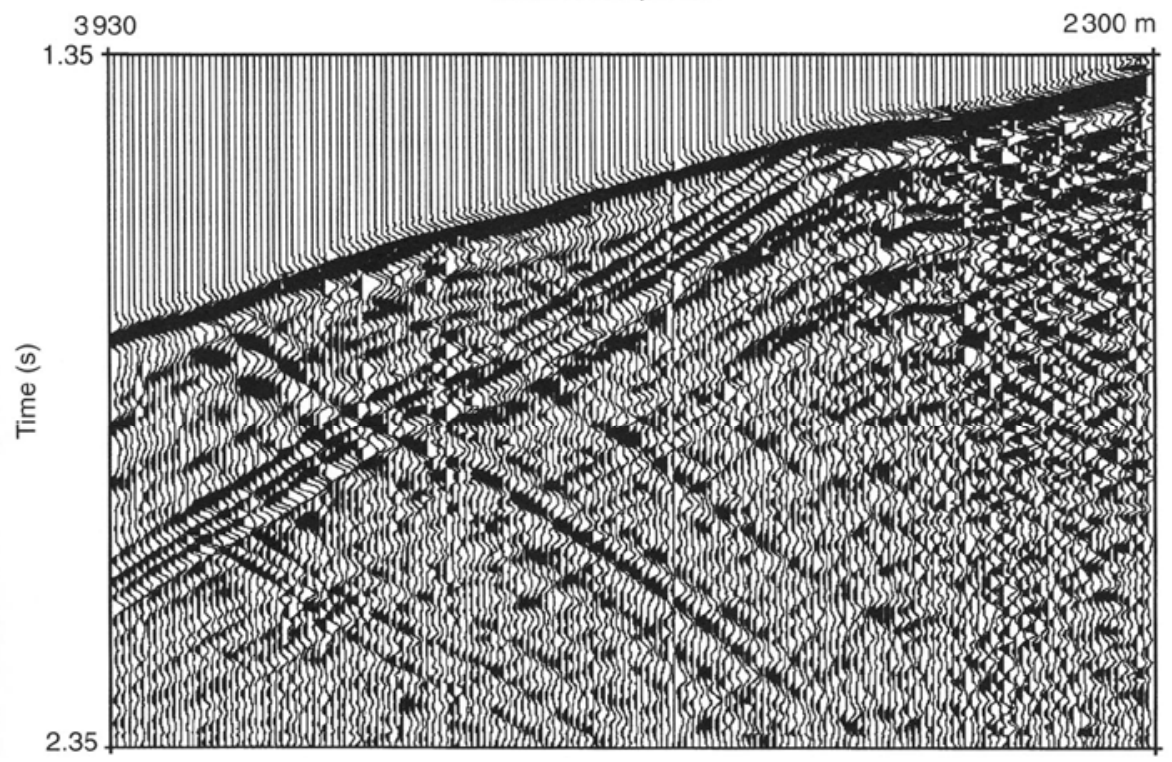

Figure 2.8 Example of offset VSP recorded with a two-component $Z$ and $H$ well geophone (from J. Mars et al., 1999). 
Well-to-well seismic

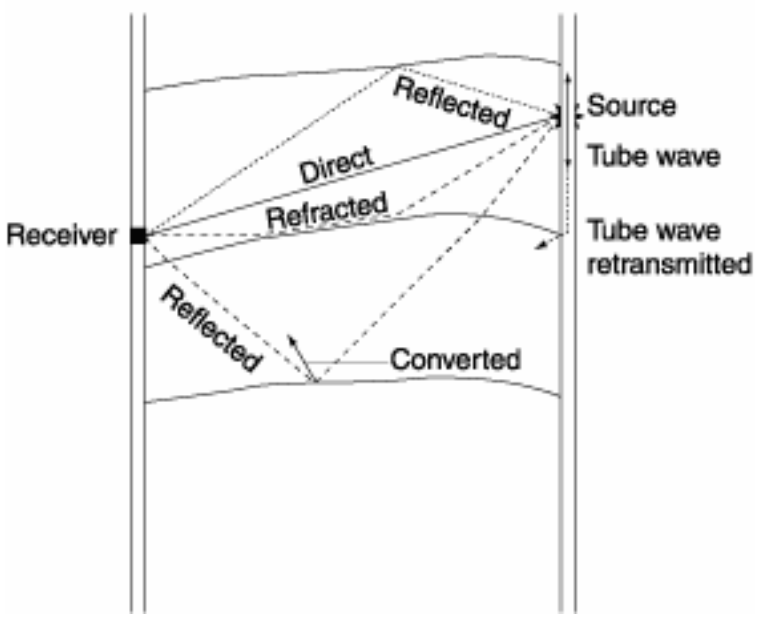

Figure 2.9 Wave ray paths in well-to-well seismic surveying.

For well-to-well seismic surveying (Figure 2.9), the observed wave field is complex. In general, the following waves are observed:

- Direct wave.

- Waves reflected and/or refracted on markers located above or below the depth of the receiver, with and without conversion phenomena.

- Conversion waves created by tube waves generated by the source. These conversion phenomena (tube waves-volume waves) occur at layer boundaries associated with strong acoustic impedance contrasts and at the bottom of the well.

When two or more wells are available, a tomographic survey can be performed to finely describe the area between the two wells. Several implementations are possible:

- Transmission tomography.

- Reflection tomography.

- Diffraction tomography.

Figure 2.3 -right is an example of transmission tomography in civil engineering, conducted in vertical wells ahead of a tunnel digger used for laying out a large diameter sewer pipe. It shows a significant alteration of the rocks in the project zone. 
Reflection tomography can also be used to image the zone between wells by processing data such as those obtained in an offset VSP (Figure 2.3 left). The source is located in one of the wells, and the receiver in the other. In the example presented, the source is a weight drop generating $S$-waves. After processing, the resulting $\mathrm{S}$-wave section shows a better vertical resolution than that obtained with a $\mathrm{P}$-wave VSP acquired in the receiving well. In civil engineering, well-to-well seismic surveying is commonly used to determine the $S$ velocities of formations. An example is presented in Chapter 1.

\subsection{Processing sequence}

Conventional VSP processing enables time-depth relationship and velocity logs to be obtained at the well, along with the VSP stacked trace, which is comparable to a very high-resolution seismic trace, without multiples. We assume here that the source and receiver are located on the same line perpendicular to the layers.

The processing sequence includes:

1. Editing (elimination of poor quality recordings)

2. Correlation by sweeps for a vibrator source and if processing was not carried out at acquisition

3. Correction of signature fluctuations (time and amplitude) using the reference geophone

4. Summing of same depth records

5. Component sorting, if a multi-component receiver is used

6. Picking of first arrival times and calculation of the time-depth relationship, and then of velocity logs (interval velocity, average velocity and RMS velocity)

7. Separation (by apparent velocity filter) of volume and guided waves, upgoing and downgoing waves

8. Flattening of upgoing and downgoing volume waves (P or S)

9. Deconvolution of upgoing volume waves by downgoing waves

10. Generation of the VSP stacked trace. Deconvolved and flattened upgoing waves are stacked within a corridor immediately following the first arrival times

11. Optional analysis of the amplitudes of the downgoing volume waves and calculation of attenuation $\log$

12. Optional guided wave amplitude analysis (VSP with hydrophone)

In the different separation methods, the separation of upgoing and downgoing waves is based, explicitly or implicitly, on the fact that both wave types have positive 
or negative apparent velocities. These wave separation methods can be divided into two categories (Mari and Coppens, 2003; Mari, 2015):

- Methods requiring flattening of the well seismic section at the time of the first arrival, before applying the separation algorithm.

- Methods that do not require flattening.

The methods or filters belonging to the first category include:

- Sum and difference filter

- Median filter

- Wiener filter

- Apparent-velocity filter, if the distance between adjacent recording depths is irregular

- Filtering by singular value decomposition (SVD).

Filters belonging to the second category include:

- Filters based on the spectral matrix (SMF)

- Parametric methods

- Apparent-velocity filter (such as the f-k filter, frequency wave number) if the distance between recording depths is regular.

Separation methods that are not based on a criterion of apparent velocity also exist, namely polarization filters to extract $\mathrm{P}$ and $\mathrm{S}$-waves.

It is often necessary to combine several methods to obtain an optimum wave separation. For instance, for an offset VSP, an apparent-velocity filter is used (f-k filter for example) to separate upgoing and downgoing waves, followed by a polarization filter to separate $\mathrm{P}$ and $\mathrm{S}$-waves. An example of $\mathrm{f}-\mathrm{k}$ filter wave separation and polarization filter is shown in Figure 2.10. The initial data are shown in Figure 2.8. On each component $(\mathrm{Z}, \mathrm{H})$, we observe upgoing and downgoing waves which can be separated by an apparent velocity filter. In this case, an $\mathrm{f}-\mathrm{k}$ filter was applied. After separation, each wave type (upgoing or downgoing) comprises P compression waves and $\mathrm{S}$ shear waves, which have similar apparent velocities. The $\mathrm{P}$ and $\mathrm{S}$-waves are separated by polarization. Figure 2.10 shows the result of the extraction of downgoing and upgoing $\mathrm{P}$ and $\mathrm{S}$-waves. The downgoing $\mathrm{P}$ appears throughout the entire recording. The downgoing $S$-wave only appears after a certain depth, corresponding to the marker on which the conversion phenomenon occurs. 

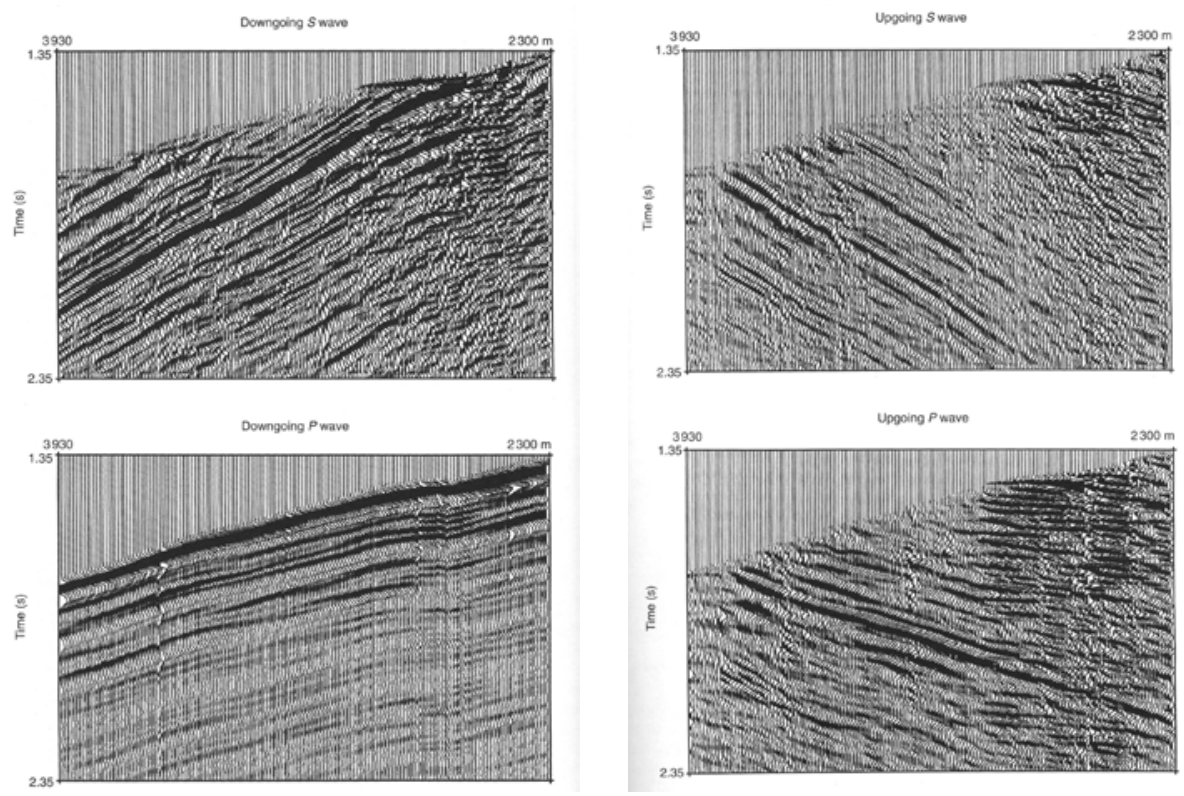

Figure 2.10 Separation of downgoing and upgoing waves by polarization filter (from Mars et al., 1999).

Figures 2.11 and 2.12 show the results of the near surface VSP processing, acquired in the 25 to $90 \mathrm{~m}$ depth interval. The source is a weight drop (Figure 2.5), the well receiver is an anchored geophone (Figure 2.4a). There is a $5 \mathrm{~m}$ distance between 2 measurement points. The listening time is $250 \mathrm{~ms}$. The time sampling interval is $0.25 \mathrm{~ms}$.

The previously described processing sequence was applied. The results of the processing are shown in Figures 2.11 and 2.12. The upgoing and downgoing waves were separated by an $\mathrm{f}-\mathrm{k}$ filter. A reference geophone, sited near the wellhead, was used to check the repeatability of the source in terms of time (TB fluctuation) and amplitude (energy). This process is essential for attenuation measurements (Figure 2.12c). 

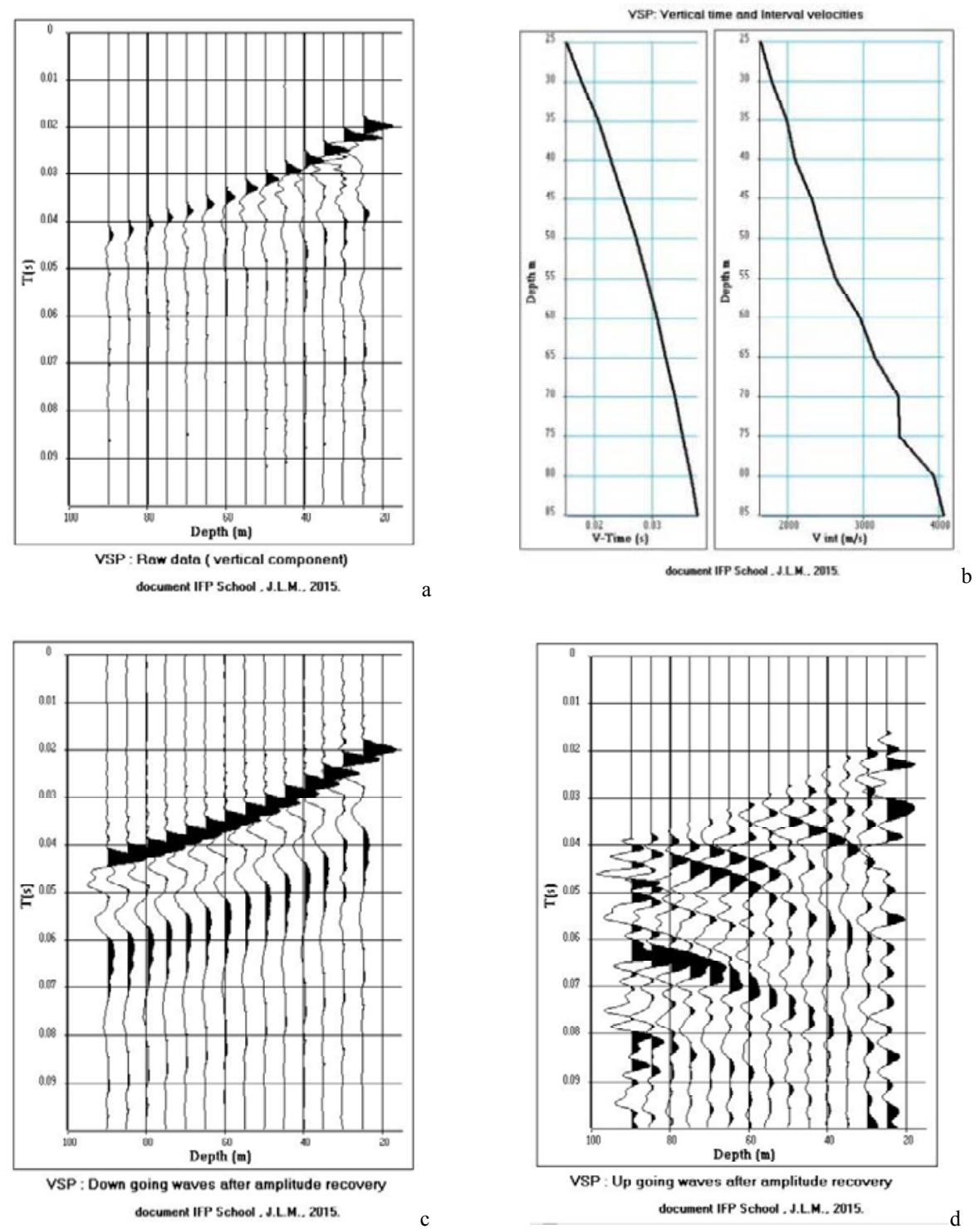

Figure 2.11 Processing of a near surface VSP. a: raw data, b: vertical time and interval velocities, c: downgoing waves, d: upgoing waves. 

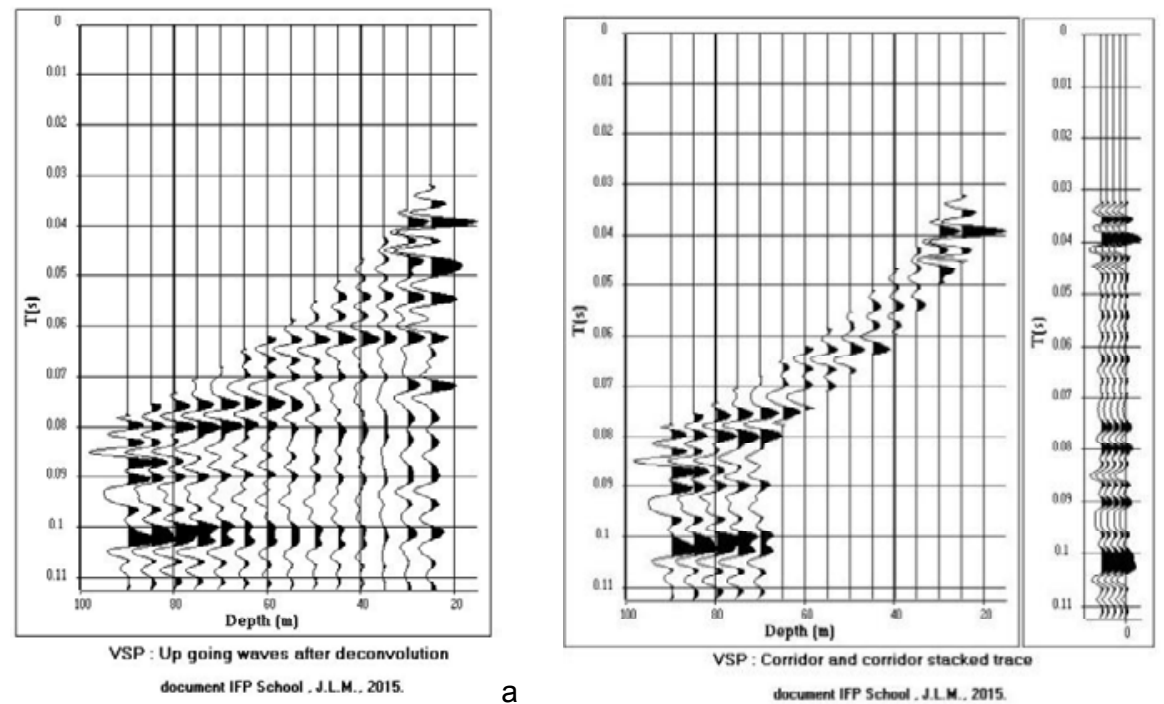

a

document IFP School .J.L. 2015.

b
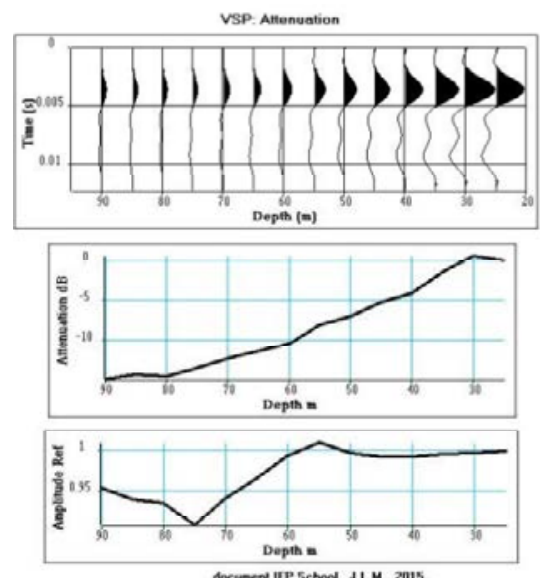

C

Figure 2.12 Processing of a near surface VSP. a: deconvolved upgoing waves, b: stacking corridor and stacked trace, c: attenuation measurement (VSP traces, attenuation log, reference). 
After wave separation, if the source and receiver are not located on the same line perpendicular to the layers, there is a difference in the processing sequence leading to a seismic image that is optimum for a geological interpretation. This is the most general situation that applies to the following cases, offset VSP, VSP in a deviated well, seismic walkaway and well-to-well seismic surveys. The processing sequence includes:

- Deconvolution of upgoing waves. The deconvolution operator is unique.

- It is extracted from traces at the bottom of the well and enables the removal of source signal effects.

- Normal moveout correction and conversion into two-way time of deconvolved upgoing waves. The purpose of this correction is to compensate for the obliquity of the raypaths induced by the source offset. The aim is to take the acquisition geometry into account. Knowledge of the velocity model is necessary to perform this correction.

- Migration: the method most commonly used with VSP is the one proposed by Wyatt and Wyatt (1982). The VSP seismic section obtained after migration is directly comparable to a surface reflection seismic section. The migrated VSP section has a lateral range of investigation of a few tens to a few hundreds of meters.

The example shown here concerns data recorded in a highly deviated well on the Wytch Farm Field on behalf of BP-Amoco and partners.

Well data were acquired in the F18 deviated well (which reached a maximum deviation of $88.5^{\circ}$ ) with a vibrator source located at a distance of $1,865 \mathrm{~m}$ (Jerry's Point (JP)) with respect to the wellhead. Recordings were carried out with a CSI-type 3-component well geophone (Schlumberger's Combinable Seismic Imager Tool). The well geophone was equipped with sensors with a natural frequency of $10 \mathrm{~Hz}$. Acquisition filters were a $2 \mathrm{~Hz}$ low-cut filter with a $6 \mathrm{~dB}$ /oct slope, and a $330 \mathrm{~Hz}$ high-cut filter with a $30 \mathrm{~dB} /$ oct slope. The source signal was emitted within the 10 to $80 \mathrm{~Hz}$ bandpass range. The duration of the frequency sweep was 16 seconds.

The velocity model used to process seismic data was created using the information provided by surface seismic and velocity curves from all wells in the vicinity of the F18 well. The velocity model was refined by inversion of first arrival time picks, minimizing the difference between measured times and the times calculated by the inversion algorithm. The difference between the calculated and measured times did not exceed 3 ms. Figure 2.13 shows the velocity model, the well trajectory, the different positions of the well geophone and the location of source points. For each source point, ray tracing shows the path followed by the downgoing wave. 
Well seismic surveying and acoustic logging
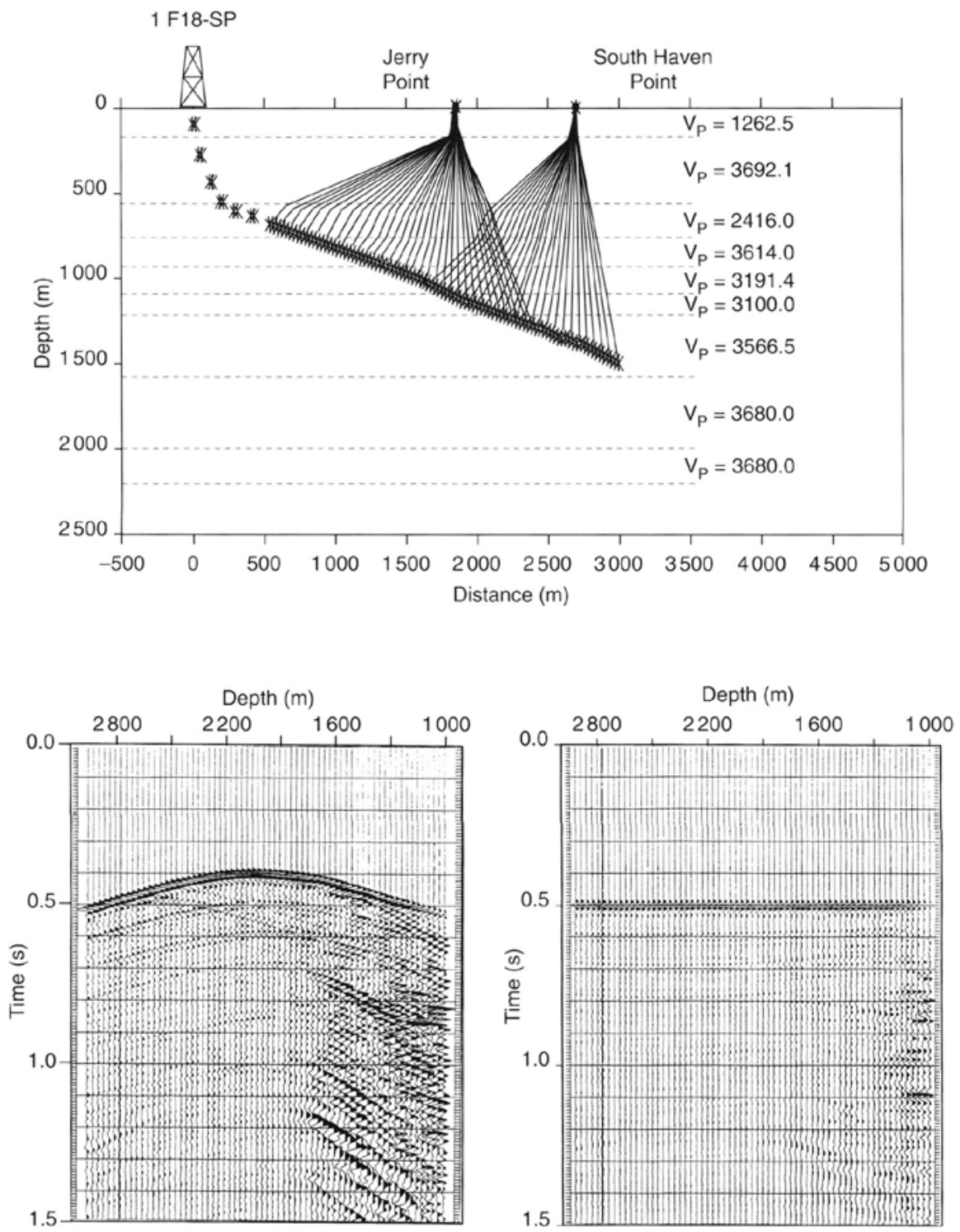

Figure 2.13 VSP in deviated well (BP exploration document). Top: Velocity model and well trajectory. Bottom: VSP data after amplitude recovery and downgoing waves. 
Figures 2.13 to 2.15 illustrate the processing sequence applied to well data obtained with the source located at Jerry Point (JP). The processing phases are as follows:

- Frequency filtering and amplitude recovery. Seismic data were filtered in the 5 to $80 \mathrm{~Hz}$ bandpass and compensated for the spherical divergence effect by application of a gain law. Each VSP trace was then normalized to the direct arrival to compensate for transmission losses. The result of this pre-processing is shown in Figure 2.13 (bottom left). The horizontal axis of the VSP section represents the cable length deployed along the well.

- Picking of first arrival times and wave separation. The VSP section was flattened on the first arrival time picks. A 7-term median filter was applied to flattened data to extract the downgoing waves (Figure 2.13 bottom right). The downgoing wave section was subtracted from the initial data. The residual section was then corrected by the first arrival times to restore each VSP trace to its initial time. The residual VSP section (Figure 2.14 top left) mainly shows the upgoing waves.

- Deconvolution. A Wiener-Levinson deconvolution (Mari, 2015) was applied to the downgoing waves (Figure 2.14 top right) and to the upgoing waves (Figure 2.14 bottom left). The operator, calculated on the downgoing field for the purpose of transforming the downgoing wavelet into a zero-phase signal, was applied to the upgoing and downgoing fields. A different operator was calculated for each VSP depth.

- Generation of the seismic image. The seismic image is obtained from the section representing the deconvolved upgoing waves. The operation involves 4 steps:

1. Calculation of the velocity model

2. NMO corrections and conversion of upgoing waves in two-way times (Figure 2.14 bottom right)

3. Calculation of equal-abscissa lines for mirror points. Figure 2.15 (left) shows the distribution of equal-abscissa lines (iso-X lines) on the section displayed in Figure 2.14 (bottom-right) after application of a gain law. The distance chosen between two iso-X lines was $25 \mathrm{~m}$

4. Migration using the method presented by Wyatt (1981). The migrated VSP section is shown in Figure 2.15 (right). The horizontal axis represents the horizontal distance between the well $(0 \mathrm{~m})$ and the different mirror points. The distance between two mirror points is $25 \mathrm{~m}$. The lateral range of investigation of the VSP section is of the order of $1,000 \mathrm{~m}$. The section is displayed in normal polarity according to the SEG convention. Under normal polarity, an upgoing compression wave reflected by a marker associated to an increase in acoustic impedance is represented by a negative amplitude value (trough) 

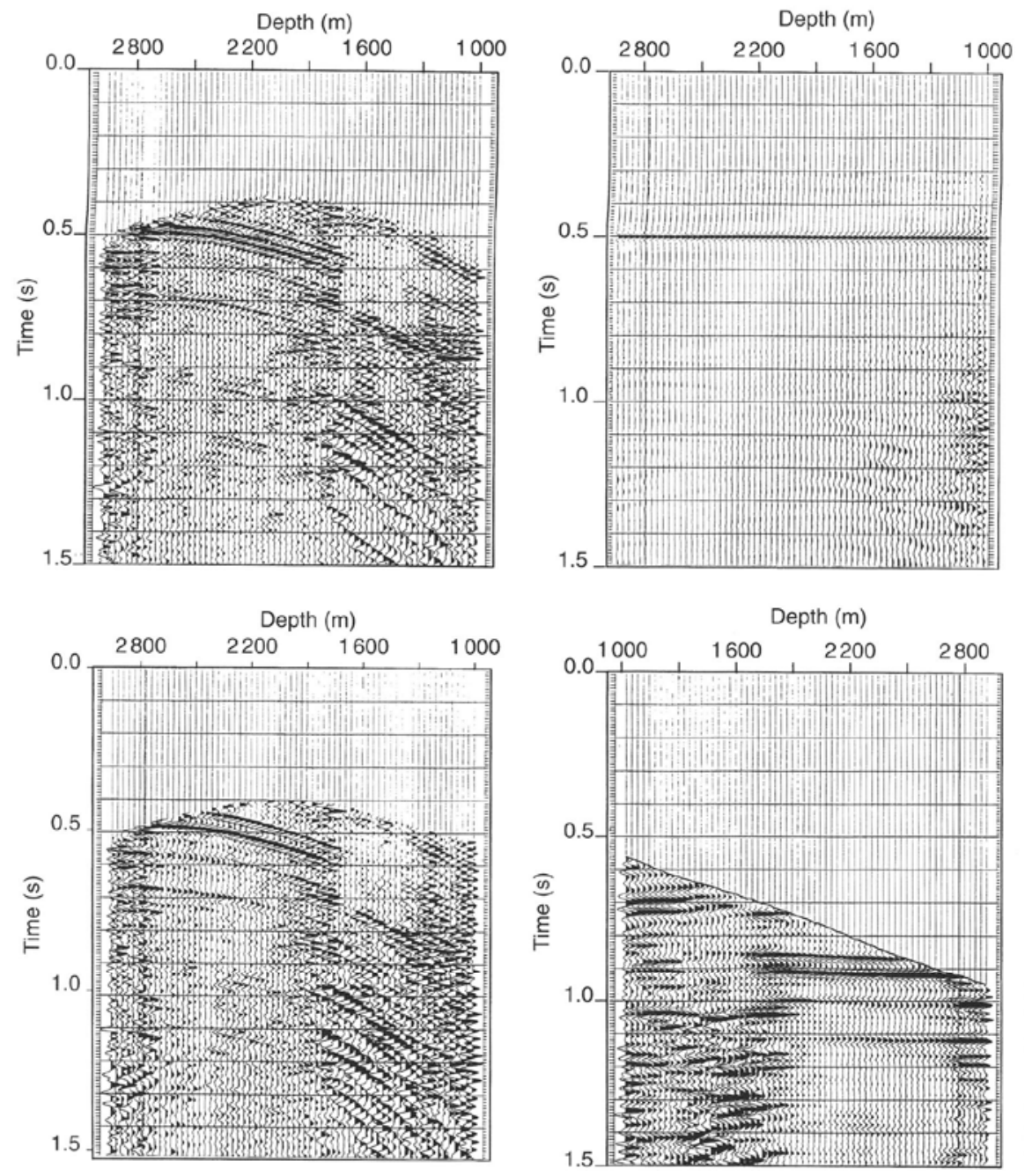

Figure 2.14 VSP in deviated well (BP exploration document). Top: Residual VSP section and deconvolved downgoing waves. Bottom: Upgoing waves after deconvolution and after NMO correction. 

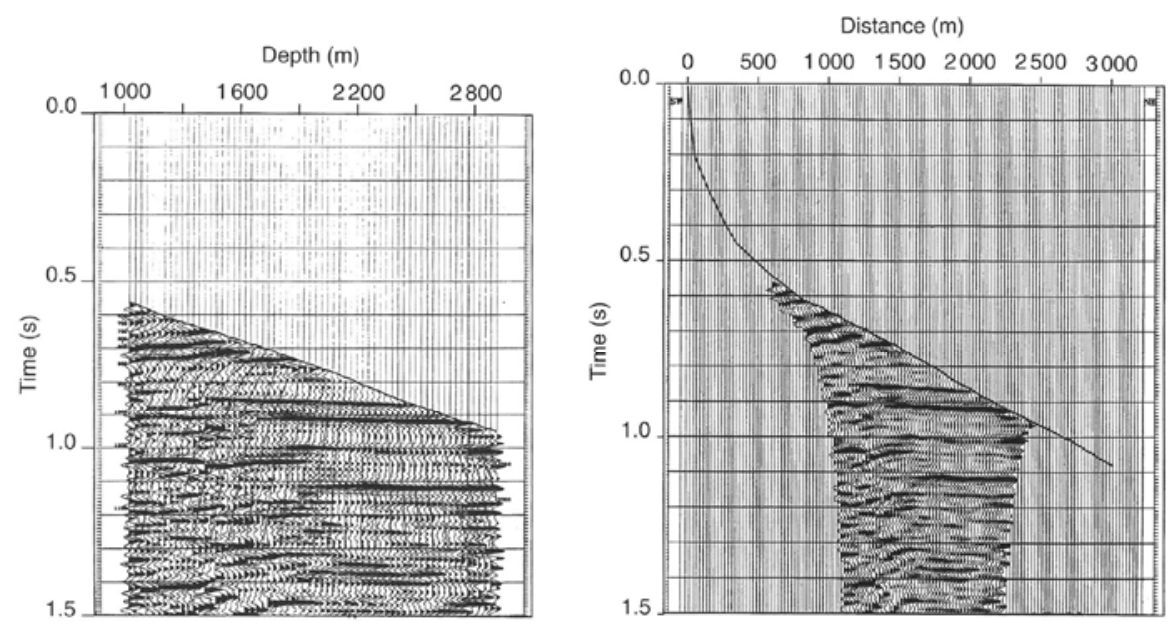

Figure 2.15 VSP in a deviated well (BP exploration document). Left: Upgoing waves after Wiener deconvolution and NMO corrections. Lines of equal abscissa $X$ (iso- $X$ ) displayed every $50 \mathrm{~m}$. Right: Migrated section.

\subsection{Application with a geotechnical dataset}

The following example comes from EDF's downhole database. This downhole is from the study presented in Chapter 1, paragraph 4 , limited to $P$ data acquired with hydrophones (see Figure 2.16).
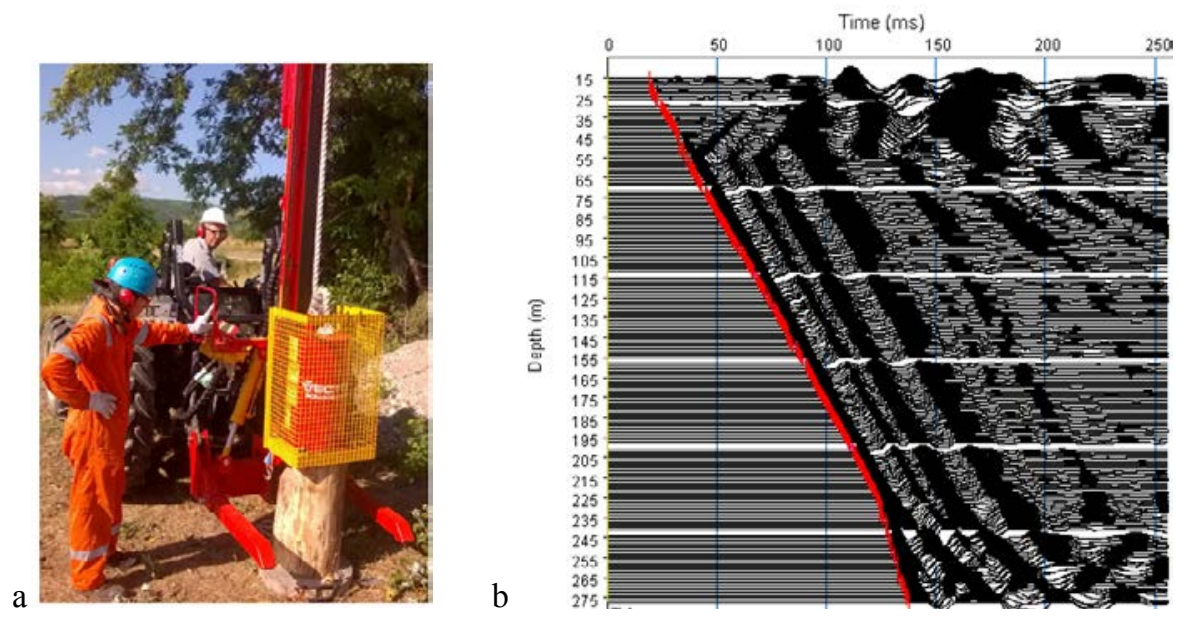

Figure 2.16 FUGRO seismic source (a) and downhole recording (b) EDF document. 
The geology of the well can be summarized as follows:

- 0 to $3 \mathrm{~m}$ : outer sand layer,

- 3 to 6 m: under sand layer,

- 6 to $21.5 \mathrm{~m}$ : sandy-gravelly alluvial deposits,

- 21.5 to $225 \mathrm{~m}$ : succession of layers of fine sand, clay and silt; sand layers dominate down to $41 \mathrm{~m}$,

- 225 to $280 \mathrm{~m}$ : shale, weathered to varying degrees.

IFP Energies nouvelles applied the following processing sequence:

- normalization of traces,

- spectral equalization deconvolution to attenuate the effect of casing-related waves and to increase the resolution,

- picking of first arrivals and velocity calculation,

- separation of upgoing and downgoing waves by wave number filtering,

- deconvolution of upgoing field,

- flattening of upgoing field by the application of static corrections,

- summation of traces within a corridor.

The deconvolved upgoing field (2.17a) is offset in time by the application of a static correction defined at each depth by the vertical time to put the events associated with subhorizontal reflectors in double time and thus enabling a direct comparison with a surface seismic recording near to the well (2.17b). The diffraction hyperbolas are neither flat nor focused in this phase of processing, as shown by the oblique diffractive event visible before $250 \mathrm{~ms}$ in the Figure 2.17b.

The upgoing waves that have been deconvolved by the downgoing field and flattened can also contain upgoing multiples. To eliminate the effects of the upgoing multiples, a narrow stacking corridor was chosen so as to retain only the reflected signal received immediately after the first arrival. The upgoing waves in the stacking corridor are added to obtain a zero-phase multiple-free stacked trace comparable to the migrated surface seismic trace closest to the well. Figure 2.18 also shows that the diffracting event before $250 \mathrm{~ms}$ is eliminated by simple summation on the VSP stacked trace. 

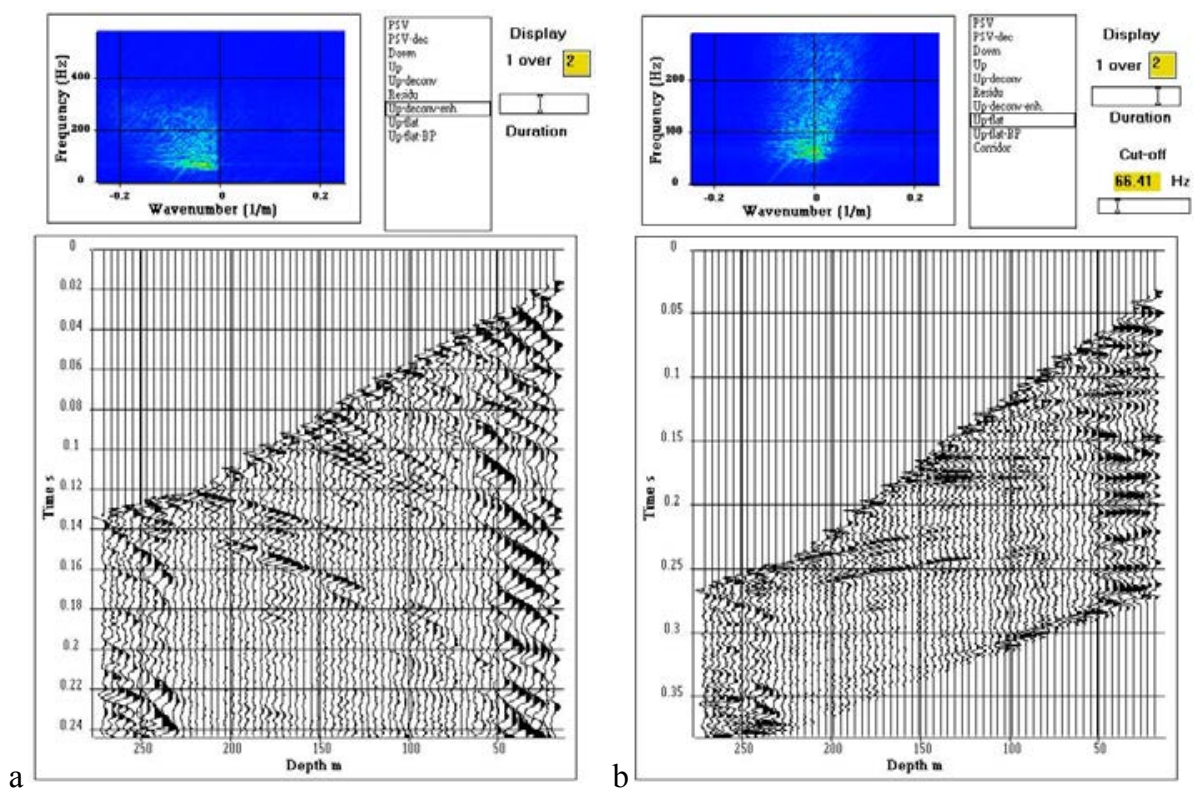

Figure 2.17 a) deconvolved upgoing field (improved signal to noise ratio), b) flattened deconvolved upgoing field.

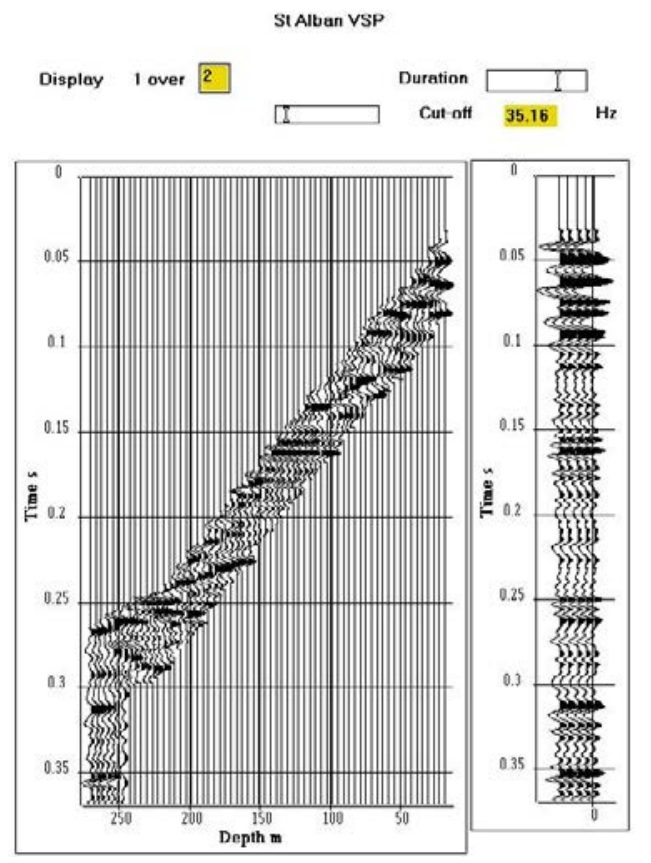

Figure 2.18 Stacking corridor and VSP stacked trace $(35$ to $190 \mathrm{~Hz})$. 
The results obtained therefore show that if the data are correctly sampled, a conventional VSP processing sequence can be adapted to downhole data. The VSP stacked trace can thus be used to tie a seismic reflection profile as shown in Figure 2.19.

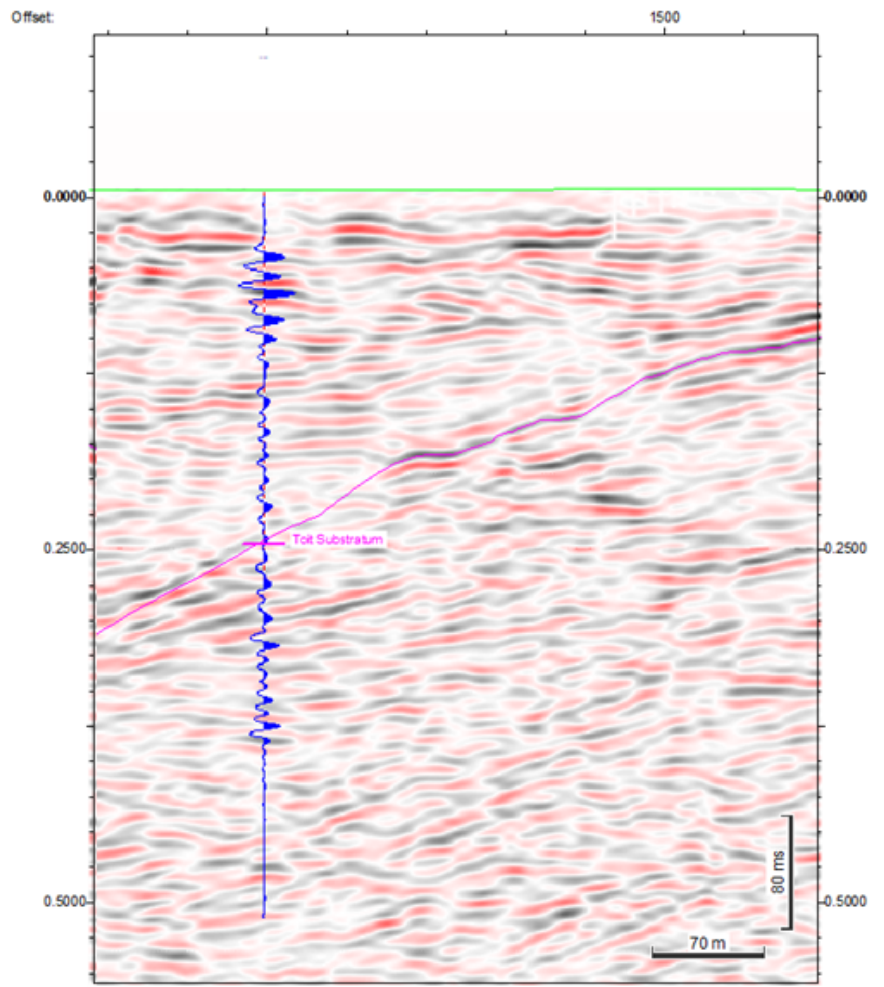

Figure 2.19 Tying of a VHR seismic section on the downhole stacked trace (EDF document).

\subsection{Conclusion}

The main applications of well seismic surveying are:

- Establishing the time-depth relationship at the well position

- Establishing a velocity model (P and/or $S$ )

- Tying seismic refraction profiles

- Validating static corrections 
- Providing a detailed image in the area around the well (taking into account the offset of the source)

- In-depth tying of seismic reflection profiles

- Identifying primary and multiple reflections

- Providing structural information, estimating reflector dip (3 component recording)

- Locating fracture zones (hydrophone measurements) and fault plans (oriented 3C receiver)

- Predicting the presence of reflectors or anomalous zones (e.g. under compaction) ahead of the drill bit, i.e. below the well for a vertical well, and ahead of the drilling front for a horizontal well

The following elements must also be considered:

- The main limitation is the lateral investigation around the well. In classic VSP, with a source offset by several meters, it is limited between the vertical resolution (quarter of wavelength) and around ten meters

- A poor coupling of the probe to the formation leads to the presence of noise, especially for the horizontal components of the well receiver.

- The anchoring force of the well receiver may be insufficient in the case of large diameter wells, resulting in poor coupling.

- Well conditions, such as with poorly cemented cased wells, can make measurements difficult. A good coupling of the well sensor to the casing does not guarantee a good coupling of the receiver to the formation. It is then necessary to make a cementation log before carrying out a VSP.

- The presence of guided waves (Stoneley waves) can be detrimental to the extraction and analysis of volume waves (mainly for hydrophone acquisition).

- Acquisition is sensitive to industrial, human and natural vibrations. It is important to avoid cable transmissions by slackening the cable when measuring.

- The acquisition duration can be estimated at 5 to $10 \mathrm{mn} / \mathrm{depth}$, for a classic VSP.

The offset VSP and the seismic walkaway enable an extension of the lateral investigation variable with depth and provide a detailed seismic survey of the vicinity of the studied objective.

Although the well seismic lateral investigation is in any case limited, having receivers close to the objectives provides a good vertical resolution, due mainly to the fact that the surface weathering zone is crossed just once. 


\section{References}

Hardage B.A., 1985, Vertical seismic profiling, Part A: principles. Geophysical Press, London.

Hardage B.A., 1985, Vertical seismic profiling, Part B: advanced concepts. Geophysical Press, London.

Hardage B.A., 1992, Cross well Seismology and Reverse VSP. Geophysical Press, London.

Huang C.F., Hunter J.A., 1981, The correlation of tube wave events with open fractures in fluid filled boreholes: current research, Part A, Geological Survey of Canada, paper 81-1A, 361-376.

Mari J.L., 1989, Q-log determination on downgoing wavelets and tube wave analysis in vertical seismic profiles. Geophysical Prospecting, 37, 257-277.

Mari J.L., Arens G., Chapellier D., Gaudiani P., 1999, Geophysics of reservoir and civil engineering, Éditions Technip, Paris, ISBN: 2-7108-0757-2.

Mari J.L., Coppens F., 2003, Well seismic surveying. Éditions Technip, Paris, ISBN: 2-7108-0776-9.

Mari J.L., 2015, Signal processing for geologists \& geophysicists, e-book, DOI:10.2516/ifpen/2011002, http://books.ifpenergiesnouvelles.fr/ebooks/signal-processing/

Mars J., Glangeaud F., Boelle J.L., Vanpe J.M., 1999, Wave separation by an oblique polarization filter, PSIPP'99. First international symposium on Physics in Signal and Image Processing, 18-19 January 1999, Paris, France, 94-108.

Wyatt K.D., Wyatt S.B., 1982, Determination of subsurface structural information using the vertical seismic profile. Geophysics, 47, 7, 1123-1128. 

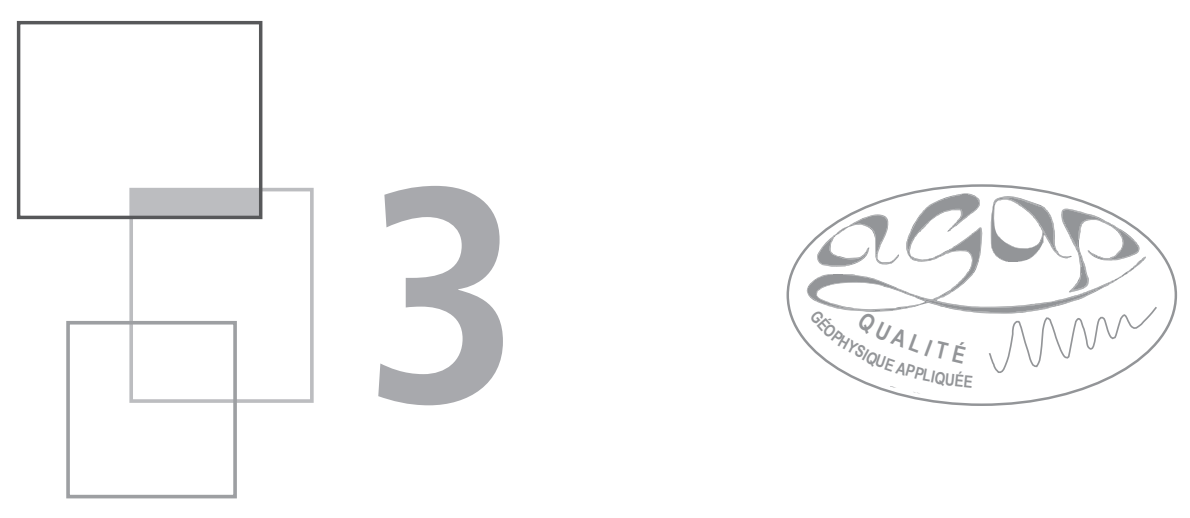

\section{Acoustic logging}

\section{J.-L. Mari, C. Vergniault, F. Coppens}

\subsection{Introduction}

For many years, the transmission of an acoustic wave through media has been used for borehole measurements. Acoustic logging is an approach to measure the sound propagation velocity in geological formations, using a device composed of a transmitter and a receiver system. Originally, this measurement method, called sonic logging, was essentially intended to measure the interval $(\Delta t)$ of arrival times of the first compression wave, with two receivers that are 25 to $50 \mathrm{~cm}$ apart, the energy being emitted by a transmitter located about $1 \mathrm{~m}$ from the first receiver. A slowness (inverse of velocity) curve is obtained from which is calculated the propagation velocity of the refracted sonic wave (15 to $30 \mathrm{kHz})$ in the formations. In this case, only the picking of the first arrival of the compression wave $(\mathrm{P})$ in the media traversed is taken into account. The use of so-called sonic logging to determine the

This chapter of Well seismic surveying and acoustic logging is published under Open Source Creative Commons License CC-BY-NC-ND allowing non-commercial use, distribution, reproduction of the text, via any medium, provided the source is cited.

(C) EDP Sciences, 2018

DOI: 10.1051/978-2-7598-2263-8.c005 
velocity of compression waves is a common and relatively well-established practice (Summers and Broding, 1952; Vogel, 1952).

Full waveform acoustic logging or acoustic coring is based on the analysis and processing of the various wave trains (refracted waves, guided waves, reflected waves) recorded by the tool.

Full wave field recordings enable the determination of the propagation velocities of the various modes and some petrophysical parameters, and the ascertainment of lithological and mechanical information (Gaudiani, 1982; Arditty, Arens and Staron, 1984; Morris, Little and Letton, 1984; Paillet and Turpening, 1984; Mari, Coppens, Gavin and Wicquart, 1992; Mari, Arens, Chapellier and Gaudiani, 1998; Mari, Gaudiani and Delay, 2011).

The borehole may be an open hole, a cased hole (steel and/or PVC), or a cemented cased hole. In the latter type, acoustic logging is used to monitor the cementation and to determine the characteristic parameters of formations (velocities...).

Acoustic logging has a vertical resolution of a few centimeters, and a lateral one of centimeters for interface modes, decimeters up to a meter for retracted modes, and up to ten meters for reflected modes. It provides detailed information of a borehole as a function of depth, in terms of acoustic wave velocities and rock petrophysical characteristics. The exploitation of the reflected modes can provide an image comparable to a time microseismic section which, in favorable cases, allows the tracking of layer boundaries and an estimation of their dip. Combined with density logging, it provides an acoustic impedance log, which is variable with depth, and is converted to time after correction, calibration and tying.

Figure 3.1 is an example of a full waveform acoustic log. The acoustic tool (left image in figure) is a flexible tool with a small diameter and composed of a transmitter and 2 receivers. The distance between the transmitter and the first receiver is $3 \mathrm{~m}$, the distance between the two receivers is $25 \mathrm{~cm}$. The depth reference is ground level. Recording depth corresponds to the depth of the point located halfway between the two receivers. The right side of the figure shows an example of an acoustic section obtained by using a transmitter-receiver pair, $3 \mathrm{~m}$ apart. In this representation, the vertical axis represents the depth at which the sensor is located ( $3 \mathrm{~m}$ in this case), and the horizontal axis represents the listening time ( $3 \mathrm{~ms}$ ). The acoustic section is composed of acoustic traces. Each acoustic trace is the acoustic recording measured by the receiver, which is $3 \mathrm{~m}$ from the transmitter, over a listening time of $3 \mathrm{~ms}$. Different wave trains can be identified on the recording. 

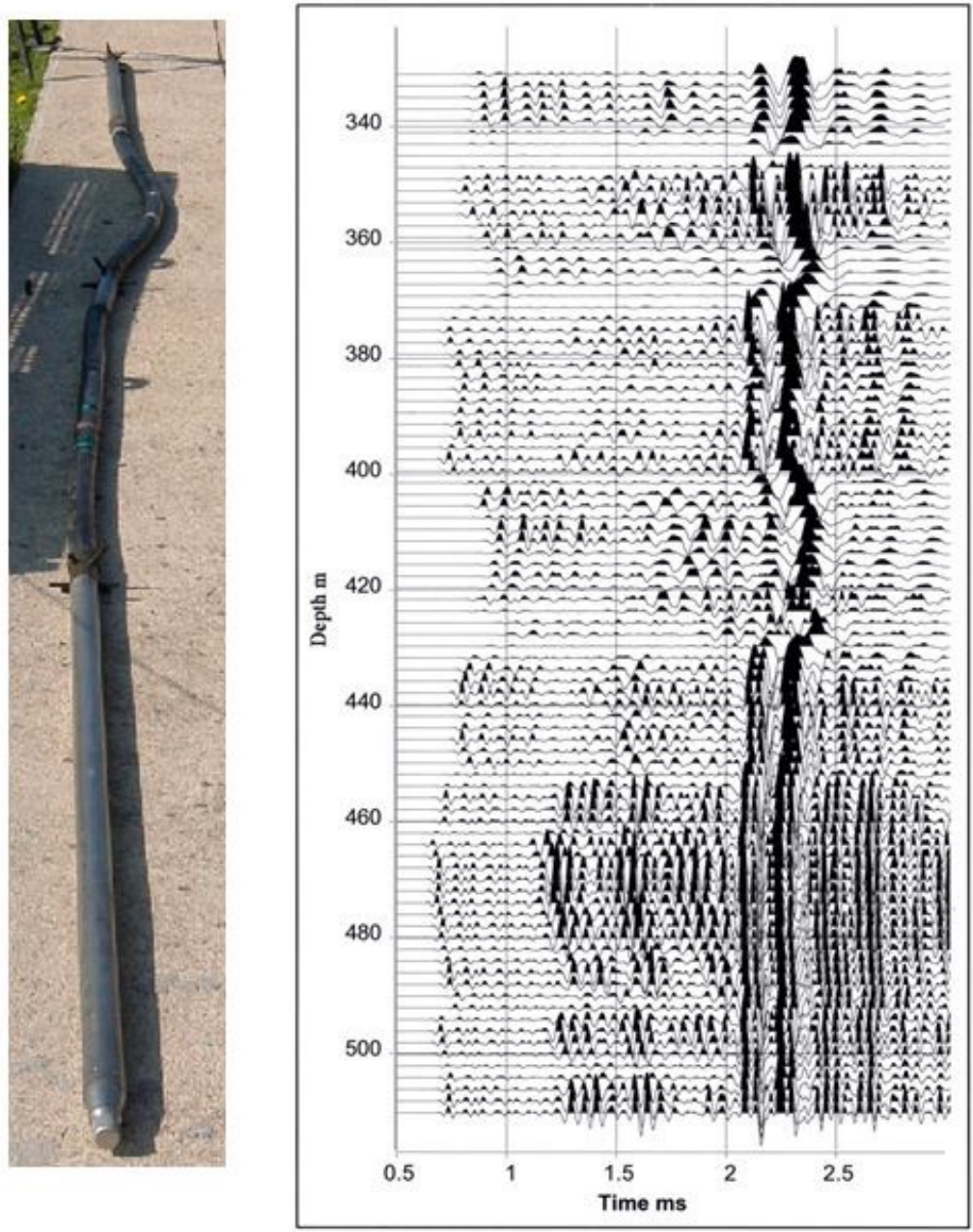

Figure 3.1 Full waveform acoustic logging - tool and acoustic section.

\subsection{Acoustic logging data acquisition}

In this section, we present:

- The necessary resources for data acquisition.

- Implementation in the field. 


\subsubsection{Necessary resources for data acquisition}

Listed below are the necessary resources in terms of equipment, vehicles and personnel.

\section{- Equipment:}

1. logging unit, which includes: a number of probes, a winch with several hundred meters of cable, to which the probes are connected, a recording and digitization unit (digitization can be done at the sensor level), a system for the visualization and printing of the field recordings, and a depth measurement system.

2. one or more acoustic probes

3. a seismic source (weight drop), if a VSP operation is planned with the acoustic logging

4. a lifting system with pulleys to lower the logging (and VSP) probes

5. equipment should be checked periodically (maintenance, calibration).

- Vehicles:

1. either: a logging unit (preferably all-terrain/off road), enabling the transport of personnel and equipment (logging probes and optional VSP probes...)

2. or: a logging unit and one vehicle or a trailer to transport the VSP source (if a VSP operation is planned with the acoustic logging).

- Personnel and expertise:

1. two suitably qualified operators to execute the procedure (winch, lowering of logging probes, acquisition);

2. one geophysicist (Head of Mission) qualified for data quality control at acquisition and can also be an operator.

\subsubsection{Implementation in the field}

In this section, we describe:

\subsubsection{Description of an acoustic logging operation in a vertical borehole}

In vertical boreholes, it is assumed that there is a cylindrical symmetry of the geological formation with respect to the borehole axis. For this measurement, the hole must be in water (borehole mud). The acoustic probe is lowered using centralizers. It is recommended to first measure the borehole diameters (caliper).

After setting the zero (probe reference) according to a reference plane (raft, rotary table...) or on the ground surface, the probe is lowered to a given depth chosen by the operator to make stationary measurements. These measurements enable the verification of the acoustic recordings, the correct operation of the tool, the repeatability of measurements, and the assessment of the signal-to-noise ratio and the 
adjustment of certain acquisition parameters (gains...). The tool is then lowered to the bottom of the borehole. A control acquisition can be made during the descent (downlog), to ensure that there will be no saturation at acquisition. The measurement operation is then carried out during the ascent (uplog), at constant velocity, according to the sampling interval in depth. A typical ascent speed is 4 to $6 \mathrm{~m} / \mathrm{min}$.

\subsubsection{Acoustic probes}

Either monopole or dipole tools are used. Monopole tools are the most commonly used. Transmitters and receivers are multidirectional (Figure 3.2a). In the fluid, transmitters generate a compression wave, which creates in the formation a compression wave ( $\mathrm{P}$-wave) and a shear wave ( $\mathrm{S}$-wave) at the refraction limit angles. Dipole acoustic tools are used to access the $S$ parameters of slow formations and are equipped with polarized transmitters and receivers. Such tools generate polarized compression waves perpendicular to the borehole axis. These compression waves create flexure modes at the well wall that generate pseudo-shear waves in the formation that propagate parallel to the well axis (Figure 3.2b).
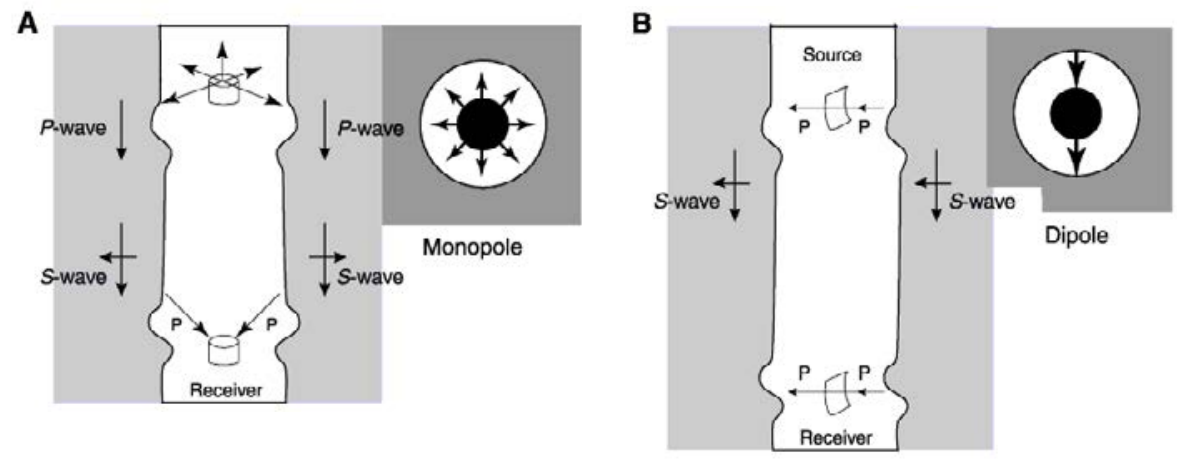

Figure 3.2 Types of Sonic Array transmitters a) Monopole transmitter emitting a multidirectional pulse. b) Dipole transmitter emitting a directed pulse (modified from Zemanek et al., 1991).

When the shear velocity of the formation is lower than the P velocity of the borehole fluid, the flexural wave travels at the $S$-wave velocity and is therefore the most reliable logging method for estimating a shear velocity log. The difficulty, however, is that these tools from the oil industry are rigid and long (about $10 \mathrm{~m}$ long and $10 \mathrm{~cm}$ in diameter). Their implementation is not suitable for geotechnical boreholes. Although an adaptation is available for the geotechnical field, namely PS suspension logging (PSSL), which involves a flexible tool. The PSSL method was originally developed in the mid-1970s by researchers at Japan's Oyo Corporation (Kaneko et al., 1990) with geophones used as receivers. Today, the companies 
Robertson Geologing and Geovista have also developed a probe with hydrophones. The gap between the sources and receivers is 2 to $3 \mathrm{~m}$ and the frequency is in the range of 100 to $1,000 \mathrm{~Hz}$. The source is a horizontal electromagnet that produces a pressure wave in the borehole fluid (electrodynamic source). At the borehole wall, this pressure wave is converted into $\mathrm{P}$ and $\mathrm{S}$ seismic waves that travel radially away from the wall of the hole. These waves are reconverted into pressure waves in the borehole fluid and detected by the receivers (vertical component for the P-wave; horizontal component for the S-wave).

An acoustic tool is characterized by:

- the type of system:

- monopole: transmission frequency $10-40 \mathrm{kHz}$

- dipole: transmission frequency $1-3 \mathrm{kHz}$

- transmitter and receiver type:

- magnetostrictive

- piezoelectric

- number of transmitters and receivers:

- standard, with one or two transmitters and two receivers

- receiving antenna with four to eight receivers

- distance between receivers: from ten to fifty centimeters

- transmitter offset relative to the first receiver: from one to five meters

- mechanical characteristics:

- rigid framework

- flexible framework

- time sampling interval:

- 5 or $10 \mu$ for a monopole tool;

- $20 \mu$ s for a dipole tool

- listening time:

- 2 or $5 \mathrm{~ms}$ for refracted mode analysis;

- $10 \mathrm{~ms}$ or more for reflected mode analysis

Figure 3.1 left shows a monopole acoustic tool, that is flexible and has a small diameter $(50 \mathrm{~mm})$, which is used for geotechnical borehole studies but also for acoustic measurements in the oil sector. The transmitter is magnetostrictive (transmission frequencies: $17-22 \mathrm{kHz}$ ). It can be equipped with two pairs of receivers (both near receivers $(1-1.25 \mathrm{~m})$ and far receivers $(3-3.25 \mathrm{~m}))$. The acoustic examples presented in Chapter 5 were obtained using this tool, developed by P. Gaudiani.

Figure 3.3 shows examples of acoustic tools. 

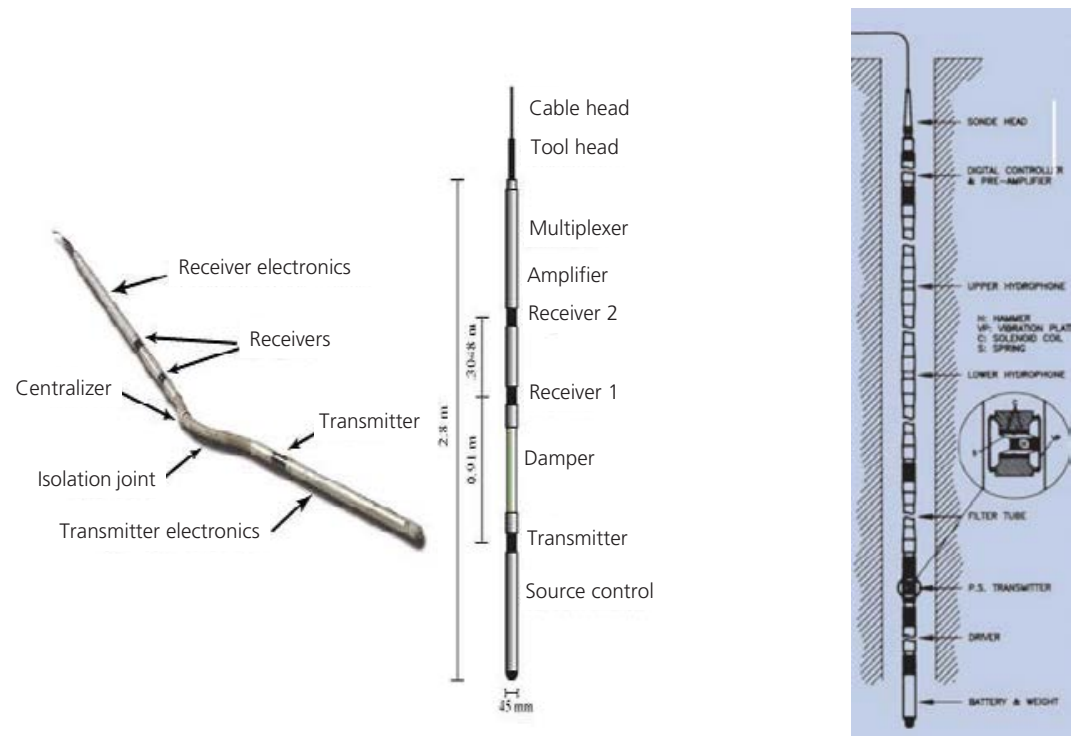

a
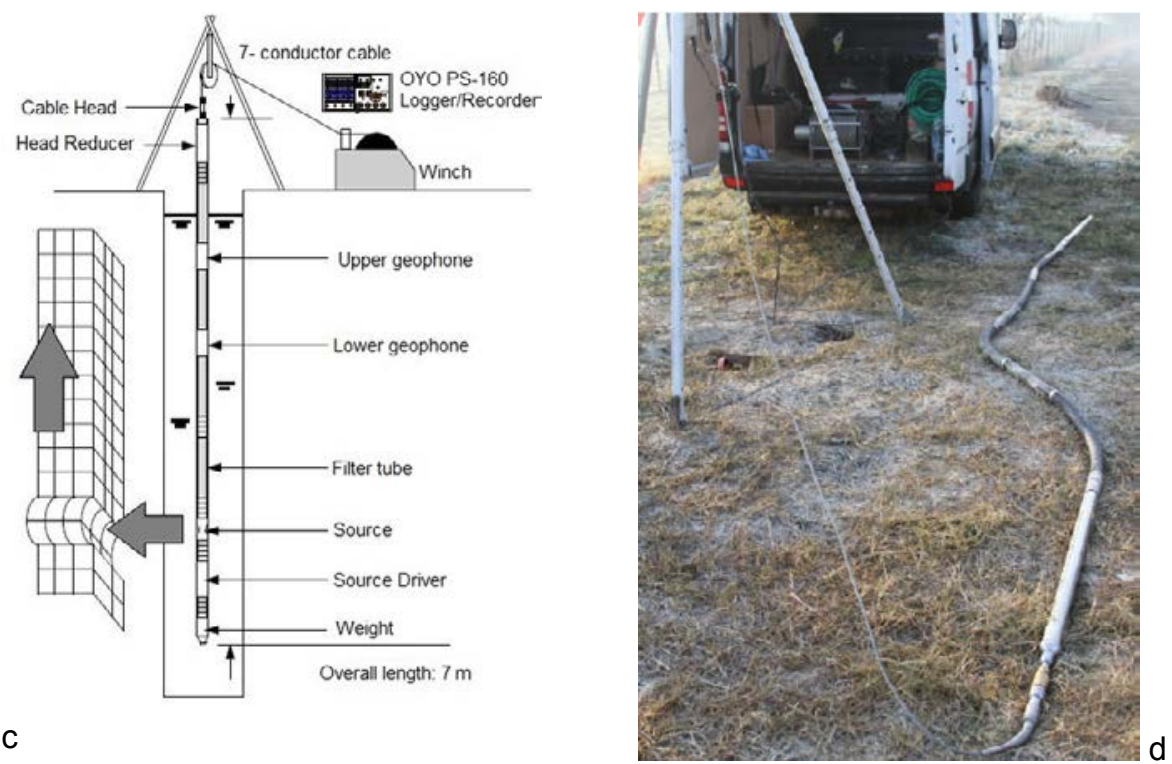

Figure 3.3 Acoustic tools. a) monopole tool (Mount Sopris); b) dipole tool (Robertson). c) and d) PSSL (OYO) principle and view of the tool (GeoVision-EDF document). 


\subsubsection{Acquisition and visualization parameters}

The acoustic recording can be visualized in the form of constant offset acoustic sections, the offset being the distance between the transmitter and a receiver. Each constant offset section is a two-dimensional record (time: vertical axis; depth or length: horizontal axis, or vice versa). The sampling interval in depth must be chosen to avoid the spatial aliasing phenomenon on the constant offset sections for subsequent processing of the acoustic data.

In practice, the sampling interval in depth is chosen to be equal to a fraction of the distance separating the tool's two receivers, which enables the refracted arrivals to simulate direct-inverse shots and to make compensated velocity measurements.

Acquisition gains must be chosen to avoid saturation, especially for guided modes. However, if acquisition is done to obtain a P-wave velocity log, one can choose gains to amplify the compression waves so as to facilitate the picking of the first arrival times (threshold), even if it means saturating the guided modes and having to make a second "run" to acquire guided modes in preserved amplitude.

\subsubsection{Acoustic logging in deviated well}

If the well is deviated, the reflected waves at the boundaries of the layers crossed by the borehole are recorded by the acoustic tool. These waves can be exploited and processed to provide detailed micro-seismic analysis in the vicinity of the well.

\subsubsection{Security}

Site security must be ensured by the Head of Mission, in accordance with the Quality System of the service provider. Access to the measurement area must be secured.

\subsubsection{Quality control}

During the ascent of the acoustic probe, the operator controls the quality of the recordings on the various receivers of the acoustic probe, particularly the noise level. It may be beneficial to reduce the speed of ascent in noisy areas, but the sampling interval in depth must remain constant.

\subsubsection{Production}

For an acoustic log, the average logging speed is between 4 and $6 \mathrm{~m} / \mathrm{min}$. This type of logging is rarely performed on its own. It is typically part of a set of measurements obtained over several "runs". 


\subsection{Acoustic waves}

In a vertical well, monopole tools can enable the recording of five propagation modes:

- refracted compression wave;

- refracted shear wave, only in fast formations $\left(\mathrm{V}_{\mathrm{S}}>\mathrm{V}_{\mathrm{P}}\right.$ fluid);

- fluid wave;

- two dispersive guided modes, which are pseudo-Rayleigh waves and Stoneley waves:

- Pseudo-Rayleigh waves are reflected conical dispersive waves (Biot, 1952) with phase and group velocities which, at low frequencies $(<5 \mathrm{kHz})$, approach the $S$ velocities of the formation, while at high frequencies $(>25 \mathrm{kHz})$ they asymptotically approach the propagation velocity of the compression wave in the fluid. These waves exist only in fast formations.

- Stoneley waves are dispersive interface waves. In fast formations, they have phase and group velocities that approach the fluid velocity at high frequencies asymptotically, and from a lower value. In slow formations, they are more dispersive and sensitive to the $S$-wave parameters of the formation. At low frequencies, Stoneley waves are analogous to tube waves observed in downhole (Chapter 1) and VSP (Chapter 2).

Full waveform acoustic measurements are represented as constant offset sections or common transmitter or receiver point gathers, similar to those used in seismic surveys. An constant offset section or acoustic coring is a set of acoustic recordings represented as a function of depth, obtained with a fixed transmitter-receiver distance.

Presented below is a set of common transmitter point gathers and a set of constant offset sections showing the different wave types that can be observed on these recordings. The common transmitter point gathers are synthetic seismograms that have been made using the modeling programs of Jacques Quiblier (1997). These programs enable the modeling of acoustic data in slow and fast formations. The formation is infinite, elastic and isotropic. It is defined by the propagation velocities of $\mathrm{P}$-waves $\left(\mathrm{V}_{\mathrm{P}}\right)$ and $\mathrm{S}$-waves $\left(\mathrm{V}_{\mathrm{S}}\right)$, by the density $\rho$, and two quality factors $\left(Q_{P}, Q_{S}\right)$ that are characteristic of the attenuation. The well of constant diameter $(16.1 \mathrm{~cm})$ is filled with water $\left(\mathrm{Vf}=1,500 \mathrm{~m} / \mathrm{s}, \rho f=1 \mathrm{~g} / \mathrm{cm}^{3}\right)$ and is of infinite length. The tool of infinite length has the acoustic properties of the fluid. It consists of a transmitter (monopole or dipole) and nine receivers (measuring points). The distance between the transmitter and the first receiver is $1 \mathrm{~m}$. The distance between 2 consecutive receivers is $12.5 \mathrm{~cm}$. The time sampling interval is $10 \mu \mathrm{s}$, the listening time $4 \mathrm{~ms}$. At each measurement point, the algorithm calculates the three components of the displacement (Ur, U $\theta, \mathrm{Uz}$ : radial, tangential and vertical displacements) and the pressure P. In our simulations, the characteristics of the formations are:

- for the slow formation $\left(\mathrm{V}_{\mathrm{S}}<\right.$ well fluid velocity):

$$
\mathrm{V}_{\mathrm{P}}=2,760 \mathrm{~m} / \mathrm{s}
$$




$$
\begin{aligned}
& V_{S}=1,380 \mathrm{~m} / \mathrm{s} \\
& \rho=2.3 \mathrm{~g} / \mathrm{cm}^{3} \\
& Q_{P}=Q_{S}=90
\end{aligned}
$$

- for the fast formation $\left(\mathrm{V}_{\mathrm{S}}>\right.$ well fluid velocity):

$$
\begin{aligned}
& \mathrm{V}_{\mathrm{P}}=4,000 \mathrm{~m} / \mathrm{s} \\
& \mathrm{V}_{\mathrm{S}}=2,000 \mathrm{~m} / \mathrm{s} \\
& \rho=2.3 \mathrm{~g} / \mathrm{cm}^{3} \\
& \mathrm{Q}_{\mathrm{P}}=\mathrm{Q}_{\mathrm{S}}=90
\end{aligned}
$$

Figure 3.4 a shows the common transmitter point gather obtained with a monopole tool in a slow formation. Without amplification, the only visible wave is the Stoneley wave. With an amplification of $60 \mathrm{~dB}$, the refracted P-wave clearly appears. The measurement of its dip enables the determination of the $V_{P}$ velocity of the medium.

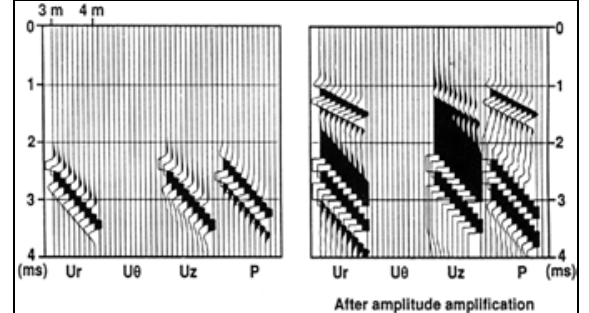

a

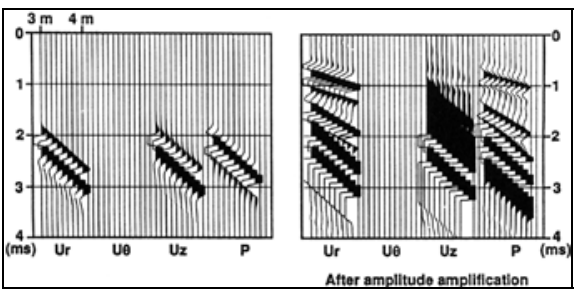

C

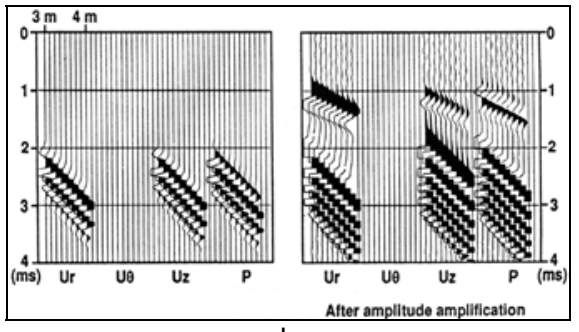

b

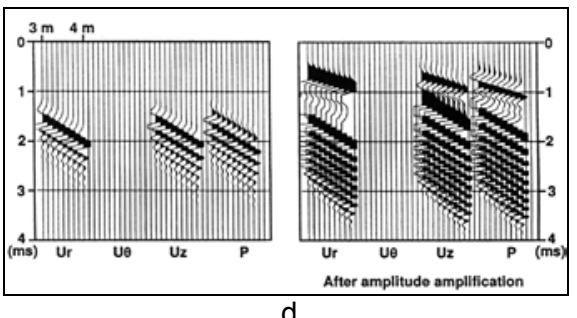

Figure 3.4 Acoustic logging in slow and fast formations. a): monopole tool in slow formation, b): dipole tool in slow formation, c): monopole tool in fast formation, d): dipole tool in fast formation.

Figure $3.4 \mathrm{~b}$ shows the common transmitter point gather obtained with a dipole tool in a slow formation. Without amplification, only the flexural mode is visible between 2 and 3.5 ms. After amplification, the refracted P-wave appears between 1 and $1.5 \mathrm{~ms}$. The flexural mode gives a very good estimate of the $V_{S}$ velocity of the formation. 
Figure $3.4 \mathrm{c}$ shows the common transmitter point gather obtained with a monopole tool in a fast formation. After amplification, the refracted P-wave appears in the $0.5-1 \mathrm{~ms}$ range, the refracted $\mathrm{S}$-wave in the $1.5-2 \mathrm{~ms}$ range, and the Stoneley wave, which is clearly visible without amplification, in the $2-3.5 \mathrm{~ms}$ range.

Figure $3.4 \mathrm{~d}$ shows the common transmitter point gather obtained with a dipole tool in a fast formation. The highly energetic flexural mode is present in the $1.5-2 \mathrm{~ms}$ range, and the refracted $\mathrm{P}$ mode is present in the $0.5-1 \mathrm{~ms}$ range after amplification.

Figure $3.5 \mathrm{a}$ is an example of a $3 \mathrm{~m}$ constant offset section, that therefore corresponds to measurements on a receiver that is $3 \mathrm{~m}$ away from the transmitter, where these propagations are clearly visible. The source is a magnetostrictive monopole transmitter. The presence of the refracted S-wave indicates that the formation is fast. When there is an impedance contrast between two formations with a dip similar to that of the plane perpendicular to the hole axis, these different waves (refractions and interface waves) can convert and reflect as shown in Figure 3.5b and reveal on the constant offset sections a number of chevron patterns at slow apparent velocity. Such reflections can also occur at casing connections, cavities and any other well wall heterogeneities.

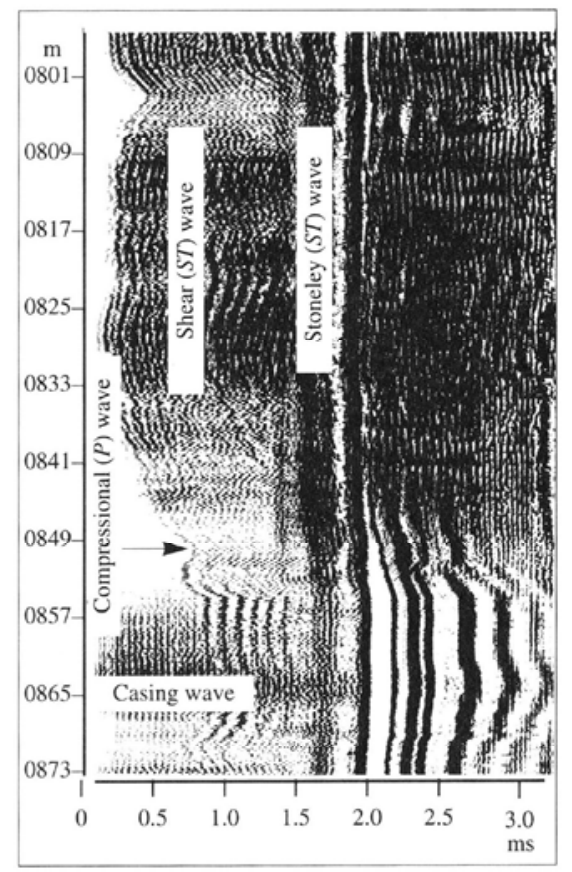

a

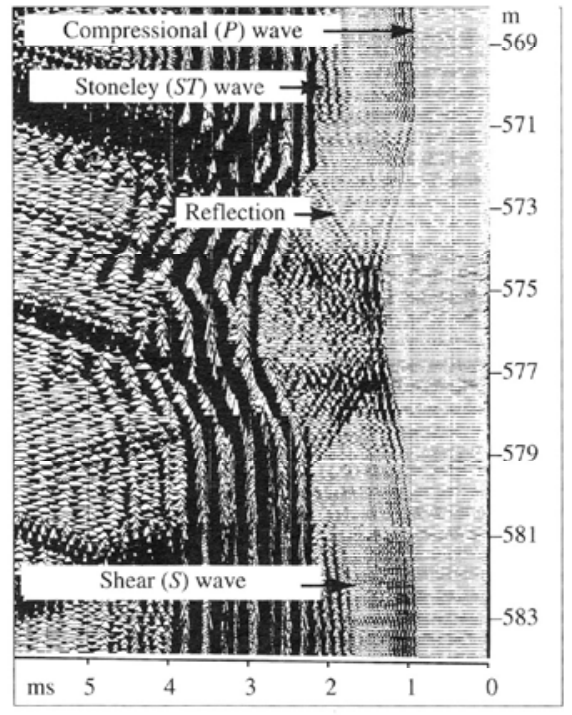

b

Figure 3.5 Acoustic sections (SEMM document). a): example of an constant offset section obtained with a monopole source. We observe the refracted P arrival, the refracted $S$ arrival, the Stoneley wave and casing waves. b): Example of refracted-reflected $P$-waves and reflected Stoneley waves at impedance contrasts in the well. On an constant offset section, these arrivals are in the characteristic form of chevron patterns at slow apparent velocity. 


\subsection{Processing sequence}

Conventional processing of an acoustic log enables time-depth relationship and velocity logs to be obtained at the well, as well as certain mechanical parameters such as the Poisson's ratio.

The processing sequence includes:

1. Editing (elimination of poor quality recordings).

2. Calculation of acoustic velocities by picking the arrival times of the different wave trains or by velocities scanning and semblance processing.

3. Quality control of velocities (measurement of the correlation coefficient) and of pickings (for example, by flattening the wave train by applying static corrections equal to the picked times).

Comments:

- If the picking algorithm uses a threshold, the detection of erroneous picks (spikes and cycle jumps) must be done when editing the velocity logs. This technique is only applicable to compression waves.

- If the velocities are measured by semblance, it is recommended to use a tool with a large offset between the transmitter and the first receiver (about 2 to $3 \mathrm{~m}$ ) and with at least 4 receivers. Measurement is facilitated if the wave trains are well separated in time.

Optional:

1. Measurement of the amplitudes of the different wave trains and calculation of the amplitude and attenuation logs.

2. Measurement of the frequencies of the different wave trains and calculation of the frequency logs (attenuation, resolution...)

3. Calculation of the acoustic porosity (Wyllie's formula)

4. Calculation of synthetic films. It is recommended that tying (block shift and minimum $\Delta \mathrm{t}$ methods) of $\Delta \mathrm{t}$ acoustic measurements on VSP measurements is carried out.

5. Calculation of elastic modules (geomechanical: choice of models used)

6. "Seismic reflection" type processing of reflected waves and obtaining microseismic sections in the vicinity of the well (deviated or horizontal wells)

Processing takes from one to several days (or even weeks: micro-seismic processing is equivalent to seismic reflection processing), depending on the processing options required. If the required processing is only the P velocity log, picked by threshold, it can be obtained in real time in the field.

Examples of conventional acoustic data processing are presented below.

The first example (Mari et al., 2011, Figure 3.6) is an example of acoustic data acquired in a fast formation (formation $V_{S}>$ well fluid $V_{P}$ ). 

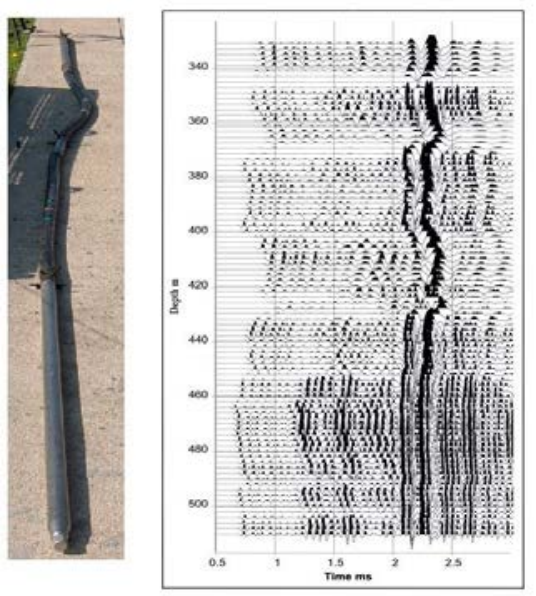

Mari et al., 2011

a

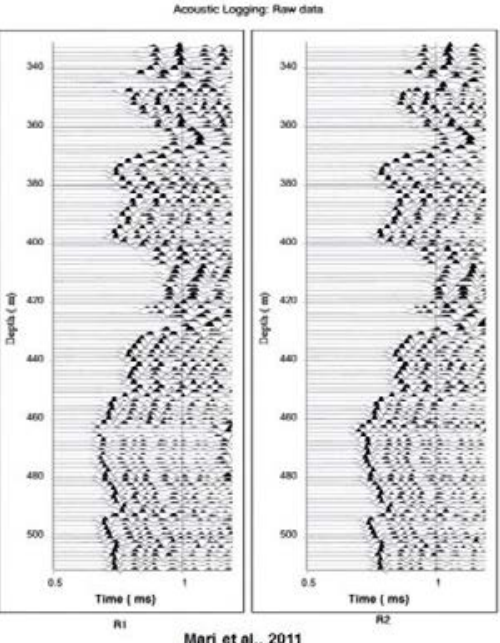

b

Figure $3.6 \mathrm{a}$ and $\mathrm{b}$ Example of acoustic data recording.

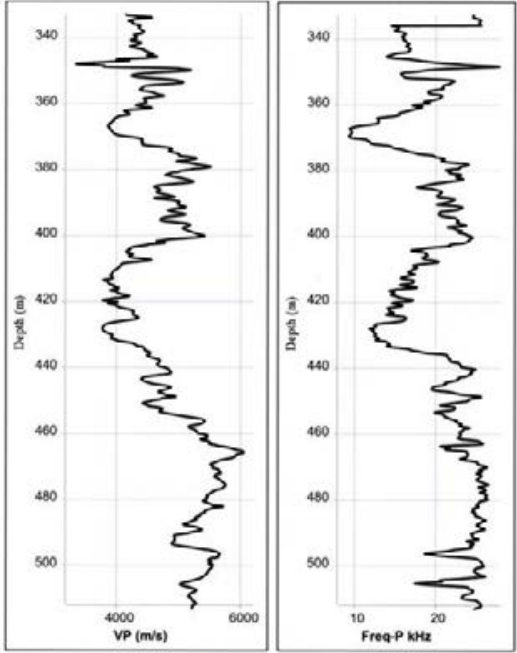

Mari et al., 2011
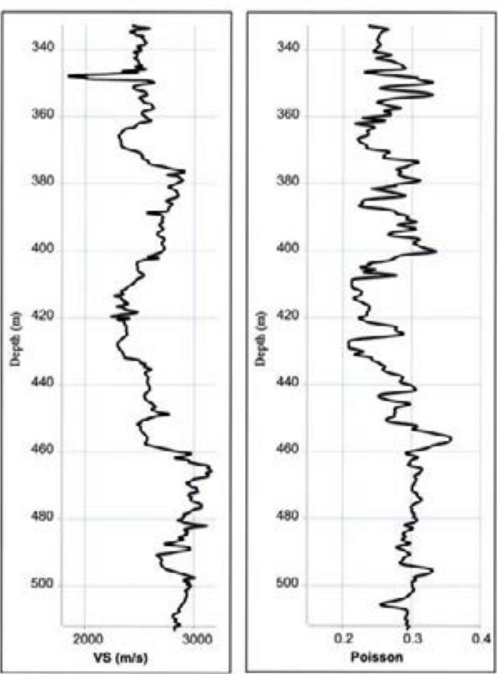

Mari et al., 2011

C

Figure $3.6 \mathrm{c}$ and d Example of acoustic data processing - velocity measurement. a): Tool and $3 \mathrm{~m}$ constant offset acoustic section. b): Acoustic recordings on 2 receivers, $25 \mathrm{~cm}$ apart. c): Compression and frequency velocity logs, d): Shear velocity and Poisson's ratio logs. 
On the $3 \mathrm{~m}$ constant offset acoustic section (Figure 3.6a), we can see the first arrival refracted $\mathrm{P}$-wave, the refracted S-wave and the associated Rayleigh waves in the 1-2 ms time interval, the latter being particularly visible for depths greater than $440 \mathrm{~m}$. Figure $3.6 \mathrm{~b}$ shows the two 3 and $3.25 \mathrm{~m}$ constant offset acoustic sections, in the 0.5-1.1 ms time interval, centered on the refracted P-wave. The Stoneley acoustic waves are visible after $2 \mathrm{~ms}$. It can be noted that the latter have a higher frequency content at depths greater than $440 \mathrm{~m}$. The processing consisted of calculating the $V_{P}$ and $V_{S}$ velocity $\log$, the Poisson's ratio $\log$, and the refracted P-wave frequency log, using the instantaneous frequency. The different logs are presented in Figure 3.6c and d.
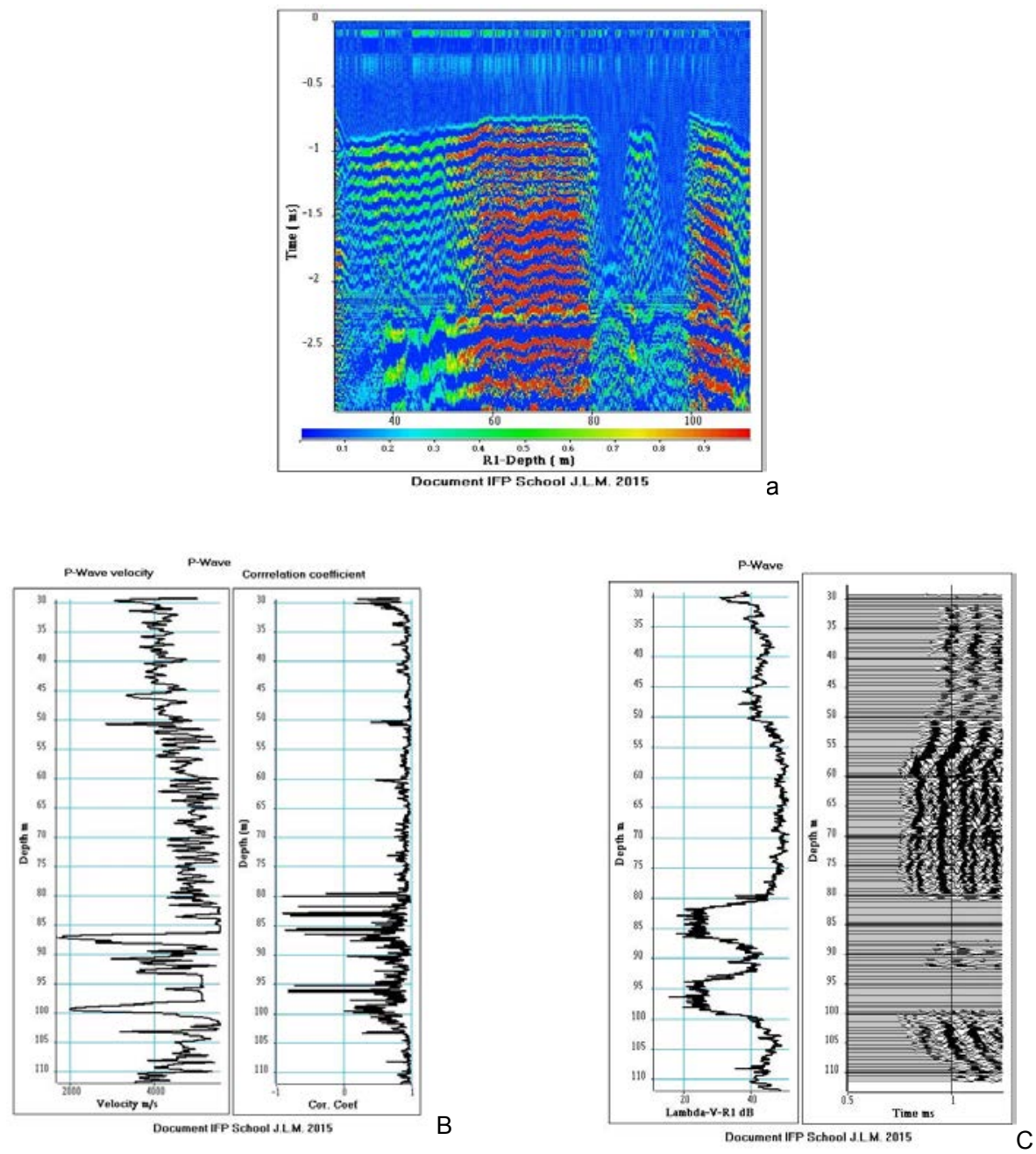

Figure 3.7 Example of acoustic data processing. a): 3m constant offset acoustic section b): Velocity log (waves) and correlation log. Low values of velocity and correlation coefficient indicate the presence of karstic levels. c): P-waves amplitude log. The very small amplitudes indicate the presence of karstic levels. 
The acoustic data of the second example (Mari and Porel, 2015) were acquired in a carbonate formation. The results are presented in Figure 3.7. Figure 3.7a shows the $3 \mathrm{~m}$ constant offset acoustic section, we can see the refracted P-wave, the refracted $\mathrm{S}$-wave and the associated Rayleigh waves, the very high frequency fluid wave at infinite apparent velocity, occurring just before the Stoneley wave. In the depth range of 80-100 m, the presence of two areas with strongly attenuated waves can be noted. Figure $3.7 \mathrm{~b}$ shows the velocity $\log$ of the refracted P-wave and the associated correlation log used for the quality control of the velocity measurement. In the low velocity and high attenuation zones, this coefficient is low. Figure 3.7c shows the amplitude $\log$ of the P-wave, obtained by singular value decomposition (SVD) method, in the same depth interval. At this interval, we note a low formation velocity, a strong attenuation, and a low correlation coefficient which all indicate the presence of karstic levels. These data are part of the case study presented in Chapter 5.

\subsection{Acoustic imaging}

In this section, we provide a simple description of the processes of refraction and reflection imaging.

\subsubsection{Refraction acoustic imaging}

The total transit time $T_{i, j}$ between a transmitter $i$ and a receiver $j$ of a refracted wave is equal to the sum of the delays in line with the transmitting point $\left(\mathrm{D}_{\mathrm{i}}\right)$ and the receiving point $\left(\mathrm{D}_{\mathrm{j}}\right)$ and the associated transit time to the refractor $\left(\mathrm{X}_{\mathrm{i}, \mathrm{j}} / \mathrm{V}\right.$ with $\mathrm{X}_{\mathrm{i}, \mathrm{j}}$ being the distance between the transmitter $i$ and the receiver $j$, and $V$ being the refractor velocity):

$$
T_{i, j}=\frac{X_{i, j}}{V}+D_{i}+D_{j}
$$

with,

$$
\frac{X_{i, j}}{V}=\sum_{k=i}^{j-1} d t_{k, k+1}
$$

The quantity $\mathrm{dt}_{\mathrm{k}, \mathrm{k}+1}$ is the propagation time in the formation between two successive positions of depth $\mathrm{k}$ and $\mathrm{k}+1$. Figure 3.8 shows the path of the refracted wave between a source $S$ at position $i$ and a receiver $R$ at position $j$. The delays $D$ are simple functions of mud parameters (thickness and velocity $\mathrm{hm}$ and $\mathrm{Vm}$ ) and the parameters of the well's weathering zone (thickness and velocity ha and $\mathrm{Va}$ ). The delay in $S$ is equal to the travel time between $S$ and $B$ minus the travel time between $\mathrm{A}$ and $\mathrm{B}$. The calculation of the delay at each recording depth enables the estimation of the extension of the well's weathering zone. This parameter is rarely measured. 
If the velocity of the well's weathering zone is greater than the formation velocity $(\mathrm{Va}>\mathrm{V})$, the measurement of slowness by the acoustic method does not lead to an estimation of formation velocity, but that of the well's weathering zone.

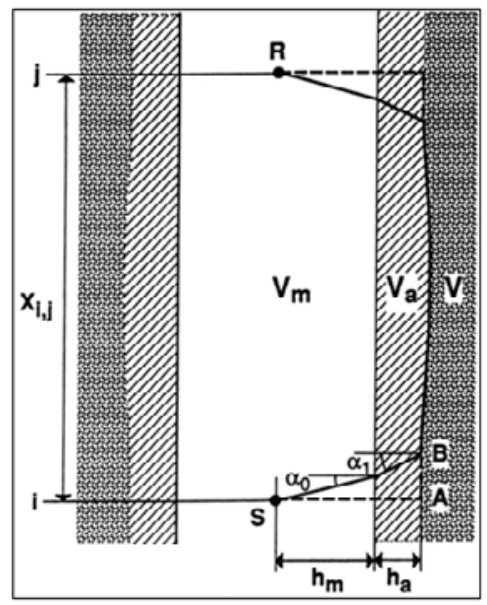

Figure 3.8 Diagram of the first refracted arrival path (from Coppens and Mari, 1995).

The average slowness of wave propagation over a given depth interval corresponds to the delay acquired by the wave over this interval. For the same depth position of the transmitter (or reciprocally, the receiver), the delay can be measured by measuring the difference in the arrival time of the wave over each receiver position (or reciprocally, transmitter) located in the depth interval. As a consequence, the slowness of a formation can be estimated by measuring the wave delay by using sorted sonic records, either in common-source point depth gathers or in common-receiver point depth gathers. The average of the two delays then forms a slowness compensated for well effects.

Slowness measurement methods based on the picking of first arrival times for each trace provide logs with a resolution equal to the distance separating two receivers (between half a foot and two feet). The most well known method is the minimum energy threshold picking method. If the threshold is poorly selected, or if attenuation or noise problems modify the energy levels, phase jumps of one or more periods (so-called cycle jumps) may occur, distorting the time measurements.

Using full waveform tools, it is possible to control the pick quality and avoid phase jumps. Picking by threshold can then be advantageously replaced by picking techniques that take into account other criteria for tracking a wave. Mari and Coppens (1992) have proposed a picking method based on the use of artificial intelligence techniques to track a particular wave from one trace to another, and from one shot point to the other. Wave tracking is done using shape and continuity criteria. The shape of the wave is defined by its amplitude and apparent frequency. 
Continuity is expressed by a small variation in shape and by a small time difference of the wave from one depth level to another. The use of such a method ensures a pick that is coherent in time, amplitude and frequency. The tool geometry (number of receivers and distance between receivers) and the acquisition geometry (advancement rate) create a redundancy of information at each measurement depth and lead to an estimation of a dispersion or error value for each parameter.

Figure 3.9 shows eight constant offset sections ( 9 to $12.5 \mathrm{ft}$ ) recorded with a multireceiver tool. The eight sections are presented on a time window of $1 \mathrm{~ms}$ framing the first arrival. The first arrival $\mathrm{P}$ picking times were used to calculate the slowness $\log$ and its measurement dispersion log (Fig. 3.10a and b).

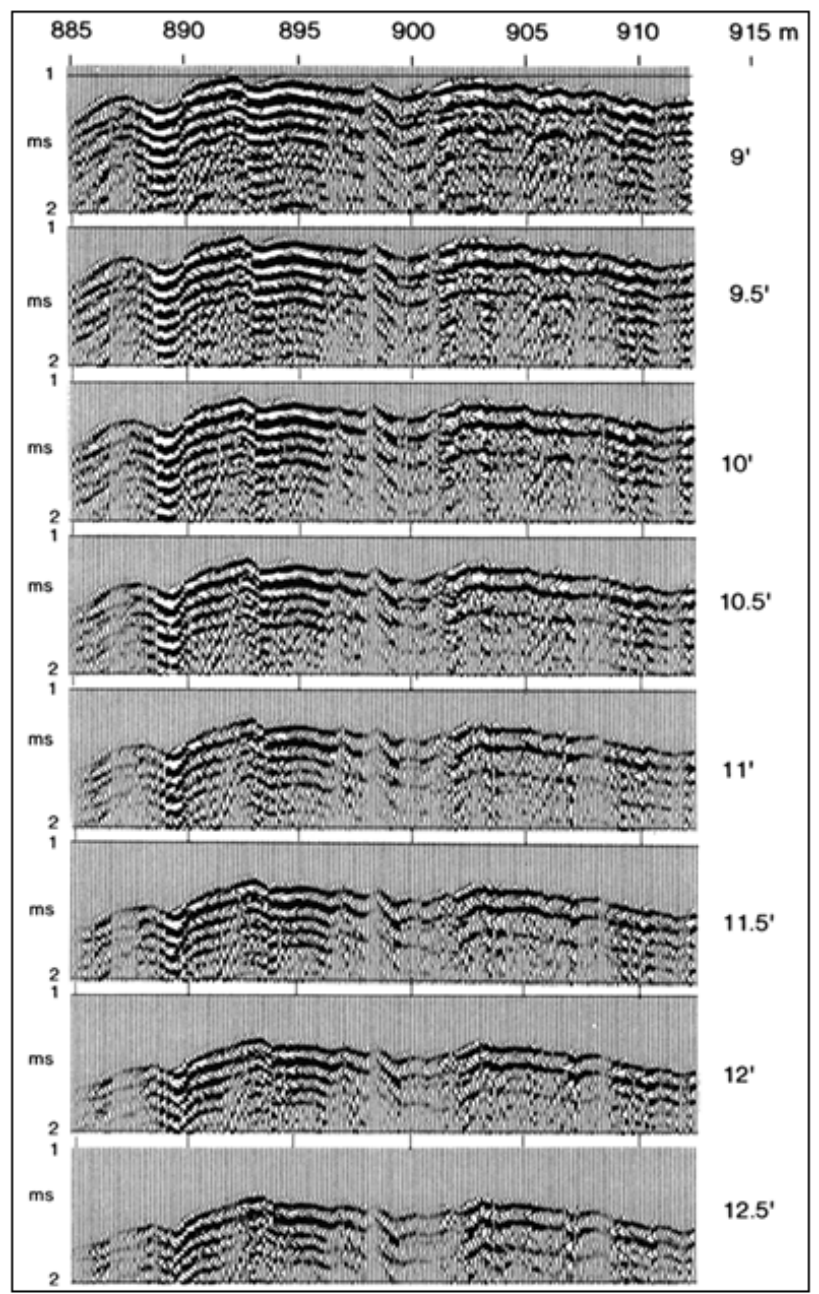

Figure 3.9 Constant offset sections ranging from 9 to 12.5 feet, recorded with a multireceiver tool (from Mari et al., 1992). 


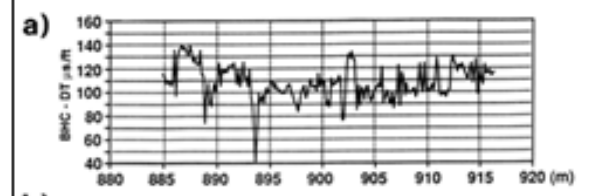

b)
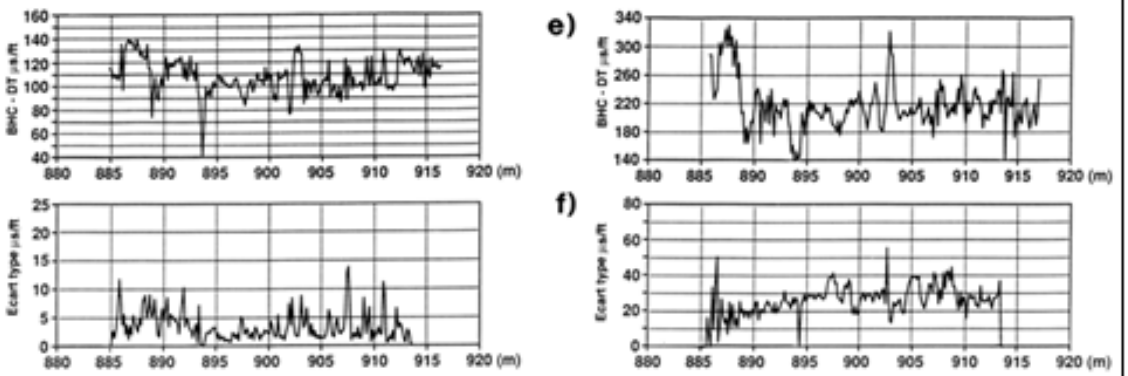

f)

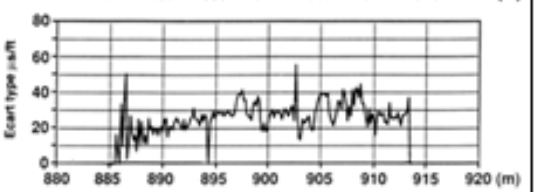

c)

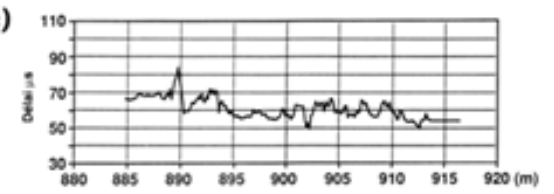

g)

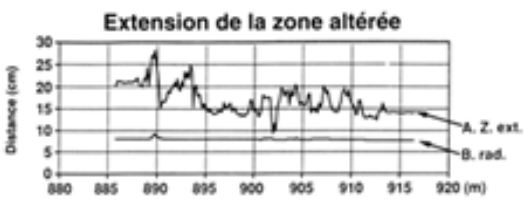

d)

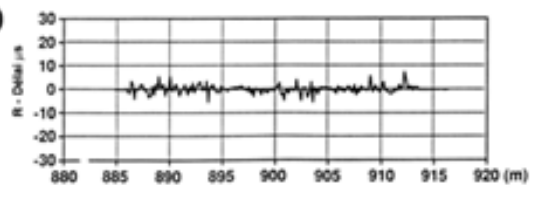

h)

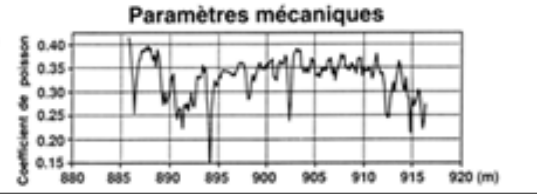

Figure 3.10 Example of acoustic logs in a sandstone reservoir (from Coppens and Mari, 1995). Monopole tool: (P wave): a) Slowness; (b) Standard deviation of slowness; c) Delay; d) Residual delay. Dipole tool (bending wave \# S wave): e) Slowness; (f) Standard deviation of slowness; g) Extension of the weathering zone ( $P$ wave); $h$ ) Poisson's ratio.

Knowing the slowness makes it possible to calculate the delays log (Fig. 3.10c). The theoretical arrival times of the refracted wave are then calculated for each shot from the slowness and delay logs. The difference between the calculated times and the actual times represent the measurement dispersion error. This is presented as a residual delay $\log$ (Fig. 3.10d) that does not exceed $5 \mu$ s, i.e. one half of the time sampling rate in the studied example.

The formation studied being a clay-sandstone slow formation (absence of refracted $S$ modes on the monopole sections), the slowness $S$ of the formation was obtained using the bending modes generated by a dipole-type tool. The measurement of the arrival times of the direct bending wave gives access to the slowness $S \log$ and its associated standard deviation log (Fig. 3.10e and $\mathrm{f}$ ). The combination of slowness $\operatorname{logs} \mathrm{P}$ and S enable the calculation of Poisson's ratio (Figure 3.10h).

The measurement of the arrival times of the refracted P-wave for each transmitterreceiver pair for the whole of the well gives access to the delay at any measurement point and therefore to an image of the extension of the weathering zone of the well. 
Figure $3.10 \mathrm{~g}$ shows the weathering zone extension log obtained in the clay-sandstone formation. This example shows that the investigation depth of the refracted mode is a few tens of centimeters. In relation to the well wall, the weathering zone locally reaches thicknesses of $20 \mathrm{~cm}$. Increases in the weathering zone in porous zones $(890-899 \mathrm{~m}, 911-916 \mathrm{~m})$ can be correlated with the presence of weakly consolidated formations. In clay zones (899-911 m), weathering zone increases correlate with shaliness.

This example shows that full waveform acoustic logging provides not only formation slowness but also imaging in the well vicinity with decimetric-to-metric scale lateral investigation for refracted modes. We show that the analysis of reflected and refracted modes makes it possible to extend the investigative power of acoustic logging.

\subsubsection{Reflection acoustic imaging}

Processing the reflected modes provides very high resolution acoustic sections (a few tens of centimeters) providing an image with an investigation depth of several meters from the well axis.

In full waveform acoustic logging, the most easily accessible document is the constant offset acoustic section. Figures 3.11 and 3.12 show the results of experimental work carried out in a quarry (Mari, Gavin, Coppens, 1994). Figure 3.11 (top) shows the geological cross section produced from the well information (a vertical well, labeled R1, and a highly deviated well). The deviated well was drilled in the $80 \mathrm{~m}$ thick white oolite layer. The abscissa origin is the wellhead of the deviated well. For the ordinates, the geological markers are referenced in terms of depth relative to the quarry top. At the abscissa of the vertical well, the deviated well is $40 \mathrm{~m}$ deep. The constant offset acoustic section (Figure 3.11, bottom) shows two types of events: isochronous events with a very high apparent velocity and oblique events. Events with high apparent velocity are refracted arrivals, interface modes (pseudo-Rayleigh and Stoneley waves) and arrivals reflected on acoustic markers parallel to the drain. Oblique events are arrivals reflected on pseudo-vertical fractures or on acoustic markers dipping with respect to the drain. At the $55 \mathrm{~m}$ abscissa, the various wave trains are strongly attenuated, indicating the presence of open fractures. Figure 3.12 shows the acoustic section after the filtering of events with a very high apparent velocity. Oblique events, combined with reflections on acoustic reflectors, are clearly visible.

The full waveform recordings provided by the multi-transmitter and multi-receiver tools used for acoustic logging make it possible to carry out a micro-seismic survey of the well, based on the analysis of the reflected or diffracted modes on acoustic impedance discontinuities within formations or at formation boundaries. 

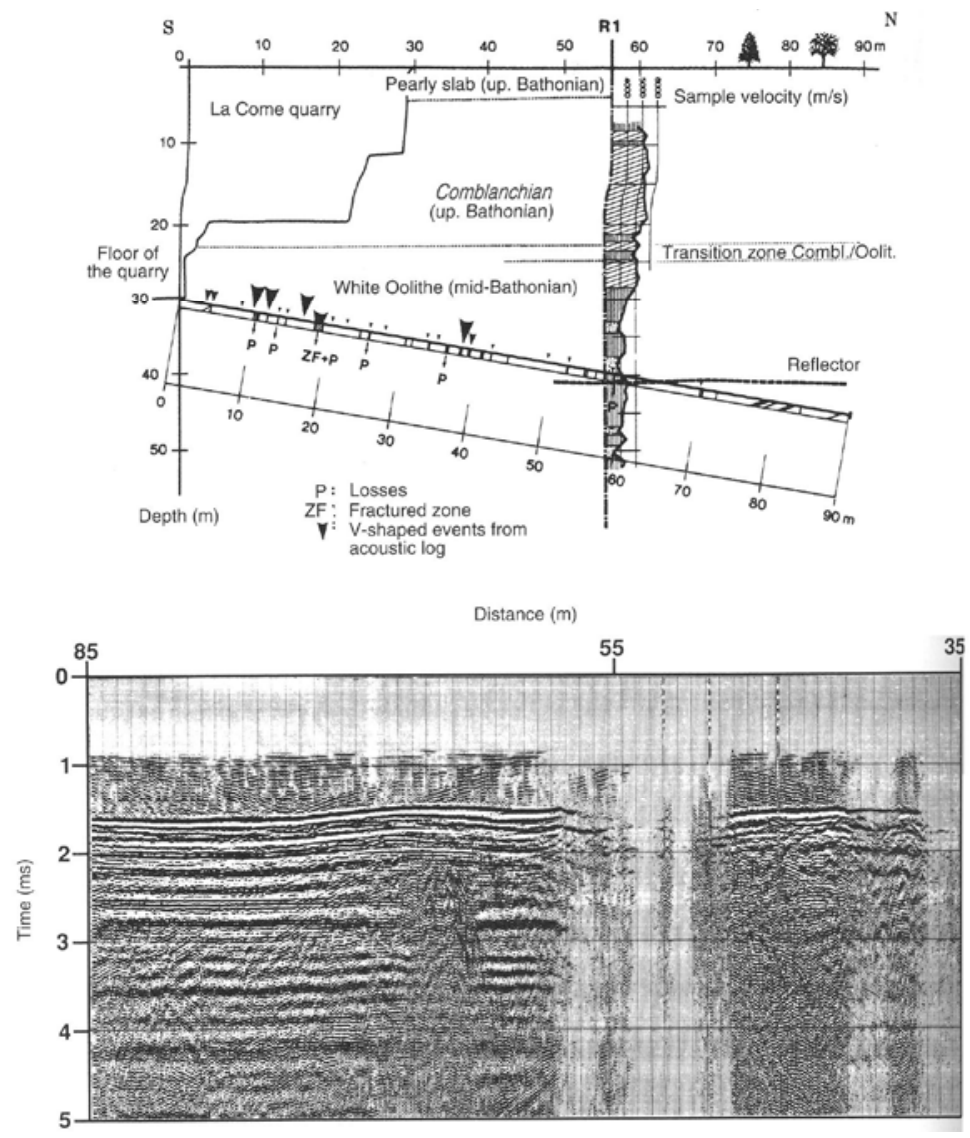

Figure 3.11 Acoustic imaging in quarry (from Mari et al., 1994). Top: Geological cross section of the Ravières quarry. Bottom: Constant offset acoustic section $(3 \mathrm{~m})$, raw data.

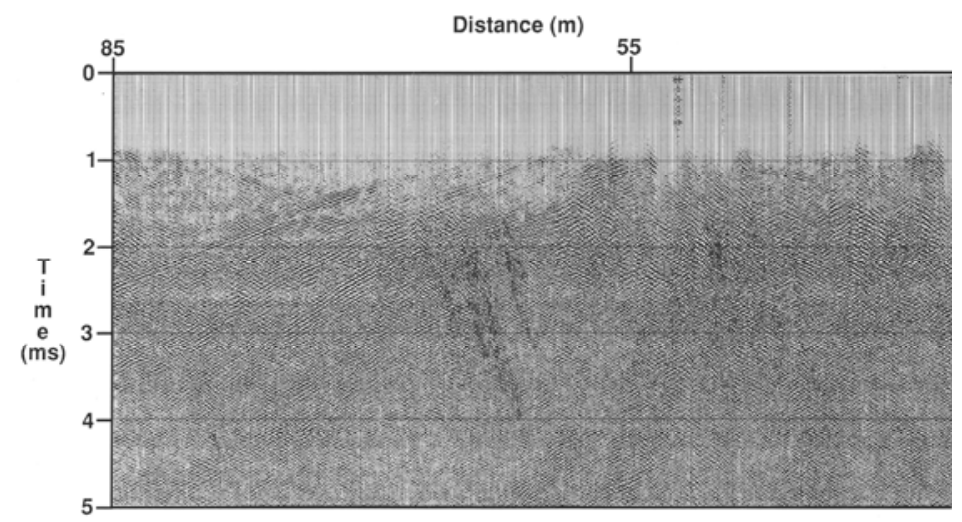

Figure 3.12 Acoustic imaging in quarry: reflected waves (from Mari et al., 1994). 
Figure 3.13 is an example of acoustic section imaging obtained in a sandstone reservoir intersected by carbonate beds (Fortin et al., 1991). The acoustic imagery clearly shows the distribution of carbonate beds and their dips relative to the well. This acoustic approach to dip estimation requires a thorough multi-coverage processing.

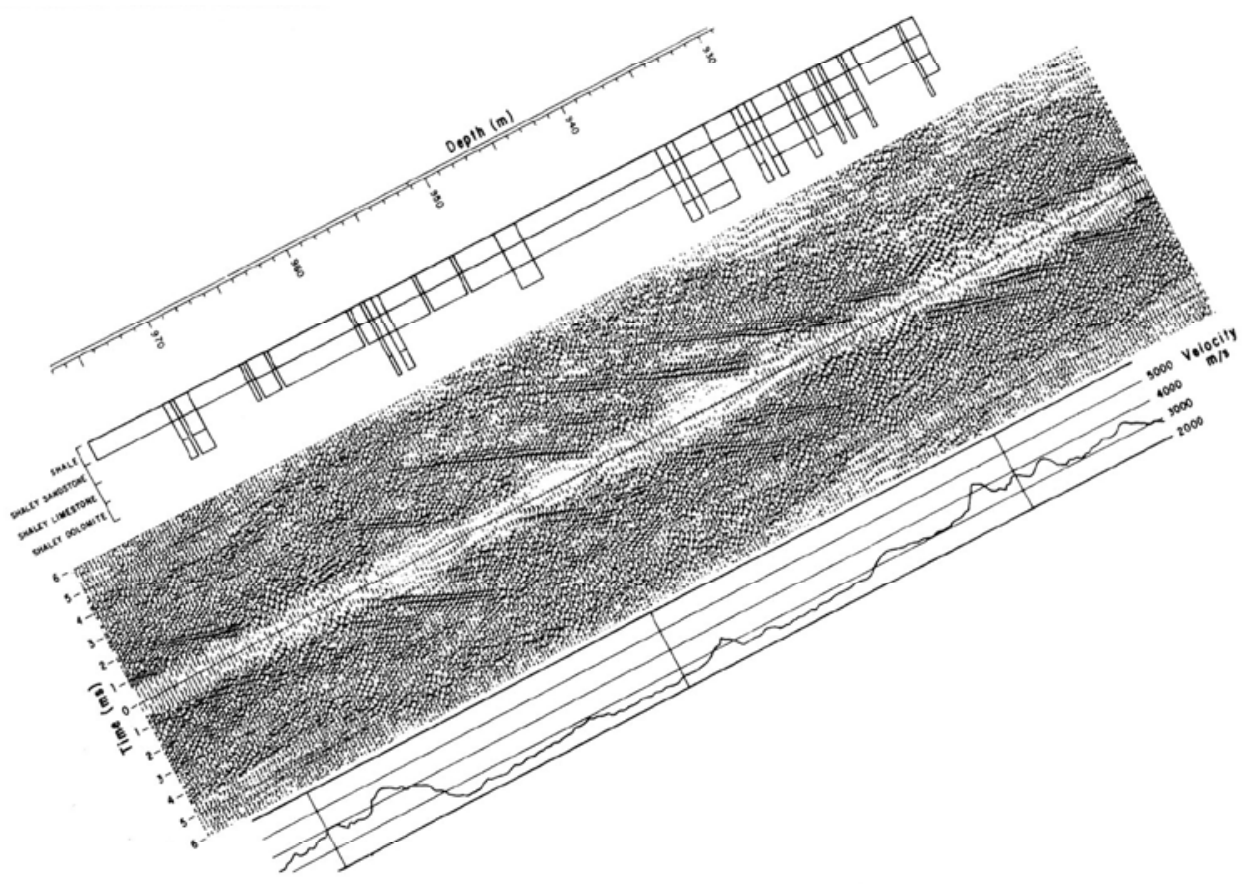

Figure 3.13 Well imaging using acoustic data: reflected waves EVA tool (SNEAP), multiple coverage processing (CGG) (from Fortin et al., 1991).

\subsection{Characterization of a formation using Stoneley waves}

Stoneley waves are used to evaluate the $S$ slowness of slow formations, to study fracturing and to provide an estimation of permeability.

The shear waves can only be generated if the $S$ velocity of the formation is greater than the velocity of the compression wave in the mud; we can then say the formation is fast (as opposed to so-called slow formations). In slow formations, the velocity of S-waves can be indirectly estimated in uncased wells from the Stoneley wave dispersion equation (Biot, 1952; Cheng et al, 1981). 
At sonic frequencies (1-20 kHz), it is therefore necessary to independently measure six parameters to derive the $S$ velocity of the formation from the Stoneley mode dispersion equation. These parameters are: the phase velocity of the Stoneley waves at a particular frequency, the fluid density, the formation density, the well diameter, and the velocity of the compression waves in the formation.

The following example is an acoustic logging recorded in a slow formation, consisting of marl in the upper part and limestone in the lower part. The boundary between marl and limestone is at $105 \mathrm{~m}$. The data were acquired with a monopole tool with three receivers spaced $20 \mathrm{~cm}$ apart. The offset between the source and the first receiver is $60 \mathrm{~cm}$. Figure 3.14 shows on the left the three constant offset sections recorded with the acoustic tool. On each section we can observe the low amplitude refracted $\mathrm{P}$-wave as a first arrival. The refracted $\mathrm{P}$-wave is followed by a wave of very high amplitude and low frequency, which is the Stoneley wave. The measurement of $\mathrm{P}$-wave and Stoneley wave velocities is carried out by semblance. The semblance panel is shown on the left of the acoustic sections. The vertical axis represents the depth, the horizontal axis is the slowness (inverse of the velocity). The semblance is color coded and expressed as a percentage (high values shown in red). The picking of the maximum semblance (indicated by the continuous black lines) provides for each wave the value of the slowness as a function of the depth. Slowness logs are then converted to velocity logs (Figure 3.14, right). We observe a high correlation coefficient between the 2 velocity logs $(0.854)$. The dominant Stoneley wave frequency is $2 \mathrm{kHz}$. At these low frequencies, the Stoneley wave dispersion equation can be approximated by a simplified equation proposed by White (1965). White's equation is as follows:

$$
\frac{1}{\mathrm{~V}_{\mathrm{st}}^{2}}-\frac{1}{\mathrm{~V}_{\mathrm{f}}^{2}}=\frac{\rho_{\mathrm{f}}}{\rho} \cdot \frac{1}{\mathrm{~V}_{\mathrm{s}}^{2}}
$$

where $V_{s t}$ is the velocity of the low frequency Stoneley wave, $V_{f}$ is the velocity of the fluid in the formation (water in this case), $V_{s}$ is the $S$ velocity of the formation, $\rho$ is the formation density, and $\rho_{\mathrm{f}}$ is the fluid density.

If the density log has not been recorded, which is the case in this example, it can be calculated from the $V_{P}$ velocity of the formation using Gardner's equation:

$$
\rho=\alpha \times V_{p}^{\beta}
$$

The equations of White and Gardner are used simultaneously to adjust the coefficient $\alpha$ and $\beta$ of Gardner's equation and to calculate the velocity $V_{s}$ and density $\rho$ of the formation with the following constraints:

1- The $S$ velocity of the formation must be lower than the P-wave velocity in the fluid.

2- Poisson's ratio must remain in the range 0.3 to 0.5 , characteristic of marls and unconsolidated formations.

Figure 3.15 shows, from left to right: the Gardner density, the $S$ velocity estimated from the Stoneley wave velocity, the $V_{P}$ to $V_{S}$ ratio and the Poisson's ratio. 

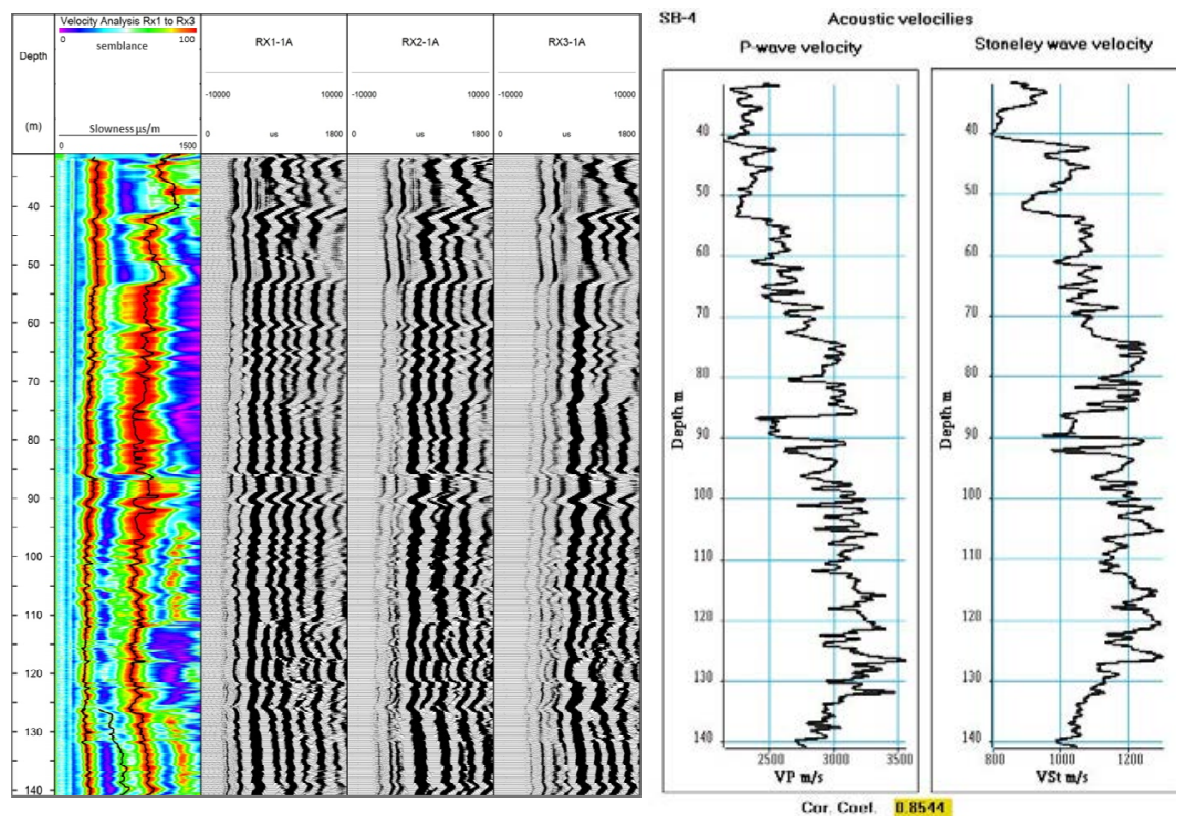

Figure 3.14 Acoustic logging in slow formation. Left: Velocity panel and acoustic sections with constant offset. Right: P-wave and Stoneley wave velocity logs.
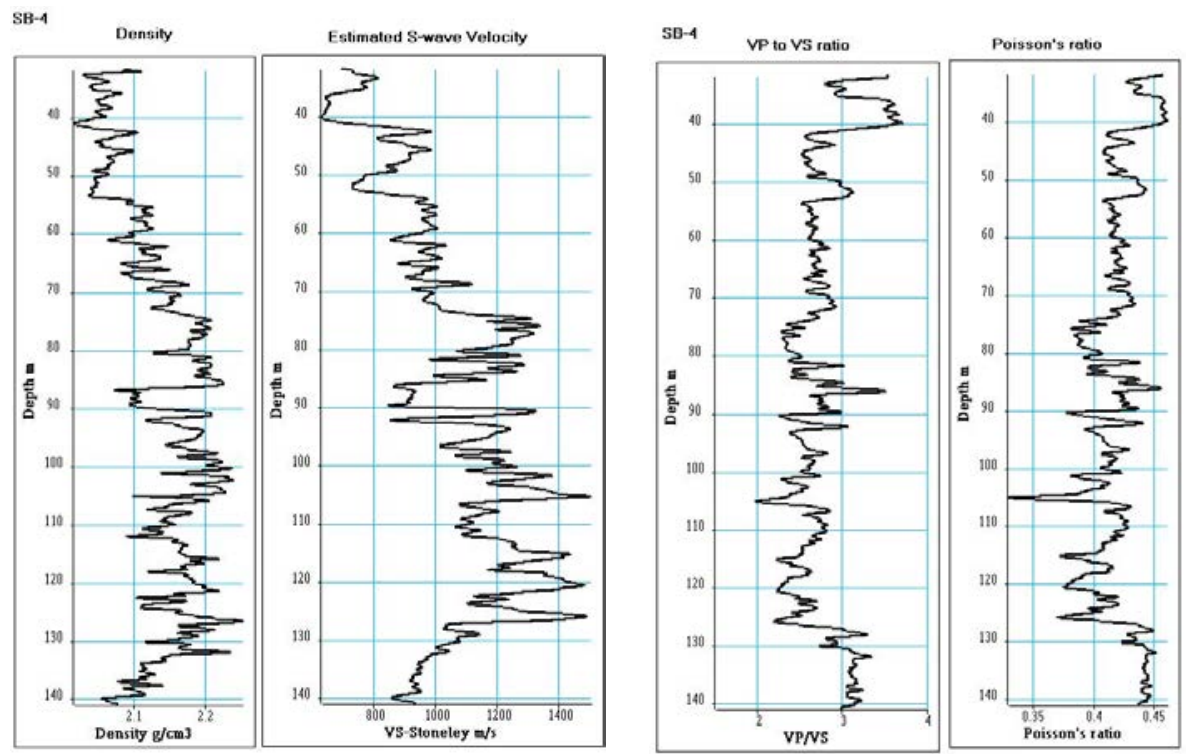

Figure 3.15 Acoustic logs, from left to right: Density, S velocity estimated from Stoneley wave velocity, $V_{p}$ to $V_{S}$ ratio, and Poisson's ratio. 
The response of the Stoneley wave is strongly related to the state of continuity of the well wall. Its transmission is guided by the water or mud interface contained in the borehole and its wall. It is therefore particularly affected by the continuity solution of the borehole wall, while its exploitation and processing highlight its fracturing and degree of opening. The attenuation of Stoneley waves (decrease of amplitude and frequency) is used to characterize the fissured medium. In addition, wave conversion phenomena are observed at the boundaries of the fractured zones. These phenomena are very pronounced on the Stoneley waves, especially in the presence of open fractures.

\subsection{Conclusion}

Compared to other logging methods, acoustic logging has an equivalent vertical resolution, but a superior ratio of lateral depth of investigation over vertical resolution. Acoustic logging has a lateral investigation in the order of centimeters for interface modes, decimeters to meters for retracted modes, and around ten meters for reflected modes.

Acoustic logging is mainly used to:

- measure the formation velocities (compression and shear) and calculate elasticity moduli (dynamic measurement 2-40 kHz);

- establish a very high resolution time-depth relationship, by integrating the slowness curve (inverse velocity);

- make synthetic seismograms to tie surface seismic reflection (see Chapter 4);

- measure the attenuation and anisotropy (dipole mode) of a formation;

- identify lithology in combination with other logs;

- study fracturing and detect heterogeneities;

- evaluate casing cementation (see Chapters 1 and 4);

- assess porosity and estimate permeability;

- measure dips;

- provide a detailed micro-seismic survey (reflected waves) in the vicinity of the well; these operations are important for highly deviated or horizontal wells.

The following elements must also be considered:

- The acoustic measurement must be made in a well filled with water (mud). It is better to work in open hole (or even a PVC-cased hole). It is desirable to make a continuous measurement of the borehole diameters (logging: calipers) to detect the caved zones. The tool must be centered using centralizers during acoustic measurements.

- Logging speed should be slow (4 to $6 \mathrm{~m} / \mathrm{min}$ ) to respect sampling conditions in terms of distance and to avoid scraping noises created by the centralizers. In general, a frequency filter (low cut: $1 \mathrm{kHz}$ ) is used at acquisition to filter these noises. 
- Acoustic measurements can be made in steel cased holes, when the casings are perfectly cemented. The presence of resonance phenomena due to poor cementation is used to evaluate cementation (cementation log).

- Well conditions, in the case of poorly cemented cased wells, can make measurements difficult. The waves associated with casing vibrations must be filtered. This processing does not always allow the volume wave characteristics of the formation to be obtained, or the measurement of the formation's parameters.

- Acoustic measurements benefit from the use of long tools (3 to $4 \mathrm{~m}$ between the transmitter and the receivers). An operation may encounter difficulties if the lifting system is not high enough. If this is the case, the tool, if flexible, can be bent before being introduced into the well. The tool can also be introduced using constituent parts that can be connected to each other.

\section{References}

Arditty P.C., Arens G., Staron P., 1984, Improvements of formation properties and evaluation through processing and interpretation results of the EVA tool records. SEG 54th Annual Meeting expanded abstracts.

Biot M.A., 1956, Theory of propagation of elastic waves in a fluid-saturated porous solid: I - Low waves in a fluid-saturated porous solid: I - Low frequency range; II - Higher frequency range. The Journal of the Acoustical Society of America, 28, 2, pp. 168-178 and 179-191.

Cheng C.H., Toksöz M.N., 1981, Elastic wave propagation in a fluid-filled borehole and synthetic acoustic logs. Geophysics, 46, 1042-1053.

Coppens F., Mari J.L., 1995, Application of the intercept time method to fullwave form acoustic data. First Break, 13: 11-20.

Fortin J.P., Rehbinder N., Staron P., 1991, Reflection imaging around a well with the Eva full-waveform tool. The Log Analyst, 32, 3, 271-278.

Gardner G.H.F., Gardner L.W., Gregory A.R., 1974, Formation velocity and density. The diagnostic basis for stratigraphic traps. Geophysics, 39, 770-780.

Gaudiani P., 1982, Acoustic coring in granite with a small diameter logging tool. Proceedings, Workshop about geophysical investigations in connection with geological disposal of radioactive waste, Nuclear Energy Agency Organization for Economic Cooperation and Development, Ottawa: 157-171.

Kaneko F., Kanemori T., Tonouchi K., 1990, Low-Frequency Shear Wave Logging in Unconsolidated Formations for Geotechnical Applications. Geophysical Applications for Geotechnical Investigation, ASTM STP 1101, F.L. Paillet and W.R. Saunders, Eds. American Society for Testing and Materials, Philadelphia, pp. 79-98.

Mari J.L., Gavin P., Coppens F., Wicquart E., 1992, Traitement des diagraphies acoustiques. Éditions Technip, Paris. 
Mari J.L., Gavin P., Coppens F., 1994, An example of acoustics and very high resolution seismic in a near-horizontal borehole. First Break, 12, 21-29.

Mari J.L., Arens G., Chapellier D., Gaudiani P., 1999, Geophysics of reservoir and civil engineering. Éditions Technip, Paris, ISBN 2-7108-0757-2.

Mari J.L., Gaudiani P., Delay J., 2011, Characterization of geological formations by physical parameters obtained through full waveform acoustic logging, Physics and Chemistry of the Earth, 36, 1438-1449, Elsevier Ltd.

Mari J.L., 2015, Signal processing for geologists \& geophysicists, e-book, DOI:10.2516/ifpen/2011002, http://books.ifpenergiesnouvelles.fr/ebooks/signal-processing/

Mari J.L., Porel G., 2015, Automated karstic reservoir analysis utilizing attributes, We N117 02, 77th EAGE Conference \& Exhibition, Madrid IFEMA, Spain, 1-4 June.

Morris C.F., Little P.M., Letton W., 1984, A new sonic array tool for full waveform logging, 59th Annual Conference of the Society of Petroleum Engineers of AIME, Houston, Texas, expanded abstracts, pp. 16-19.

Paillet F.L., Turpening R., 1984, Borehole and surface to borehole seismic applications in fracture characterization. SEG 54th Annual Meeting expanded abstracts.

Quiblier J., 1997, Propagation des ondes en géophysique et en géotechnique. Modélisation par méthodes de Fourier. Éditions Technip, Paris.

Rosenbaum J.H., 1974, Synthetic micro-seismograms logging in porous formation. Geophysics, 39, 14-32.

Summers G.C., Broding R.A., 1952, Continuous Velocity Logging. Geophysics, 17, 598-614.

Vogel C.B., 1952, A seismic logging method. Geophysics, 17, 579-586.

White J.E., 1965, Seismic waves: Radiation, transmission and attenuation. McGrawHill Book Company, New York.

Zemanek J., Williams D.M., Schmitt D.P., 1991, Shear-wave logging using multipole sources, The log Analyst, 32, 3, 233-241. 

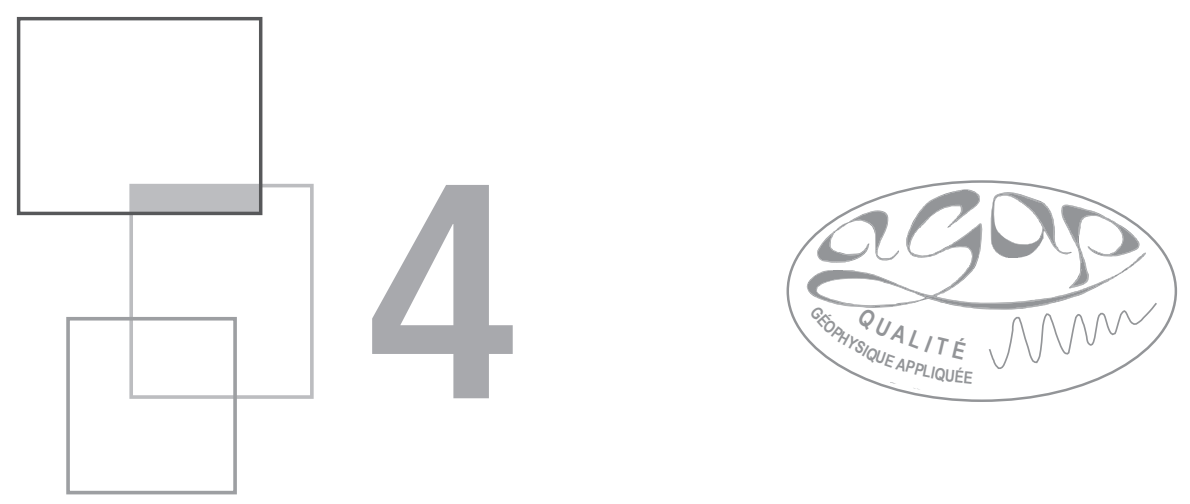

\title{
Tying surface seismic data
}

\author{
J.-L. Mari, P. Meynier
}

\subsection{Introduction}

Conventionally, surface seismic surveys provide sub-surface images in time in two or three dimensions (2D or 3D). Well measurements are data obtained as a function of depth. VSP-type well seismic surveys provide both time images (VSP sections) comparable to those obtained by surface seismic surveys, and surveys (velocity for example) in depth, comparable to those obtained by logging measurements (for example, acoustic logging). The comparison of measurements in depth (acoustic logging) and measurements in time requires time or depth conversion of one of the two datasets.

This chapter of Well seismic surveying and acoustic logging is published under Open Source Creative Commons License CC-BY-NC-ND allowing non-commercial use, distribution, reproduction of the text, via any medium, provided the source is cited.

(C) EDP Sciences, 2018

DOI: $10.1051 / 978-2-7598-2263-8 . c 006$ 
Acoustics is the most natural link between geophysics and logging. Although functioning in very different frequency bands (a few tens of $\mathrm{kHz}$ for acoustic logging and a few tens to a few hundred $\mathrm{Hz}$ for Very High Resolution (VHR) seismic surveys), acoustic and seismic well measurements are governed by the same laws of wave propagation.

This chapter shows:

- the principle of depth conversion of surface seismic methods using VSP data (Vertical Seismic Profile, Chapter 2);

- the influence of cementation on acoustic measurements;

- the principle of the calibration of formation velocity measurements obtained by acoustic logging with those provided by VSP;

- the principle of time conversion of acoustic data (acoustic logging, Chapter 3) and the calculation of synthetic seismograms;

The data used in this chapter are near surface data derived from a 3D VHR seismic survey, a vertical seismic profile, and a full waveform acoustic log.

\subsection{D VHR seismic survey and VSP}

The acquisition device is composed of a receiving device and a transmitting device. The receiving device, stationary during acquisition, is composed of 2 parallel lines of 24 geophones, spaced $2 \mathrm{~m}$ apart. The distance between the 2 geophone lines is $4 \mathrm{~m}$. The device consists of 11 source lines, oriented perpendicular to the geophone lines (in-line direction) with 11 shots fired per line. The distance between 2 shots on a line is $2 \mathrm{~m}$. The distance between 2 source lines is $4 \mathrm{~m}$. The direction of the source lines is cross-line. There is no overlap between transmitting and receiving devices. The distance between the 2 devices is $4 \mathrm{~m}$. The source used is a weight drop (Chapter 2, Figure 2.5).

Seismic data processing provided a 3D block of 13 in-line sections spaced $1 \mathrm{~m}$ apart (Mari and Herold, 2015). Each section is composed of 44 Common Mid-Point gathers (CMP) $1 \mathrm{~m}$ apart. The listening time has been limited to $250 \mathrm{~ms}$, the time sampling step is $0.5 \mathrm{~ms}$. Figure 4.1 shows the seismic acquisition device (left) and an example of in-line and cross-line seismic sections derived from the $3 \mathrm{D}$ block (right). The two sections presented (section 6 in the in-line direction, and section 23 in the cross-line direction) intersect in the middle of the $3 \mathrm{D}$ block. They have been filtered in the $15-150 \mathrm{~Hz}$ bandwidth, which provides an excellent signalto-noise ratio. The CMP point located at the intersection of the in-line seismic section 3 and cross-line 6 is located about twenty meters from a borehole in which a VSP has been recorded.

VSP data is used to tie surface seismic data. The VSP in this case is a near surface VSP, recorded in a steel cased vertical well. 

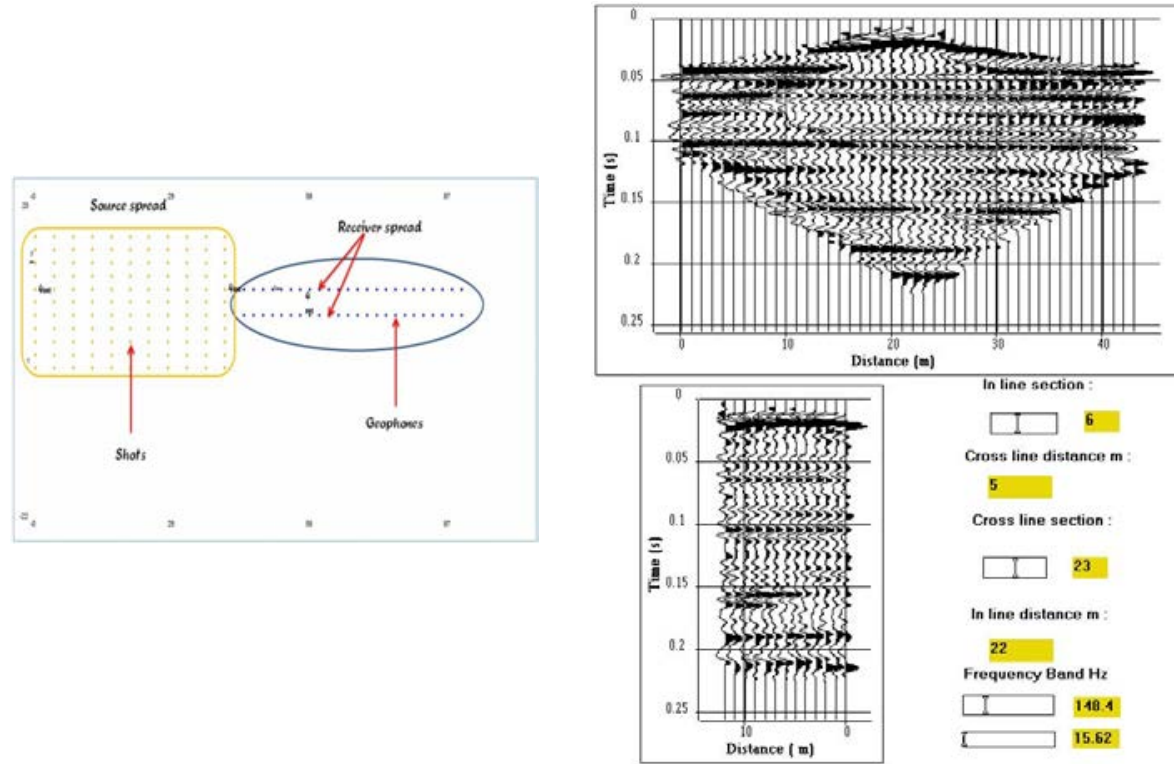

document IFP School. J.L.M. 2016.

Figure 4.1 3D seismic survey; left: acquisition device, right: time sections.

The acquisition and processing sequence are described in Chapter 2 and the processing results are presented in Figures 2.11 and 2.12. It should be noted that the depth of the receiver varies between 25 and $85 \mathrm{~m}$, the surface source being slightly offset $(5 \mathrm{~m})$ relative to the wellhead. There is a $5 \mathrm{~m}$ distance between two successive positions of the geophone in the well.

Figure 4.2 shows:

- Top left: unprocessed VSP recording;

- Top right: the vertical time-depth relationship and the interval velocity law at the seismic sampling interval in depth, i.e. $5 \mathrm{~m}$;

- Bottom left: the stacking corridor of the VSP section and the VSP stacked trace;

- Bottom right: Tying of the seismic section on the VSP stacked trace at the intersection of the in-line 3 and cross-line 6 seismic sections.

The VSP stacked trace, duplicated 5 times, is inserted in the in-line section 3 at the CMP position associated with the cross-line section 6 . The correlation coefficient between the seismic trace and the VSP corridor trace at the point of intersection is greater than 0.72 , thus showing a good time fit of the seismic horizons. However, slight differences between the amplitudes observed on the surface seismic and the VSP stacked trace can be noted. This difference is due to the choice of amplitude compensation laws used for the two data sets. For surface seismic, an AGC-type 
gain law on a short window (30 ms) was used to highlight the reflectors close to the surface, which had the effect of increasing the amplitude of the reflectors.

It can be noted that the VSP allows a calibration of the surface seismic in the depth range $(25$ to $85 \mathrm{~m}$ ) where the measurements were made, but also under the well. The VSP stacked trace highlights reflectors that appear at times (two way times) greater than $80 \mathrm{~ms}$ and are below the well. Seismic reflectors can be seen beyond $100 \mathrm{~ms}$.

This example illustrates the predictive role of VSP: prediction under the well.
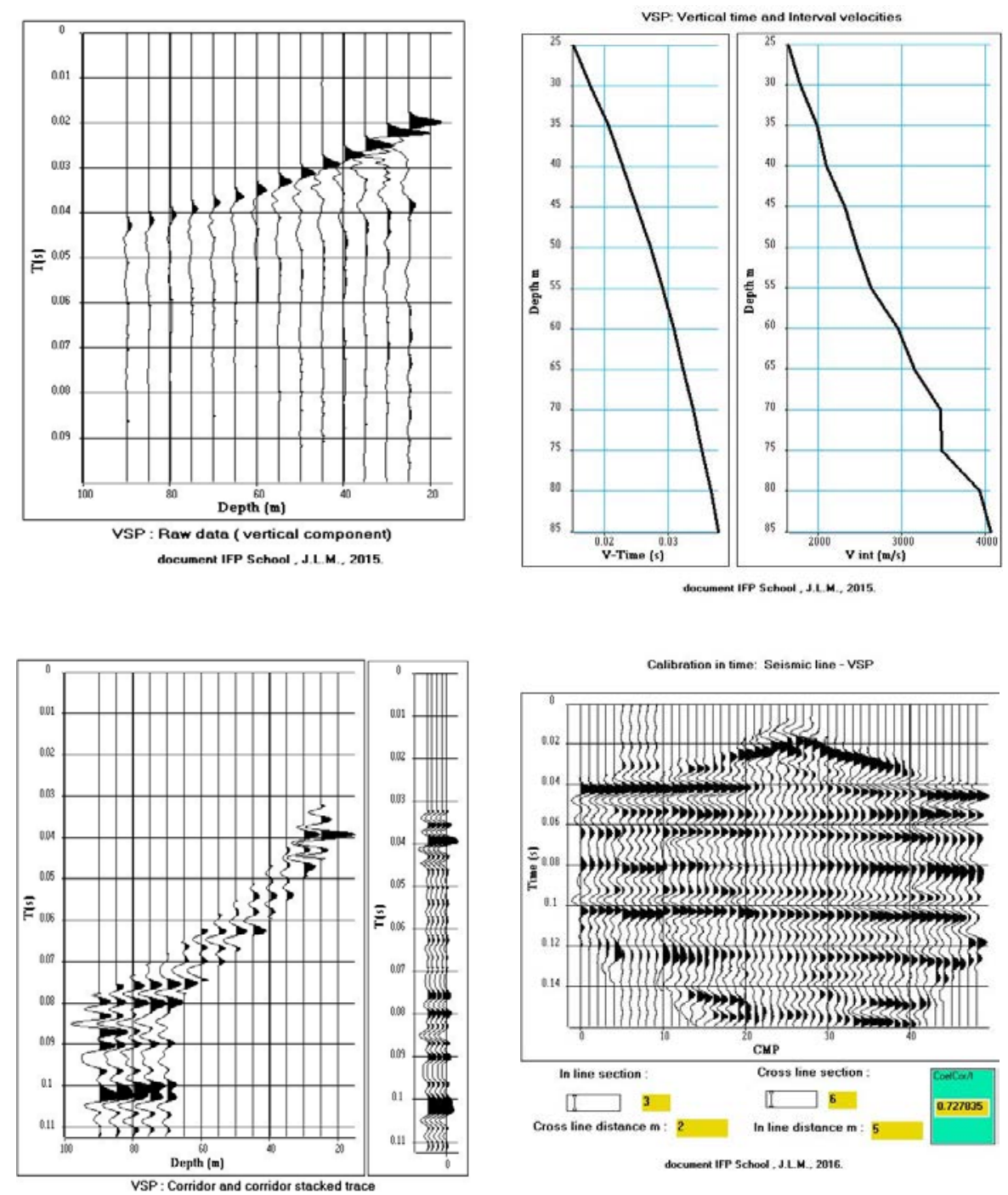

Jocument IFP School , J.L.M., 2015.

Figure 4.2 Tying a seismic section using VSP. 
The time-depth law $T=f(Z)$ can be used to convert time seismic sections into depth seismic sections. The procedure can be summarized as follows:

- The vertical times T measured on the VSP must be transformed into vertical two way times TWT as a function of the depth $Z$ : TWT $=f(Z)$.

- $\quad$ Law TWT $=f(Z)$ must be inverted $Z=f^{-1}(T W T)$

- Law $Z=f^{-1}$ (TWT) should be sampled with a depth sampling rate $\Delta z$ : $\mathrm{Z}=\mathrm{f}^{-1}$ (TWT, $\Delta \mathrm{z}$ ). The sampling rate $\Delta \mathrm{z}$ must be chosen to avoid aliasing phenomena between the time to depth conversion procedure.

- The conversion is done by vertical translation between a time position TWT and a depth position $Z$. The horizons will not be moved laterally on the sections. As a result, if there are dips, the time sections must be migrated before depth conversion.

Figure 4.3 shows the conversion in depth of the seismic time sections from Figures 4.1 and 4.2.
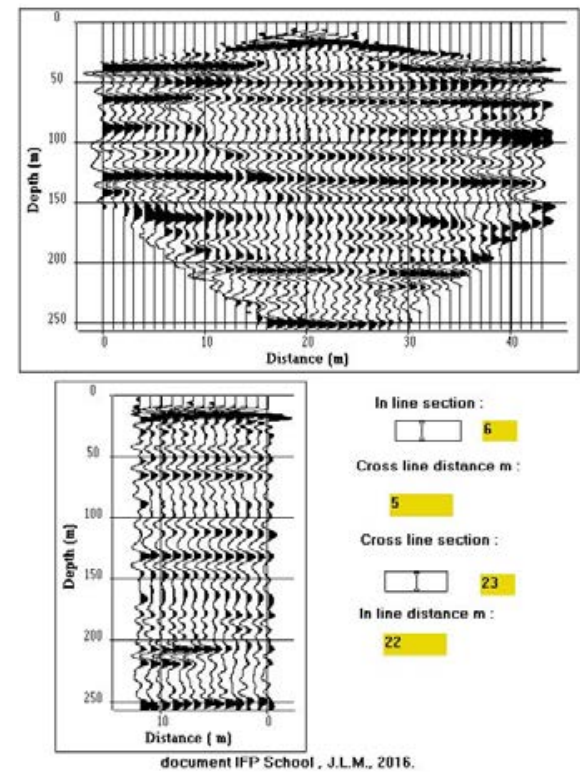

Calibration in depth: Seismic line - VSP

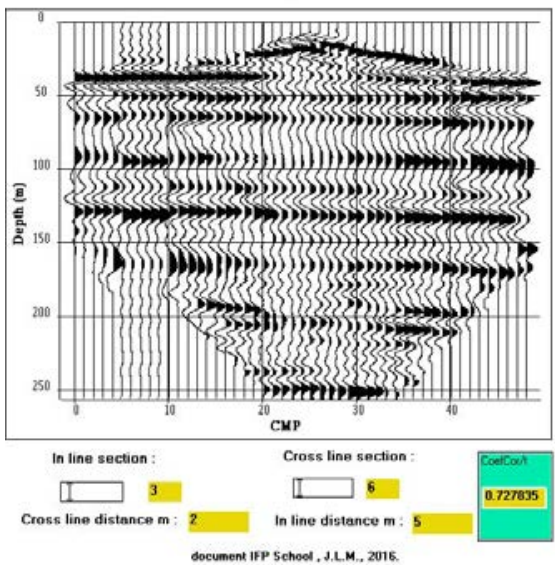

Figure 4.3 3D seismic in depth.

Reflectors can be seen down to $250 \mathrm{~m}$ deep. Figure 4.3, right, shows the tying in depth by VSP stacked trace of the in-line seismic section 3 at the intersection with the cross-line seismic section 6. 


\subsection{Acoustic logging}

A full waveform acoustic log (Chapter 3) was recorded in the borehole. The borehole is steel cased and poorly cemented. The acoustic tool (see Chapter 3, Figure 3.1 left) is a monopole type flexible tool with a small diameter $(50 \mathrm{~mm})$ used in its wide configuration, with a far transmitter-receiver distance ( 3 to $3.25 \mathrm{~m})$. The sampling interval in depth is $2 \mathrm{~cm}$. The sampling interval in time is $5 \mu \mathrm{s}$ and the listening time is $5 \mathrm{~ms}$. Figure 4.4 shows the 2 acoustic sections.

Full waveform ncoustic section

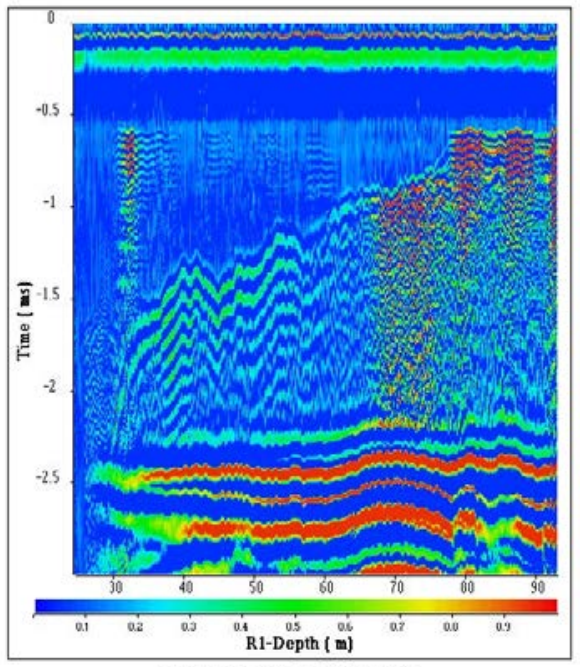

document IFP School . J.L.M. 2016.

Cementation Index
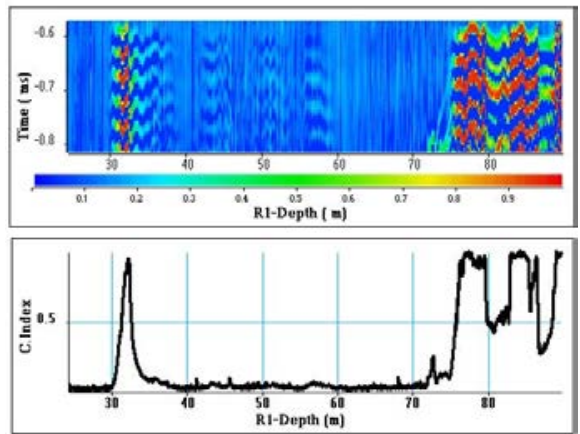

Full waveform acoustic section

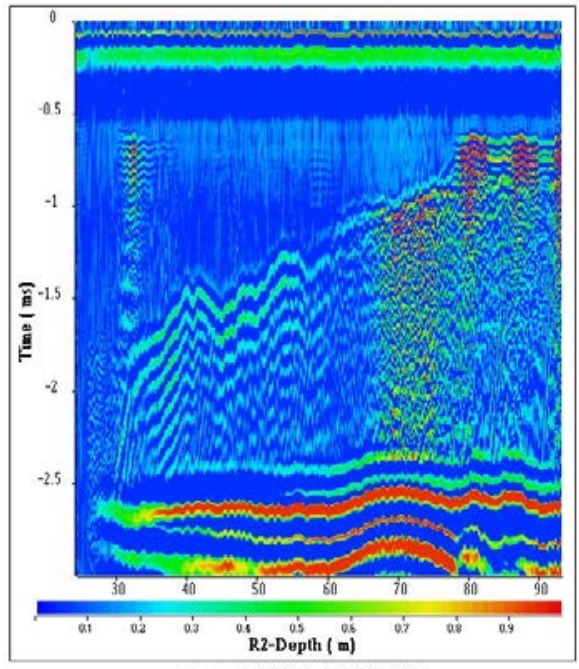

documaent IFP School , J.L.M., 2016.

Cementation Index
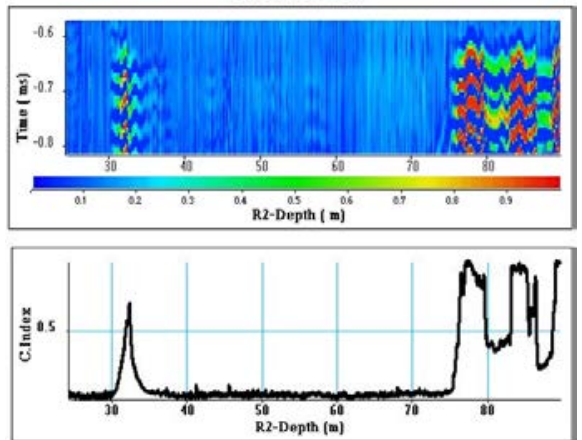

Figure 4.4 Acoustic sections and cementation logs. 
The acoustic sections show:

- Synchronization signals in the time interval $0-0.5 \mathrm{~ms}$. These electronic signals have no geological meaning.

- Resonances in the time interval $0.6-0.8 \mathrm{~ms}$, locally in depth. These resonance phenomena are related to poor cementation between the casing and the formation. In the 75 to $90 \mathrm{~m}$ depth range, the resonances interfere with the acoustic signals that propagate through the formation.

- Formation refracted waves. The first arrival times of these waves vary from 1.8 to $0.7 \mathrm{~ms}$ in the depth range $30 \mathrm{~m}$ to $80 \mathrm{~m}$. This change in arrival time indicates a gradual increase in formation velocity with depth. There is also a change in the character of the acoustic signal: low frequency in the range 30 to $65 \mathrm{~m}$, high frequency and noise for depths greater than $65 \mathrm{~m}$.

- Stoneley waves. These high amplitude waves, guided by the borehole wall, appear after $2.4 \mathrm{~ms}$. They are influenced by casing.

The lower part of Figure 4.4 shows the acoustic sections in the time interval 0.6 to $0.8 \mathrm{~ms}$ where the resonances are mainly observed. The resonance level can be estimated by calculating the energy of the acoustic signal over the time interval. The normalized acoustic signal energy as a function of depth is an acoustic log that is used to provide a log indicative of cementation quality, referred to here as $\mathrm{C}$ index (cementation index). The $\mathrm{C}$ index indicates areas of poor cementation, especially in the 30 to $35 \mathrm{~m}$ range and at depths greater than $75 \mathrm{~m}$.

\subsection{Acoustic logs}

Acoustic logging is mainly used to provide formation velocities by measuring the arrival time difference of the different wave trains at the different receivers of the tool, in this case R1 and R2 at $3 \mathrm{~m}$ and $3.25 \mathrm{~m}$ respectively from the acoustic source. Figure 4.5 shows the following logs for refracted P-waves:

- The P-wave velocity $\log \left(\mathrm{V}_{\mathrm{P}}\right)$ calculated from the time difference $\delta$ t between the acoustic signals observed on the receivers R1 and R2

- The correlation log between the acoustic signals observed on the receivers $\mathrm{R} 1$ and R2, after compensation for $\delta \mathrm{t}$. A high value of the correlation coefficient indicates a strong similarity between the two signals and a good velocity measurement. In this example, the correlation coefficient is greater than 0.75 for more than $70 \%$ of the measured velocities. It is used to edit the log.

- P-wave velocity log after editing

- The instantaneous frequency log, which clearly shows the change in the frequency content of the acoustic signal at $65 \mathrm{~m}$. 

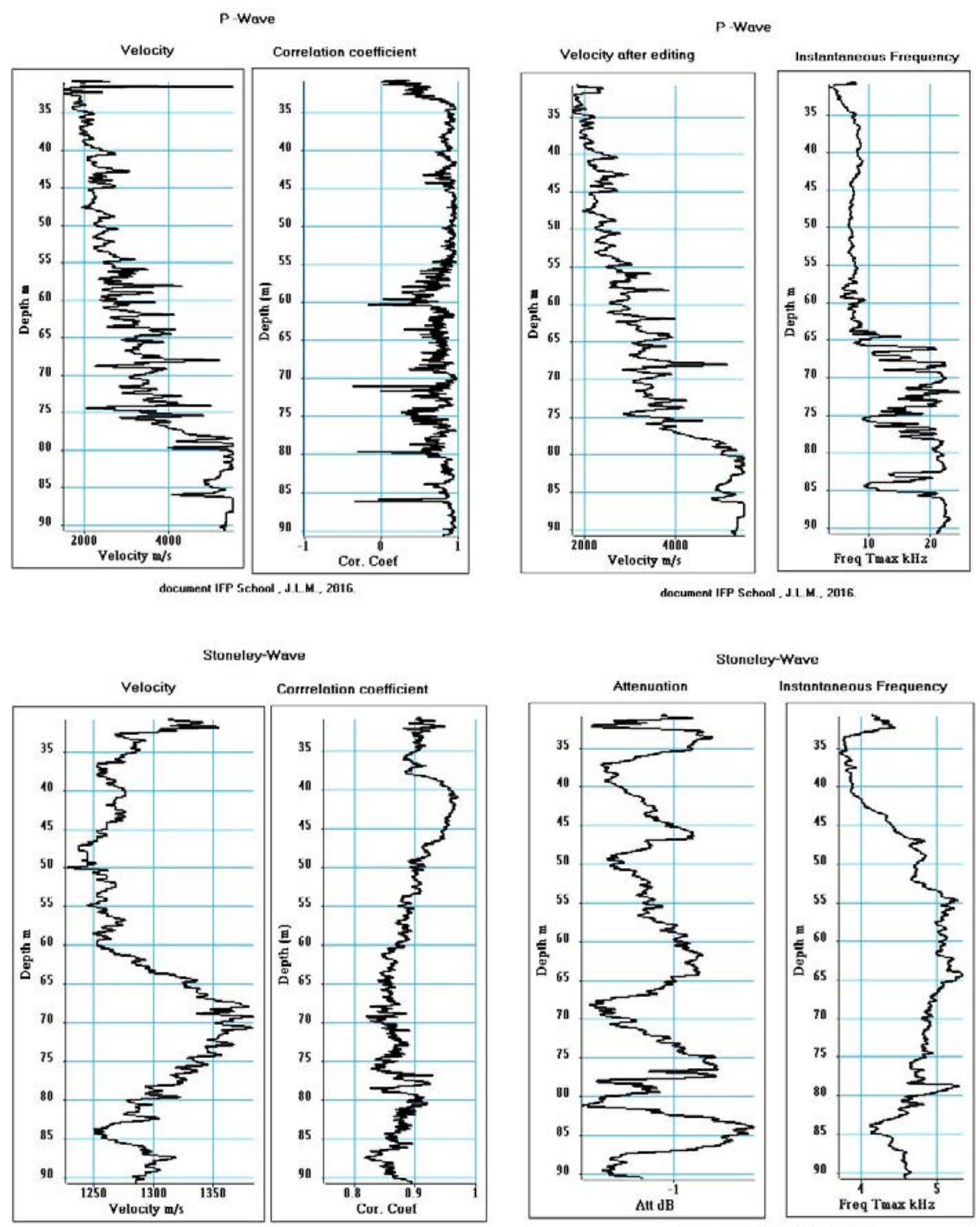

document IFP School .J.L.M.. 2016.

document IFP School , J.L.M., 2016.

Figure 4.5 Acoustic Logs: P-waves and Stoneley waves.

The lower part of Figure 4.5 shows the acoustic logs associated with the Stoneley waves:

- The velocity log and its associated correlation coefficient log. The very high values of the correlation coefficient $(>0.8)$ indicate that the measured velocity values are accurate. 
- The attenuation log that shows that these waves are barely attenuated. These waves are sensitive to the borehole wall conditions and therefore to the presence of casing. It is worth using the information provided by the Stoneley waves in an open hole to characterize the geological formation and in particular to detect the presence of fractures.

- The frequency log. These waves are dispersive and low frequency (between 4 and $5 \mathrm{kHz}$ ).

\subsection{Time conversion of acoustic logs and calculation of the synthetic seismogram}

The velocity $\log$ is a measurement made according to depth, sampled at regular intervals ( $2 \mathrm{~cm}$ in this case). It can be used to obtain a time-depth law by integrating the acoustic transit time as a function of depth. At a given depth, the acoustic transit time is equal to the depth sampling interval divided by the formation velocity. The integration of the acoustic transit time provides the integrated time, conventionally known as the Integrated Transit Time (ITT(Z)). If the borehole is vertical, the ITT can be compared to the vertical time provided by the VSP.

The integrated transit time ITT $(Z)=f(Z)$ can be used to convert a depth log into time log and to insert these logs on the seismic sections in time. For this purpose, ITT(Z) must be set in two-way time. The depth-time conversion of the log will be done by vertical translation between a position $\mathrm{Z}$ in depth, and a time position ITT $(Z)$ with a regular time sampling interval $\Delta t$ : ITT $(Z)=f(Z, \Delta t)$. The sampling interval $\Delta \mathrm{t}$ must be chosen to avoid aliasing phenomena between the depth domain and the time domain. $\Delta \mathrm{t}$ must be chosen as a sub-multiple of the seismic sampling interval, to change the scale between the logging measurements and the seismic measurements.

Figure $4.6(\mathrm{a}$ and $\mathrm{b}$ ) shows the time conversion of velocity and cementation $\operatorname{logs}$ measured in depth. The velocity $\log$ is used to calculate a reflectivity $\log$ (Figure 4.6c) that was filtered in terms of frequency and under-sampled at $0.5 \mathrm{~ms}$ (seismic sampling interval in time).

On the filtered reflectivity log, a high amplitude reflector can be seen at around $70 \mathrm{~ms}$.

The filtered reflectivity log is known as the synthetic seismogram. It is used as the VSP stacked trace to calibrate the seismic horizons observed on seismic sections in time. The synthetic seismogram, duplicated 5 times, is inserted into the in-line section 3 at the CMP position associated with cross-line section 6 (Figure 4.6d). It can be noted that the $70 \mathrm{~ms}$ horizon is not present on the seismic section or on the VSP stacked trace (Figure 4.2). At $70 \mathrm{~ms}$, the velocity log increases abruptly. This phenomenon occurs where poor cementation is detected (Figure 4.6b). The presence of the horizon at $70 \mathrm{~ms}$ is an artifact related to a velocity anomaly due to the 
poor cementation between the casing and the formation. The measured acoustic velocity represents the formation velocity for times under $70 \mathrm{~ms}$. However, the correlation coefficient between the seismic trace and the synthetic seismogram at the intersection point is greater than 0.7 , showing a good tying of the seismic horizons in the time interval 38-60 ms. It falls to 0.5 if we consider the interval $38-80 \mathrm{~ms}$.

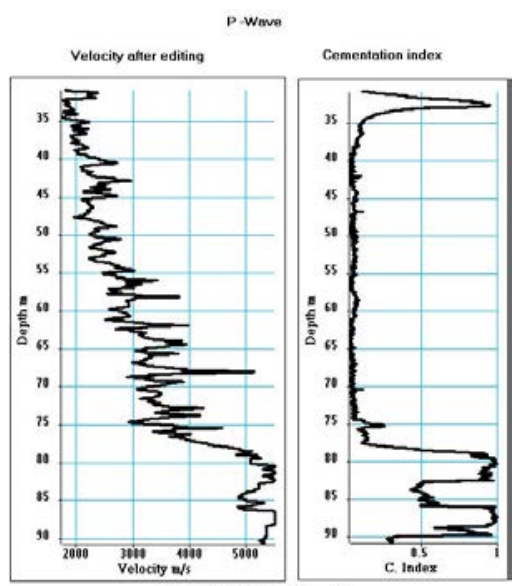

a

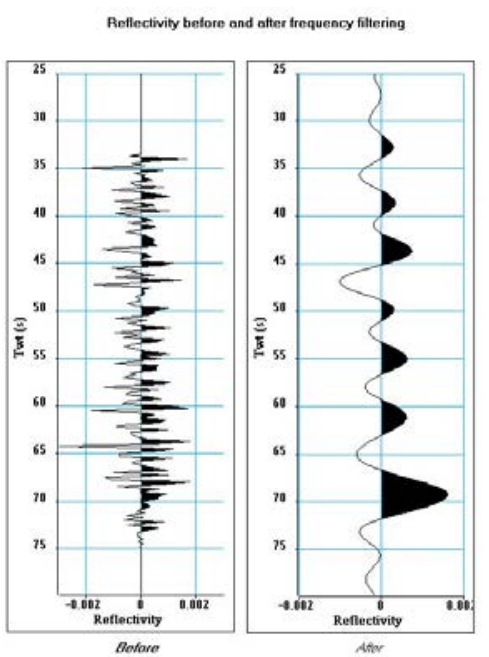

c

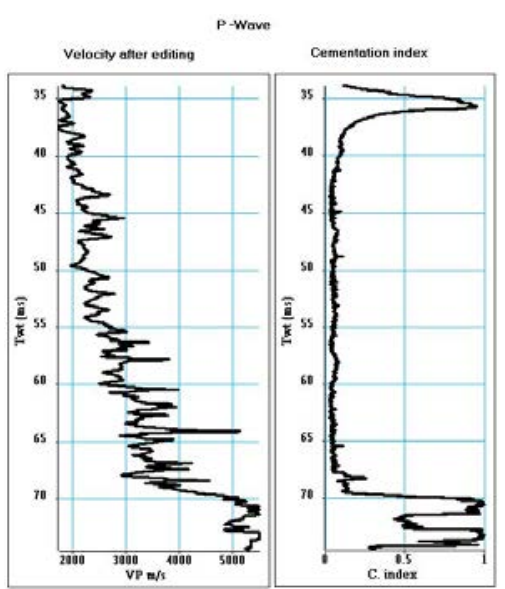

b

Socueers IFP Schoot, J.L.M., 2016

Calibration in time: Seismic line - Acoustic logging

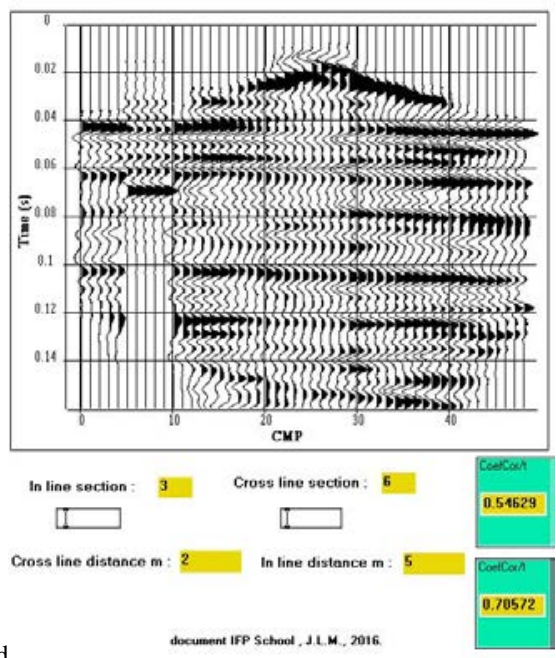

Figure 4.6 Seismic section and synthetic seismogram before "block shift"; a: velocity log and cementation log in depth; b: velocity log and cementation log in time; c: reflectivity before and after frequency filtering; $d$ : raw tying in time of the seismic section with frequency filtered reflectivity. 


\subsection{Integrated sonic time and VSP vertical time}

Figure 4.7 shows a comparison between the integrated sonic time and the VSP vertical time. The times are set to 0 , at $30 \mathrm{~m}$ deep, a depth from which the acoustic measurement can be made. In this acquisition the water level was detected at $30 \mathrm{~m}$. It can be seen that the two-time curves are superimposable in the 30 to $77 \mathrm{~m}$ range. From $77 \mathrm{~m}$, sonic times are shorter than the VSP times. The drift curve, which is the difference between the sonic times and the VSP times, clearly shows this phenomenon. To reconcile sonic and VSP times, the acoustic velocities must be modified so that the recalculated integrated sonic times are closer to the measured VSP vertical times.

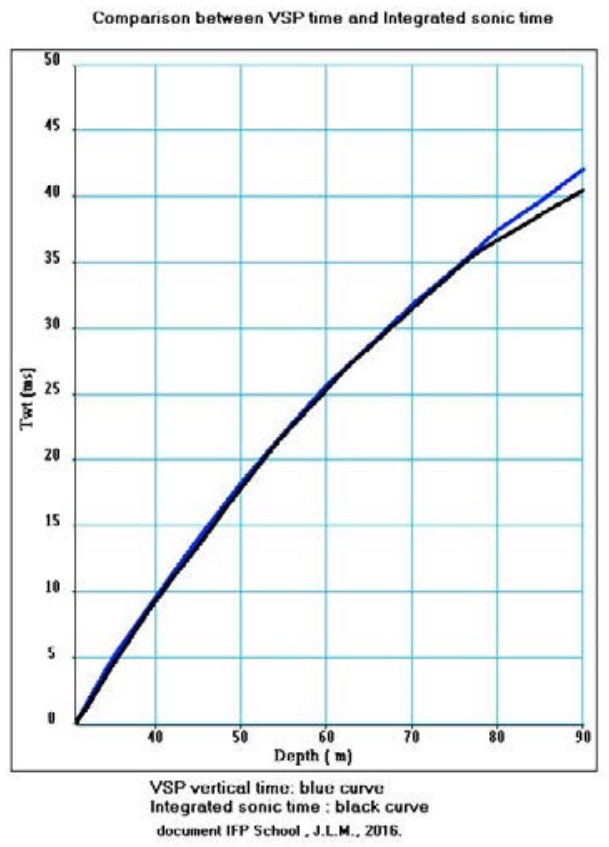

a

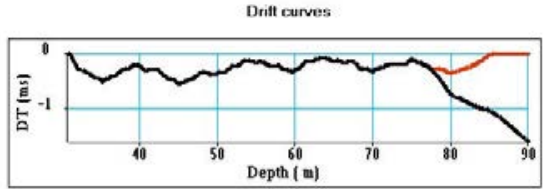

Drift curves between VSP vertical time and Integrated sonic times beforo Block shift componsatian black curn afler Black shit campensation red curve

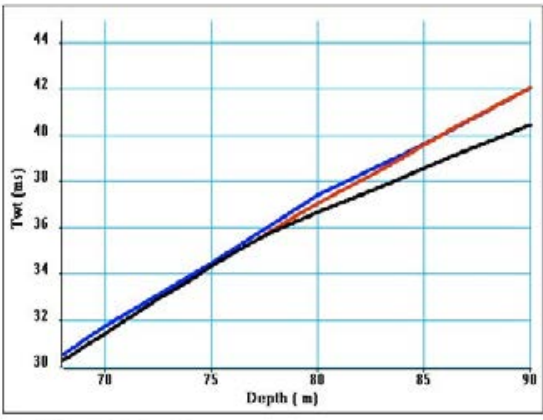

VSP vertical time: blue curve

Integrated tonic time before block shift compensation : black curve Inteqrated sonic time after block shift compensation : red curve

document IFP School , J.L.M., 2016.

b

Figure 4.7 VSP time and integrated sonic time - block shift method; a: comparison of VSP times and integrated sonic times; $b$ top: drift curves before and after velocity compensation by the "block shift" method; b bottom: comparison of VSP and integrated sonic times before and after velocity compensation using the "block shift" method. 
This procedure cannot guarantee that the acoustic velocities thus corrected are the exact velocities of the formations.

Acoustic velocity anomalies have several origins:

- measurement-related anomalies: noise and cycle skipping for picking based on the threshold, stretching (difficult to detect),

- anomalies linked to formations: poor cohesion between grains (measured velocity too low), vacuoles (measured velocity too high),

- anomalies related to the wave path: invasion, cavities, mud paths (in the case of large diameter holes), alteration of the borehole wall,

- anomalies due to poor cementation (as in the example shown here).

The refracted acoustic wave can propagate in the washed or invaded zone of the formation due to the invasion phenomenon and not in the virgin zone. The seismic wave (VSP) emitted at the surface, propagates mainly in the virgin formation. To obtain acoustic velocities in the virgin zone, it is necessary to correct or tie the acoustic velocity log with propagation time measurements in the virgin zone obtained from the VSP picked times. For this purpose, the drift curve is used to determine the values of velocity correction to apply to the measured acoustic velocities so that the new integrated times are closest to the VSP vertical times. The drift curve can be approximated by straight line segments. A velocity correction value will be calculated for each line segment. In the example presented here, the drift curve can be approximated by 2 straight-line segments, the first in the 30 to $77 \mathrm{~m}$ depth range, the second in the 77 to $90 \mathrm{~m}$ depth range. In the first interval, we note that the time difference is constant on average $(0.5 \mathrm{~ms})$. This value corresponds to the precision of the picking. As a result, the sonic velocity curve will not be modified in this depth range. In the 77 to $90 \mathrm{~m}$ range, the drift curve has a significant gradient that can be compensated for by a constant velocity correction value. The correction method is known as a "block shift" (Boyer and Mari, 1997). Figure 4.7b, top, shows the drift curve before and after "block shift" compensation, and, bottom, the comparison of the VSP times and the integrated sonic times before and after "block shift" compensation. Figure 4.8 ( $\mathrm{a}$ and b) shows, in depth and time, the velocity logs after "block shift" correction and the cementation logs. The corrected velocity log was used to calculate a reflectivity log (Figure 4.8c) that was filtered in terms of frequency and under-sampled at $0.5 \mathrm{~ms}$.

On the filtered reflectivity log, we can see that the high amplitude reflector of around $70 \mathrm{~ms}$ has disappeared. The reflectivity log was inserted into the seismic section and the correlation coefficient between the reflectivity log and the seismic trace at the well was measured at 0.77 , thus confirming a good tie of the seismic horizons in time.

This example shows that synthetic seismograms can be used to tie seismic sections, after the acoustic velocity logs have been validated on measurements of vertical time obtained by VSP. 


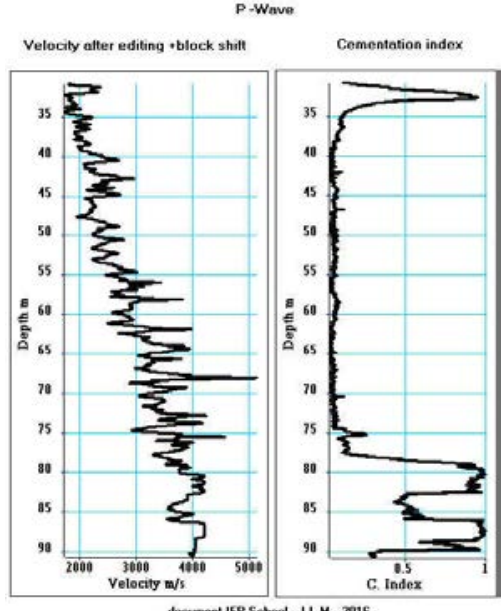

a

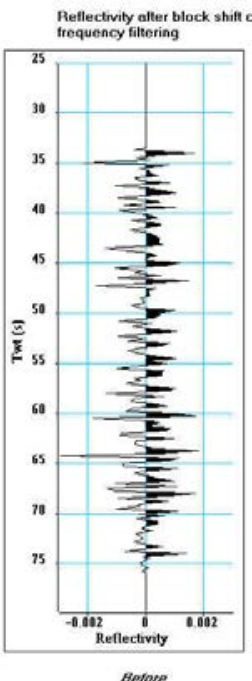

C

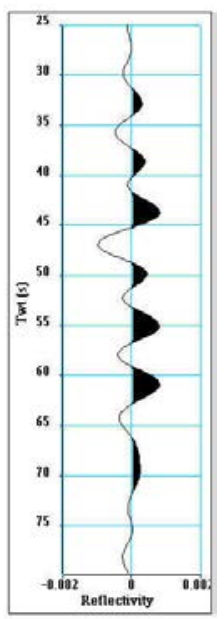

Aner

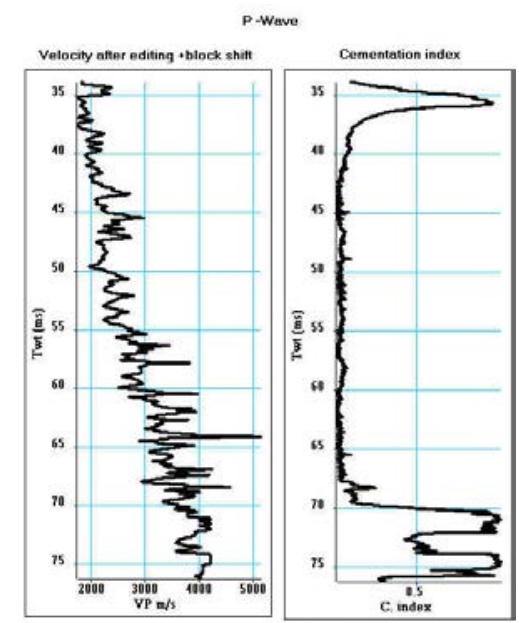

b

document IfP Schood , J.L. . 2016.

Calibration in time: Seismic line - Acoustic logging after Block shitt
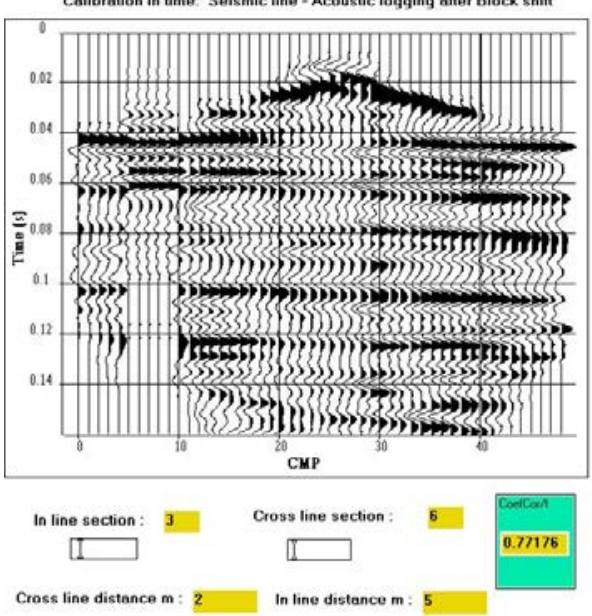

d

Figure 4.8 Seismic section and synthetic seismogram after block shift; a: velocity log and cementation log in depth; b: velocity log and cementation log in time; c: reflectivity before and after frequency filtering; $d$ : raw tying in time of the seismic section with reflectivity filtered in terms of frequency. 


\subsection{Conclusion}

This example presents the use of VSP and acoustic logging for tying surface seismic sections. Figure 4.9 shows the comparison between tying the section using acoustic logging (synthetic seismogram) and the use of VSP stacked trace. The synthetic seismic traces and the VSP stacked trace are inserted into the in-line seismic section 3 at the intersection with the cross-line seismic section 6 . The synthetic seismogram enables the reflectors to be tied in the depth range where the logs have been recorded. The VSP stacked trace allows the tying in the same depth range, but it also enables the prediction of reflectors under the well, particularly in the 90 to $140 \mathrm{~m}$ range.

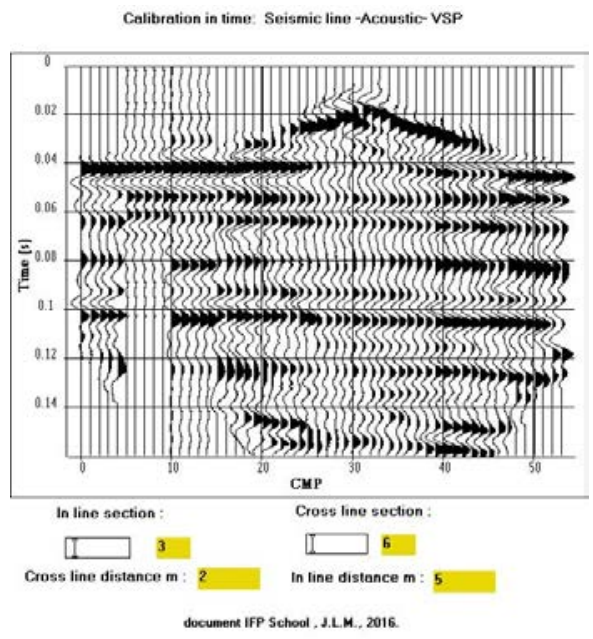

a

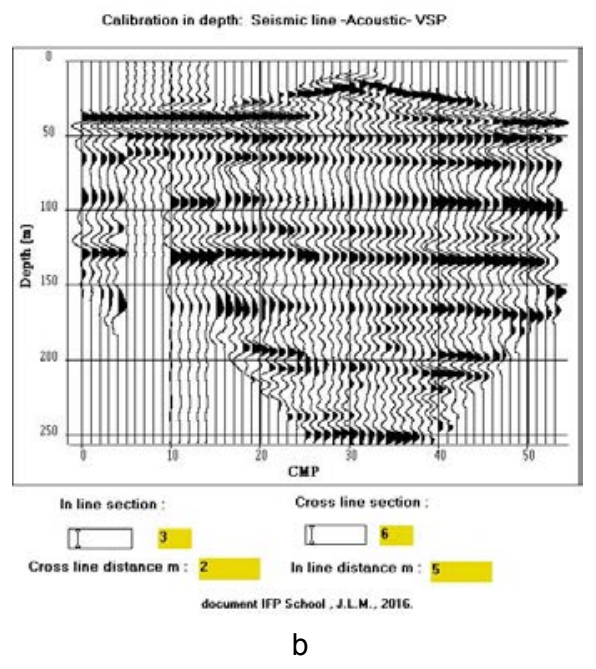

Figure 4.9 Tying of a seismic section using a VSP and an acoustic log; a: in time, b: in depth.

\section{References}

Boyer S., Mari J.L., 1997, Seismic surveying and well logging. Éditions Technip, Paris. Mari J.L., Herold D., 2015, Seismic Processing Tutorial: using the SPW Software, EAGE Publications bv. 

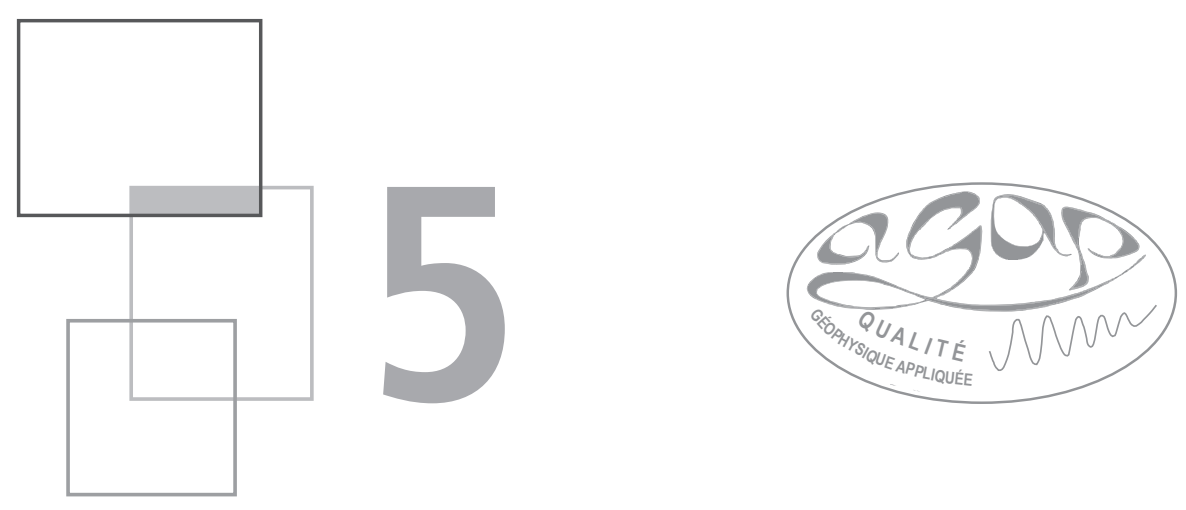

\section{Contribution of seismic}

and acoustic methods

\section{to the characterization of karstic formations}

\section{J.-L. Mari, G. Porel}

\subsection{Introduction}

Over the past decade, many underground aquifers have been developed as experimental sites. These sites are designed for in situ measurements and calibration of flow, transport and/or reactions in underground reservoirs that are heterogeneous by nature.

This chapter of Well seismic surveying and acoustic logging is published under Open Source Creative Commons License CC-BY-NC-ND allowing non-commercial use, distribution, reproduction of the text, via any medium, provided the source is cited.

(C) EDP Sciences, 2018

DOI: $10.1051 / 978-2-7598-2263-8 . c 007$ 
One such Hydrogeological Experimental Site (HES) was built by the University of Poitiers (France) near its campus, for the purpose of providing facilities to develop long-term monitoring and experiments for a better understanding of flow and transfers in fractured rocks [2], [3], [4], [5].

After a brief review of the geological context, this chapter shows the contribution of seismic and acoustic methods to the characterization of a karstic carbonate reservoir. The different geophysical methods studied are:

- 3D surface seismic method

- Well seismic methods: ambient noise measurements and Vertical Seismic Profiles (VSP) survey

- Acoustic method: full waveform acoustic logging

This chapter shows the value of combining different geophysical methods to describe geological formations at different scales to detect karstic bodies and to quantify flows.

\subsection{Geological context}

The aquifer studied is 20 to $130 \mathrm{~m}$ in depth and consists of tight karstic carbonates of Middle Jurassic age. It lies on the borderline, called the "Poitou threshold", between the Paris and the Aquitaine sedimentary basins (Figure 5.1). The Hydrogeological Experimental Site (HES) covers an area of 12 hectares over which 35 wells were drilled to a depth of $120 \mathrm{~m}$ (Figure 5.1). The top of the reservoir was flat and horizontal 150 million years ago, before being eroded and weathered during the Cretaceous and Tertiary ages. Today the reservoir top is shaped with hollows and bumps with a magnitude reaching up to $20 \mathrm{~m}$.

The site construction phase started in 2002 and to date 35 wells have been bored over the whole thickness of the reservoir. Most wells are fully documented, with drilling records and logs of various types, including gamma ray, temperature, and acoustic logs. In addition, two wells were entirely cored.

Hydrogeological investigations show that maximum pumping rates vary from well to well and range from 5 to $150 \mathrm{~m}^{3} / \mathrm{h}$. However, the aquifer responds fairly evenly to the hydraulic stress of a pumped well. This is assumed to be the consequence of a local karstic flow in open conduits. The presence of karstic drains is supported by recent well logs using optic (OPTV) or acoustic (BHTV) imaging. Almost all wells have shown caves and conduits that were intersected by the walls of the boreholes, with average apertures sometimes in the range of 0.2 to $0.5 \mathrm{~m}$.

These conduits are mostly enclosed in three thin horizontal layers at depths of $35 \mathrm{~m}, 88 \mathrm{~m}$ and $110 \mathrm{~m}$. Of course, these layers are intercepted by vertical wells and this potentially results in a good connection between wells and karstic drains. This connection is mainly controlled by the degree to which drains are re-opened 
in the vicinity of the well. The hydraulic slug tests show in some cases a very rapid propagation of the pressure wave over large distances (up to more than $100 \mathrm{~m}$ ). These observations have enabled the mapping of a diffusivity distribution and illustrated the important connections between the wells (Figure 5.1, bottom). Preferential connections are visible along the N90 direction (wells M13-M21M22-M19 and wells M04-M06-M11). Ultimately it was considered crucial to better define the geometry of the reservoir with a resolution compatible with both the scale of a well, and also with the scale of the entire experimental site. It was decided that high-resolution geophysical tools are well designed to undertake this kind of investigation.
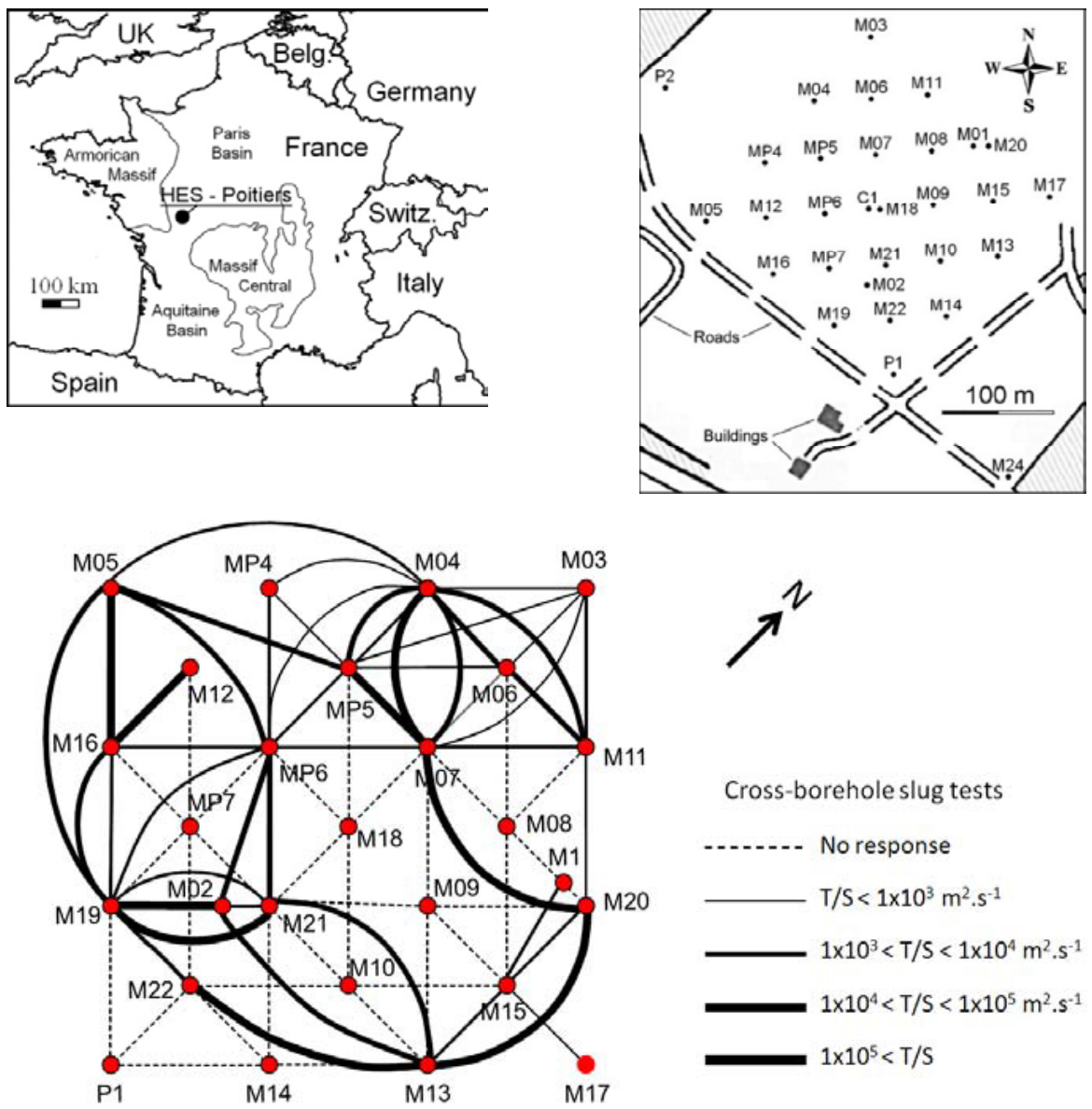

Cross-borehole slug tests

No response

$\mathrm{T} / \mathrm{S}<1 \times 10^{3} \mathrm{~m}^{2} \cdot \mathrm{s}^{-1}$

$1 \times 10^{3}<\mathrm{T} / \mathrm{S}<1 \times 10^{4} \mathrm{~m}^{2} \cdot \mathrm{s}^{-1}$

$1 \times 10^{4}<\mathrm{T} / \mathrm{S}<1 \times 10^{5} \mathrm{~m}^{2} \cdot \mathrm{s}^{-1}$

$1 \times 10^{5}<\mathrm{T} / \mathrm{S}$

Figure 5.1 Hydrogeological Experimental Site in Poitiers. Top: site map and well locations. Bottom: diffusivity map from slug test. 


\subsection{D seismic acquisition and processing}

Due to the limitations of the studied area, the length of the seismic line could not exceed $250 \mathrm{~m}$ in the in-line direction. The extension of the area is $300 \mathrm{~m}$ in the cross-line direction, perpendicular to the in-line direction of the lines. As a result, 20 receiver lines were implemented, with a $15 \mathrm{~m}$ distance between adjacent lines.

Figure 5.2 (top left) shows a map of the seismic lines and wells. Data acquisition was made with a 48 channel recorder and a single geophone $(10 \mathrm{~Hz})$ per trace. An explosive source $(25 \mathrm{~g}$ ) was detonated, making it easy to identify and select first arrivals.
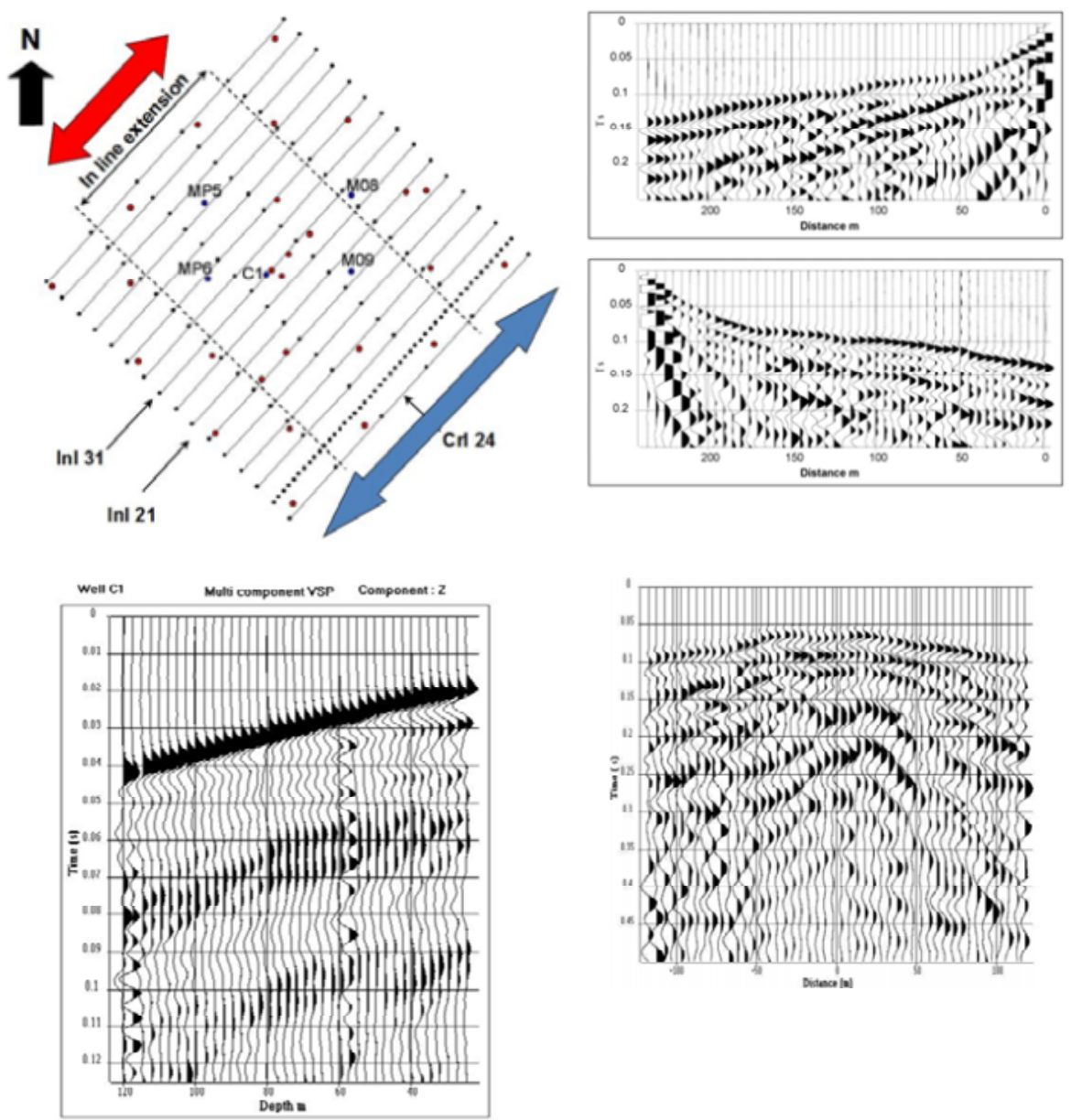

Figure 5.2 3D seismic acquisition. Top left: Seismic line implementation and well location (red points). Top right: Example of direct and reverse in-line shot points. Bottom left: Vertical seismic profile (VSP) at well C1. Bottom right: example of cross-line shot point. 
A 5 m distance between two adjacent geophones was selected to avoid any spatial aliasing. A direct shot and a reverse shot were recorded per receiver line ("in-line" shots). Figure 5.2 (top right) shows an example of an in-line direct and reverse shot gather. Three shot points in the cross-line direction were fired at distances of $40 \mathrm{~m}$, $50 \mathrm{~m}$ and $60 \mathrm{~m}$ from the receiver line under consideration. Figure 5.2 (bottom right) shows an example of a cross-line shot gather. The range of offsets was selected to optimize the quality of the seismic image over the reservoir depth interval, i.e. between $40 \mathrm{~m}$ and $130 \mathrm{~m}$. A $40 \mathrm{~m}$ minimum offset distance was chosen to reduce the influence of the surface waves. The time sampling interval was $0.25 \mathrm{~ms}$ and the recording length was $0.5 \mathrm{~s}$.

The processing sequence has been described in detail in several publications (Mari \& Porel [1] and Mari \& Delay [6]), so it is only briefly explained here. Each shot point was processed independently (both in the cross-line direction and in the in-line direction) to obtain a single-fold section with a sampling interval of $2.5 \mathrm{~m}$ (half the distance between 2 adjacent geophones) in the in-line direction. The processing of an in-line direct and reverse shot gather has enabled a single-fold section with an in-line extension of $240 \mathrm{~m}$ to be obtained (indicated by a blue arrow on the seismic line map) while a cross-line shot gather has provided a single-fold section with an in-line extension of $120 \mathrm{~m}$ (indicated by a red arrow on the seismic lines map).

A 3D seismic refraction tomography [7] was carried out to map the irregular shape of the top of the karstic reservoir and to obtain static corrections and a velocity model of the overburden. To add information to the inversion procedure, we used in-line and cross-line cross shots simultaneously, with an offset of $60 \mathrm{~m}$. The shots were selected to ensure that the refracted wave was the first arrival wave, regardless of the source receiver distance. The picked times of the first seismic arrivals for all shots (in-line and cross-lines shots), the depth map of the top of the reservoir (defined from the wells) and the velocity model obtained by the Plus-Minus [8] method were used as input data for the inversion procedure. The inversion results obtained with 3D data emphasize the previously mentioned geological structures [9], providing a better understanding of their alignments and shape (corridor of fractures). Furthermore, no cavities were detected near the surface.

The processing sequence includes: amplitude recovery, deconvolution, wave separation (SVD method for extracting refracted waves and combining the SVD and F-K methods for filtering surface waves), static corrections (obtained by inversion tomography) and normal move-out (NMO) corrections. A VSP was recorded in well C1 (Figure 5.2, bottom left). VSP data were processed to obtain a time versus depth relationship and a velocity model. The velocity model has been used to apply the NMO corrections. The VSP time versus depth law was also used to convert the time sections into depth sections with a $0.5 \mathrm{~m}$ depth sampling interval. The singlefold depth sections were merged to create the $3 \mathrm{D}$ block. The width of the block in the in-line direction is $240 \mathrm{~m}$, and $300 \mathrm{~m}$ in the cross-line direction.

In the in-line direction, the abscissa zero indicates the location of the source line. The abscissa of the reflecting points varies between $-120 \mathrm{~m}$ and $120 \mathrm{~m}$ in the in-line direction. The distance between two reflecting points is $2.5 \mathrm{~m}$. In the cross-line 
direction, the distance between two reflecting points is $5 \mathrm{~m}$. The depth sections were deconvolved to increase the vertical resolution. They were then integrated to transform a 3D amplitude block into a pseudo velocity block, using velocity functions (sonic logs recorded at wells C1, MP5, MP6, M08, M09) as constraints. The pseudo velocity sections of the 3D block thus obtained were merged with those obtained by refraction tomography to create a $3 \mathrm{D}$ extended velocity model from the surface (Figure 5.3).
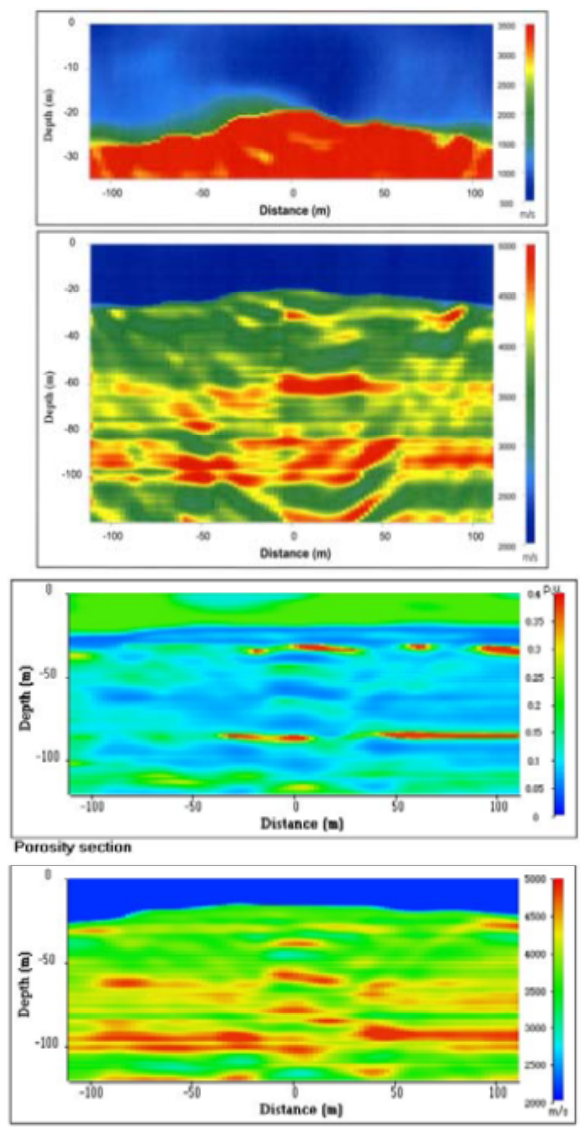

Velocity section
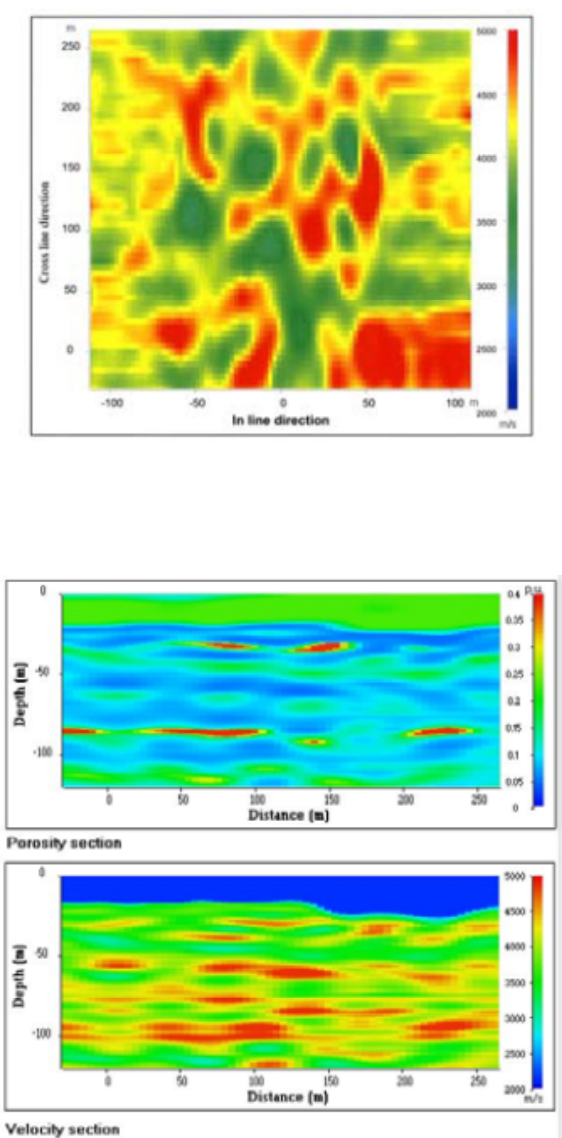

Figure 5.3 3D seismic processing. Top left: in-line 31 pseudo-velocity section (upper part: zoom of 0 to $35 \mathrm{~m}$ depth interval). Top right: pseudo-velocity map at $87 \mathrm{~m}$ depth. Bottom left: in-line 21 pseudo-velocity and porosity seismic sections. Bottom right: cross-line 24 pseudo-velocity and porosity seismic sections.

Figure 5.3 top left shows the results obtained for the in-line 31 seismic section extracted from the 3D extended velocity model. It also shows the velocity map at a depth of $87 \mathrm{~m}$ (Figure 5.3 top right). The 3D velocity model shows the large 
heterogeneity of the aquifer reservoir in the horizontal and vertical planes. To quantify the porosity variations within this aquifer, the seismic interval velocities were first converted into resistivity values. For this purpose, the empirical relationship between seismic velocity and resistivity proposed by Faust [10] was used. Resistivity values were then converted into porosity values, using Archie's law [11]. Figure 5.3 (bottom) shows the pseudo velocity and porosity seismic sections for the in-line 21 and cross-line 24.

The resulting 3D seismic pseudo-porosity block revealed three high-porosity layers, at depths of 35 to $40 \mathrm{~m}, 85$ to $87 \mathrm{~m}$ and 110 to $115 \mathrm{~m}$. The 85 to $87 \mathrm{~m}$ layer is the most porous, with porosities higher than $30 \%$, which represents the karstic part of the reservoir. Figure 5.4 shows the distributions of porous bodies in the 80 to $90 \mathrm{~m}$ and 100 to $120 \mathrm{~m}$ depth intervals.
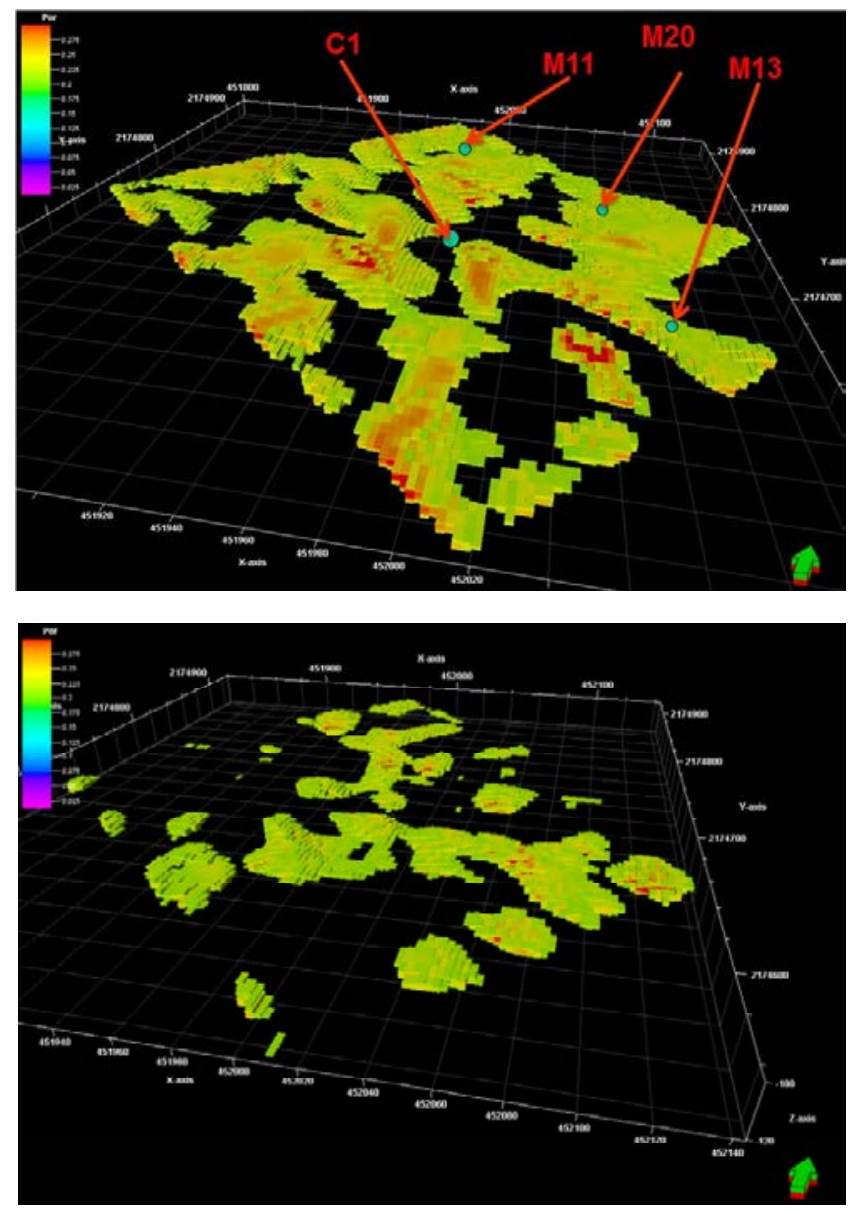

Figure 5.4 Distribution of karstic bodies. Top: in the 80 to $90 \mathrm{~m}$ depth interval. Bottom: in the 100 to $120 \mathrm{~m}$ depth interval. 
The 3D block is composed of elementary cells $(2.5 \mathrm{~m}$ in the in-line direction, $5 \mathrm{~m}$ in the cross-line direction, and $1 \mathrm{~m}$ deep), which clearly show the connectivity of the karstic bodies. The local validation of the results obtained by the $3 \mathrm{D}$ seismic method was achieved using full waveform acoustic data and VSP, recorded in 11 wells in 2014 and 2015 respectively. Acoustic logging and VSP have higher vertical resolution than the $3 \mathrm{D}$ seismic method, however, their lateral investigation was restricted to the vicinity of the well. 11 wells were selected: C1, M03, M05, M11, M13, M14, M20, M22, MP5, MP6 and MP7.

In this chapter, we show the results obtained from wells C1, M11, M13 and M20. The well locations are indicated in Figures 5.1 and 5.4.

\subsection{Well seismic measurements}

For VSP acquisition, the seismic source was a lightweight drop and the borehole sensor was a hydrophone. The sampling interval depth was $2.5 \mathrm{~m}$. Before each shot, the ambient noise was recorded. The VSPs were highly corrupted by Stoneley waves (tube waves). The conversion of down-going P-waves into up-going Stoneley waves was observed at the level of the karstic bodies. This phenomenon occurs in highly permeable formations.

Figure 5.5 shows the data recorded at well $\mathrm{C} 1$. The phenomenon of the conversion of P-waves into Stoneley waves can be identified at a depth of $60 \mathrm{~m}$ (Figure 5.5, top right). Indeed, it can be observed that the first arrival, which is the down-going $\mathrm{P}$-wave, is highly attenuated at a depth of $60 \mathrm{~m}$. At this depth, the P-wave is partly converted into a down-going Stoneley wave, which is reflected at the bottom of the well. The VSP data were processed to extract the down-going and up-going Stoneley waves. The down-going Stoneley wave can be extracted using a velocity filter, the velocity being the apparent velocity of the Stoneley wave. A narrow-band wavenumber filter applied after the velocity correction is equivalent to a velocity filter in the $\mathrm{f}, \mathrm{k}$ domain. The velocity was determined with a velocity scan. For a given velocity value, the Stoneley wave and residue are extracted, the difference between the initial VSP data and the estimated down-going Stoneley wave was calculated. The selected velocity was the velocity that minimized residues. The apparent velocity of the Stoneley mode is about $1,300 \mathrm{~m} / \mathrm{s}$. The same procedure was applied to extract the up-going Stoneley wave, but the apparent velocity was negative.

A Hilbert transform was applied to the different wave fields to estimate their amplitude (instantaneous envelope). Figure 5.5 (bottom left) shows the increase in amplitude of the Stoneley waves. The instantaneous amplitudes of the up-going Stoneley waves were stacked in a small corridor located after the arrival time of the down-going P-wave, to obtain a body wave to Stoneley wave conversion factor (Figure 5.5, bottom right), which relates to a karstic level at $57 \mathrm{~m}$ in depth. 

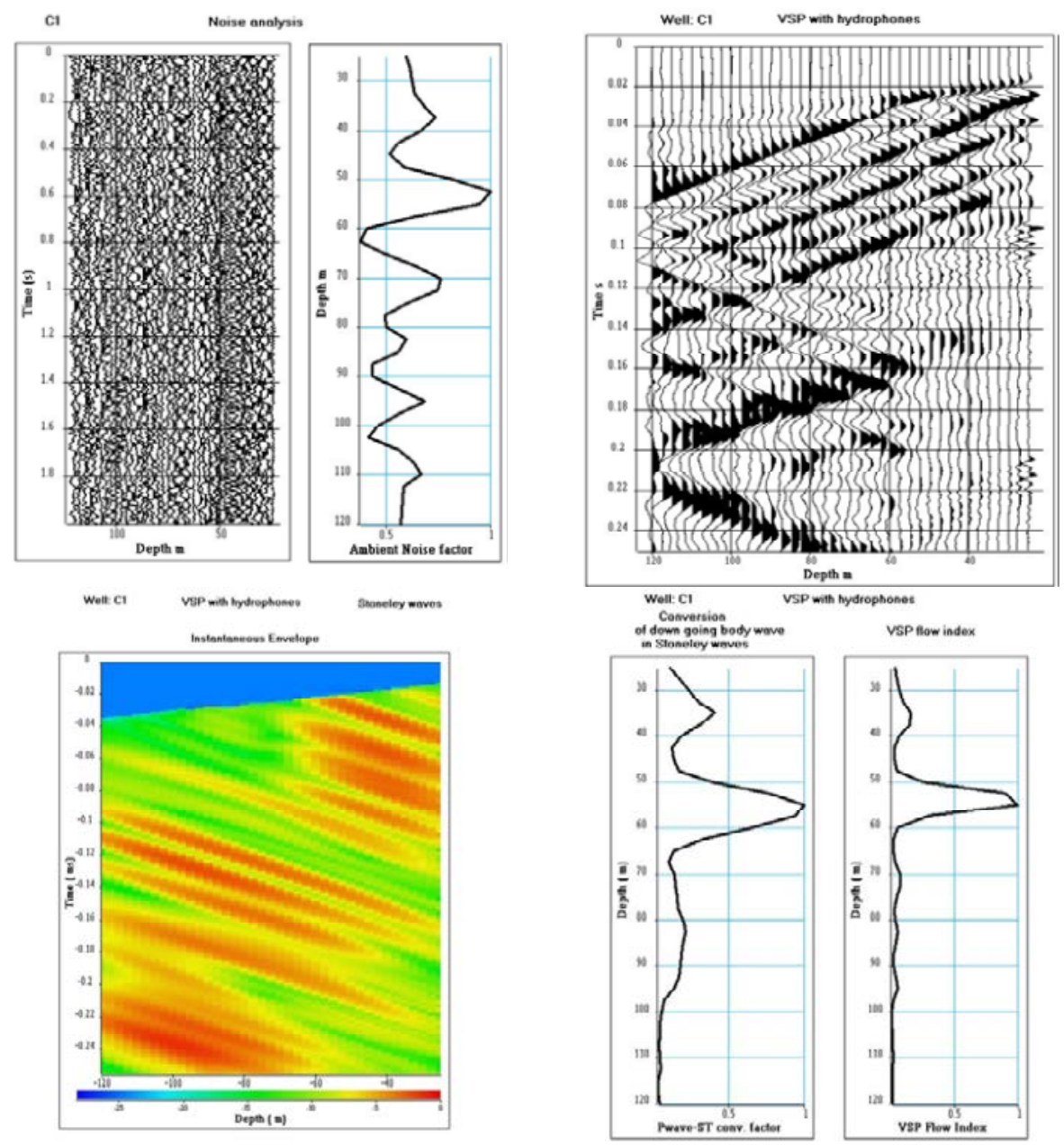

Figure 5.5 Flow detection using both ambient noise measurement and VSP data at well C1. Top left: Ambient noise and ambient noise factor. Top right: VSP data showing a high level of Stoneley waves. Bottom left: Up-going Stoneley waves (instantaneous envelope). Bottom right: P-wave to Stoneley wave conversion factor and VSP flow index.

Assuming that flow circulation in the karstic network generates a rise in ambient noise [12], the analysis of the seismic noise was carried out to detect the presence of flows [13]. For this purpose, the average and the variance of the amplitude spectrum of each noise trace was calculated. We noted a significant increase in the ambient noise factor, defined as the relationship between the average and the variance of the spectrum, at the level of karstic bodies. The analysis of the ambient noise therefore shows that the variations of the ambient noise factor correlate with the level of 
conversion of P-waves into Stoneley waves. Figure 5.5 (top left) shows the ambient noise and its associated ambient noise factor. The attribute, named VSP flow index, defined as the product of the ambient noise factor by the body wave to Stoneley wave conversion factor (Figure 5.5, bottom right) was used to detect both karstic bodies and flow.
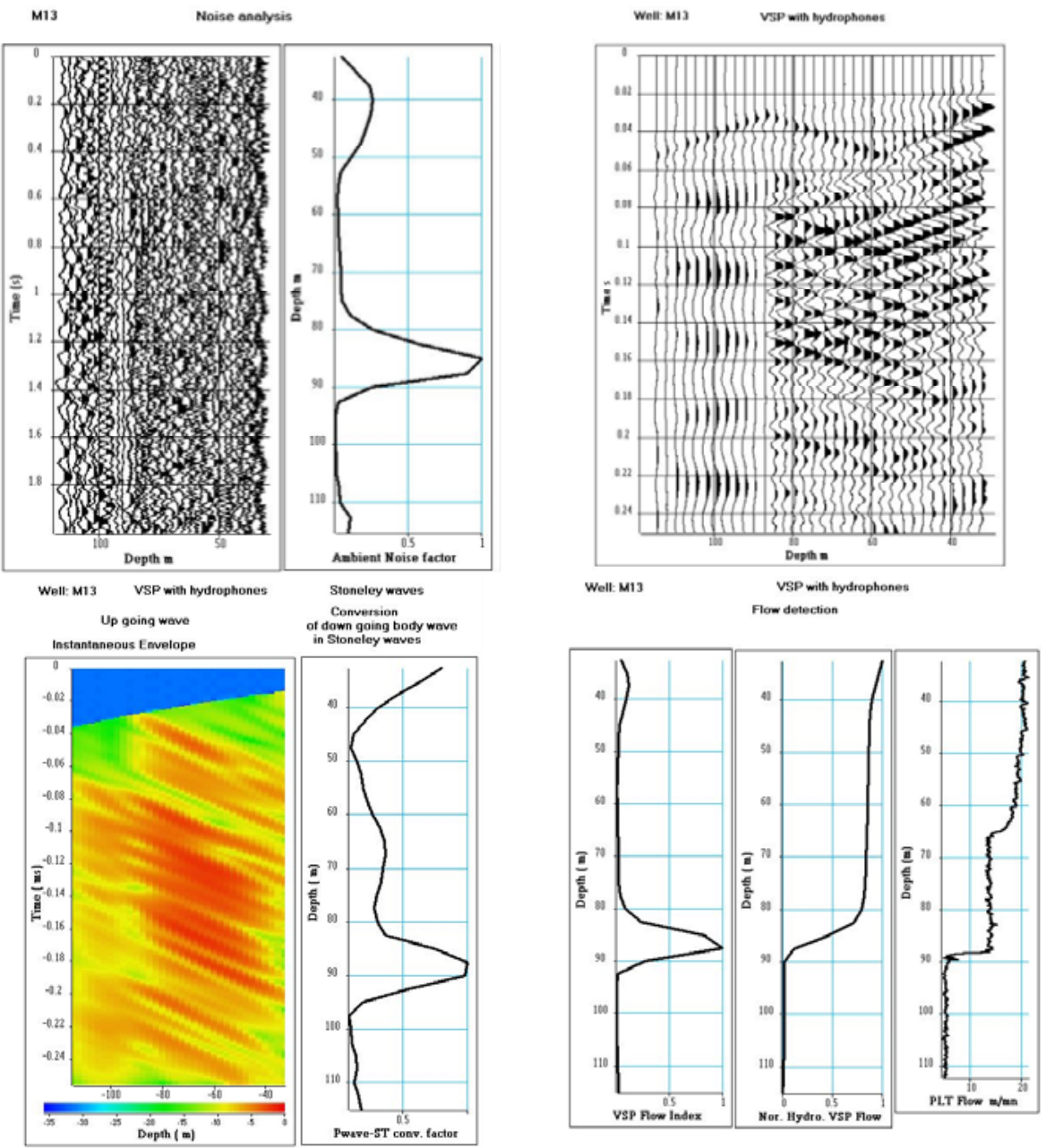

Figure 5.6 Flow detection using both ambient noise measurement and VSP data at well M13. Top left: Ambient noise and ambient noise factor. Top right: VSP data showing a high level of Stoneley waves. Bottom left: Up-going Stoneley waves and P-wave to Stoneley wave conversion factor. Bottom right: Detection of flow at $87 \mathrm{~m}$ deep and comparison of VSP flow with PLT flow. 
The analysis of ambient noise and of the increase in the P-body waves to Stoneley waves conversion is currently the only method available to detect the flow in this C1 well. Due to the small borehole diameter, it was not possible to run BHTV and PLT logs in well C1. However, the karstic level at a depth of $57 \mathrm{~m}$ was confirmed by acoustic logging.

The same procedure was therefore applied to the dataset recorded in well M13 (Figure 5.6).

Figure 5.6 shows:

- Top left: the ambient noise and its associated noise factor, which detects a karstic body between 85 and $87 \mathrm{~m}$, and predicts a flow.

- Top right: The VSP data. A down-going Stoneley wave reflected at a depth of $85 \mathrm{~m}$ can be noted. The conversion of the down-going P-wave into an up-going and down-going Stoneley wave can also be observed at the same depth.

- Bottom left: The instantaneous amplitude of the up-going Stoneley waves and the associated conversion factor between the P-wave and the Stoneley wave, which confirms the presence of a karstic body between 85 and $90 \mathrm{~m}$.

- Bottom right: the VSP flow index, which predicts a flow between 85 and $87 \mathrm{~m}$. The VSP flow index has been integrated in depth from bottom to top to mimic a flowmeter in order to compare with a PLT log. A good correlation between the 2 logs can be noted, taking into account that the vertical resolution is not the same for the $2 \operatorname{logs}(2.5 \mathrm{~m}$ for the VSP, and $1 \mathrm{~cm}$ for the PLT).

The flow variation of the PLT $\log$ at $65 \mathrm{~m}$ deep is due to a change of the borehole diameter.

\subsection{Monopole full waveform acoustic logging}

The transmission of an acoustic wave through geological formations is used for formation characterization. Monopole-type tools are the most commonly used for this purpose.

Monopole sources and receivers are multidirectional. Sources generate compression in the fluid, creating in the formation a compression wave (P-wave) and a shear wave ( $\mathrm{S}$-wave) at the refraction limit angles. In a vertical well, these tools are used to record five propagation modes: the refracted compression wave; the refracted shear wave (only in fast formations); the fluid wave; and two dispersive guided modes - the pseudo Rayleigh waves (only in fast formations) and the Stoneley waves. Acoustic logging enables the measurement of vertical propagation velocities and the frequencies of the different waves recorded.

The analysis of the acoustic waves recorded on each receiver of the logging tool is used to calculate additional logs, defined as acoustic attributes, useful for the characterization of the formation, such as: amplitude, shape index, wavelength 
and attenuation logs. The acoustic tool used for the field experiment was a flexible monopole tool with two far offset receivers (3 m (R1) and $3.25 \mathrm{~m}$ (R2) offsets).

At the level of a karstic body, we observed a strong attenuation of the refracted P-wave and a distortion of the acoustic signal that made it difficult to pick the refracted P-wave arrival times. Processing based on Singular Value Decomposition (SVD, [14]) was carried out independently on the 2 offset sections. The refracted wave signal space was given by the first Eigen section obtained by SVD:

$$
\underline{\mathrm{r}}^{\mathrm{sig}}=\lambda_{1} \underline{\underline{u}}_{1} \underline{\mathrm{v}}_{1}^{\mathrm{T}}
$$

$\mathrm{v}_{1}$ is the first singular vector giving the time dependence, and it is therefore named the normalized wavelet, $\mathrm{u}_{1}$ is the first singular vector giving the amplitude in depth, and is therefore called the propagation vector and $\lambda_{1}$ the associated eigenvalue. The amplitude variation of the refracted wavelet over the depth interval is $\lambda_{1} u_{1}$.

A cost function based on the correlation of normalized wavelets $V_{1}$ extracted from the two constant offset sections enables the simultaneous calculation of the velocity $\mathrm{V}$ of the formation, and the correlation coefficient between the wavelets.

SVD processing leads to the calculation of a specific attribute used to detect karstic levels. The attribute, called the Noise/Signal detector, is the product of 3 normalized terms:

- A velocity term: $C V=1-\left(\mathrm{V} / \mathrm{V}_{\max }\right)$. The lower the velocity, the higher the velocity term. In karstic zones, a high CV coefficient is observed.

- An amplitude term: $C A=1-\left(A / A_{\max }\right)$, with $A=\lambda_{1} \underline{u}_{1}$. In karstic zones, a high CA coefficient is observed.

- A correlation term: CCor $=1$-(Cor/Cor $\left.{ }_{\max }\right)$, Cor being the correlation coefficient between two normalized wavelets. In karstic zones, a high CCor coefficient is observed.

Figure 5.7 shows the acoustic data from well M13. On the $3 \mathrm{~m}$ constant offset section, we can clearly see:

- the refracted P-waves between 0.5 and 1 milliseconds,

- the converted refracted shear waves between 1.2 and 1.8 milliseconds,

- the Stoneley modes after 2 milliseconds.

One can notice a strong attenuation of all waves between 85 and $90 \mathrm{~m}$, highlighted by the Noise/Signal detector log. The BHTV log confirms the presence of a karstic layer. The results are consistent with the seismic measurements (VSP flow index) and PLT flow (Figure 5.6).

Figure 5.8 compares BHTV log, VSP flow index, Noise/Signal detector (acoustic logging) and PLT flow at well M11. A karstic body with a flow was clearly detected between 85 and $90 \mathrm{~m}$. 

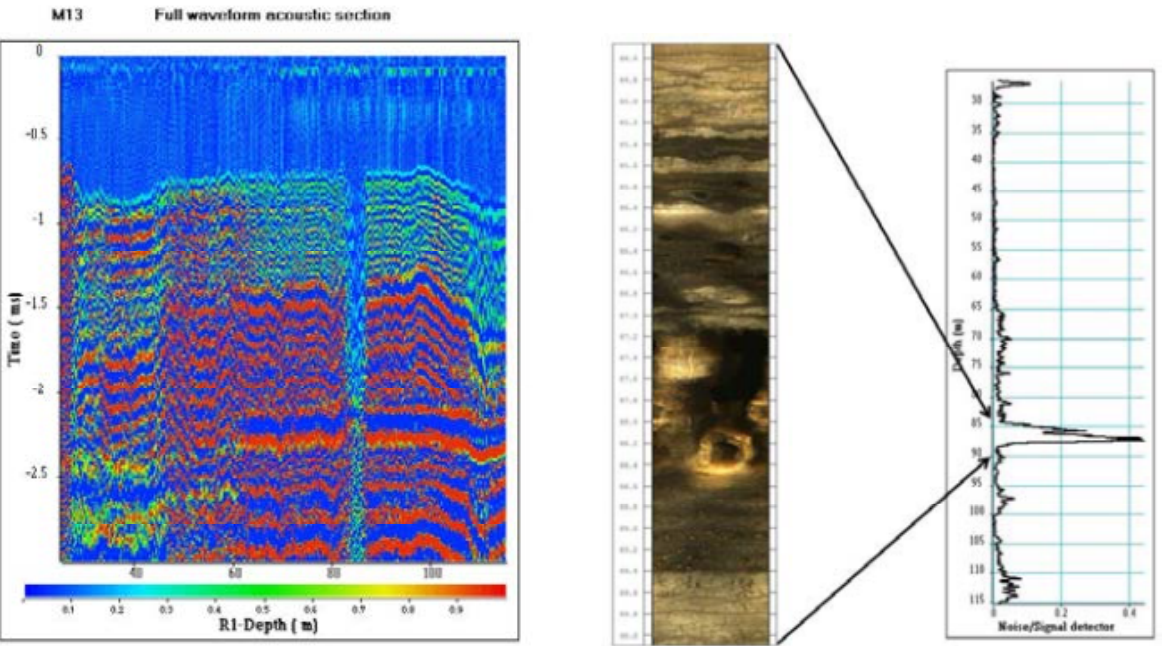

Figure 5.7 Acoustic data at well M13. Acoustic section (left) and comparison between BHTV and noise/signal detector (right).
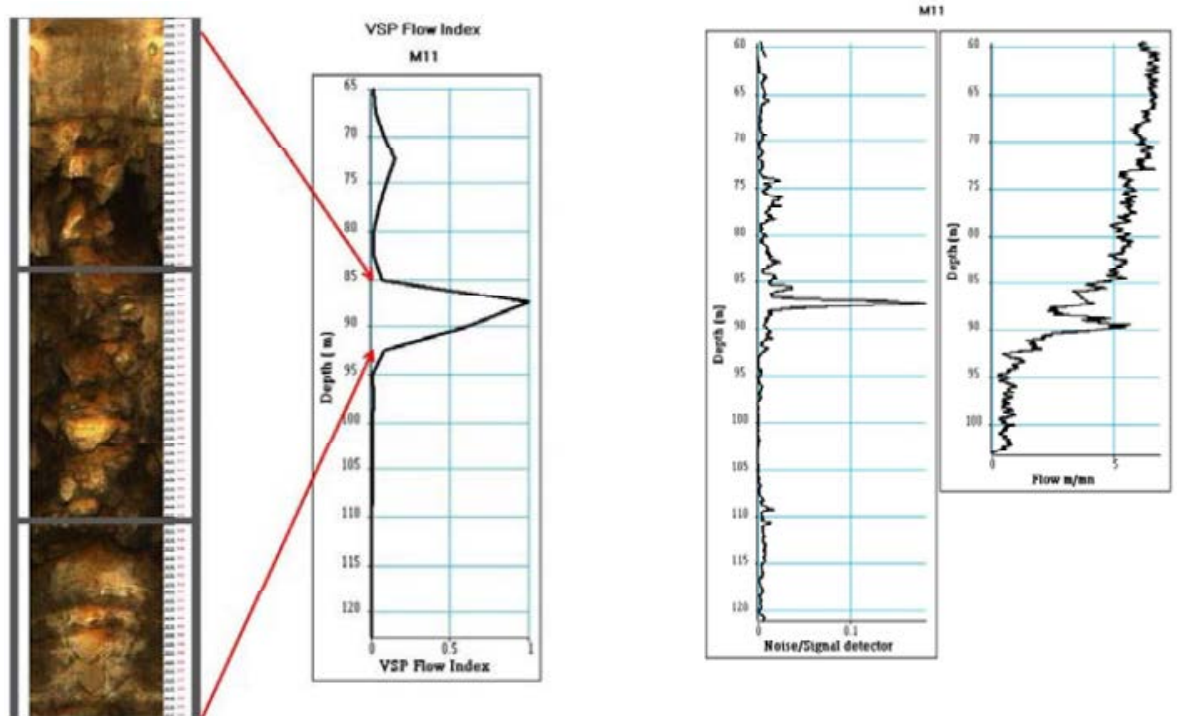

Figure 5.8 Flow detection at well M11. Comparison between BHTV, VSP flow index, noise/signal detector (acoustic logging) and PLT. 
Figure 5.9 is a synthesis of the methods developed to detect karstic bodies and to quantify flows. It gathers data from acoustic logging, ambient seismic noise, VSP data, OPTV and PLT flow metering.
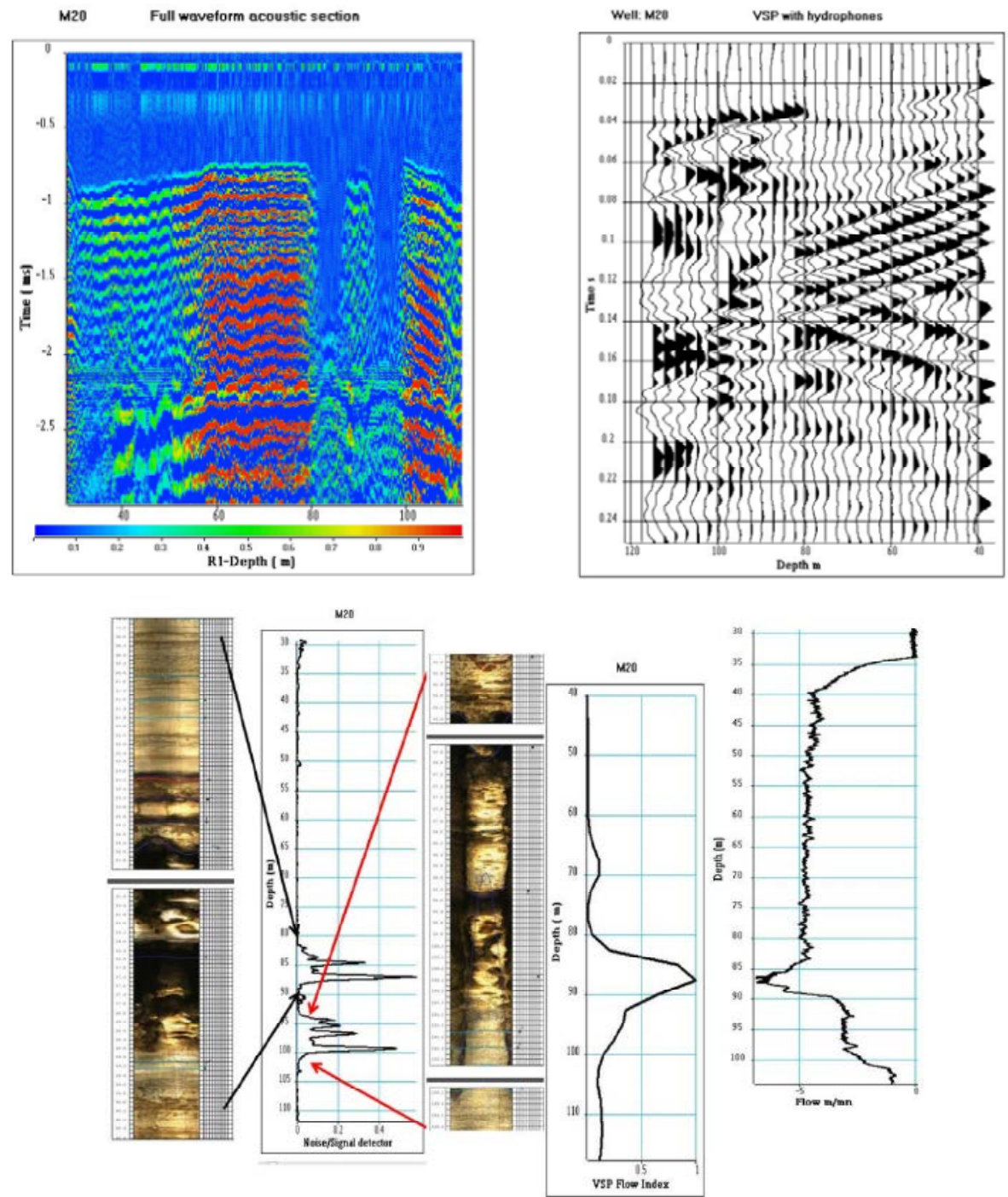

Figure 5.9 Flow detection at well M20. Top: Full waveform acoustic data (left) and VSP data (right). Bottom: comparison between OPTV, Noise/signal detector (acoustic data), VSP flow index and PLT log. 
Regarding the data recorded in well M20, the $3 \mathrm{~m}$ constant-offset acoustic section shows:

- the refracted P-waves between 0.5 and 1 milliseconds

- locally, the converted refracted shear waves between 1.2 and 1.8 milliseconds

- the fluid waves characterized by very high frequencies in the order of $30 \mathrm{kHz}$

- the Stoneley wave modes

An analysis of the acoustic data and the calculations made from the Noise/Signal detector have enabled the detection of karstic levels in two depth intervals between 82 and $88 \mathrm{~m}$ and between 95 and $100 \mathrm{~m}$. In these intervals the acoustic section shows a strong attenuation of the refracted P-wave. The presence of the 2 karstic layers was validated by the OPTV logs.

The VSP shows a down-going Stoneley mode which is strongly attenuated at $82.5 \mathrm{~m}$ deep. The phenomena of a conversion from a down-going P-wave to Stoneley waves can be observed between 82.5 and $100 \mathrm{~m}$. The processing of VSP data and the ambient noise analysis confirmed that the 82.5 to $100 \mathrm{~m}$ depth interval is a karstic layer and detect the presence of flow. A PLT log obtained during pumping in well M04 validates the results of the acoustic-seismic experimentation.

\subsection{Conclusion}

This chapter has shown the benefit of combining different geophysical methods to describe geological formations at different scales. The aquifer studied, 20 to $130 \mathrm{~m}$ in depth, consists of tight karstic carbonates.

In 2004, a seismic reflection and refraction survey was carried out on the study site [1]. An analysis of the seismic refraction tomography was made to calculate the velocity distribution in the karst aquifer cover, and to map the top of this reservoir. The 3D seismic data were processed to obtain, following inversion, the distribution of the seismic velocities in the reservoir. The result was a high-resolution 3D seismic block. This enables the identification of three high-porosity, presumably waterproducing layers, at depths of 35 to $40 \mathrm{~m}, 85$ to $87 \mathrm{~m}$ and 110 to $115 \mathrm{~m}$. The 85 to $87 \mathrm{~m}$ deep layer is the most porous, with porosities of over $30 \%$, which represents the karstic part of the reservoir.

To locally validate the results obtained by the $3 \mathrm{D}$ seismic method, full waveform acoustic data and VSP were recorded in 11 wells, VSP and acoustic methods having a higher vertical resolution than the surface seismic method.

A methodology has been developed to detect flow using both ambient noise measurement and VSP data recorded with a hydrophone sensor. The VSP, recorded in water wells, were highly corrupted by Stoneley waves (tube waves). Conversion of the down-going P-waves into Stoneley waves was observed at the level of the karstic bodies. This phenomenon occurs in highly permeable formations. The analysis of the ambient noise shows that the variations of its characteristics (spectral variance) 
are correlated with the conversion level of P-waves into Stoneley waves. An attribute, the VSP flow index, was calculated to detect both karstic levels and flows.

Full waveform acoustic data were recorded both to locally validate the results obtained by the seismic methods (3D and VSP) and to evaluate the potential of the acoustic method to detect karstic bodies with a very high resolution $(0.25 \mathrm{~m}$ deep). A methodology has also been developed to process the acoustic data generated by the flows in the karst conduits. The methodology is based on Singular Value Decomposition processing, which is used to estimate simultaneously the velocity of the formation, the amplitude of the acoustic signal, and the level of noise. An attribute, called the Noise/Signal detector, was calculated to detect karstic levels.

The seismic (3D, VSP) and acoustic data were compared with OPTV logging data and PLT data. The flows predicted by seismic methods were confirmed by PLT data.

The conclusions of the study are:

- The 3D seismic block can be used to build a 3D model of karst aquifers,

- Conversion of P-waves into Stoneley waves was observed in the VSP data at the top of the producing levels,

- The variations of the spectral characteristics of the ambient noise are strongly correlated with flow measurements (PLT) and the conversion of P-waves to Stoneley waves,

- Analysis of ambient noise and conversion of body waves into Stoneley waves could also be used to detect flow circulation.

Therefore, we can conclude that 3D seismic, full waveform acoustic logging and VSP enable the description of karstic formations at different scales.

\subsection{Acknowledgements}

We thank the University of Poiters for granting us their permission to use the data. We thank Benoît Nauleau and Denis Paquet for their technical support. We thank Patrick Meynier for his support in the acquisition of the VSP data. We thank Pierre Gaudiani for the acquisition of full waveform acoustic data.

\section{References}

[1] Mari J.L., Porel G., 2007, 3D seismic imaging of a near - surface heterogeneous aquifer: a case study, Oil and Gas Science and Technology, Rev IFP 63, 179-201. doi: $10.2516 /$ ogst/2007077.

[2] Bernard S., Delay F., Porel G., 2006, A new method of data inversion for the identification of fractal characteristics and homogenization scale from hydraulic pumping tests in fractured aquifers. Journal of Hydrology 328, 647-658. 
[3] Kaczmaryk A., Delay F., 2007a, Interpretation of interference pumping tests in fractured limestone by means of dual-medium approaches. Journal of Hydrology 337, 133-146. doi: 10.1016/j.jhydrol.2007.01.004.

[4] Kaczmaryk A., Delay F., 2007b, Improving dual-porosity-medium approaches to account for karstic flow in a fractured limestone. Application to the automatic inversion of hydraulic interference tests. Journal of Hydrology 347, 391-403. doi: 10.1016/j.jhydrol.2007.09.037.

[5] Bourbiaux B., Callot J.P., Doligez B., Fleury M., Gaumet F., Guiton M., Lenormand R., Mari J.L., Pourpak H., 2007, Multi-Scale Characterization of a Heterogeneous aquifer through the Integration of Geological, Geophysical and Flow Data: A Case Study, Oil and Gas Science and Technology, Rev IFP 61, 347-373.

[6] Mari J.L., Delay F., 2011, Contribution of Seismic and acoustic methods to reservoir model building, in "Hydraulic Conductivity / Book 1", ISBN 978953-307-288-3, InTech-Open Access Publisher, DOI: 10.5772/22051.

[7] Mari J.L., Mendes M., 2012, High resolution near surface imaging of fracture corridors and cavities by combining Plus Minus method and refraction tomography, Near Surface Geophysics 10, 185-195, DOI: 10.3997/1873-0604.201 1052.

[8] Hagedoorn G.J., 1959, The Plus-Minus method of interpreting seismic refraction sections, Geophysical Prospecting 7, 158-182.

[9] Mari J.L., Porel G., Bourbiaux B., 2009, From 3D Seismic to 3D Reservoir Deterministic Model Thanks to Logging Data: the Case Study of a Near Surface Heterogeneous Aquifer, Oil and Gas Science and Technology, Rev IFP 64, 119131. DOI: $10.2516 /$ ogst/2008049.

[10] Faust L.Y., 1953, A velocity function including lithologic variation, Geophysics $18,271-288$.

[11] Archie G. E., 1942, The electrical resistivity log as an aid in determining some reservoircharacteristics, Petroleum Technology 146, 54-62.

[12] Aslanyan A., Davydov D., 2012, Spectral Noise Logging, SNL-6, Technical overview, TGT Oilfield Services, www.tgtoil.com

[13] Mari J.L., Porel G., 2016, Flow detection using well seismic data, Tu P2 02, 78thEAGE Conference \& Exhibition, Vienna, Austria, 30 May-2 June.

[14] Mari J.L., Porel G., 2015, Automated karstic reservoir analysis utilizing attributes, We N117 02, 77th EAGE Conference \& Exhibition, Madrid IFEMA, Spain, 1-4 June. 


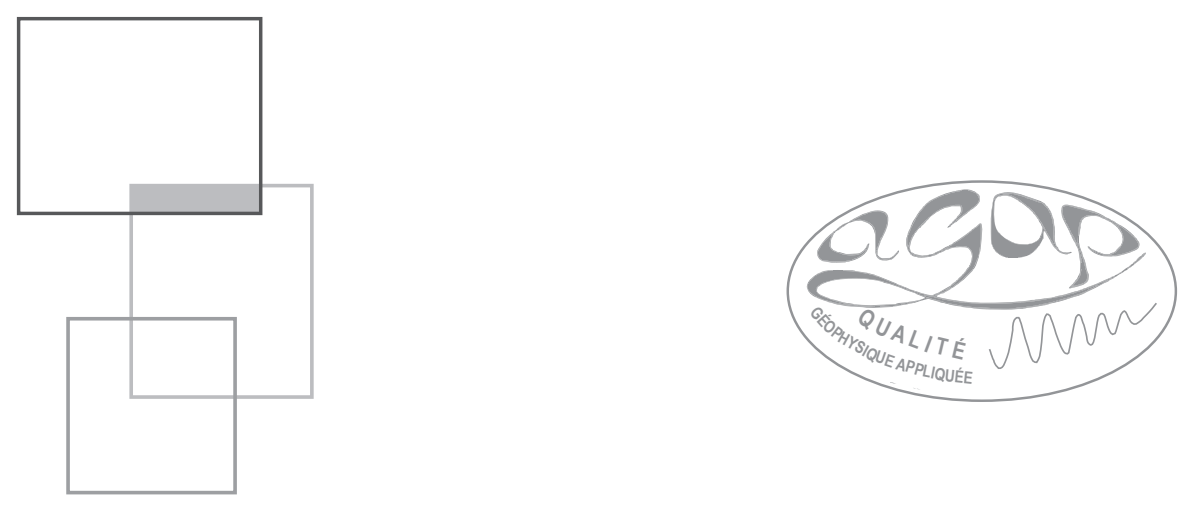

\section{Conclusion}

\section{J.-L. Mari, C. Vergniault}

This book provides a state of the art overview of borehole seismic methods and acoustic logging methods, for application in geotechnology and civil engineering fields, and also presents examples of data acquisition and analysis from the oil sector that are transposable if required with the necessary realism to near surface studies (in the fields of geotechnology, hydrogeology and seismic hazards).

Indeed, Chapter 1 details the methodology of acquisition and analysis for routine measurements in geotechnology to establish shear velocity (Vs) logs. These measurements can be downhole, uphole and crosshole. The added value compared to the ASTM standards is to provide recommendations for the acquisition methodology (calibration procedures for the geophysical measurement chain, tools for trajectory or inclination measurements, and impact of downhole tube waves) and for processing (carrying out a two phase analysis to avoid artifacts related to real paths or refracted waves) and also for combining useful methods (possibility of controlling cementation, possibility of using two boreholes in crosshole analysis, provided that

This chapter of Well seismic surveying and acoustic logging is published under Open Source Creative Commons License CC-BY-NC-ND allowing non-commercial use, distribution, reproduction of the text, via any medium, provided the source is cited.

(C) EDP Sciences, 2018

DOI: $10.1051 / 978-2-7598-2263-8 . c 008$ 
this is combined with downhole acquisition). For a deep survey where an uncased borehole can be used, PSSL should undoubtedly be recommended. The measurement can be supplemented with full waveform acoustic logging (Sonic FWF) to improve vertical resolution with Stoneley modes. However, it remains preferable to have a data surplus in the first meters, with a downhole or crosshole, because this section is usually cased, outside of the water table, and an invasion of the formation by a sealant, which would distort PSSL measurement, cannot be excluded.

Chapter 2 shows that it is possible to acquire a near-surface VSP (between 0 and $100 \mathrm{~m}$ ), using the same means as for a downhole. After processing, the benefit of VSP is that it provides a seismic trace without multiples that is directly comparable to a surface seismic section in the vicinity of the borehole. It is important to note that the lateral investigation can be increased by offsetting the source relative to the borehole. This technique is called Offset Vertical Seismic Profiling (OVSP). The image obtained after processing is thus a single-fold seismic section. Finally, a Seismic Walkaway is a series of offset VSPs, with the surface source situated at several locations corresponding to successively increasing offsets with respect to the borehole. Therefore, the image obtained after processing is a section with a low degree of multiple-fold coverage. In addition, a VSP provides an image of the geological formations below the borehole.

Chapter 3 illustrates that acoustic logging recordings with a conventional monopole probe can be used to obtain not only a P-wave velocity log, but also imaging in the well vicinity with decimetric to metric scale lateral investigation for refracted modes. In addition, the analysis of the reflected and diffracted modes with multitransmitter and multi-receiver tools makes it possible to extend the investigative power of acoustic logging and to make a micro-seismic survey of the well. The response of the Stoneley wave is strongly related to the state of continuity of the borehole wall. The attenuation of Stoneley waves (decrease of amplitude and frequency) is used to characterize the fissured medium. In addition, wave conversion phenomena are observed at the boundaries of the fractured zones. These phenomena are very pronounced on the Stoneley waves, especially in the presence of open fractures.

When the shear velocity of the formation is lower than the P velocity of the borehole fluid it cannot be measured with a conventional monopole tool. It is then necessary to implement a dipole-type acoustic tool equipped with polarized transmitters and receivers. Such tools generate polarized compression waves perpendicular to the borehole axis. These compression waves create flexural modes at the well wall that generate pseudo-shear waves in the formation that propagate parallel to the well axis. The flexural wave travels at the $S$-wave velocity and is therefore the most reliable logging method for estimating a shear velocity log. An adaptation is available for the geotechnical field, namely PS suspension logging (PSSL) which involves a flexible tool.

Using a near-surface dataset (3D seismic, VSP and full waveform acoustic logging), Chapter 4 illustrates: the principle of depth conversion of surface seismic methods using VSP data, the influence of the cementation on acoustic measurements, the principle of calibration of the formation velocity measurements obtained by 
acoustic logging with those provided by the VSP, as well as the principle of time conversion of acoustic data and the calculation of synthetic seismograms.

Chapter 5 presents an innovative example of the application of borehole seismic methods and logging techniques. The example describes the contribution of seismic and acoustic methods to the characterization of karstic formations. For this purpose, it appears that a 3D seismic block can be used in hydrogeology to build a 3D model of karstic aquifers. VSP data characterize karst levels in two ways. Firstly through the conversion of P-waves to Stoneley waves at the top of the most porous levels, and secondly through the analysis of ambient noise which is at its maximum at the level of the water producing layers. Finally, full waveform acoustic logging also enables the characterization of karstic formations, but on a different scale. At the level of a karstic body, we observe a strong attenuation of the refracted $\mathrm{P}$-wave and a distortion of the acoustic signal. The analysis of the acoustic waves recorded simultaneously on the two receivers of a monopole acoustic tool can be implemented to calculate a Singular Value Decomposition (SVD) of the logs, which makes it possible to define acoustic attributes. The attribute, called the Noise/Signal detector, is the product of three normalized terms (velocity coefficients (CV), amplitude coefficient (CA), correlation coefficient (CCor). In karstic zones, a rise in these three coefficients was observed, therefore the analysis of ambient noise (seismic and acoustic) and the conversion of body waves into Stoneley waves can be used to detect and quantify flow circulation, while a 3D seismic block can be used to build a 3D model of karstic aquifers. We can therefore conclude that 3D seismic surveys, full waveform acoustic logging and VSP enable the characterization of karstic formations at different scales. 


\section{PROfile}

\section{Well seismic surveying and acoustic logging}

\section{Jean-Luc Mari and Christophe Vergniault}

pproaches that are typically applied in deep exploration geophysics, combining different seismic and logging methods, can be technically adapted for certain geotechnical or hydrogeological surveys or some site characterizations in the framework of seismic hazard studies. Currently it is entirely feasible to implement this type of geophysical surveying if the situation requires.

After reviewing the current state of knowledge regarding borehole measurements of subsurface shear velocities applied to the geotechnical field, this book illustrates the feasibility of carrying out vertical seismic profiles (VSPs) and logs in this field.

This approach also illustrates the value of combining velocity measurements of formations provided by borehole seismic tools (VSP) and acoustic (sonic) tools.

An innovative example of the application of borehole seismic and logging methods is then presented in the case study of a relatively near-surface (from 20 to $130 \mathrm{~m}$ ) karst carbonate aquifer. It shows how a multi-scale description of the reservoir can be carried out by integrating the information provided by different 3D-THR surface seismic methods, full waveform acoustic logging, VSP with hydrophones, borehole optical televiewer and flow measurements.

In this book the authors provide readers with guidelines to carry out these operations, in terms of acquisitions as well as processing and interpretation. Thus, users will be able to draw inspiration to continue transferring petroleum techniques and other innovative methods for use in near-surface studies.

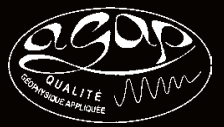

